University of Rhode Island

DigitalCommons@URI

Open Access Dissertations

1989

\title{
OPTIMIZATION AND USE OF TALC IN DIRECT COMPRESSION TABLET FORMULATIONS
}

Shabbir S. Dawoodbhai

University of Rhode Island

Follow this and additional works at: https://digitalcommons.uri.edu/oa_diss

\section{Recommended Citation}

Dawoodbhai, Shabbir S., "OPTIMIZATION AND USE OF TALC IN DIRECT COMPRESSION TABLET FORMULATIONS" (1989). Open Access Dissertations. Paper 341.

https://digitalcommons.uri.edu/oa_diss/341

This Dissertation is brought to you for free and open access by DigitalCommons@URI. It has been accepted for inclusion in Open Access Dissertations by an authorized administrator of DigitalCommons@URI. For more information, please contact digitalcommons-group@uri.edu. 


\author{
OPTIMIZATION AND USE OF TALC IN \\ DIRECT COMPRESSION TABLET \\ FORMULATIONS \\ BY \\ SHABBIR S. DAWOODBHAI
}

A DISSERTATION SUBMITTED IN PARTIAL FULFILLMENT OF THE . REQUIREMNTS FOR THE DEGREE OF

DOCTOR OF PHILOSOPHY

IN

PHARMACEUTICAL SCIENCES

UNIVERSITY OF RHODE ISLAND

1989 


\section{DOCTOR OF PHILOSOPHY DISSERTATION \\ OF}

SHABBIR S. DAWOODBHAI

APPROVED :

DISSERTATION COMMITTEE

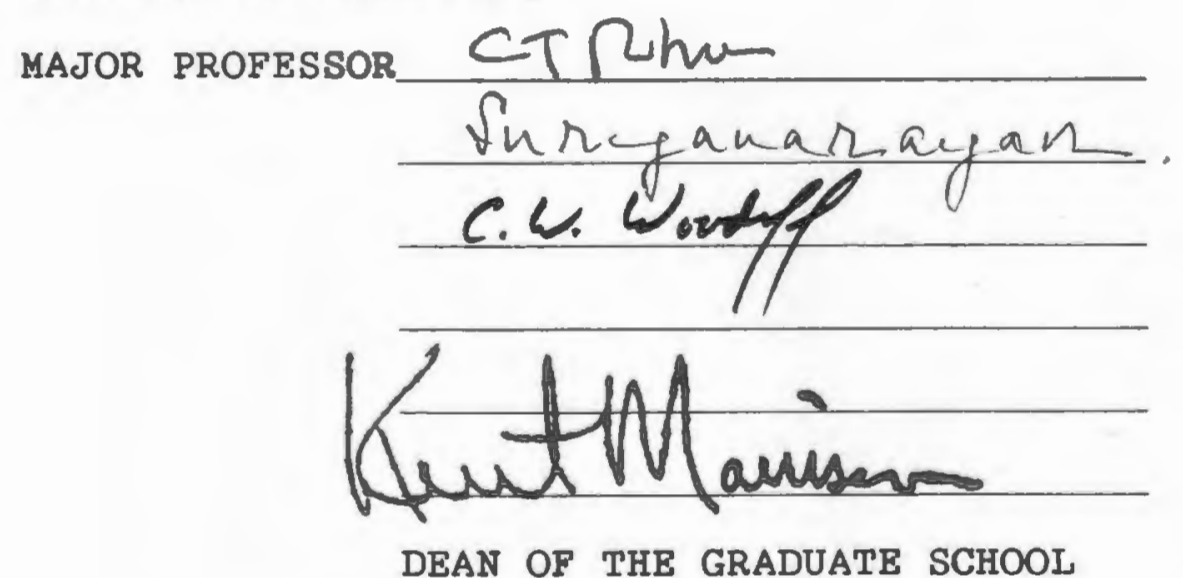

DEAN OF THE GRADUATE SCHOOL

UNIVERSITY OF RHODE ISLAND 1989 


\section{ABSTRACT}

Talc is extensively used in a wide variety of cosmetic products, particularly in powder products. Talc keeps the skin feeling smooth and dry. Talc in the pharmaceutical industry is used as a glidant and lubricant. Glidants such as talc improve flow properties of powder by decreasing interparticulate friction, by decreasing van der Waals forces and electrostatic charges, by changing particle size distribution, and by decreasing the effect of humidity on surfaces of host particles by forming a mechanical barrier. The loosely bound lattice layers slide over each other and form roller structures which explains its lubrication characteristics. Talc has less deleterious effect compared to magnesium stearate on tablet in vitro properties.

Talcs from different size grades were evaluated for their use in direct compression tablet formulations. Lubricant efficiencies of talcs were measured using ejection force values. The Supra grade of the Cyprus Industrial Mineral company talc was found to be most efficient of the grades tested as lubricant and also gave tablets of more acceptable in vitro properties than tablets lubricated with magnesium stearate only.

Additionally talcs in substantial percentages were evaluated for their potential as a direct compression matrix material. With commonly used excipients such as microcrystalline cellulose and lactose, the formulations 
were self lubricating and the tablets ejected easily. Tablets with very low friability, high crushing strength, rapid dissolution rates, good weight uniformity, content uniformity and potency of drugs were obtained. At similar compression forces, tablet hardness with the 300 grade of Alabama, Altalc, and Beaverwhite talcs was significantly greater than corresponding 400 and 500 grades.

An optimum direct compression tablet formulation of a conventional theophylline tablet was achieved using the technique of response surface methodology and successive quadratic programming (SQP). The response surfaces were obtained from a second order uniform precision hexagonal design. The tablet formulation was optimized for mean in vitro dissolution time using friability, hardness, ejection force and disintegration time as constraints within the experimental region by the SQP algorithm. The response surface model was validated by preparing and evaluating the predicted formulation. The characteristics of the tablet formulation were analyzed by principal component analysis. Sensitivity analysis of optimal solution was performed for each constraint, while all remaining constraints were held constant. The robustness of the response surface model was evaluated by simulation for error in the compression force values due to its inherent variation. Although pharmaceutical scientists have previously reported optimization studies, the approach used in this thesis has 
significant advantages and has not apparently been previously used for the optimization of pharmaceutical formulation.

A completely novel use for talc as a major matriz component in direct compression tablet formulation, has been proposed and examined. A robust and efficient response surface experimental design and mathematical optimization technique has been evaluated for application to the pharmaceutical sciences. The computer search method has the disadvantage of frequently giving a plural solution for suitable formulations. With the classical Lagrangian method, it can become difficult to solve the resultant set of simultaneous equations especially for nonlinear problems. The SQP method is more efficient and robust compared to previously published optimization techniques including SUMT (Successive Unconstrained Minimization Technique). The SQP method can also be used to obtain solution to the problems solved by the previously mentioned optimization methods. 


\section{ACKNOWLEDGEMENTS}

I would like to offer my sincere gratitude to my major professor Dr. Christopher T. Rhodes for his advice, guidance and kind support. I greatly appreciate the opportunities Dr. Christopher T. Rhodes has created for me. Our association has progressively become more enjoyable and fruitfull. Dr. Christopher T. Rhodes kind support greatly helped me in finishing the dissertation in time.

A special thank you for Dr. E.R. Suryanarayan, for his guidance and ready availibility for many helpful discussions. His pleasant and friendly help is greatly appreciated.

I also thank Dr. Charles Woodruff, Dr. Hosein Zia, Dr. David Woodford, and Dr. G. Verma for their assistance, encouragment and guidance. I appreciate the guidance and assistance of Dr. William D. Lawing, Dr. Edward Carney, Dr. Gregory Peck on statistical analysis.

I appreciate the advice and encouragement from all my friends. Also I would like to thank Nina Kajiji and the staff at academic computer center for their assistance with SAS programs. Last but not least, I would like to offer my thanks to my parents and family members for their constant support, encouragement and love. 


\section{PREFACE}

This dissertation is written in the MANUSCRIPT plan option. It is divided into three sections. Section I is introduction and literature review of optimization. Section II, the main body of dissertation comprises four manuscripts, which have been written in the format required by specific journals for publications. Section III, the appendices consists of additional analytical data, computer programs, additional manuscript and patent information. An alphabetical bibliography of the entire dissertation is at the end of the thesis.

Manuscript I will be submitted for publication in the journal of Drug Dev. Indus. Pharmacy.

Manuscript II has been published in the journal of Drug Dev. Indus. Pharmacy 13, 2441 (1987).

Manuscript III will be submitted for publication in the journal of Pharmaceutical Technology. This manuscript has a US patent claim.

Manuscript IV will be submitted for publication in the Journal of Phamaceutical Sciences.

Manuscript $V$ has been accepted for publication in the journal Drug Dev. Indus. Pharmacy (1989). 
CONTENTS

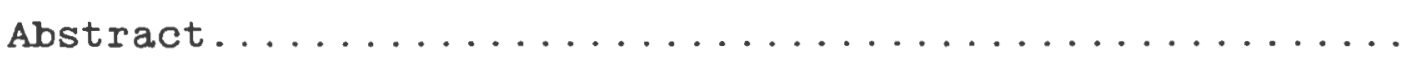

Acknowledgements....................... v

Preface........................... vi

Contents............................... vii

List of tables...........................

List of Figures........................

List of Presentations and Publications................

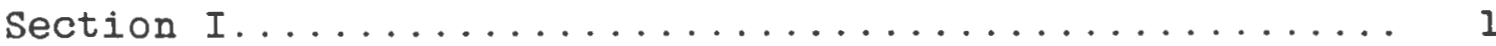

1. Introduction and objectives............... 2

2. Optimization Literature Review............... 6

3. References.........................

Section II............................ 17

\section{MANUSCRIPT I}

Pharmaceutical and Cosmetic Uses of Talc.

1. Introduction....................... 19

2. Cosmetic Uses of Talc................... 19

3. Talc as a Glidant..................... 23

3.1. Mechanism for Improved Powder Flow............. 25 
4. Talc as a Lubricant..................... 26

4.1. Mechanism of Lubrication................... 29

4.2. Effect of Talc on In Vitro Properties.......... 30

4.2.1. Mechanical strength................. 30

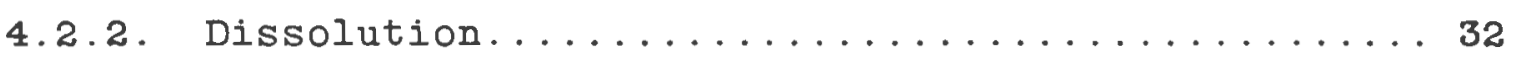

4.3. Effect of Talc on Chemical and Physical Stability of Tablets..................... 34

5. Miscellaneous Uses of Talc................ 35

6. Conclusions........................ 36

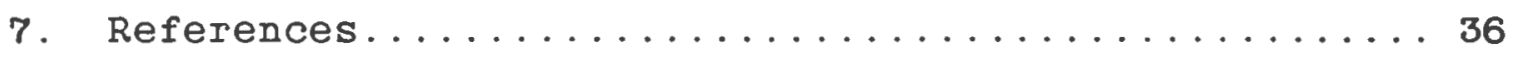

MANUSCRIPT II

Glidants and Lubricant Properties of Several Types of Talcs Abstract.............................. 40

Introduction......................... 40

Materials and Methods.................... 41

Results and Discussion................... 44

Conclusions............................ 67

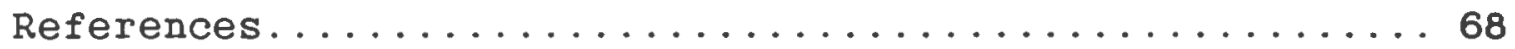

MANUSCRIPT III

Use of Talc as a Major Component of Direct Compression Tablets Matrix.

Abstract............................ 
Introduction........................ 7 I

Materials and Methods.................... 72

Results and Discussion................... 75

Conclusions......................... 88

References.......................... 89

\section{MANUSCRIPT IV}

Optimization of Tablet Formulations

Containing Talc.

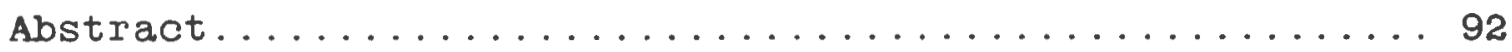

Introduction............................ 93

Theory............................... 94

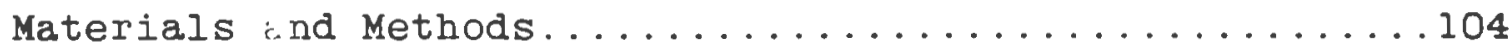

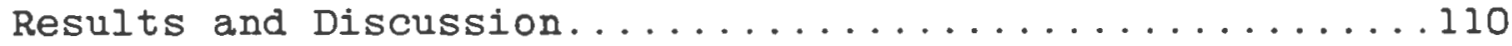

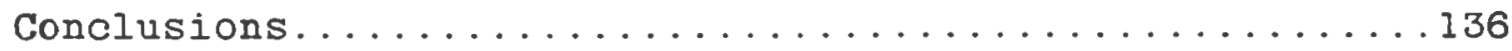

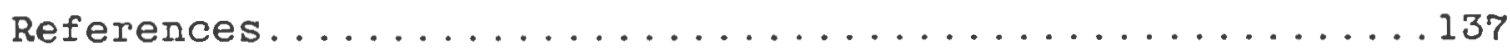

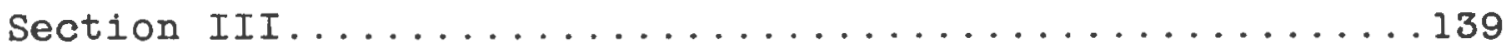

Appendices

A. General and Analytical Data............... 140

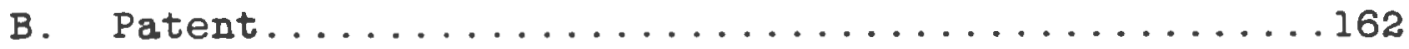

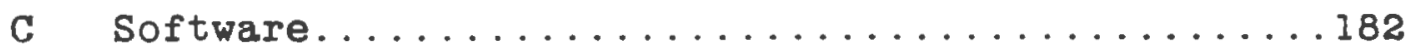

D. MANUSCRIPT $\vee \ldots \ldots \ldots \ldots \ldots \ldots \ldots \ldots \ldots \ldots$ 


\begin{abstract}
MANUSCR.IPT V
The Effect of Moisture on Powder Flow and on Compaction and Physical stability of Tablets

1. Introduction.....................260

2. Effect of Moisture on The Flow of Powders...262

3. Effect of Moisture on Compaction of Powders.266

4. Effect of Moisture on Physical Stability....270

4.1. Moisture Gain...................270

4.2. Moisture Loss.....................274

4.3. Moisture Gain Followed by Moisture Loss...275

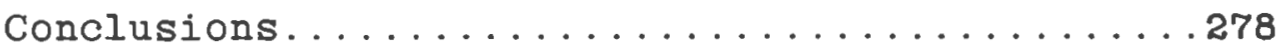

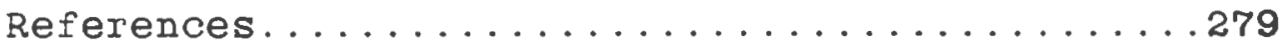

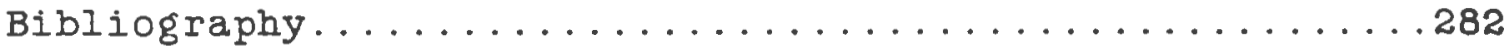




\section{LIST OF TABLES}

MANUSCRIPT I

1. Utilization of Talc in Cosmetic Products.......2 20

\section{MANUSCRIPT II}

1. Properties and Sources of Talcs Jsed in this study...................... 42

2. Formulations Jsed For Evaluating Lubricant Efficiencies of Talcs................44

3. Reproducibility of Flow Rates................5l

4. Reproducibility of Linearity of Powder Flow..... 51

5. Comparisons of Mass Flow Rates and Linearity Values of Acetaminophen and Emcompress Powder Mixture.................... 55

6. Properties of Hydrochlorothiazide Tablets...... 61

7. Properties of Acetaminophen Tablets...........62

8. Dissolution Rate of Acetaminophen From Tablets... 63

9. Dissolution Rate of Hydrochlorothiazide From Tablets.......................65

10. Properties of Acetaminophen Tablets After Physical Stability Test..............66

\section{MANUSCRIPT III}

1. Properties of Tales Used in this Study.........74 
2. Properties of Formula I Tablets Weighing 400mg... 77

3. Dissolution Properties of Hydrochlorothiazide

from Formula I and its Formula VI Tablets......78

4. Properties of Formula VI Tablets Weighing $400 \mathrm{mg} . .79$

5. Properties of Formula II and Formula III

Tablets Weighing 400mg................ 81

6. Dissolution Properties of Niacin from Formula II,

Formula III and their Formula VI Tablets...... 82

7. Properties of Formula IV and Formula $V$

Tablets Weighing 400mg............... 83

8. Dissolution Properties of Phenylpropanolamine

from Formula IV and Theophylline from

Formula $V$ and their Formula VI Tablets........ 84

MANUSCRIPT IV

1. Properties of Second Order Design Requiring

Same Number of Experimental Runs for Two

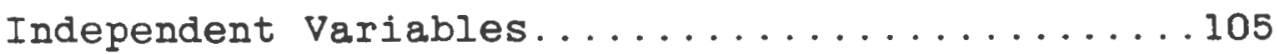

2. Experimental Design for Two Factors............107

3. The Parameters Obtained by Non-Linear Regression

Analysis, for Gompretz Equation............114

4. Experimental Values of Response Variables....... I15

5. Multiple Regression Analysis Equation for Each Response Variable...................... 116 
6. Optimum Formulation at Compression

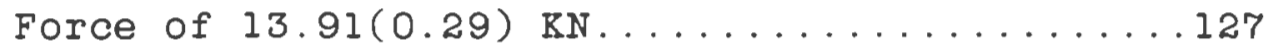

7. Comparison of Predicted and Experimental Values

of Response Variables for Optimum Formulation...128

8. Variance Analysis of the First four

Principal Components.................. 132

9. Coefficients of Eigenvectors Associated with

First Two Principal Components............133

10. Simulation Generated Coefficients of the

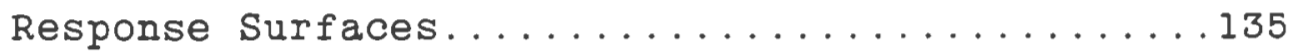

Appendix A

1. Dissolution Method in Matrix and Lubricant study. . . . . . . . . . . . . . . . . . . . 145

2. Ultra-Violet Analysis of Dissolution Sample in Matrix and Lubricant Study................... 146

3. Formulations and Tableting Data of Lubricant Study for Hydrochlorothiazide (10.0\%)......... 147

4. Formulations and Tableting Data of Lubricant Study for Acetaminophen (5.0\%)................148

5. Formulations and Tableting Data of Lubricant Study for Hydrochlorothiazide (10.0\%)..........149

6. Formulations and Tableting Data of Lubricant Study for Niacin, Phenylpropanolamine and 


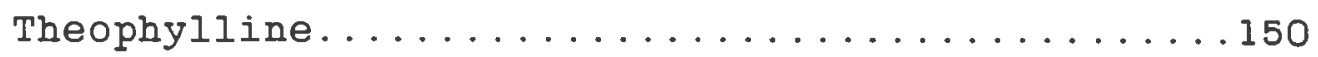

7. Baseline Formulations and Tableting Data for

Lubricant Study Using Magnesium Stearate.......151

8. Properties of Hydrochlorothiazide Tablets

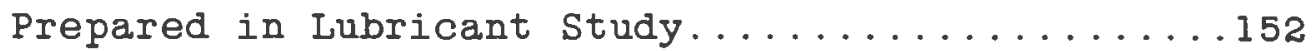

9. Dissolution Properties of Hydrochlorothiazide

Tablets Lubricated with Talc and Magnesium

Stearate Combination as Compared to

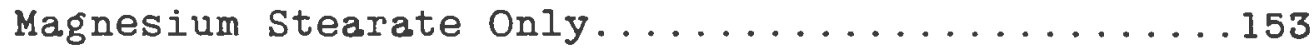

10. Properties of Niacin, Theophylline and

Phenylpropanolamine Tablets Prepared in the

Lubricant study........................ 154

11. Dissolution Properties of Tablets Containing

Niacin Prepared in Lubricant Study.............. 155

12. Dissolution Properties of Tablets Containing

Theophylline Prepared in Lubricant Study........156

13. Dissolution Properties of Tablets Containing

Phenylpropanolamine Prepared in Lubricant Study..157 


\section{IIST OF FIGURES}

MANUSCRIPT II

1. Effects of Talc on Flow Rate of Powder Mixture... 52

2. Effects of Talc on Flow Rate of Powder Mixture... 53

3. Effects of Talc on Flow Rate of Powder Mixture... 54

\section{MANUSCRIPT IV}

1. Dissolution Curves of Theophylline from Tablets of Random Formulation Number $1(*), 2(+), 3(0) \ldots 111$

2. Dissolution Curves of Theophylline from Tablets of Random Formulation Number $4(*), 5(+), 6(0) .112$

3. Dissolution Curves of Theophylline from Tablets of Random Formulation Number $7(*), 8(+), 9(0) \ldots 113$

4. Contour Plot of Disintegration Time Data........118

5. Three Dimensional Plot of Disintegration

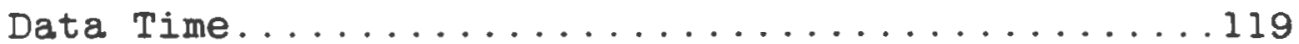

6. Contour Plot of Ejection Force Data...........120

7. Three Dimensional Plot of Ejection Force Data....121

8. Contour Plot of Percent Friability Data.........122

9. Three Dimensional Plot of Percent

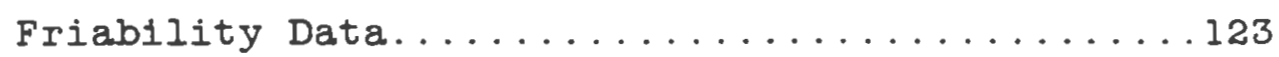

10. Contour Plot of Mean In Vitro

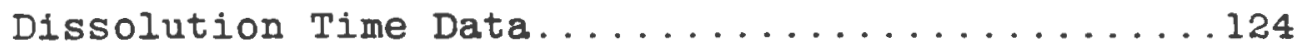


11. Three Dimensional Plot of Mean In Vitro

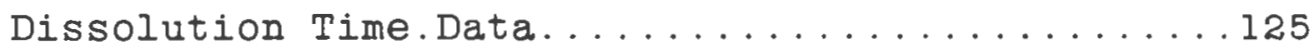

12. Optimum Mean In Vitro Dissolution Time Data as

a Function of Hardness Constraint............130

13. Optimum Mean In Vitro Dissolution Time Data as

a Function of Precent Friability Constraint......131

Appendix A

1. Hydrochlorothiazide UV Calibration Curve........141

2. Theophylline UV Calibration Curve............. 142

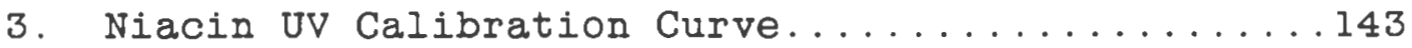

4. Phenypropanolamine UV Calibration Curve......... 144

5. Optimum Mean In Vitro Dissolution Time Data as

a Function of Hardness Constraint in

Standardized Scores in Optimization study......158

6. Optimum Mean In Vitro Dissolution Time Data as

a Function of Precent Friability Constraint in

Standardized Scores in Optimization Study......159

7. Rate of Change of MDT In Vitro With

Respect to Friability as a Functon of Mid-Point

of Friability in Optimization Study...........160

8. Rate of Change of MDT In Vitro With

Respect to Hardness as a Functon of Mid-Point

of Hardness in Optimization Study...........161

xvi 


\section{LIST OF PRESENTATIONS AND PUBLICATIONS}

Presentations

1. Glidants and Lubricant Properties of Several Types of Talcs. S. Dawoodbhai and C.T. Rhodes Interphex USA, New York, N.Y., April 1987.

2. Use of Talc as a Major Matrix Component in Direct Compression Tablets. S. Dawoodbhai and C.T. Rhodes American Association of Pharmaceutical Scientists, Orlando, FL. November 1988.

Publications

1. Glidants and Lubricant Properties of Several Types of Talcs. Drug Dev. Indus. Pharmacy, 13, 2441, (1987). S. Dawoodbhai, H.R. Chueh and C.T. Rhodes.

2. The Effect of Moisture on Powder Flow and on Compaction and Physical Stability of Tablets Drug Dev. Indus. Pharmacy, (1989).

S. Dawoodbhai and C.T. Rhodes. 
Section I 
INTRODUCTION

Formulation of new drugs and reformulation of established drugs into tablet dosage forms with different excipients is an ongoing process in the pharmaceutical industry. By combining the method of direct compression for manufacturing of tablets and an optimization technique, it is possible to save expenses in terms of time, labor and material costs.

Talc in the pharmaceutical industry has mainly been used as a glidant (1-10). Its use as a lubricant with antiadherent properties has been studied (11-20). Its mechanism of lubrication has been attributed to loosely bound lattice layers sliding over each other in the direction of motion to form roller like structures (21). When the sliding surfaces have alternating direction of motion the rollers would need to unravel and reform in the opposite direction (21). This can occur efficiently only when sufficient space is available between sliding surfaces. At high compaction forces the relative density of the tablet and the radial die wall force increases. Consequently, less space becomes available between the tablet and the die wall, and therefore talc efficiency as lubricant may decrease with increase in compaction force (22). Therefore, an additional more efficient lubricant on equal weight basis, such as magnesium stearate, is combined with talc. There have been conflicting reports regarding the combined use of talc with 
magnesium stearate, (15). However, talc has much less deleterious effect on tablet properties compared to magnesium stearate (16-20). For example, talc gives harder tablets $(16,17)$ and does not delay dissolution rate of drugs $(19-20)$.

The use of talc as a matrix component in a direct compression formulation is completely novel. The use of talc as a matrix component confers the following possible advantages. Combination of talc with other material will help to reduce the cost of direct compression matrix in a formulation. Talc has an adsorbent property ( $22-23$ ). This adsorbent property may possibly explain why talc has less deleterious effect on the dissolution rate of the drug compared to the other hydrophobic lubricants such as magnesium stearate. There is some experimental evidence to suggest that presence of an adsorbent at the dissolution site will increase the saturation solubility of the drug and thereby enhance the dissolution rate of the drug (24). Furthermore, talc as a matrix component may in some cases completely eliminate the need for using magnesium stearate as a lubricant in that formulation.

Objectives of this study

1. To evaluate relative lubricant efficiency and the tablet in vitro properties of a number of different types of 
talcs in combination with magnesium stearate. The talc containing tablets in vitro properties will be compared with those of tablets not containing any talc, but just magnesium stearate only as the lubricant.

2. To examine the potential uses of a number of talos as a major matrix component for commonly used drugs in direct compression tablet formulations. A number of different talcs will be examined for their in vitro properties to asses potential usefulness of these talcs, as a direct compression formulation matrix component. Furthermore, properties of tablets from formulations not containing talc in the matrix will be prepared and their properties compared with those containing talc.

3. To apply an optimization technique to the study of the processing and formulation variables using talc as a major matrix component in direct compression tablet formulation for a drug. In addition, an optimum formulation for tablets containing talc as a major matrix component of direct compression formulation will be prepared, as predicted by the optimization technique and the properties compared with actual values obtained experimentally. 
4. To perform sensitivity analysis of the optimal solution - In addition errors in the ' $X$ ' (dué to variation in the compression force values) will be examined by simulation.

5. To identfy the important tablet properties that characterize the tablet formulation using principal component analysis, in the optimization study. 
Literature review*

Computer Optimization

Schwartz and coworkers (25), used a half fractional factorial based orthogonal, non-rotatable central composite design, for five independent variables. Although nine tablet properties were measured, the optimization procedure involved locating a set of constraints based on three tablet properties namely disintegration time, hardness, and percent drug dissolved at 50 minutes such that a feasible solution existed, but further tightening of constraints would produce no feasible solution. The grid search program then printed out all the formulations possible that satisfied the feasibility region requirements. The optimal solution was then selected from the multiple suitable solutions suggested by the grid search.

Schwartz and coworkers (26) also showed how the trend in optimal solution can be used as an effective guide for efficient trouble shooting during production while working within the NDA (New Drug Application) limits for the product. Principal component analysis can be used for identifying the important tablet properties that characterize the tablet formulation (27). Of the nine

More detailed consideration of pertinent literature is contained in the various manuscripts. 
tablet formulation characteristics examined, it was found that the most important property of the tablet was the percent drug dissolved at 50 minutes since it explained 95.4\%, while the second most important tablet property was the tablet disintegration time since it explained an additional $3.9 \%$, of the tablet formulation characteristics (26). The contributions of the remaining tablet properties were negligible in explaining the tablet formulation characteristics (27). Similarly selected main properties of any drug delivery system could be used for evaluation during routinely performed quality control and quality assurance programs as a more economical approach. Only if one or more of these main properties were not acceptable or deviated from their limits, would it become necessary to evaluate the complete set of properties of that drug delivery system to identify the possible problems and their corresponding solutions.

Down et al (28) used an orthogonal but nonrotatable central composite design, for two formulation variables and one processing variable. Optimization of tablet property was carried out similarly to schwartz and coworkers method, with a constraints set consisting of tablet thickness, hardness, friability, and ejection force. They were apparently the first to report that the compression force values were difficult to achieve exactly because of compression variations of the tablet press and 
the die fill variations (28). Therefore the mean compression force values were used for multiple regression analysis.

Keeping the tablet weight constant Bohidar et al (29) varied the ratio of drug to the excipient, by using drug potency as one of the formulation variables. A half fractional factorial based orthogonal, non-rotatable central composite design, for five independent variables was used (29). Sequential prediction analysis was carried out as follows (29). For a range of acceptable tablet properties, the values of corresponding independent variable were obtained. All the independent variables were kept at a constant optimal value, except for drug potency variable and the most influential variable. For each drug potency, the most influential factor was varied within the optimal range previously obtained, and the tablet properties were predicted using the second order response surface equations. Then the values for the most influential variable were selected to give the most suitable compromise for the tablet properties for each of the potencies. Then the tablets at each of the potencies were prepared, using individualized value of the most influential variable and the remaining independent variables at their accepted optimal value (29).

Nagai and co-workers used a composite design based on full factorials to study the dissolution properties for the solid dispersions of flufenamic acid (30) and 
griseofulvin (31) using two and three formulation factors respectively. The former experimental design had rotatability property. The optimization in both cases was concerned with obtaining formulation with high dissolution rate and good stability of dissolution properties. The computer optimization technique similar to Schwartz and coworkers was used.

Mathematical Optimization

Fonner et al (32) studied the levels of binder (stearic acid) and disintegrant (corn starch) for optimization of the time for 50\% drug release in vitro (T50\%) using response surface equations for friability and tablet volume as constraints. The two formulation factors were studied using an orthogonal but non-rotatable central composite design (32). The optimal solution was more sensitive to changes in tablet volume compared to percent friability (32). In addition, tablet friability was minimized using time for $50 \%$ of the drug to be eliminated in urine and tablet volume, as the constraints (32). Fonner et al also applied the Lagrangian method to the data obtained by Reier et al to minimize capsule weight variation (32). The machine speed and flowability of powder were the two independent variables to be optimized subject to constraint of mean gross capsule weight. 
The Lagrangian method is a mathematical nonlinear programming method that locates the optimum directly and does not search for infeasible solution points $(32,33)$. It generates only feasible solutions. It efficiently handles inequality as well as equality constraints. The objective function always has the equality form. The inequality constraints are converted to equality by slack variables. Each constraint has its Lagrange multiplier. The Lagrange multiplier is a penalty that must be paid for violating a given constraint. The Lagrangian is the resultant lagrange function that is to be optimized. The optimum solution 1s a stationary point; that is, at this point the partial derivative of the Lagrangian is zero with respect to each of the independent variable, the slack variables and the Lagrange multipliers. So, the partial derivatives are calculated with respect to each of these variables and set equal to zero. The optimal solution is obtained by solving a set of simultaneous equations $(32,33)$.

In another study Nagai and coworker (34) used half fractional factorials and axial spacing of 1.713 to obtain a non-rotatable spherical composite design. The formulation factors were studied for their effects on dissolution and chemical stability of indomethacin solid dispersion (34). A mathematical optimization for high dissolution rate as measured by T50\% value using good stability of dissolution properties and chemical stability as constraints was 
achieved by the use of sequential unconstrained minimization technique (SUMT) (34). This mathematical optimization technique transforms a constrained optimization problem to unconstrained optimization problem (Eq. l) by adding penalty

$P(x, r)=F(x)-r \sum_{i=1}^{m} \ln \left[g_{i}(x)\right]+(1 / r)\left[\sum_{j=1}^{p}\left[h_{j}(x)\right]^{2}\right.$

terms for inequality constraints $\left(g_{i}\right)$ (Eq. 2), equality constraints $\left(h_{j}\right)$ (Eq. 3 ), to the objective function $F(\mathbf{x})$

$$
\begin{aligned}
& g_{i}(x) \geq 0 \quad i=1,2, \ldots m \\
& h_{j}(x)=0 \quad j=1,2, \ldots . p .
\end{aligned}
$$

The penalty parameter ( $r$ ) has a relatively large value when the search is first initiated. The minimization of the unconstrained penalty function $P(x, r)$ is carried out by a general unconstrained non-linear optimization method. The optimum (miminimum solution) at point $\mathbf{x}(r)$ is obtained when $r$ is sufficiently close to zero, that is $1 / r$ approaches infinity value, which means that the value of $x$ has to be minimized greatly to keep the penalty term as minimal as possible. The SUMT like Lagrangian and unlike schwartz search method gives a single solution strictly obtainable as best formulation. 
The simplex search method was used for optimization of a capsule formulation with respect to its dissolution and compaction rate (35). Four independent formulation variables were studied (35). Fitting of this experimental data to second order response surface equation is not warranted, since this is a first order optimization technique. In addition, to overcome the unconstrained nature of this optimization technique, an overall response was created and optimized. This overall response consisted of two dissolution rate and one compaction rate dependent variables, which were arbitarily weighed and linearly combined (35).

Two formulation and two processing variables were studied by half fractional factorial design (36). First order response surfaces were found to be adequate for the two properties to be optimized for enteric coated tablets (36). The steepest descent gradient method searches for independent variables values for which the gradient vector equals to zero. Therefore the steepest descent method can terminate at any type of stationary point, for example, minimum or saddle point, to give approximate optimal solution (34). If it is a saddle point, then indirect second order method should be used to move away from the saddle point. Since the method of steepest descent is an unconstrained optimization technique, only the response regarding the disintegration time in the intestinal fluid 
was minimized and the optimal solution obtained also satisfied the additional restriction of resistance to disintegration in gastric fluid (36).

The computer search method has the disadvantage of frequently giving a plural solution for suitable formulations (34). With the classical Lagrangian method, it can become difficult to solve the resultant set of simultaneous equations especially for nonlinear problems. Therefore a numerical method such as SUMT or SQP must be used to locate the optimal solution point. The SQP method is more efficient and robust compared to previously published optimization techniques including SUMT (33). The SQP method can also be used to obtain solution to the problems solved by the previously mentioned optimization methods.

\section{References}

1. G. Gold, R. N. Duvall and P. T. Palmero, et al., J. Pharm. Sci., 57, 667 (1968).

2. P. York, J. Pharm. Sci., 64, 1216 (1975).

3. H. G. Kristensen and V. G. Jensen, Dansk Tidsskr. Farm., 43, 205 (1969).

4. F. C. Hammerness and H. O. Thompson, J. Pharm. Sci., $47,58(1958)$. 
5. G. Gold, R. N. Duvall, and B. T. Palmero, et al., J. Pharm. Sci., 55, 1291 (1966).

6. A. Kassem and S. Said, Can. J. Pharm. Sci., 10, 92 (1975).

7. G. Gold and B. T. Palmero, J. Pharm. Sci., 54, 310 (1965).

8. G. Gold and B. T. Palmero, J. Pharm. Sci., 54, 1517 (1965).

9. G. Gold, R. N. Duvall, and B. T. Palmero, et al., J. Pharm. Sci., 57, 2153 (1968).

10. G. Reier, R. Cohn, and S. Rock, et al., J. Pharm. Sci., 57, $660(1968)$.

11. E. Nelson, L. W. Nagvi, and L. W. Busse, et al., J. Pharm. Sci., 43, 596 (1954).

12. W. A. Strickland, E. Nelson, and L. W. Busse, et al., J. Pharm. Sci. 45, 51 (1956).

13. W. A. Strickland, T. Higuchi and L. W. Busse, J. Pharm. Sci., 49, 35 (1976).

14. C. J. Lewis and E. Shotton, J. Pharm. Pharmacol., 17, Suppl. 82 S (1965).

15. B. Mechtersheimer and H. Sucker, Pharm. Tech., 10, 38 (1986).

16. Y. Matsuda, Y. Minamida and S. Hayashi, J. Pharm. Sci., $65,1155(1976)$.

17. P. L. Jarosz and E. L. Parrott, Drug Dev. Indus. Pharm., 4, 259 (1984). 
18. E. Shotton and C. J. Lewis, J. Pharm. Pharmacol., 16, $111 \mathrm{~T}(1964)$.

19. G. Levy and R. H. Gumtow, J. Pharm. Sci., 52, 1139 (1963).

20. T. A. Iranloye and E. L. Parrott, J. Pharm. Sci., 67, $535(1978)$

21. D. Train and J. A. Hersey, J. Pharm. Pharmacol., 12, $97 \mathrm{~T}(1960)$

22. F. Ganjian, A. J. Cutie and T. Jochsberger, J. Pharm. Sci., 69, 352 (1980).

23. D. Sorby, J. Pharm. Sci., 54, 667 (1961)

24. D. E. Wuster and G. P. Polli, J. Pharm. Sci., 50, 403 (1961).

25. Schwartz, J. B. Flamholz, J. R.;Press, R. H. J. Pharm. Sci. 1973, 62, 1165-1170.

26. Schwartz, J. B.;Flamholz, J. R.;Press, R. H. J. Pharm. Sci. 1973, 62, 1518-1519.

27. Bohidar, N. R.; Schwartz, J. B.;Restaino, F. A.; J. Pharm. Sci. 1975, 64, 966-969.

28. Down. J. R. B.; Miller. R.A.; Chopra. S. B.; Millar. J. F. Drug Dev. Indus. Pharm. 1980, 6, 311-330.

29. Bohidar, N. R.;Bavitz, J. F.; Shiromani, P. B. Drug Dev. Indus. Pharm. 1986, 12, 1503-1510.

30. Takayama. B.; Nambu. N.; Nagai. T. Chem. Pharm. Bull. $1983,31,4496-4450$.

31. Takai. T.; Takayama. B.; Nambu. N.; Nagai. T. Chem. 
Pharm. Bull. 1984, 32, 1942-1947.

32. Fonner, Jr., D. E.; Buck. J. R.; Banker, G. S. J. Pharm. Sci. 1970, 59, 1587-1596.

33. Reklatis. G. V.; Ravindran. A.; Ragsdell. K. M.; "Engineering Optimization: Methods and Applications John Wiley and Sons, Inc. New York, Mew York, pp , 1983.

34. Takayama. B.; Imaizumi. H.; Nambu. N.; Nagai. T. Chem. Pharm. Bull. 1985, 33, 292-300.

35. Shek, E.; Ghani, M.; Jones, R. E. J. Pharm. Sci. 1980, $69,1135-1142$.

36. Dincer. S.; Ozdurmus. S.; J. Pharm. Sci. 1977, 67, 1070-1073. 
Section II 


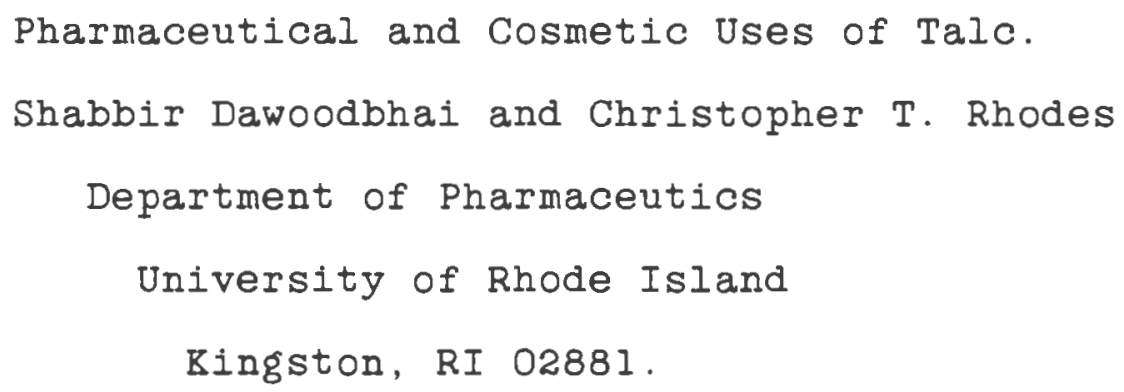

1. Introduction

2. Cosmetic Uses of Talc.

3. Talc as a Glidant

3.1. Mechanism for Improved Powder Flow

4. Talc as a Lubricant

4.1. Mechanism of Lubrication

4.2. Effect of Talc on In Vitro Properties

4.2.1. Mechanical Strength

4.2.2. Dissolution

4.3. Effect of Talc on Chemical and Physical Stability of Tablets

5. Miscellaneous uses

6. Conclusions

7. References 
1. Introduction.

Talc is a mineral with the composition of $3 \mathrm{MgO} \cdot 4 \mathrm{SiO}_{2} \cdot \mathrm{H}_{2} \mathrm{O}$, and referred to as hydrous magnesium silicate (1). The structure consists of MgO sheet sandwiched between two silica sheets. Each layer is electrically neutral, and the adjacent layers are held together by only weak van der waals forces (1). The mineral composition of talc may vary depending on the geographical source of the deposit $(1,2)$. Impurities in the form of calcium silicate and calcium carbonate makes the powder abrasive, while iron oxide or magnesium ferric silicate makes talc greyish in appearance $(1,2)$. Very finely powdered talc is boiled in $2 \%$ hydrochloric acid and subsequently in weaker hydrochloric acid solution to remove iron and other soluble impurities. Finally the talc is thoroughly washed with water and dried at $100^{\circ} \mathrm{C}$ (2). (For the variety of cosmetics products in which talc is a major component, see Table 1.)

\section{Cosmetic Uses of Talc}

Talc is used as face, body and foot powder to keep skin smooth, cool and dry (3). The smoothness of talc felt by human hands is dependent on its slip characteristic. The slip characteristic is dependent on particle size and shape. Talc has lamellar particle shape and this produces the 
Table 1. Utilization of Talc in Cosmetic Products. $\therefore$

Product

Face powder

$10-75$

Foot powder

Baby powder

Pressed powder

Bleaching mask

Dry shampoos

Pre-electric

Talc sticks

Foot spray

Dusting powder Percent Talo

Purpose of Talc

Ref \#

Keeps skin smooth and dry 3

Keeps skin smooth and cool 3

Keeps skin smooth and dry 3,4

Easy spread of rougher color 3

Absorbs sebaceous secretions 3

Absorbs sebaceous secretions 3

Absorbs sebaceous secretions

and provides slip for shaver 3,6

Cooling and refreshing 3

Keeps skin cool, smooth, dry 7

and fragmented 
slippery feel (1). The larger the individual plate the better the slip. Italian talcs have excellent siip characteristics (1). More than $98 \%$ of the talc particle size, especially in baby powders, should be less than 74 um (1). Apparent bulk and tap density of talc is proportional to particle size distribution. The finer the distribution the lower the apparent density (1). Baby powders are Iike talcum dusting powders, but contain an antiseptic, with less perfume and more absorbent for example $20 \%$ rice starch and 15\% zinc oxide to increase the covering power of talc (4). Talc has low water wettability (5), absorption (3) and adsorption capacity (5), so it is common to include starch, kaolin, precipitated calcium carbonate or magnesium carbonate to increase absorbancy for products such as face powders $(1,3,6,7)$. These carbonates also serve as the carrier for perfume (6). To enhance powder adherance and thereby improve powder feel on the skin, the metallic stearates for example magnesium stearate or zinc stearate are added (3). Magnesium stearate is prefered over zinc stearate because it is less toxic if powder is accidentally ingested (3). Substances such as kaolin, titanium dioxide, magnesium oxide, zinc oxide may be included in formulation to improve the covering power of talc (3). Currently available alternatives to talc include rice starch (3) and Pullulan (3), however, they are expensive. since talc absorbs sebaceous secretions it is used in dry shampoos (3), 
and in pre-electric shave talc sticks $(3,6)$. Veegum or colloidal magnesium aluminum silicate is used as a binder for pre-electric shave talc sticks $(3,6)$. Skin exhibits higher friction when rubbed on smooth surface as compared to relatively rough surface because of skins flexibility ( 8 ). A decrease averaging $50 \%$ in frictional force was observed with a polished or rough metal probe after application of talc to the skin (8). This effect of talc is attributed to its low shearing strength per unit area and the talcs ability to adhere to stainless steel surface of metal probe (8).

Pressure packaging of talc formulated powder for use as a foot spray is not necessary because of reasonably good delivery to skin using conventional packaging ( 3 ). Talc containing foot sprays are mainly used for their refreshing fragrance and cooling effect (3). They are not used as antiperspirant sprays because talc has poor adherance to the skin and its antiperspirant effect is small (3). As a fragrance carrier, cosmetic talc must hold the fragrance oil on its surface and release it unchanged (1). Total powder in an aerosol formulation should be less than $15 \%$ to avoid blockage of valve activator, and the powder size of all particles should be fine enough to pass through the mesh size 200 (6). Some of the ingredients that are often combined with talc in a formulation for example zinc oxide, zinc stearate, kaolin, and calcium carbonate 
cannot be used because they all agglomerate in presence of propellant (6). However, talc presents no great problem in getting satisfactory valve function, because of the lubricating characteristics of talc (9).

Talc particle size in aerosol formulations should be $50 \mathrm{~m}$ or less to aid in dispersion $(1,6,9,10)$. The dispersibility of talc becomes better as zeta potential increases above $70 \mathrm{mV}$ (11). In propellant mixtures, propylene glycol monoisostearate was the most effective suspending agent and dispersing agent. Other dispersing agents showed little differences among themselves and were less effective (10). Talc sprays have to be shaken vigorously (3) since talc has a high density and therefore it settles faster than starch or aluminum chlorhydrate (10 ). Talc settling velocity can be reduced and final sedimentation volume can be increased by using long hydrocarbon chain alcohols, glycerol and sorbitol, any type of surfactant in low concentration of 0.005 to $0.1 \%$, or small quantities of water immiscible liquids e.g. $0.2 \%$ to $5.0 \%$ of caprylic acid, capronic acid, or oleic acid (12).

\section{Talc As Glidant}

Free and uniform flow rate of powder mixtures is an important formulation consideration for the manufacture of solid dosage forms. Gold et al. (13) has shown the importance of uniformity of powder flow using two 
formulations both of which had similar flow rates. The tablets made on single punch press from the formulation which did not flow uniformly had a higher coefficient of weight variation compared to formulation which did flow uniformly. Presence of talc decreased the capsule weight variation by making the powder flow more uniform(14). However, talc had no effect on mean capsule weight (14). Optimal talc concentration for improving flow has been reported to be about $0.5 \%(15)$ and $2 \%(16,17,18)$ using powder flow and shear cell studies. The percent of fines (particle sizes smaller than 40 to 200 mesh) can be a major factor that influences the percent of glidant required for improving the powder flow rate $(15,18)$. Therefore, glidants should mainly consists of very fine particles. To a certain extent talc in concentration of 2 to $3 \%$ can increase the flow rate of powder lacking in percent fines (18). Gold et al. (19) has shown that addition of talc does not always result in an increase in flow rate. This stresses the importance of powder particle size distribution on flow.

Magnesium stearate was able to increase flow factor (16) and flow rate $(15,19)$ of tablet excipients such as lactose to a greater extent compared to talc. However, magnesium stearate causes a much sharper decrease in flow rate when used above its optimum concentration compared to talc $(15,19)$. 


\subsection{Mechanism for Improved Powder Flow}

It has been suggested that cornstarch (15), talc of fine particle size $(15,16)$ and also siliconized talc (21) form a mono particulate layer onto host powder particles. The smoothing out of the host particle surface that takes place, helps to decrease both the friction and mechanical interlocking of host particles $(15,16,21)$. In addition, the host-host interactions at particles contact points would be replaced by weaker glidant-glidant forces $(15,16,21)$. Glidants such as magnesium stearate and talc tend to reduce van der Waals interparticulate cohesive forces among host particles (15). The interparticulate van der Waals forces increase as particle size decreases. Talc and cornstarch also tend to fill the void spaces between particles (15).

Talc has a laminar crystalline structure, which rolls up into a spherical or roller structure when subjected to low shearing forces as generated by flow. These spheres of talc improve flowability of powders $(16,20)$. Siliconized talc was able to improve flow rate of powder (as measured using a flowometer) to a greater extent compared to non-siliconized talc. The latter produced higher flow rates compared to unlubricated powder (21). In addition talc is also able reduces the static charges on powder particles surfaces $(22,23)$.

Static charges on particles surfaces is one of the reasons for poor powder flow. Static charges on particles 
can be reduced by decreasing the percent of fines (22) and by increasing the percent of humidity (22). However, increase in humidity may decrease the chemical stability of some drugs and physical stability of the dosage form. Furthermore, increase in humidity and/or change in particle size distribution may have detrimental effects on mixing, flow and tablet compaction of powders.

Tablet lubricants in relatively low concentrations can significantly lower static charges on powders $(22,23)$. Talc and magnesium stearate were equally effective in concentration ranging from $0.1 \%$ to $5 \%$, in progressively decreasing electrostatic charges on materials (23). It is interesting to note that stearic acid was found to be ineffective for reducing electrostatic charges on powder materials evaluated (23).

These substances may be decreasing static charges by decreasing friction and forming a protective coat on surface of particles thereby minimizing contact between host particles. Since magnesium stearate has a more deleterious effect on tablet hardness and dissolution, it appears that talc is the better choice for reducing electrostatic charges on powder material flowing through hopper.

\section{Talc As A Iubricant}

In tableting, lubricants are required for reducing friction and preventing the binding between the tableting 
mass and die wall during compression and ejection.

Lubricants also prevent picking and sticking of tableting mass to upper and lower punches respectively. Lubricants can help to reduce capping and laminating. Properly lubricated formulation will provide unblemished tablets of good appearance and uniform weight. In addition the tablet press tooling can operate with minimal wear and stress.

Lubricant efficiency of tablet lubricants have been evaluated mainly using single punch press (24-27) and rotary press (28) and more specialized equipment (29,30). It has been observed that after addition of lubricant, values of compression force decreased and the difference between compression and transmitted force became significantly reduced (24). The majority of studies have measured $R$ values and/or ejection force for evaluation of lubricant efficiency.

Magnesium stearate in concentration of about 1 or $2 \%$ provides maximal lubricant efficiency as evaluated by $R$ values $(25,30)$. Magnesium stearate is a more efficient lubricant compared to talc on equal weight basis. However, increasing the concentration of talc decreases ejection force and increases $R$ values (24-27). Talc should preferably be used in concentration greater than $0.5 \%$ (30). Compared to incorporation method the mixing of lubricants with formulation prior to compaction yielded better lubrication (30). 
There are conflicting reports about the use of talc in combination with magnesium stearate (28). The Mechtersheimer et al. (28) study offers the following observations on interactions between talc and magnesium stearate with the flat face punch tooling. Talc used alone or mixed simultaneously in combination with $0.3 \%$ magnesium stearate led to an increase in ejection forces. Further increase in talc concentration progressively lowered values of ejection force close to that obtained with $0.3 \%$ magnesium stearate alone. Talc added before or after magnesium stearate did not lower the ejection force values below those obtained with $0.3 \%$ of magnesium stearate alone (28). The residual die wall forces behaved similarly to ejection force values. However, increasing concentration of talc beyond $2 \%$ reduced the residual die wall forces below that obtained with $0.3 \%$ magnesium stearate (28). Talc used alone or mixed simultaneously with magnesium stearate led to an increase in the die wall force. However, by increasing talc concentration beyond $1 \%$ or by adding talc before or after magnesium stearate, the die wall forces decreased below that obtained with $0.3 \%$ magnesium stearate used alone (28). It is not clear whether these observations were due to the sequence of mixing or partially different mixing times for magnesium stearate and talc. The recommendation that talc should be added before magnesium stearate needs to be further validated. 
Additional observations of interest reported by Mechtersheimer et al. were that with addition of increasing concentration of talc, the residual die wall force increase were not as pronounced with curved face punches as compared to flat face punches (28). With curved face punches, therefore, one can decrease residual die wall force, by compensating the reduced amount of magnesium stearate used with an increase in the concentration of talc. The die wall pressure and the residual die wall pressure generated in response to increase in compression force is greater for curved face punches than that for flat face punch tooling and are not significantly altered by increasing the talc concentrations ( 28 ).

\subsection{Mechanism of Lubrication}

Talc is classified as boundary type lubricant whose main action is to promote anti-adherance during compression (26). More precisely talc is a laminar type boundary lubricant (20). In tableting sufficient lubricant should be used to maintain a film on the surface of the die, so that the friction observed would be mainly due to shearing of lubricant - lubricant film. Therefore, the effectiveness of a lubricant coat will depend on its shear strength, the force with which it adheres to the metal of the die, its resistance to penetration by material of the compact and its resistance to wear (29). 
The shear strength of stearic acid and its salts was reported to be almost constant with increase in compaction pressure (29). The shear strength of talc was higher compared to that of stearic acid and its salts when subjected to constraining loads ( 20 ).

The mechanism of lubrication by talc is attributed to loosely bound lattice layers sliding over each other when placed between moving surfaces (20). The laminar layers roll up in the direction of motion, to form a roller like structures. The roller mechanism explains the high coefficient obtained on alternating the direction of motion of sliding surfaces, since the roller would have to be unravelled and be reformed in opposite direction (20). For roller mechanism to act efficiently, sufficient space for roller to form must be available between sliding surfaces. This space becomes less available at high compaction forces because the relative density of tablet becomes high. This consequently results in greater radial die wall force and friction (20).

\subsection{Effect of Talc on Tablet In Vitro Properties}

\subsubsection{Mechanical Strength}

Mixing of lubricants with a formulation prior to compaction yielded harder tablets compared to the incorporation method (30). For brittle materials the axial 
and radial tensile strengths for dibasic calcium phosphate tablets (31) and the crushing strength of sucrose tablets (32) were not greatly affected by lubricants because of new surfaces generated by fracture of particles during compression.

For plastically deforming materials the axial and radial tensile and crushing strength of tablets were reduced by lubricants $(31,32)$. This is because the coating of the particle surface by lubricants reduces the extent of bonding between particles during compression (25,31,32). Magnesium stearate markedly decreased the axial tensile strength relative to radial tensile strength for microcrystalline cellulose tablets even at $0.25 \%$ concentration, and progressively for aspirin and anhydrous lactose with increasing magnesium stearate concentration (31). While the effects with talc up to 6 to $8 \%$ on the axial to radial ratio of tensile strength was a moderate decrease for microcrystalline cellulose tablets and only a slight decrease for aspirin tablets (31). Jarosz and Parrott (31) concluded that for microcrystalline cellulose tablets the capping potential was greater with magnesium stearate compared to talc. However, with anhydrous lactose tablets a slight increase in ratio of axial to radial tensile strength was observed (31). Using microcrystalline cellulose as a. direct compression excipient in formulation, it was shown that tablets lubricated with $1 \%$ of various talcs in 
combination with $0.25 \%$ magnesium stearate gave tablets of higher crushing strength compared to tablets lubricated with $0.5 \%$ magnesium stearate lubricated tablets (33).

4.2.2. Dissolution

Excipients used in a formulation can affect a products in vitro properties, such as the drugs dissolution rate and may also affect its bioavailability. Talc, although a hydrophobic lubricant, does not seem to have as deleterious effect on dissolution of drugs as does magnesium stearate $(33,34,35)$. Levy et al. (34) reported that initial dissolution rate of salicylic acid from a rotating disk was faster with talc as a lubricant compared to magnesium stearate. Levy et al. (34) also concluded that hydrophobic lubricants retard dissolution rate of drugs contained in compressed tablets by prolonging disintegration time and by reducing the area of interface between drug particle and solvent. Using compressed disk of aspirin, salicylic acid and equimolar mixture of aspirin and salicylic acid an increase in concentration of magnesium stearate from 0.1 to 5\% progressively slowed dissolution rate (35), while 0.1 to $5 \%$ of talc did not affect the dissolution rates of these drugs ( 35 ). It has been postulated that the stearates soften and spread under compression to provide a more coherent coverage of matrix than talc $(34,35,36)$. 
Another possible reason as to why talc has less deleterious effects than magnesium stearate is that due to its adsorption ability talc may not retard water penetration to the extent suggested by its hydrophobicity. Also an adsorbent like talc would provide a large surface area for adsorption of drugs from solution, thereby maintaining a high concentration gradient for the precipitated drug to redissolve. Wuster et al. (37) has shown that presence of an adsorbent increases dissolution by increasing the apparent saturation concentration for a drug.

For a given adsorbent the affinity and extent of adsorption will depend on nature of drug (molecular weight, pKa, lipophillicity) and its environmental conditions ( $\mathrm{pH}$, ionic strength and temperature). Adsorption studies of drugs by talc have shown that talc has a much lower adsorption affinity and capacity compared to adsorbents like kaolin (38) and activated charcoal $(39,40)$. Using activated attapulgite (41), which is a similar mineral to talc, it was shown that the rate of drug absorption was less rapid compared to an aqueous solution but much faster compared to formulation containing activated charcoal. In addition, the drug bioavailability in presence of attapulgite was complete as with aqueous solution, but incomplete in presence of activated charcoal. Monkhouse et al. $(42,43)$ have reported that rapid dissolution of drugs by rapid desorption from an adsorbent surface of silica type compounds occurred and that 
H-bonding and van der Waals forces accounted for this rapid desorption. So the adsorption by talc of a drug with poor aqueous solubility would facilitate the drugs dissolution rate and the desorption will allow full availability of drug. The desorption of drug and adsorption of solvent molecules onto adsorbent surface will occur as the contents at adsorption site becomes diluted.

4.3. Effect of Talc on Chemical and Physical stability of Tablets.

Aspirin in presence of talc showed 1\% decomposition compared to $15 \%$ decomposition in presence of magnesium stearate, when tablets containing aspirin, phenacetin, and caffeine were stored at $45^{\circ} \mathrm{C}$ for 5 weeks (44). Of the four USP talcs that were studied only one of the talc induced aspirin instability to the maximum extent of producing about $1 \%$ salicylic acid when the tablets were stored for 4 weeks at $40^{\circ} \mathrm{C}$ and at relative humidity of $90 \%$ (2). The $\mathrm{pH}$ of the talcs did not appear to be related to aspirin stability, and washing talcs with hydrochloric acid greatly reduced the influence of talcs on aspirin stability (2). It was concluded that impurities in talc responsible for reducing aspirin stability were calcium carbonate, calcium silicate, but not aluminum silicate or ferric oxide (2). Nazareth et al. (45) reported that formulations containing calcium succinate alone or in combination with calcium carbonate, 
but not calcium carbonate alone accelerated decomposition of aspirin into salicylic acid in tablets stored at room temperature or $45^{\circ} \mathrm{C}$ at unspecified humidity conditions. Physical stability of tablets, containing acetaminophen, stored at $40^{\circ} \mathrm{C}$ in dry condition for ten weeks, showed that those tablets lubricated with $1 \%$ talc plus $0.25 \%$ magnesium stearate had better appearance compared to tablets lubricated with $0.5 \%$ magnesium stearates only. In addition the hardness and rapid disintegration times of these tablets did not change (34).

\section{Miscellaneous Uses of Tale}

Polymer films use dispersed insoluble solid filler materials such as talc to accelarate the build up of film coat structures on particles or tablets, thereby reducing coating time and costs (46). Talc gave a more varied and complex surface than titanium dioxide (46), and it was suggested that this may be due to variation in elemental content of talcs as determined by their source of deposit (46).

Talc in the range of 0 to $50 \%$ was included as an additive in the formulation of an enteric-coated microcapsules prepared by spray drying. Presence of talc greatly improved the microcapsules flow properties and compressibility for tableting. In addition, the greater the 
percentage of talc used the greater was the increase in tablets crushing strength (47).

\section{Conclusions}

Talc is extensively used in a wide variety of cosmetic products, particularly in powder products. Talc keeps the skin feeling smooth and dry. Talc in the pharmaceutical industry is used as a glidant and lubricant. The glidants such as talc improve flow properties of powder by decreasing interparticulate friction, by decreasing van der Waals forces and electrostatic charges, by changing particle size distribution, and probably by decreasing the effect of humidity on surfaces of host particles by forming a mechanical barrier. The loosely bound lattice layers slide over each other and form roller structures which explains its lubrication characteristics. Talc has less deleterious effect compared to magnesium stearate on tablet in vitro properties.

\section{References}

1. R. W. Grexa and C. J. Parmentier, Cosmet. Toiletries, 94, 29 (1979).

2. G. Gold and J.A. Campbell, J. Pharm. Sci., 53, 52 ( 1964$)$.

3. V. Kinglake, Soap Perfume Cosmet., 54, 399 ( 1981 ).

4. V. Kinglake, Soap Perfume Cosmet., 54, 607 (1981). 
5. T. Mifsui, S. Fukushima and S. Takada, J. Soc. Cosmet. Chem., 23, 525 (1972).

6. Anon, Soap Perfume Cosmet., 55, 368 (1982).

7. R. L. Raymond, Cosmet. Toiletries., 94, 49 (1979).

8. A. F. El-Shimi, J. Soc. Cosmet, Chem,, 28, 37 (1977).

9. A. Herzka, J. Soc. Cosmet. Chem., 21, 553 (1970).

10. J. J. Sciarra, A. Iannacone and L. Mores, J. Soc. Cosmet. Chem., 27, 209 (1976).

11. T. Mitsui and S. Takada, J. Soc. Cosmet. Chem., 20, 335 (1969).

12. P. Rohdewald, Cosmet. Perfume, 90, 35 (1975).

13. G. Gold, R.N. Duvall, B.T. Palmers et.al., J. Pharm. Sci. 57, 2153 (1968).

14. G. Reier, R. Cohn, S. Rock et.al., J. Pharm. Sci. 57, 660 ( 1968$)$.

15. G. Gold, R.N. Duvall, B.T. Palmers and J.G. Slater, J. Pharm. Sci., 57, 667 (1968).

16. P. York, J. Pharm. Sci., 64, 1216 (1975).

17. H. G. Kristensen and V. G. Jensen, Dansk Tidssky. Farm., 43,205 (1969).

18. F. C. Hammerness and H. O. Thompson, J. Pharm. Sci., 47, $58(1958)$.

19. G. Gold, R.N. Duvall, B.T. Palmero and J.G. Slater, J. Pharm. Sci., 1291 (1966).

20. D. Train and J. A. Hersey, J. Pharm. Pharmacol., 12, 97T (1960). 
21. A. Kassem and S. Said, Can. J. Pharm. Sci., 10, 92 (1975).

22. G. Gold and B. T. Palmers, J. Pharm. Sci., 54, 310 (1965).

23. G. Gold and B. T. Palmers, J. Pharm. Sci., 54, 1517 ( 1965$)$.

24. E. Nelson, L.W. nagri, L.W. Busse and T. Higuchi, J. Pharm. Sci., 43, 596 (1954).

25. W. A. Strickland, E. Nelson, I. W. Busse and T. Higuchi, J. Pharm. Sci., 45, 51 (1956).

26. W. A. Strickland, T. Higuchi and L.W. Busse, J. Pharm. Sci., 49, 35 (1976).

27. C. J. Lewis and E. Sholton, J. Pharm. Pharmacol., 17, Suppl. 82 S (1965).

28. B. Mechtersheimer and H.Sucker, Pharm. Tech., 10, 38 (1986).

29. C.J. Lewis and D. Train, J. Pharm. Pharmacol., 17, 577 (1965).

30. Y. Matsuda, Y. Minamuda and S. Hayashi, J. Pharm. Sci., 65,1155 (1976).

31. P. L. Jarozz and E.L. Parrott, Drug Dev. Indus. Pharm., 4259 ( 1984$)$.

32. E. Shotton and C.J. Lewis, J. Pharm. Pharmacol., 16, $111 \mathrm{~T}(1964)$.

33. S. Dawoodbhai, H.R. Chueh and C.T. Rhodes, Drug Dev. Indus. Pharm., 13, 2441 (1987). 
34. G. Levy and R.H. Gumtow, J. Pharm. Sci., 52, 1139 (1963).

35. T.A. Iranloye and E.L. parrott, J. Pharm. Sci., 67, 535 (1978).

36. Shah, A.C., and Mlodozeneic, A.R., J. Pharm. Sci., 66, 1377 ( 1977 ).

37. D. E. Wuster and G.P. Polli, J. Pharm. Sci., 50, 403 (1961).

38. N. H. Batuyios and E.A. Brecht, J. Pharm. Sci., 46, 524 (1957).

39. F. Ganjian, A.U. Cutie and T. Jochskerger, J. Pharm. Sci., 69, 352 (1980).

40. D. Sorby and E.M. Plein, J. Pharm. Sci., 50, 355 (1961).

41. D. Sorby, J. Pharm. Sci., 54, 677 (1965).

42. D. C. Monkhouse and J.I. lach, J. Pharm. Sci., 61, 1430 (1972).

43. D. C. Monkhouse and J.O. Lach, J. Pharm. Sci., 61, 1435 (1972).

44. M. R. Nazareth and C.I. Huyck, J. Pharm. Sci., 50, 620 (1961).

45. M. R. Nazareth and C.L. Huyck, J. Pharm. Sci., 50, 608 $(1961)$.

46. J. W. Parker, G.E. Peck and G.S. Banker, J.Pharm. Sci. 63, $119(1974)$.

47. H. Takenaka, Y. Kawashima and S.Y.Lin, J. Pharm. Sci 69, $1388(1980)$. 


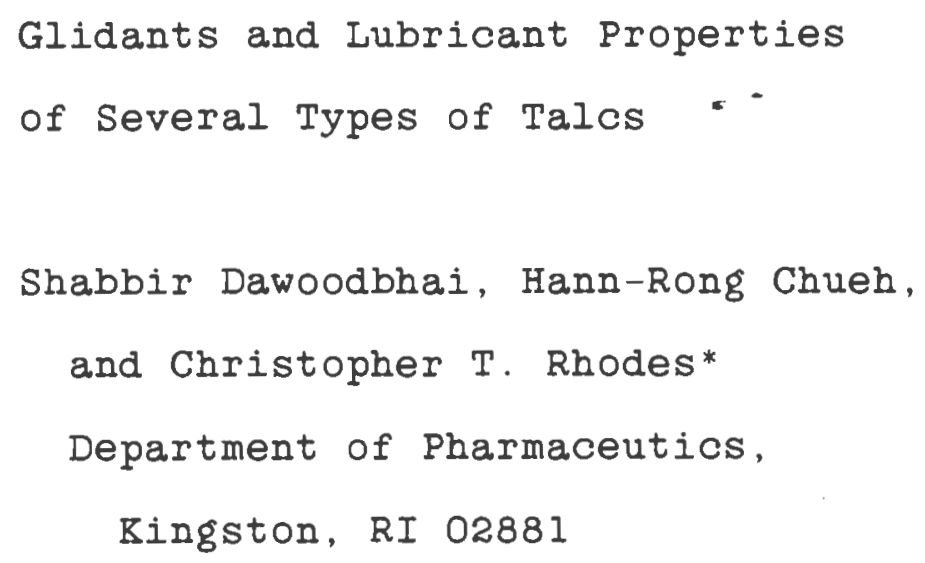

\begin{abstract}
Glidant and lubricant efficiencies of a number of different types of talos were evaluated. The in vitro properties of tablets lubricated with talos were compared to those lubricated with magnesium stearate. Talc lubricated tablets showed superior in vitro properties compared to magnesium stearate lubricated tablets. Different sources of talcs showed significant differences in glidant and lubricant efficiencies.
\end{abstract}

\title{
INTRODUCTION
}

A number of different types of talas were obtained from Cyprus Industrial Mineral Company. The objective of this study was to determine the potential glidant and lubricant efficiencies of these talcs. Also to determine the effects of these talos on tablets in vitro properties 
and to test the physical stability of some of these tablets.

\section{METHODS}

\section{Glidant Properties of Talcs}

The physical properties of the talcs available from the Cyprus Industrial Mineral Company are shown in Table 1. A recording powder flowmeter was used for evaluating the glidant efficiencies of these talcs. The recording powder flowmeter equipment consisted of a Mettler PR-1200 top loading electronic balance connected to a strip chart recorder with a linear potentiometer. The linear potentiometer reduced the analog signal output from the balance to a level suitable for input into the strip chart recorder. The glass funnel used as the hopper had $12 \mathrm{~cm}$ top diameter, $11 \mathrm{~cm}$ length and $1.2 \mathrm{~cm}$ orifice diameter. $100 \mathrm{~g}$ of powder was poured into the funnel with the orifice closed. When the orifice was opened the powder flowed into the beaker and a trace was obtained on the strip chart recorder. The chart speed was set at $30 \mathrm{~cm} / \mathrm{min}$.

The formulation used for the powder flow study consisted of 55\% Emcompress and 45\% acetaminophen which had been mixed for 5 minutes on a turbula mixer. The talc was 
TABLE 1

Properties and Sources of Tales Used in This Study

Geographic Density (Ibs/ft) Percent Undersize

Talcs ${ }^{\mathrm{a}}$ Source Loose Tapped Median(um) 'lOum 20 um

\begin{tabular}{|c|c|c|c|c|c|c|}
\hline Altalc $300^{*}$ & Montana & 20 & 48 & 6 & 75 & 95 \\
\hline Altalc $400^{*}$ & Montana & 16 & 41 & 4 & 90 & 98 \\
\hline Altalc 500* & Montana & 14 & 37 & 3 & 95 & 99 \\
\hline Alabama $300^{*}$ & Alabama & 19 & 51 & 6 & 68 & 86 \\
\hline Alabama 400* & Alabama & 16 & 45 & 4 & 80 & 97 \\
\hline $\begin{array}{l}\text { Beaverwhite } \\
325^{*}\end{array}$ & Montana & 21 & 40 & 6 & 66 & 88 \\
\hline Supra & Italian & 26 & 58 & 15 & 39 & 64 \\
\hline $\begin{array}{l}\text { Suprafino } \\
\text { Alpha Glide }\end{array}$ & Italian & 16 & 44 & 5 & 85 & 99 \\
\hline $\begin{array}{l}200^{*} \\
\text { Alpha GIide }\end{array}$ & Italian & 26 & 59 & 13 & 41 & -- \\
\hline $325^{*}$ & Italian & 16 & 40 & 5 & 88 & -- \\
\hline
\end{tabular}

$a_{A I l}$ Products and Information Supplied By Cyprus Industrial Minerals Company.

*USP Grade 
then added in concentration of $0.0 \%$ to $0.5 \%$ and mixed for further 3 minutes. The flow of each of the $100 \mathrm{~g}$ of formulation was done in triplicate. The mass flow rate and the linearity were determined.

\section{Lubricant Properties of Talcs}

An instrumented stokes B-2 rotary press was used for evaluating the lubricant efficiencies of talcs. The compression and ejection forces were measured by the piezo electric transducers located in the eyebolt and the ejection cam respectively. The analog data from the piezo

electric transducers were converted to the digital form by the analog to the digital converter. The digital output was then collected and analyzed on Apple II computer.

$250 \mathrm{~g}$ of the formulation as shown in Table 2 was prepared and mixed for 6 minutes on the turbula mixer. The tablets were compressed at fixed press settings and the press speed was set at 24 revolutions per minute. The output of force against time data was collected for 10 tablets per minute in triplicate.

The tests done to determine the in vitro properties of the tablets prepared included USP weight variation test, crushing strength, friability, USP disintegration test and USP dissolution test. In addition the physical stability test was done on tablets made with model acetaminophen formulations as shown in which Table 2 which additionally 
also contained $0.5 \%$ of primogel. The physical stability test involved storing the tablets in an oven at $40^{\circ} \mathrm{C}$ in closed and open containers, in dry environmental conditions, for 10 weeks. The properties of these tablets were compared to their initial properties prior to start of the physical stability study. The data were evaluated using one way fixed effects ANOVA and least significant difference test, at significance level of 0.05 .

\section{RESULTS AND DISCUSSION}

\section{Powder Flow Studies}

The literature suggests that the 3 major factors that influence the flowability of powders are the particle properties, the environmental conditions and the testing methods. The particle properties includes the particle shape (1). The spherical and the oblong shaped particles flow easily while the sharp edged particles flow less readily. The flow becomes poorer with irregularly shaped particles and the flow is even more adversely affected by the formation of bridges which tends to occur particularly with plate shaped and the fibrous type particles. Glidants are postulated to improve the flowability of powders by decreasing the surface rugosity of the irregularly shaped particles $(1,2)$ and also by reducing van der Waals 
TABLE 2

Formulations Used For Evaluating Lubricañt Efficiencies of Talcs

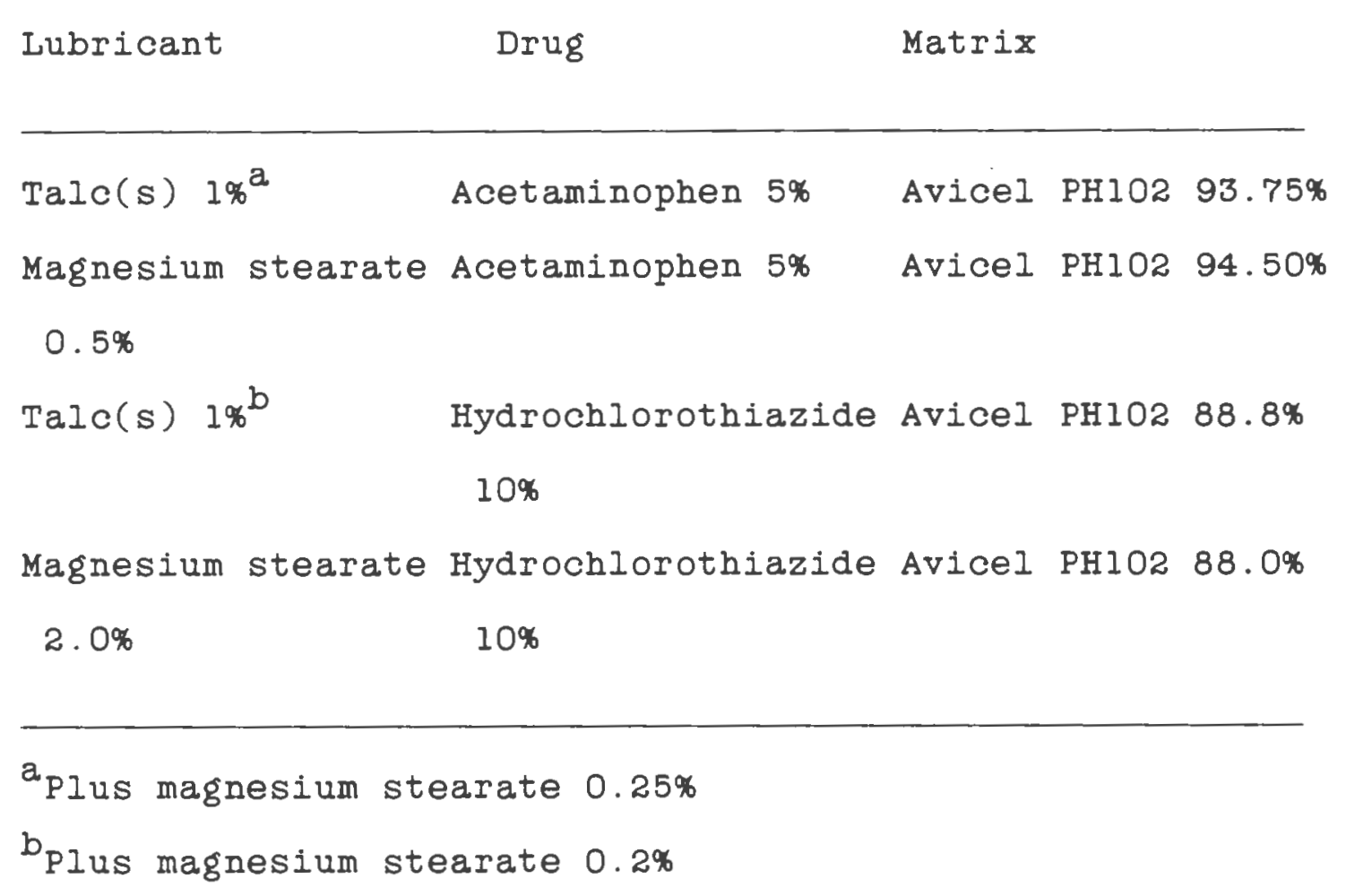


attractions $(2,3)$ among particles, thereby preventing formation of bridges.

The particle size is another easily evident factor that differs between the free flowing and the poor flowing or cohesive powders. The cohesive powders poor flow is due to their large surface area available for interparticulate friction resulting in development of electrostatic charges and the adsorption of moisture and gases. It is postulated that glidants tend to minimize these tendencies and collect very fine host particles on glidant surfaces $(1,2)$.

Another particle property that influences the powder flow is the particle size distribution. Several studies have shown that the powder flow is greatly influenced by the proportion of the fines present in the powder. The flow rate of a ternary mixture of magnesium oxide was shown to increase as proportion of fines in the mixture was increased (4). However, an excess of fines usually adversely affects the powder flow (3). Other particle properties that tend to affect the flow are the particle density, the particles elastic and plastic deformation properties (5).

The second major factor that influences the flow of the particles is the environment. The humidity affects the particle moisture content. In addition to adsorbing moisture, the particles adsorb gases and impurities present in the environment (5). 
The third major factor that affects the flowability of the powders is the testing methods. Some of the factors that can control the rate at which the powder emerges from the circular orifice are the shape of the hopper $(6,7)$. The flow contours of powder in a flat bottom hopper have been studied. The particles in the center of the hopper flow faster, and the particles next to the wall flow the slowest. The stationary region of powder next to the wall of the hopper slows the flow rate of the powder adjacent to the wall. This wall effect is minimal when the difference between diameter of container and the diameter of hopper orifice is greater than 30 times the diameter of the particle and also when the ratio of the diameter of the container to that of the orifice is greater than the value 2.5 (8). The height of the powder column in the hopper does not affect the flow rate, unless the head of the powder column falls below the height of 2.5 times the diameter of the container at which point the flow rate will increase (8). Another factor that affects the flow of powder from the hopper is the bulk density. One of the reasons why addition of fines to regular size particles increases the flow rate is that, the fines tend to fill the voids between the larger particles and thereby increase the bulk density. Consequently a greater mass per unit volume is discharged and therefore the flow rate is increased. However, the use of very high percentage of fines will fully fill the voids 
between the larger particles and therefore increase the interparticulate friction ( 8 ).

The single most important factor that influences the flow rate is hopper orifice diameter $(4,8)$. The flow rate in grams per second is proportional to the orifice diameter raised to the power $n$, for many materials the value of $n$ is between 2.5 and 3.2 (6).

Jones and Pipel (4), and Danish and Parrot (8) have developed more precise relationships between the diameter of hopper orifice and the flow rate. These equations take into consideration the factors that are functions of particle size, particle shape, particle surface roughness, the density of the powder material and the hopper geometry. Most of the studies in the literature have expressed results in terms of flow rate. Another function that is important in addition to flow rate is the uniformity or the linearity of flow. This was evaluated qualitatively by Gold et al. (9) and quantitated by Hegde et al (7) using the linearity powder flow index. The linearity powder flow index is the difference between the square of the least square correlation coefficient and the minimal value of 0.8 multiplied by 100 . The linearity combined with flow rate can be of great help in formulation development, quality control and scale up trouble shooting. 


\section{Glidant Properties of Tales}

The basic avenues available for improving the flow rate of powders are precompression, wet granulation, and addition of glidants. The selection of glidants and their concentration is empirical since there is no generally acceptable method for evaluating the glidant effectiveness. Gold et al. (3) highlighted some of the ways in which the glidants affect the powder flow. They obtained f-values which is the ratio of the powder flow rate in the presence of the glidant compared to the flow rate in the absence of the glidant. F-values greater than one indicated increased flow rate, while f-values less than one indicated decreased flow rate upon addition of glidant. Using lactose powder they showed that addition of up to $20 \%$ of fines increased f-values. However, addition of talc or magnesium stearate produced even higher f-values compared to addition of fines. Therefore glidants increased the flow rate by an additional mechanism other than just an increase of the percent of fines. They also found that talc was less able to increase the flow compared to magnesium stearate. They suggested that magnesium stearate was able to decrease van der Waal's forces to a greater extent compared to talc. Perhpas talc would have been a more efficient glidant if the surface rugosity of the lactose powder particles used was high. Further increases in the concentrations of magnesium stearate and talc decreased the flow rates probably by 
altering the particle size distribution of the lactose powder.

The talcs used in this powder flow study are commercially available and their physical properties are shown in Table 1. The powder loose density ranged from 14 to $26 \mathrm{lbs} / \mathrm{ft}^{3}$ while the tapped density ranged from 37 to 58 lbs $/ \mathrm{ft}^{3}$. The median particle size ranged from 3 to $15 \mathrm{um}$. The percent undersize, for ' 10 um particle size ranged from 39 to $95 \%$ and for $<20$ um particle size ranged from 64 to 99\%. There is no correlation apparent between the talcs physical properties and-their glidant efficiencies.

As shown in Table 3 and 4 the relative standard deviation values for flow rate and linearity data are extremely low indicating very highly reproducible results. The mass flow rate data of the powder flow study are shown in Figure 1,2 and 3 . Using quite low talc concentrations, it was found that Ultraglide 325, Altalc 400, Beaverwhite tales gave maximal flow rate at $0.1 \%$ talc concentration. In addition Supra, Alabama 300 and Alabama 400 also gave maximal flow rate at $0.1 \%$ concentration. The remaining 4 talcs, Altalc 500, Ultraglide 200, Suprafino, Altalc 300 gave increasing flow rate up to $0.25 \%$ talc concentration.

Table 5. compares the flow rate and linearity data for $0.1 \%$ and $0.25 \%$ of talcs concentrations. In summary, supra has best glidant action at $0.1 \%$, while Altalc 500 has 
TABLE 3

Reproducibility of Flow Rates

\begin{tabular}{cccccc} 
Percent & Flow Rate $(\mathrm{gm} / \mathrm{sec})$ & Relative standard \\
Altalc 300 & 1 & 2 & 3 & Deviation (\%) \\
0 & 10.79 & 10.83 & 10.84 & 0.28 \\
0.1 & 11.46 & 11.55 & 11.69 & 0.95 \\
\hline
\end{tabular}

TABLE 4

Reproducibility of linearity of Powder Flow

\begin{tabular}{cccccc}
\hline $\begin{array}{c}\text { Percent } \\
\text { Altalc } 300\end{array}$ & 1 & 2 & 3 & $\begin{array}{c}\text { Relative Standard } \\
\text { Deviation \% }\end{array}$ \\
\hline 0 & 19.78 & 19.80 & 19.76 & 0.1 \\
0.1 & 19.80 & 19.90 & 19.87 & 0.26 \\
\hline
\end{tabular}




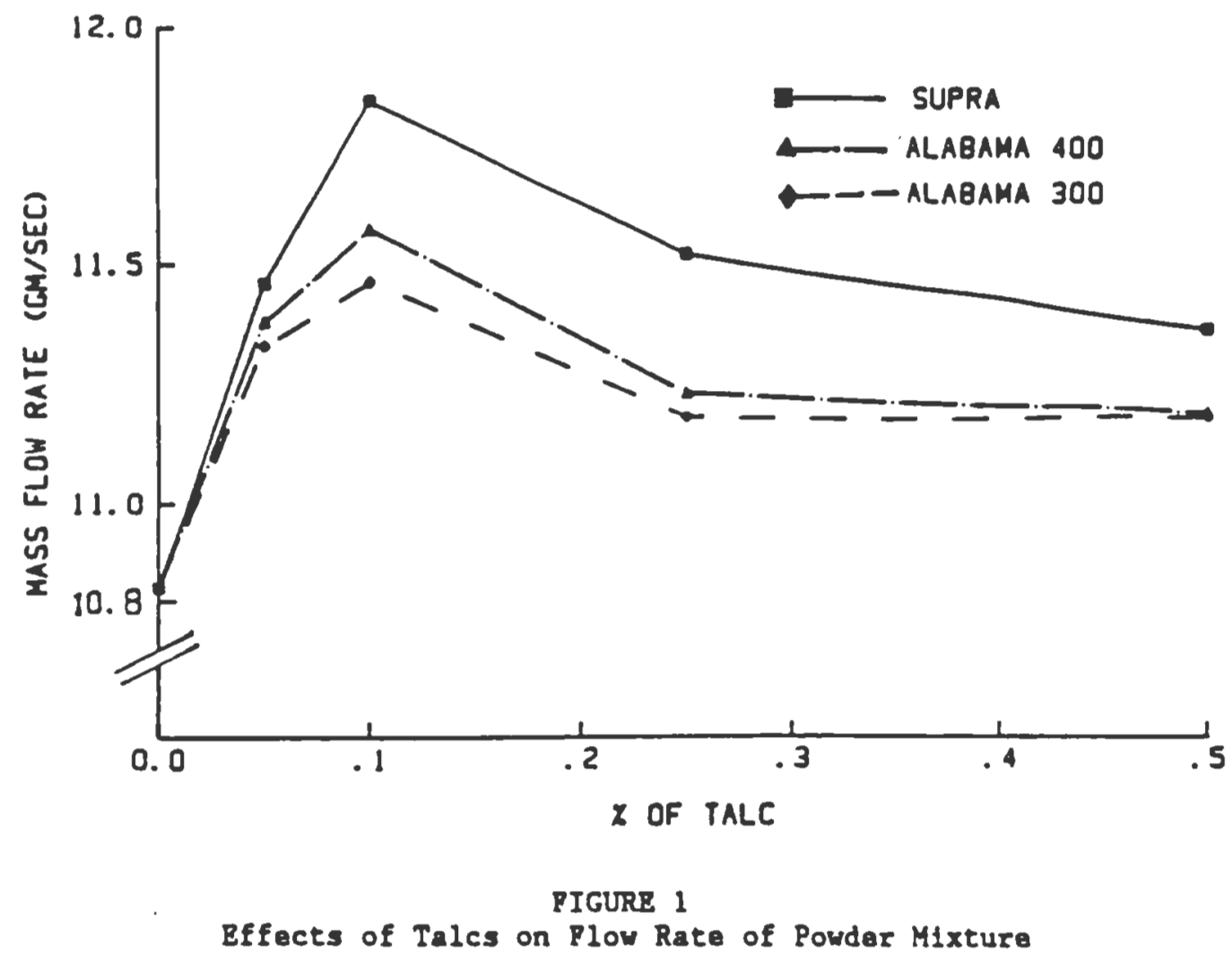




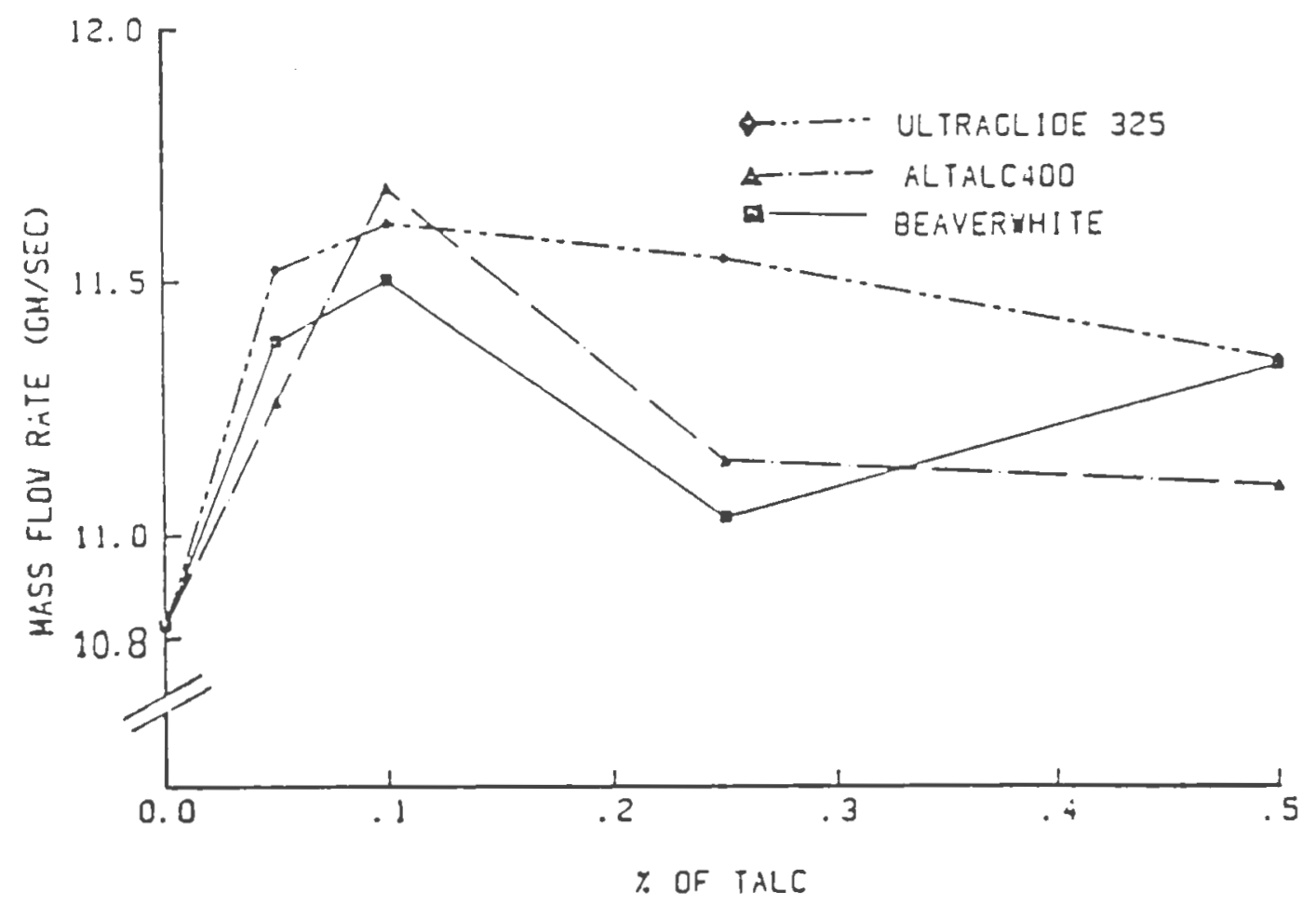

FIGURE 2

Fefects of Tales on Flow Rate of Powder Mixture 


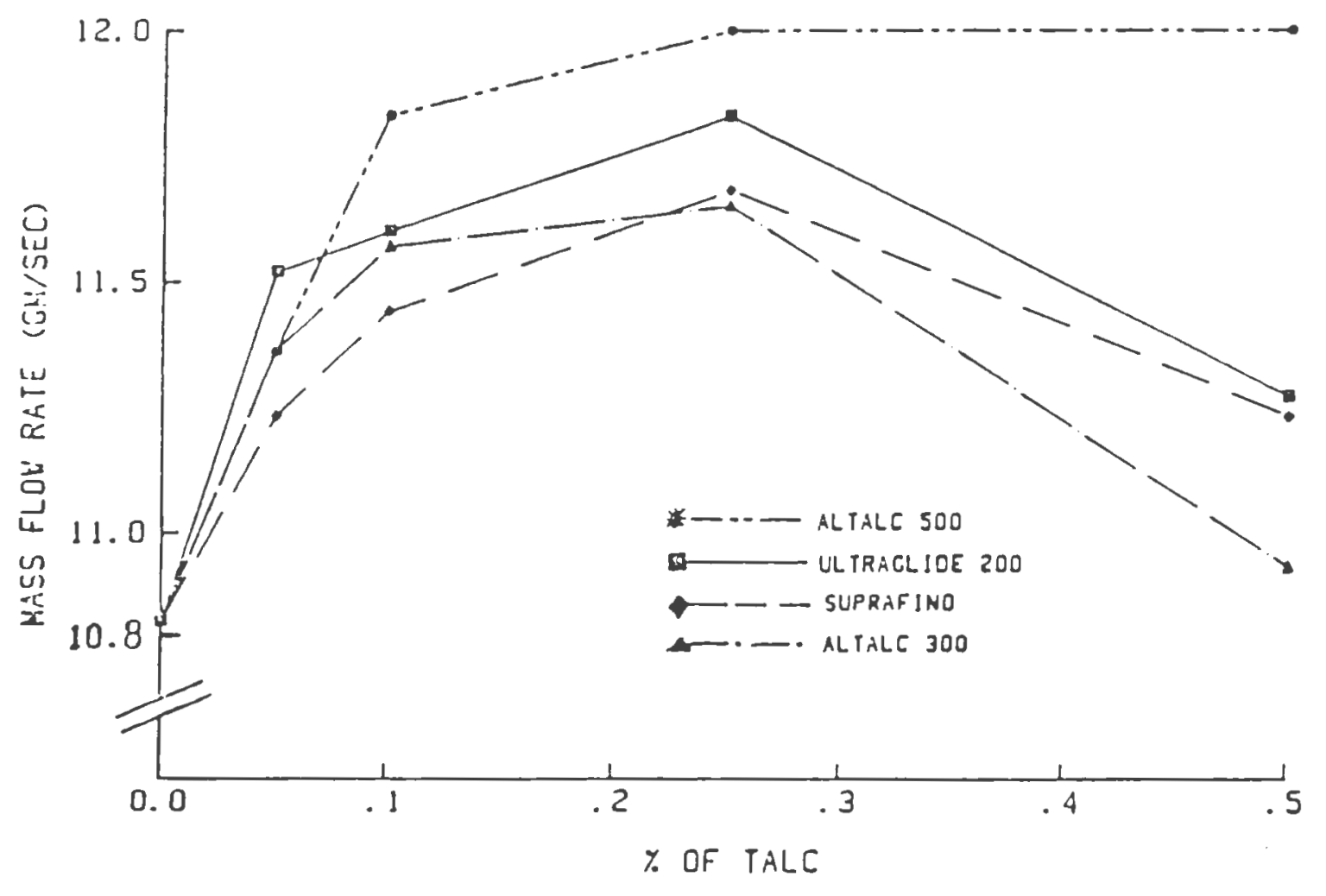

FIGIRE 3

Effects of Talcs on Flow Rate of Powder Mixture 
TABLE 5

Comparisons of Mass Flow Rates and Lineárity Values of Acetaminophen and Emcompress Powder Mixture

\begin{tabular}{|c|c|c|c|c|}
\hline \multirow[b]{2}{*}{ Talc } & \multicolumn{2}{|c|}{$0.10 \%$} & \multicolumn{2}{|c|}{$0.25 \%$} \\
\hline & $\begin{array}{c}\text { Flow rate } \\
\text { (G/sec) }\end{array}$ & Linearity & $\begin{array}{c}\text { Flow rate } \\
(G / \text { sec })\end{array}$ & Linearity \\
\hline
\end{tabular}

$\begin{array}{lcccc}\text { Altalc 500 } & 11.83 & 19.86 & 12.04 & 19.86 \\ \text { Supra } & 11.84 & 19.85 & 11.52 & 19.85 \\ \text { Ultraglide } & 11.60 & 19.86 & 11.83 & 19.82\end{array}$

200

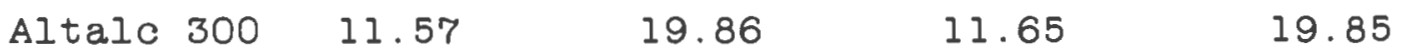

$\begin{array}{lllll}\text { Suprafino } & 11.44 & 19.78 & 11.68 & 19.86\end{array}$

$\begin{array}{lllll}\text { Altalc } 400 & 11.68 & 19.80 & 11.14 & 19.80\end{array}$

$\begin{array}{lllll}\text { Ultraglide } & 11.61 & 19.82 & 11.54 & 19.82\end{array}$

325

$\begin{array}{lllll}\text { Alabama } 400 & 11.57 & 19.81 & 11.23 & 19.80\end{array}$

$\begin{array}{lllll}\text { Beaverwhite } & 11.50 & 19.84 & 11.03 & 19.84\end{array}$

325
Alabama 300
11.46
19.80
11.18
19.81 
best glidant action at $0.1 \%$ and $0.25 \%$ of talc

concentrations. The glidant efficiency of $0.1 \%$ supra or Altalc 500 is same as that of $0.25 \%$ Ultraglide 200 . As the flow rate increased with addition of talc, linearity also tended to increase, although no statistically significant differences in linearity values could be shown.

\section{Tablet Lubricants Studies}

There are studies in the literature that have investigated the use of talc as tablet lubricant. Efficient lubrication in tablet manufacturing is of considerable importance in order to promote the production of elegant tablets at an optimum rate with minimum stress on the tablet press, by facilitating the ejection of tablets. Talc is particularly helpful in preventing the sticking and picking of tableting mass to the punch faces (10). While magnesium stearate is more useful for preventing the binding of the tableting mass to the die wall (10). The efficiency of lubricants may be evaluated by determination of their physical properties such as water solubility (11), shear strength (12) and melting point (13). These studies report that efficient lubricants tend to have low water solubility, low shear strength and low melting point. However, critical review of the literature suggests that lubricant efficiency is better predicted by evaluation on instrumented tablet press compared to evaluation based on the physical and 
chemical properties of the lubricants. The lubricant efficiency on an instrumented tablet press can be evaluated in a variety of ways. Addition of lubricant to a formulation increases the force transmitted to the lower punch and decreases the frictional force at die wall (14). The $R$-values range from 0.6 for poor lubricant to 1.0 for perfect lubricant. The $R$ values have been criticized for not being sufficiently sensitive. Other studies have also measured frictional force at die wall and/or radial die wall force. Probably a better indicator of lubricant efficiency is the ejection force, since it takes into consideration the adhesion force as well as the frictional force at the die wall. The ejection energy (15) may be a more accurate indicator of lubricant efficiency. Decrease in ejection force or ejection energy values indicate improvement in lubricant efficiency.

\section{Lubricant Properties of Talcs}

The lubricant efficiencies of talcs were evaluated by measuring the force required for the ejection of $300 \mathrm{mg}$ acetaminophen tablets. Using one way fixed effects ANOVA and the least significant difference test, the lubricant efficiency of $1 \%$ Altalc 300 and $1 \%$ supra was found not to be significantly different from that of $0.25 \%$ magnesium stearate. One percent of Alabama 300 and the Altalc 400 was 
$15.3 \%$ less efficient while $1 \%$ Alabama 400 was $29.8 \%$ less efficient compared to $0.25 \%$ magnesium stearate.

The lubricant efficiencies of talcs were also determined using model hydrochlorothiazide formulation as shown in Table 2. The lubricant efficiencies were evaluated using ejection force values. Compared to $1 \%$ Supra, the lubricant efficiency of $1 \%$ Alabama $300,1 \%$ Altalc 400 and $1 \%$ Alabama 400 was $3.9 \%$ less efficient, while Altalc 300 was 10\% less efficient.

Several studies have evaluated the efficiency of lubricants using ejection force values $(13,14,15,16,17)$. The evaluation of lubricant efficiency of talc based on ejection force values as in this study and in the literature $(11,14,15,17)$ indicates that on equal weight basis talc is less efficient than magnesium stearate. Numerous studies have shown that lubricant efficiency can be improved by increasing concentration of lubricant. Magnesium stearate lubricant action is due to formation of a film which coats the surfaces of the tableting mass $(16,18)$, and the tooling. Talc is a laminar solid whose layers slip and roll over one another in the direction of motion (19). Lubricant efficiency of talc is unlikely to increase with increase in compaction force because this rolling over action of talc becomes restricted. In addition higher concentration of talc is required compared to magnesium stearate because talc forms a barrier of monoparticulate layer while magnesium 
stearate forms a molecular film barrier $(16,18)$.

Furthermore, the lubricant efficiency of magnesium stearate increases with increasing mixing time, because it shears during mixing and becomes attached onto the unlubricated surfaces $(18,20)$. Matsuda et al (15) showed that better lubricant efficiency was obtained when magnesium stearate and talc was mixed with granules just prior to compaction compared to incorporation of lubricant at the granulation stage.

Both talc and magnesium stearate are hydrophobic lubricants $(10,11)$. However, magnesium stearate is more efficient at covering the surfaces of the particles compared to talc (15) and therefore able to interfere with bonding between particles during consolidation. Therefore magnesium stearate has much greater deleterious effect than talc on tablet hardness $(16,17,20,21)$ and percent friability.

Furthermore, magnesium stearate prolongs disintegration time (16,20,22) and unlike talc, the magnesium stearate decreases the dissolution rate of drug $(23,24)$. Therefore there is merit in examining the possible use of magnesium and talc combinations (17) in order to optimize the lubricant efficiency and tablet performance properties.

\section{Tablet Properties}

The in vitro properties of the tablets made in this study from model acetaminophen formulations and model 
hydrochlorothiazide formulation are shown in Table 6 and 7 .

The appearance of these tablets were evaluated in a controlled, double blind cross over study. The model acetaminophen formulations tablets appearance were similar in all respects for various talcs and magnesium stearate lubricated tablets. However, the magnesium stearate only and the Altalc 400 lubricated tablets had slightly more cracked edges. In case of the hydrochlorothiazide formulation the magnesium stearate lubricated tablets had pitted top and bottom surfaces and slightly cracked edges. These defects were absent in all talc lubricated tablets.

The talc lubricated tablets of model acetaminophen or hydrochlorothiazide formulations were considerably harder in varying degrees compared to magnesium stearate and Alabama 300 lubricated tablets. Also the tablets lubricated with the talcs had better friability properties. In particular the Altalc 300, and Altalc 400 lubricated tablets gave considerably less friable tablets compared to magnesium stearate lubricated tablets. The disintegration time of talc lubricated tablets disintegration time ranged from 22 to 25 seconds. There was no statistically significant difference in the dissolution rate of acetaminophen from $1 \%$ talc plus $0.25 \%$ magnesium stearate lubricated tablets compared to $0.5 \%$ magnesium stearate lubricated tablets as shown in Table 8 . The dissolution rate of hydrochlorothiazide from $1 \%$ talc plus $0.2 \%$ magnesium 
Table 6

Properties of Acetaminophen Tablets

\begin{tabular}{|c|c|c|c|c|c|c|c|}
\hline Lubricant & $\begin{array}{l}\text { Tablet } \\
\text { Weight (mg) }\end{array}$ & $2^{R S I)^{b}}$ & $\begin{array}{l}\text { Percent } \\
\text { llegvier }\end{array}$ & $\begin{array}{r}\text { IIardness }{ }^{d} \\
\left(K_{g}\right)^{-}\end{array}$ & $\begin{array}{l}\text { Percent } \\
\text { llarder }\end{array}$ & $\begin{array}{l}\text { Percent } \\
\text { Iriability }\end{array}$ & $\begin{array}{l}\text { Dis integration } \\
\text { lime (sec) }\end{array}$ \\
\hline Alabama 400 & 306.8 & 0.30 & 104.7 & 12.0 & 131.9 & 0.18 & 25 \\
\hline Altalc 400 & $303.6 \mathrm{f}$ & $0.41 \mathrm{~g}$ & $103.6 \mathrm{r}$ & $11.3 \mathrm{i}$ & 124.2 & 0.07 & 25 \\
\hline Alabama 300 & $300.3 \frac{f}{f}$ & $0.68^{\prime \prime}$ & 102.5 & 10.5 & $115.4 !$ & 0.14 & 25 \\
\hline Alta|c 300 & $299.4^{t}$ & $0.47^{8}$ & $102.2^{1}$ & $10.2 !$ & $112.1 !$ & 0.07 & 25 \\
\hline Supra & 293.1 & 0.720 & 100.0 & 10.3 & 113.2 & 0.21 & 25 \\
\hline $\begin{array}{l}\text { Magnesium } \\
\text { Stearate }\end{array}$ & 309.2 & $0.43^{g}$ & - - & 9.1 & 100.0 & 0.30 & 25 \\
\hline
\end{tabular}

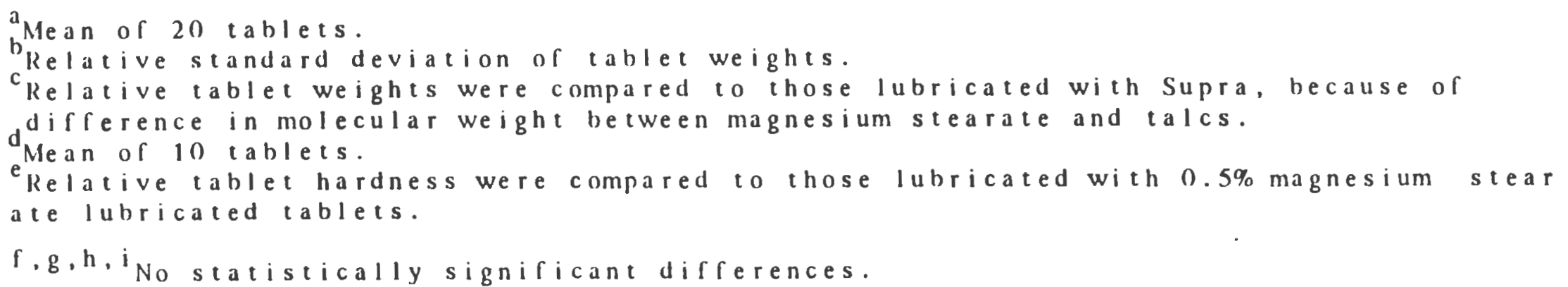


Iable 7

Properties of llydrochlorothiazide lablets

\begin{tabular}{|c|c|c|c|c|c|c|c|}
\hline l.ubricant & $\begin{array}{l}\text { lablet }{ }^{a} \\
\text { Weight }(\mathrm{mg})\end{array}$ & $R S D^{b}$ & $\begin{array}{l}\text { l'ercent } \\
\text { lleavier }\end{array}$ & $\begin{array}{l}\text { Hardness } \\
(K g)\end{array}$ & $\begin{array}{l}\text { Percent } \\
\text { llarder }\end{array}$ & $\begin{array}{l}\text { Percent } \\
\text { litability }\end{array}$ & $\begin{array}{c}\text { Dis integration } \\
\text { Time (Sec) }\end{array}$ \\
\hline Altalc 300 & 246.6 & 0.28 & 102.3 & 5.3 & 120.5 & 0.04 & 20 \\
\hline Alabama 300 & 245.0 & $0.16^{\mathrm{g}}$ & 101.6 & 4.4 & 100.0 & 0.12 & 18 \\
\hline Supra & 243.3 & 0.33 & 100.9 & $5.1 \mathrm{~h}$ & $115.9_{h}$ & 0.08 & 20 \\
\hline Alta $\mid c \quad 400$ & 242.2 & $0.15^{\mathrm{g}}$ & 100.5 & $4.7^{n}$ & $106.8^{n}$ & 0.08 & 20 \\
\hline Alabama 400 & 241.1 & 0.31 & 100.0 & $4.8^{h}$ & $109.1^{h}$ & 0.12 & 22 \\
\hline $\begin{array}{l}\text { Magnesium } \\
\text { Stearate }\end{array}$ & 257.1 & 0.91 & - - & 2.8 & $\ldots$ & 0.50 & 25 \\
\hline
\end{tabular}

\footnotetext{
Mean of 20 tablets.

Relative standard deviation of tablet weights.

CRelative tablet weights were compared to those lubricated with Alabama 400 because of difference in molecular weight between magnesium stearate and talcs.

Mean of 10 tablets.

Relative tablet hardness were compared to those lubricated with Alabama 300 because of greater percent of magnesium stearate used (Table 2 ).

r. ${ }^{\text {No }}$ statistically signiricant dirferences.
} 
TABLE 8

Dissolution Rate of Acetaminophen From Tablets

\begin{tabular}{lccccc}
\hline & \multicolumn{5}{c}{ Percent of drug dissolved* } \\
& 15 min & 30 min & 40 min & 60 min \\
\hline Altalc 300 & $59.3(4.1)$ & $81.4(1.2)$ & $89.9(0.1)$ & $97.6(2.5)$ \\
Altalc 400 & $51.2(1.5)$ & $72.0(2.4)$ & $81.2(1.6)$ & $93.4(1.2)$ \\
Alabama 300 & $55.5(5.0)$ & $74.7(6.4)$ & $83.2(5.3)$ & $93.6(0.2)$ \\
Alabama 400 & $59.3(2.7)$ & $79.4(1.7)$ & $84.4(1.6)$ & $93.5(1.5)$ \\
Supra & $60.2(6.4)$ & $81.4(3.2)$ & $90.3(4.2)$ & $96.8(3.2)$ \\
Magnesium & $54.3(2.9)$ & $81.5(1.4)$ & $93.1(0.2)$ & $99.4(0.5)$ \\
Stearate & & & & \\
\hline
\end{tabular}

* The value in parenthesis is standard deviation. 
stearate lubricated tablets compared to $2.0 \%$ magnesium stearate lubricated tablets was statistically significantly different for example, at 10 minutes the percent of hydrochlorothiazide dissolved from magnesium stearate only lubricated tablet is $56 \%$ compared to $92 \%$ from talc lubricated tablets, see Table 9. The properties of tablets made from the model acetaminophen formulations to which $0.5 \%$ primogel had been added was evaluated after undergoing physical stability test as shown in Table 10. The tablets lubricated with $1 \%$ talc and $0.25 \%$ magnesium stearate had less cracked edges compared to tablets lubricated with $0.5 \%$ magnesium stearate. The open and closed container tablets showed a decrease in mean weight of about $2.5 \%$ while Altalc 400 and Altalc 300 lubricated tablets showed a decrease in weight of $2.0 \%$ and $1.4 \%$ respectively. The hardness values remained unchanged compared to their initial values at the start of the physical stability test. The disintegration time values for talc and magnesium stearate only lubricated tablets was 25 seconds.

The relationship between lubricant efficiency and effects of lubricants on tablet hardness has yet to be fully delineated. In case of magnesium stearate as the tablet lubricant, the decrease in tablet hardness correlates with the increase in disintegration time $(16,20)$ because the hydrophobicity decreases the contact angle of water with 
TABL.L: 9

Dissolution Rate of llydrochlorothiazide lirom Tablets

\begin{tabular}{|c|c|c|c|c|c|c|c|}
\hline & & & Perc & ent of Drug & Dissolved & & \\
\hline & & $5 \mathrm{~min}$. & $10 \mathrm{~min}$. & $15 \mathrm{~min}$ & $25 \mathrm{~min}$ & $35 \mathrm{~min}$ & $60 \mathrm{~min}$. \\
\hline Magnesil & $\mathrm{um}$ & & & & & & \\
\hline Stearat & & $34.5(4.5)$ & $56.6(1.4)$ & $75.8(4.9)$ & $89.0(2.3)$ & $95.3(2.3)$ & $99.2(0.8)$ \\
\hline$A|t a| c$. & 300 & $78.0(1.2)$ & $89.8(1.0)$ & $96.4(1.2)$ & $98.2(0.6)$ & $98.6(0.5)$ & $98.8(0.7)$ \\
\hline$A|t a| c$ & 400 & $78.6(2.0)$ & $91.7(1.5)$ & $94.6(0.6)$ & $98.4(0.9)$ & $99.5(0.7)$ & $100(0.0)$ \\
\hline Al a bama & 300 & $83.1(2.6)$ & $92.0(1.5)$ & $95.6(1.6)$ & $99.0(0.9)$ & $99.7(0.4)$ & $100(0.0)$ \\
\hline Al a bama & 400 & $78.9(0.8)$ & $93.0(1.3)$ & $96.2(1.5)$ & $99.8(0.4)$ & $100(0.0)$ & $100(0.0)$ \\
\hline Supra & & $77.5(2.5)$ & $92.0(2.0)$ & $95.4(1.0)$ & $99.2(0.7)$ & $99.7(0.3)$ & $100(0.0)$ \\
\hline
\end{tabular}

*The value in parenthesis is standard deviation. 


\section{TABLE 10}

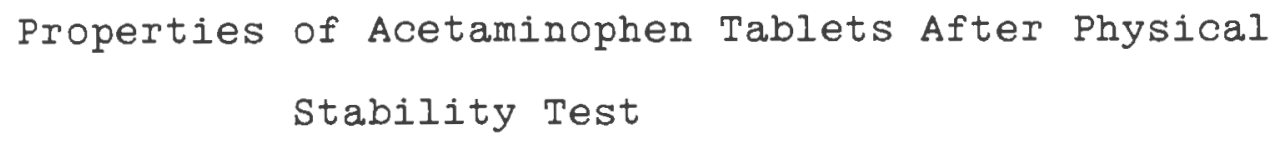

Decrease in Percent Mean Weight

Magnnesium

\begin{tabular}{lrrcc} 
Container Altalc & 300 & Altalc 400 & Supra & Stearate \\
Open & 2.5 & 2.4 & 2.5 & 2.5 \\
Close & 1.4 & 2.0 & 2.4 & 2.5 \\
\hline
\end{tabular}


capillary pore in the tablet (22). Levy and Gumtow found that magnesium stearate retarded the dissolution rate of salicylic acid, and that the presence of starch as disintegrant did not improve the dissolution from tablets lubricated with magnesium stearate (23). Similarly, a prolonged mixing of magnesium stearate in a formulation, decreased the dissolution rate of salicylic acid (20). The dissolution rate of salicylic acid and aspirin decreased somewhat exponentially with increase in magnesium stearate concentration but the presence of talc had no effect on dissolution rate (24).

\section{CONCLUSIONS}

The data from the literature and the present study clearly indicate that talc has excellent glidant properties and is likely to be of great value in remedying any powder flow problem. Quite low concentrations of talc have a very substantial effect on powder flow. Although the lubricant efficiency of talc (as quantified by ejection forces) is less than equal weights of magnesium stearate, talc by itself or in combination with magnesium stearate has considerable potential as a lubricant.

Tablets made with talc as a lubricant have a significantly better appearance and hardness than comparable tablets containing magnesium stearate. For some drugs at least the dissolution rate of talc lubricated tablets is 
superior to those lubricated by magnesium stearate alone. Different sources of talc show significant differences in glidant and lubricant efficiency. In summary, the talcs studied in this investigation clearly merit careful consideration as pharmaceutical adjuvants. For hydrochlorothiazide, often regarded as the classic example of a drug liable to biological availability problems, tablets lubricated by talc have improved dissolution compared to similar tablets lubricated by magnesium stearate above. Additionally, for some systems talc can improve hardness, friability and appearance. It is noteworthy that different sources of talc show significant variation in their effect on tablet properties. Thus, companies using talc for pharmaceutical purposes should give attention to uniformity of the quality of the material which they use.

Work on the pharmaceutical uses of talc is continuing in this laboratory and will be published in due course.

\section{REFERENCES}

1. R.J.Lantz and J.B. Schwartz in "Pharmaceutical Dosage Forms: Tablets," 2, H.A. Lieberman and L. Lachman, eds., Marcel Dekker, Inc., (1981), p 22.

2. P. York, J. Pharm. Sci., 64, 1216 (1975).

3. G. Gold, R.N. Duvall, B.T. Palermo and J.G. Slater, J. Pharm, Sci., 57, 667 (1968).

4. T.M. Jones and N. Pilpel, J. Pharm. Pharmacol, 18;81 
(1966).

5. G.E. Amidon and M.E. Houghton, Pharm. Manufacturing, 7, 21 (1985).

6. N. Pilpel in "Bentley's Textbook of Pharmaceutias," E.A. Rawlins, ed., Bailliere Tindall, 1977, p 248.

7. R.P. Hegde, S.W. Rheingold and C.T. Rhodes, J. Pharm. Sci., 74, 11 (1985).

8. F.Q. Danish and E.L. Parrott, J. Pharm. Sci., 60, 548 (1971).

9. G. Gold, R.N. Duvall, B.T. Palmero and J.G. Slater, J. Pharm. Sci., 57, 1291 (1966).

10. G. Banker, G. Peck and G. Bailey, in "Pharmaceutical Dosage Forms: Tablets", 1, H.A. Lieberman and L. Lachman, eds., Marcel Dekker, Inc. 1980, p 88.

11. W.A. Strickland, T. Higuchi and L.W. Busse, J. Pharm. Sci., 49, 35 (1976).

12. C.J. Lewis and D. Train, J. Pharm. Pharmacol, 17, 577 (1965).

13. E. Shotton and C.J. Lewis, J. Pharm. Pharmacol., 17, Suppl. 825 (1965).

14. E. Nelson, L.W. Nagvi, L.W. Busse and T. Higuchi, J. Pharm. Sci., 43, 596 (1954).

15. Y. Matsuda, Y. Minamida and S. Hayashi, J. Pharm. Sci., 65, 1155 (1976).

16. W.A. Strickland, E. Nelson, L.W. Busse and T. Higuchi, Pharm. Sci., 45, 51 (1956). 
17. B. Mechtersheimer and H. Tucker, Pharm. Tech., 10, 38 (1986).

18. G.K. Bolhuis, C.F. Lerk, H.T. Zijlstra and A.H. DeBoer, Pharm. Weekblad, 110, 317 (1975).

19. D. Train and J.A. Hersey, J. Pharm. Pharmacol., 12, 977 ( 1960$).$

20. A.C. Shah and A.R. Mlodozeneic, J. Pharm. Sci., 66, 1377 ( 1977 ).

21. P.L. Jarosz and E.L. Parrott, Drug Dev. Ind. Pharm., 4, $259(1984)$.

22. D. Ganderton, J. Pharm. Pharmacol., 21, Suppl., 95 (1969).

23. G. Levy and R.H. Gumtow, J. Pharm. Sci., 52, 1139 (1963).

24. T.A. Iranloye and E.L. Parrott, J. Pharm. Sci., 67, 535 ( 1978$)$. 


\title{
Use of Talc as a Major Component of a Direct Compression Tablets Matrix
}

\author{
Shabbir. Dawoodbhai and Christopher T. Rhodes \\ Department of Pharmaceutics \\ University of Rhode Island \\ Kingston, RI 02881-0809.
}

Talcs in substantial percentages were evaluated for their potential as a direct compression matrix material. With commonly used excipients such as microcrystalline cellulose and lactose, the formulations were self lubricating and the tablets ejected easily. Tablets with very low friability, high crushing strength, rapid dissolution rates, good weight uniformity, content uniformity and potency of drugs were obtained. At similar compression forces, tablet hardness with 300 grade of Alabama, Altalc, and Beaverwhite talcs was significantly greater than corresponding 400 and 500 grades.

\section{Introduction}

Talc has been evaluated as a glidant and as a lubricant with anti-adherent properties on its own or in combination with magnesium stearate (1-6). It has been shown that talc has much less deleterious effect on tablet in vitro properties compared to magnesium stearate (2-8). 
In particular the hardness of the tablets made with direct compression materials such as microcrystalline cellulose $(4,5,7,8)$ and of lactose $(5-8)$ is greatly decreased by magnesium stearate. Hence, we decided to investigate whether talc could be used in large percentages as a major component of tablet matrix in combination with commonly used direct compression excipients such as microcrystalline cellulose and lactose. Our objectives were to obtain formulations that had good flow and compressibility properties for commonly used drugs using talc as a major component in direct compression formulations. In addition it was hoped that these tablet formulations would have low friability, good hardness, rapid disintegration and dissolution rates.

\section{Materials}

The direct compression formulations had the following percentages $(w / w)$ composition:

Formula I - Hydrochlorothiazide 6.25\% (Schering Corporation, Kenilworth, New Jersey), talc $21 \%$ or $26 \%$ (Cyprus Industrial Minerals Company, Mobile, Alabama), Primogel 4\% (Generichem Corporation, Little Falls, New Jersey), and Avicel PH-102 $68.75 \%$ or $63.75 \%$ (FMC, Philadelphia, Pennsylvania), 80g mixed for 3 minutes 45 seconds. 
Formula II - Niacin 6.25\% (Sigma Chemical, St. Louis, Missouri), talc $30 \%$, and Avicel PH-102, $55 \mathrm{~g}$ mixed for 3 minutes 23 seconds.

Formula III - Niacin 6.25\%, talc 10\%, Primogel 4\% and direct tableting lactose $79.75 \%$ (Scheffield Products, Norwich, New York), $100 g$ mixed for 1 minute 32 seconds.

Formula IV - Phenylpropanolamine 12.5\% (Sigma Chemical, St. Louis, Missouri), talc $26 \%$ and Avicel PH-102 61.50\%, $80 \mathrm{~g}$ mixed for 5 minutes.

Formula V - Theophylline 25.0\% (Sigma Chemical, St. Louis, Missouri), talc $21.0 \%$, and Avicel PH-102 50\%, $100 \mathrm{~g}$ mixed for 5 minutes 20 seconds.

Formula VI - Magnesium stearate 1 or 2\% (Fisher Scientific, Fair Lawn, New Jersey) was used in place of talc for formulas I to $V$ above, with the above respective quantities and corresponding mixing times. The properties of the talcs used in this study are shown in Table 1.

\section{Method}

The components of the various tablet formulations were mixed in the turbula mixer. An instrumented Stokes B-2 rotary tablet press was used as described previously (4). Five tablets were evaluated for appearance (magnifying glass), ten tablets were evaluated for friability (Erweka Friabilator; Chemical and Pharmaceutical Industry, New York, 
Table 1: properties of talcs used in this study.

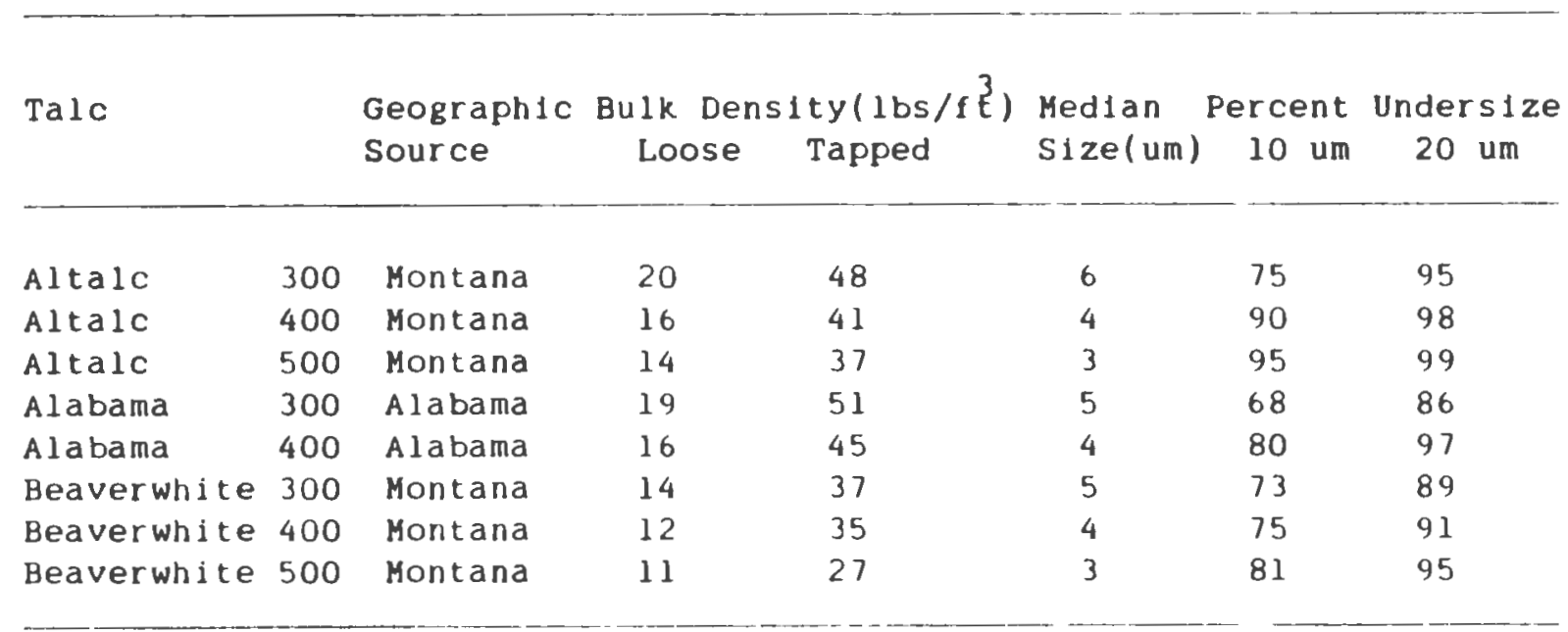

Information obtained from Cyprus Industrial Minerals company. 
New York), and crushing strength (Erweka Hardness Tester; Chemical and Pharmaceutical Industry, New York, New York). Six tablets were evaluated for disintegration time (USP Disintegration Time Tester, Vanderkamp; Van-Kel Industries, Chatham, New Jersey), and dissolution of drug (Basket or Paddle, USP; Vanderkamp; Van-kel Industries, Chatham, New Jersey). Dissolution test procedures specified in the USP monographs were used for hydrochlorothiazide and theophylline. For niacin and phenylpropanolamine the paddle method at $50 \mathrm{r} . \mathrm{p} . \mathrm{m}$. was used with $900 \mathrm{ml}$ and $500 \mathrm{ml}$ respectively of degassed deionized distilled water as dissolution medium. Additionally, to ensure total release of drug, the agitation speed was increased to 150 r.p.m for 45 minutes at the end of which a sample of dissolution medium was obtained, this sampling time is referred to as $T_{\infty}$. The samples concentration were measured on the Diode Array Spectrophotometer (Hewlett Packard; Loveland, Colarado) at the wavelengths specified in the USP. Dilutions of the sample were necessary for the theophylline tablets.

\section{Result and Discussion}

The appearance of all the tablets were pharmaceutically elegant. In general, the talc containing tablets had virtually no surface defects such as pitting, edge chipping or cracking, while slightly cracked or chipped 
edges were occasionally found on the baseline formulation VI tablets. The talc containing tablets surface had matt appearance, and infrequently showed sight faint grey specs on the tablet surface or faint grey line on the side of the tablets, while the baseline tablets had a slightly more glossy appearance.

The data for formula I (Tables 2 and 3 ) demonstrates that the tablets of weight with low relative standard deviation and good compressibility can be produced. The ejection forces (lubrication) were similar for all the talcs. At similar compression forces the tablet hardness with the 300 grade of the Alabama, Altalc, Beaverwhite, was statistically significantly greater than the corresponding 400 and 500 grades. These tablets of formula I had very low friability and rapid disintegration times. The dissolution rate was similar from these talc containing tablets with high and low tablet hardness values. The dissolution rate of hydrochlorothiazide was rapid and exceeded the USP requirement of not less than $60 \%$ release by 30 minutes. The baseline formulation VI (Tables 3 and 4) had lower ejection force and similar properties as formulation I tablets with regard to weight variation, disintegration time and dissolution rate. In addition, both formula I and its baseline formula VI tablets had acceptable content uniformity and potency of hydrochlorothiazide tablets, as 
Table 2: Properties of formula I tablets weighing 400mg.

\begin{tabular}{|c|c|c|c|c|c|c|c|c|c|}
\hline \multicolumn{2}{|l|}{ Talc } & Percent & $\begin{array}{l}\text { Compression } \\
\text { Force }(\mathrm{KN})\end{array}$ & $\begin{array}{l}\text { Ejection } \\
\text { Force }(\mathrm{KN})\end{array}$ & $\begin{array}{l}\text { Weight } \\
\text { RSD }\end{array}$ & Hardness & $\begin{array}{l}\text { Percent } \\
\text { Friability }\end{array}$ & \multicolumn{2}{|c|}{$\begin{array}{l}\text { Disintegratio } \\
\text { Time (seconds }\end{array}$} \\
\hline Alabama & 300 & 21.0 & $13.9(0.3)$ & $0.38(0.01)$ & 0.3 & $12.4(0.5)$ & 0.1 & 23 & $3-26$ \\
\hline Alabama & 300 & 26.0 & $13.6(0.3)$ & $0.42(0.01)$ & 0.3 & $6.6(0.7)$ & 0.3 & 26 & -30 \\
\hline Alabama & 400 & 21.0 & $13.7(0.3)$ & $0.40(0.01)$ & 0.3 & $11.5(0.5)$ & 0.1 & 21 & $1-23$ \\
\hline Alabama & 500 & 21.0 & $13.8(0.2)$ & $0.38(0.01)$ & 0.3 & $10.8(0.4)$ & 0.1 & 21 & $1-22$ \\
\hline Altalc & 300 & 21.0 & $13.9(0.2)$ & $0.39(0.01)$ & 0.3 & $14.3(0.5)$ & 0.2 & 20 & -23 \\
\hline Altalc & 400 & 21.0 & $13.7(0.2)$ & $0.38(0.01)$ & 0.3 & $11.2(0.3)$ & 0.2 & 20 & -23 \\
\hline Altalc & 500 & 21.0 & $13.7(0.3)$ & $0.38(0.01)$ & 0.3 & $10.0(0.8)$ & 0.2 & 22 & -24 \\
\hline Beaverwhite & 300 & 21.0 & $13.8(0.2)$ & $0.39(0.01)$ & 0.3 & $13.4(0.4)$ & 0.2 & 20 & -22 \\
\hline Beaverwhite & 400 & 21.0 & $13.7(0.2)$ & $0.39(0.01)$ & 0.2 & $12.6(0.3)$ & 0.2 & 22 & $2-26$ \\
\hline Beaverwhite & 500 & 21.0 & $13.8(0.3)$ & $0.39(0.01)$ & 0.3 & $11.1(1.1)$ & 0.2 & 22 & $2-24$ \\
\hline Mag. Stearat & & 1.0 & $12.1(0.2)$ & $0.07(0.00)$ & 0.3 & $5.2(0.7)$ & 0.7 & 7 & $7-12$ \\
\hline
\end{tabular}

All values in parenthesis are standard deviations 
Table 3: Dissolution properties of hydrochlorothiazide

from formula $I$ and its formula VI tablets

Formulation Percent of Drug Released at Time (minutes)

$\begin{array}{llccc}\text { Talc or } & \text { Formulation } & \text { Percent of Drug Released at Time (minutes) } \\ \text { Magnesium Stearate } & \text { Percentage } & 30 & 40 & \text { Too }\end{array}$

$\begin{array}{lcccrr}\text { Alabama } & 300 & 21.0 & 89.6(3.1) & 93.0(2.1) & 99.4(0.6) \\ \text { Alabama } & 300 & 26.0 & 87.5(2.9) & 92.4(3.3) & 100.4(1.0) \\ \text { Alabama } & 400 & 21.0 & 83.6(3.5) & 87.5(4.1) & 100.5(1.2) \\ \text { Alabama } & 500 & 21.0 & 89.2(4.6) & 93.8(4.0) & 100.0(0.8) \\ \text { Altalc } & 300 & 21.0 & 97.2(1.2) & 101.2(1.3) & 104.7(0.6) \\ \text { Altalc } & 400 & 21.0 & 86.2(3.3) & 91.4(3.1) & 100.4(1.0) \\ \text { Altalc } & 500 & 21.0 & 85.8(2.5) & 91.6(2.4) & 99.6(1.1) \\ \text { Beaverwhite } & 300 & 21.0 & 90.1(0.5) & 94.4(0.5) & 100.0(0.9) \\ \text { Beaverwhite } & 400 & 21.0 & 89.5(1.0) & 93.5(1.1) & 99.3(1.2) \\ \text { Beaverwhite } 500 & 21.0 & 88.9(1.9) & 93.5(1.5) & 100.6(0.8) \\ \text { Magnesium Stearate } & 1.0 & 85.2(11.3) & 92.7(5.7) & 98.2(2.4)\end{array}$

All values in parenthesis are standard deviations 
Table 4: Properties of formula VI tablets weighing $400 \mathrm{mg}$

\begin{tabular}{|c|c|c|c|c|c|c|c|c|}
\hline Drug & $\begin{array}{l}\text { Percent } \\
\text { Mg.Str. }\end{array}$ & $\begin{array}{l}\text { Compression } \\
\text { Force }(\mathrm{KN})\end{array}$ & $\begin{array}{l}\text { Ejection } \\
\text { Force (KN) }\end{array}$ & $\begin{array}{l}\text { Welght } \\
\text { RSD }\end{array}$ & Hardness & $\begin{array}{l}\text { Percent } \\
\text { Fr1abil1ty }\end{array}$ & $\begin{array}{l}\text { Disint } \\
\text { Time ( }\end{array}$ & $\begin{array}{l}\text { egration } \\
\text { ninutes) }\end{array}$ \\
\hline Hydrochlorothiazlde & 1.0 & $12.1(0.2)$ & $0.07(0.00)$ & 0.3 & $5.2(0.7)$ & 0.7 & 0.1 & -0.2 \\
\hline Niacin ${ }^{\star}$ & 2.0 & $11.9(0.2)$ & $0.09(0.01)$ & 0.3 & $11.5(0.8)$ & 0.1 & 0.6 & -0.9 \\
\hline Niacin & 2.0 & $13.8(0.2)$ & $0.60(0.01)$ & 0.3 & $8.9(1.5)$ & 0.3 & 7.5 & -9.0 \\
\hline Phenyl propanolamine & 2.0 & $8.5(0.1)$ & $0.11(0.00)$ & 0.3 & $6.4(0.7)$ & 0.2 & 0.2 & -0.4 \\
\hline Theophylline & 2.0 & $11.9(0.2)$ & $0.12(0.00)$ & 0.3 & $7.5(0.5)$ & 0.2 & 0.6 & \\
\hline
\end{tabular}

* Niacin tablets of weight $375 \mathrm{mg}$.

Mg.Str. refers to magnesium stearate.

All values in parenthesis are standard deviations 
determined by USP dissolution test. It is noteworthy that all the talc containing formulations hat "considerably greater tablet crushing strength and lower friability compared to their baseline formulation. The data for the formula II (Tables 5 and 6 ) shows that tablets with high crushing strength, low percent friability, shorter disintegration time and rapid dissolution rate can be obtained with the talc present at the $30 \%$ level. The tablets weight relative standard deviation were very low and the properties of the tablets obtained with different talc grades were similar. The baseline formulation VI (Tables 4 and 6 ) had slightly lower ejection force, and lower relative standard deviation for tablet weight but prolonged disintegration time. The dissolution rate from the baseline formulation was faster compared to formula II tablets. The tablets of formula III (Tables 5 and 6 ) and its baseline formulation VI (Tables 4 and 6) have very similar properties except that the formula III tablets have much greater hardness, and shorter disintegration time.

Tables 7 and 8 show the data for formula IV. These tablets have very similar properties to their baseline formulation VI (Tables 4 and 8 ). However, the baseline formulation had lower ejection force and slightly shorter 
Table 5: Properties of formula II and formula III tablets weighing 400mg

\begin{tabular}{|c|c|c|c|c|c|c|c|c|}
\hline Talc & & Percent & $\begin{array}{l}\text { Compression } \\
\text { Force }(\mathrm{KN})\end{array}$ & $\begin{array}{l}\text { Ejection } \\
\text { Force (KN) }\end{array}$ & $\begin{array}{l}\text { Welght } \\
\text { RSD }\end{array}$ & Hardness & $\begin{array}{l}\text { Percent } \\
\text { Frlability }\end{array}$ & $\begin{array}{l}\text { Disintegration } \\
\text { Time (minutes) }\end{array}$ \\
\hline Alabama & 300 & 30.0 & $12.0(0.5)$ & $0.34(0.01)$ & 0.8 & $11.8(1.1)$ & 0.3 & $0.4-0.8$ \\
\hline Alabama & 400 & 30.0 & $12.0(0.4)$ & $0.34(0.01)$ & 0.7 & $11.3(0.3)$ & 0.3 & $0.4-0.8$ \\
\hline
\end{tabular}

* Refers to formula III

All values in parenthesis are standard deviations 
Table 6: Dissolution properties of niacin from formula II, formula III and their formula vi tablets

\begin{tabular}{lccccc}
\hline & & Formulation & Percent of & Drug Released at Time (minutes) \\
Magnesium stearate & Percentage & 5 & 10 & Too \\
\hline & & & & & \\
\hline
\end{tabular}

All values in parenthesis are standard deviations 
Table 7: Properties of formula IV and formula V tablets weighing $400 \mathrm{mg}$

\begin{tabular}{|c|c|c|c|c|c|c|c|c|}
\hline Talc & & Percent & $\begin{array}{l}\text { Compression } \\
\text { Force }(\mathrm{KN})\end{array}$ & $\begin{array}{l}\text { Ejection } \\
\text { Force }(\mathrm{KN})\end{array}$ & $\begin{array}{l}\text { We } 1 \text { ght } \\
\text { RSD }\end{array}$ & Hardness & $\begin{array}{l}\text { Percent } \\
\text { Fr1ab111ty }\end{array}$ & $\begin{array}{l}\text { Disintegration } \\
\text { Time (minutes) }\end{array}$ \\
\hline Beaverwhite & 300 & 26.0 & $8.4(0.2)$ & $0.24(0.01)$ & 0.3 & $7.0(0.6)$ & 0.1 & $0.8-1.0$ \\
\hline Beaverwhite & 300 & 21.0 & $12.0(0.3)$ & $0.27(0.01)$ & 0.8 & $12.8(3.5)$ & 0.1 & 0.3 \\
\hline
\end{tabular}

All values in parenthesis are standard deviations 
Table 8: Dissolution properties of phenylpropanolamine from formula IV and theophylline from formula $V$ and their formula $V I$ tablets

Formulation Percent of Drug Released at Sampling Times

Talc or Magnesium Stearate Percentage

1

2

$\begin{array}{lrlrr}\text { Beaverwhite } 300 & 26.0 & 85.1(10.5) & 94.9(7.7) & 100.0(4.1) \\ \text { Magnesium Stearate } & 2.0 & 81.4(9.6) & 89.6(6.0) & 100.0(2.2) \\ \text { Beaverwhite 300 } & 21.0 & 90.6(5.8) & 92.6(4.9) & 99.7(0.8) \\ \text { Magnesium Stearate } & 2.0 & 96.8(1.5) & 97.8(0.9) & 97.9(0.5)\end{array}$

Formula IV sampling times in minutes were 5,10 and Too

Formula VI sampling times in minutes were 30,40 , and Too

All values in parenthesis are standard deviations 
disintegration time compared to formula IV tablets.

The formula $V$ tablets (Tables 7 and 8 ) have much greater crushing strength, very low percent friability, rapid disintegration, higher ejection forces, and slightly higher tablet weight relative standard deviation compared to the baseline formulation VI tablets (Tables 4 and 8 ). Although the dissolution of theophylline from the baseline formulation VI tablets was slightly more rapid compared to formula IV tablets, both formulations exceeded the USP requirement of not less than $80 \%$ release in 45 minutes. In addition, the tablets from both formulations had acceptable. content uniformity and potency of theophylline as determined by the USP dissolution test.

Talc, although an hydrophobic material like magnesium stearate, does not seem to have as deleterious effect on dissolution of drugs as does magnesium stearate (2-4,6). Using compressed disk of aspirin, salicylic acid and equimolar mixture of aspirin and salicylic acid an in increase in concentration of magnesium stearate from 0.1 to $5 \%$ progressively slowed dissolution rate (2). While 0.I to $5 \%$ of talc did not affect the dissolution rates of these drugs (2). It has been postulated that the stearates soften and spread under compression to provide a more coherent coverage of matrix than talc $(2-3)$. In this study we found that even with very large percentages of talc the dissolution rates of the drugs remained quite similar to 
those obtained with the baseline formulations containing 1 or $2 \%$ of magnesium stearate. Levy et al. (3) reported that initial dissolution rate of salicylic acid from rotating disk was faster with talc compared to magnesium stearate. Levy et al. (3) concluded that hydrophobic lubricants retard dissolution rate of drugs contained in compressed tablets by prolonging disintegration time and by reducing the area of interface between drug particle and the solvent.

Another possible reason as to why talc has less deleterious effect than magnesium stearate is that due to its adsorption ability talc may not retard water penetration to the extent suggested by its hydrophobicity. Also an adsorbent like talc would provide a large surface area for adsorption of drugs from solution, thereby maintaining a high concentration gradient for the precipitated drug to redissolve. The commonly used pharmaceutical excipient such as microcrystalline cellulose has also been shown to adsorb drugs (9). Wuster et al. (10) has shown that the presence of an adsorbent increases the dissolution by increasing the saturation concentration for the drug.

Adsorption studies of drugs by talc have shown that talc has a much lower adsorption affinity and capacity compared to kaolin (11) and activated charcoal (12,13). Using activated attapulgite (14), which is a similar mineral to talc, it was shown that the rate of drug absorption was less rapid compared to an aqueous solution. However, the 
drug bioavailibility in presence of attapulgite was complete as with aqueous solution. Monkhouse et ai. $(15,16)$ reported that dissolution of relatively insoluble drugs such as hydrochlorothiazide can be enhanced by miniscular drug delivery system, which involves rapid desorption of drug from the large surface area of adsorbent of silica type compounds.

For plastically deforming materials the tensile strength and the crushing strengths of tablets are reduced by materials used as lubricants. This is because the coating of the particle surface by lubricant reduces the " extent of bonding between particles during compression $(5,7,8)$. Magnesium stearate was reported to markedly decrease the axial tensile strength relative to radial tensile strength for microcrystalline cellulose tablets even at $0.25 \%$ concentration. While the effects with talc up to 6 to $8 \%$ on the axial to radial ratio of tensile strength was a moderate decrease for microcrystalline cellulose tablets (5). Jarosz and Parrott (5) concluded that for microcrystalline cellulose tablets the capping potential was greater with magnesium stearate compared to talc. It is note worthy that in this study that the tablets of hydrochlorothiazide and theophylline containing microcrystalline cellulose with $21 \%$ talc had greater crushing strength compared to their baseline tablets containing 1 or $2 \%$ magnesium stearate respectively. In 
addition tablets of phenylpropanolamine containing microcrystalline cellulose with $26 \%$ talc had similar hardness compared to their baseline tablets containing $2 \%$ magnesium stearate. Also for anhydrous lactose tablets increase in magnesium stearate concentrations progressively decreased the ratio of axial to radial tensile strength. However, with talc a slight increase in ratio of axial to radial tensile strength was observed with anhydrous lactose tablets (5). Therefore the capping potential for anhydrous lactose tablets was greater with magnesium stearate compared to talc. In this study niacin tablets containing lactose and $10 \%$ talc had greater tablet crushing strength compared to tablets containing $2 \%$ magnesium stearate. In general, the friability of all talc containing tablets was less or similar to their respective baseline formulations. Gadalla et al. (6) recently reported that $3 \%$ of talc was most suitable lubricant for formulation of double compressed aspirin tablets while magnesium stearate was found to be the worst suitable lubricant.

\section{Conclusions}

Talc can successfully be used as a major component of direct compression tablet formulation. The talc containing tablets prepared during this study had good weight uniformity, content uniformity and potency of the drugs. Tablets with very low friability, high crushing 
strength, and rapid dissolution rates were obtained using talc in large percentages as a major component of tablet matrix with commonly used excipients such as microcrystalline cellulose and lactose. It is believed that the results presented in this paper strongly support the contention that talc may well have an important role to play as a major component in direct compression tablet matrices. The economic advantages of talc/microcrystalline cellulose matrices together with significant improvement of some tablet properties indicates that formulators may well find it advantageous to consider the use of these hybrid systems.

\section{References}

1. B. Mechtersheimer and H. Sucker, "The Effects of PunchFace Geometry and Different Magnesium Stearate/Talc Combinations on Tableting Properties," Pharm. Tech., $10,38-45(1986)$.

2. T.A. Iranloye and E.I. Parrott, "Effects of Compression Force, Particle Size, and Lubricants on Dissolution Rate," J. Pharm. Sci., 67, 535-539 (1978).

3. G. Levy and R.H. Gumtow, "Effects of Certain Tablet Formulation Factors on Dissolution Rate of Active Ingredient III," J. Pharm. Sci., 52, 1139-1144 (1963).

4. S. Dawoodbhai, H.R. Chueh and C.T. Rhodes, "Glidant and Lubricant Propeties of Several Types of Talcs," Drug Dev. Indus. Pharm., 13, 2441-2467 (1987). 
5. P.I. Jarosz and E.L. Parrott, "Effects of Lubricants on Tensile Strengths of Tablets, "Drug Dev. Indus. Pharm., 4, 259-273 (1984).

6. M.A. Gadalla, M.H. Hameed and A.A. Ismail, "Lubricants as a Factor Affecting In Vitro Properties of Double Compressed Tablets," Drug Dev. Indus. Pharm., 14, 11071123 (1987).

7. A.C. Shah and A.R. Mlodozeniec, "Mechanism of Surface Lubrication: Influence of Duration of IubricantExcipient Mixing on Processing Characteristics of Powders and Properties of Compressed Tablets," J. Pharm. Sci., 66, 1377-1382 (1977).

8. G.K. Bolhuis, C.F. Lerk, H.T. Zijlstra and A.H. De Boer, "Film Formation by Magnesium Stearte During Mixing and its Effect on Tabletting," Pharm. Weekblad, $110,317-325(1975)$.

9. S. Okuda, H. Nakahara and H. Isaka, "Adsorption of Drugs on Microcrystalline Cellulose suspended in Aqueous Solutions," Chem. Pharm. Bull., 35, 761-768 (1987).

10. D.E. Wuster and G.P. Polli, "Investigation of Drug Release From Solids IV," J. Pharm. Sci., 50, 403-406 (1961).

11. N.H. Batuyious and E.A. Brecht, "An Investigation of the Incompatibilities of Quaternary Ammonium Germicides 
in Compressed Troches I.," J. Pharm. Sci., 46, 524-531 (1957).

12. F. Ganjian, A.J. Cutie and T. Jochsberger, "An In Vitro Adsorption Studies of Cimetidine," J. Pharm. Sci., 69, $352-353(1980)$.

13. D. Sorby and E.M. Plein, "Adsorption of Phenothiazine Derivatives by Kaolin, Talc, and Norit," J. Pharm. Sci., 50, 355-357 (1961).

14. D. Sorby, "Effect of Adsorbents on Drug Absorption I," J. Pharm. Sci., 54, 667 (1961).

15. D.C. Monkhouse and J.L. Lach, "Use of adsorbents in Enhancement of Drug Dissolution I," J. Pharm. Sci., 61, $1430-1435(1972)$.

16. D.C. Monkhouse and J.L. Lach, "Use of adsorbents in Enhancement of Drug Dissolution II," J. Pharm. Sci., $61,1435-1441(1972)$. 
Optimization of Tablet Formulations Containing Talc.

Shabbir Dawoodbhai (1), E.R. Suryanarayan (2), C.W. Woodruff (3) and C.T. Rhodes (1).

(1) Dept. of Pharmaceutics, and (2) Dept. of Mathematics, University of Rhode Island, Kingston, RI 02881. (3) Miles Pharmaceuticals, West Haven, CT 06516.

\begin{abstract}
An optimum direct compression tablet formulation of a conventional theophylline tablet was achieved using the technique of response surface methodology. and successive quadratic programming (SQP). The response surfaces were obtained from a second order uniform precision hexagonal design. The tablet formulation was optimized for mean in vitro dissolution time using friability, hardness, ejection force and disintegration time as constraints within the experimental region by the SQP algorithm. The response surface model was validated by preparing and evaluating the predicted formulation. The characteristics of the tablet formulation were analyzed by principal component analysis. Sensitivity analysis of optimal solution was performed for each constraint, while all remaining constraints were held constant. The robustness of the response surface model was evaluated by simulation for error in the compression force values due to its inherent variation.
\end{abstract}


Properties of drug delivery systems are affected by the characteristics of the drug and other formulation ingredients, and the processing stresses. Optimization techniques can help to achieve the principal objectives of any dosage form. Moreover, the optimal solution can be further used for trouble shooting of problems during manufacture (1). Computer optimization technique has been applied to tablets $(1-4)$ and solid dispersions $(5,6)$. Bohidar et al (4) optimized multiple potency tablets by computer optimization and with the additional use of a sequential prediction analysis technique. Optimization by. use of the first order unconstrained optimization method has been reported for manufacture of capsules (7) and for enteric coating of tablets ( 8 ). Mathematical optimization techniques dealing with constrained non-linear programming problems, reported so far include classical Lagrangian method (9) used for tablet formulation, and more recently successive unconstrained minimization technique (SUMT) for solid dispersion (10). Mathematical optimization techniques can do all that the computer optimization technique do and have the additional advantage of providing a singular solution (10). More importantly, any successful optimization process should efficiently move toward the goal of the objective function and show robustness by its ability to achieve the optimal solution for a wide variety of problems (11). The purpose of constrained optimization is 
to obtain values of independent variables that will produce the desired optimum response for the chosen objective function subject to various constraints (11). With constrained optimization problems, the optimal values for independent variables must simultaneously satisfy the constraints (11). The objective of the present study was to evaluate an efficient and a robust optimization technique for obtaining solution to a non-linear programming problem. The technique consists of an equiradial hexagonal uniform precision design and successive quadratic programming. The aim was to increase the drug dissolution rate from the tablet without adversely changing other properties of the tablet. It is believed that this work represents the first publication dealing with these specific optimization methods for pharmaceutical purposes.

\section{THBORY}

Response surface methodology are sets of efficient experimental designs for use in the optimization process (12-14). Response Surface Methodology (RSM) attempts to model unknown functional relationships between the response variable and the independent variables by designed experiment. Suitable approximation to the true functional relationship can usually be achieved by a low order polynomial fitted in the relatively small region of interest as defined by the experimental range of the independent 
variables. A response surface obtained from an experimental design can be of the first order and therefore follow the properties of proportionality and additivity. The response surface designs used in the Iiterature include the first order designs such as simplex (7) and fractional factorial (8). If significant curvature is present in the true surface then a second order polynomial is fitted. The complete second order response surface $(\hat{Y})$ can be written as follows for n variables:

$$
\hat{Y}=b_{0}+\sum_{h=1}^{n} b_{h} X_{h}+\sum_{h, k=1}^{n} b_{h k} X_{h} X_{k} \quad h \leq k .
$$

Where $X_{h}$ and $x_{k}$ are independent variables, $b_{0}$ is the $Y$ intercept, $b_{h}$ causes surface to shift along $x_{h}$ and $x_{k}$ axis, $b_{h k}(h$; $)$ controls the surface rates of curvature, $b_{h k}(h=$ k) controls the surface rotation.

\section{Second Order Response surface Designs and their} Properties-A second order response surface design requires that each of the quantitative factors, must take on at least three levels (14). In addition the number of experimental runs must be greater than or equal to the number of coefficients in the second order model, for a given set of independent variables $(12-14)$. At the same time it is desirable to use a design that allows a maximal return for minimum number of experiments. The ratio of the number of the experimental runs, to the maximum number of coefficients in the second order response surface model is called 
redundancy (13). The second order response surface designs in the literature have been based on factorial and fractional factorial central composite design (2-10). Experimental designs are further classified into orthogonal, rotatable and uniform precision types according to the variance properties of the predicted response (12-14). An orthogonal non-rotatable design gives estimators of regression coefficients that are uncorrelated, that is the covariances between the pure second order coefficients are also zero. However, the variance of predicted response is a function of both distance and direction from center of an orthogonal non-rotatable design (12-14). Variance of predicted response for a rotatable design is less than that of orthogonal design, unless the predicted response is being considered at the design center, and is only a function of distance from the center of the design, and not of the direction (12-14). Hence, rotatable designs are valuable in canonical analysis of response surfaces where rotation of design around its center would not change the variance of the predicted response. Therefore it is always worthwhile to use rotatable experimental design. Rotatable design property is obtained by choice of peripheral points position and does not depend on the number of center points. The equiradial designs consist of points equally spaced at a unit distance from the origin of a circle and are rotatable. 
Conditions to be met for any experimental design to be rotatable are specified in (Eqs. 2-5) (12-14).

$$
\begin{aligned}
& \sum_{i=1}^{n} x_{h i} x_{k i}=0 \quad(h, k=1,2, \ldots . l ; h \neq k) \\
& \sum_{i=1}^{n} x_{g i} x_{h i} x_{k i}=0 \\
& \sum_{i=1}^{n} x_{f i} X_{g i} x_{h i} X_{k i}=0 \quad\{(f, g) \neq(h, k)\} \\
& \sum_{i=1}^{n} x_{h i}^{4}=3 \sum_{i=1}^{n} x_{h i}^{2} x_{k i}^{2}(h \neq k)
\end{aligned}
$$

To obtain a design which is both rotatable and orthogonal the number of center points required becomes large. For example, a 3*3 factorial is a non-rotatable, orthogonal experimental design and it would require seven additional center points with modified axial spacing of \pm 1.414 to have properties of rotatability and orthogonality. Hence, the use of uniform precision design in which the variance of predicted response is the same at design center as at any other region within a unit distance from design center. Repetition of an experimental trial under same controllable conditions allows determination of the estimate of mean sum of square pure error for the lack of fit test and a better estimate of the response at the design center. Additionally, replication of center points can allow experiments to be run in orthogonal blocks and permit 
the attainment of uniform precision or orthogonal-rotatable design properties (12-14). The order of experiment should be randomized. Randomization assists in minimizing effect of any uncontrollable factors that exert a consistent bias (13).

Optimization by Successive Quadratic Programming-Of all the methods compared for solving general nonlinear constrained optimization problem (Eqs. 6-9),

$$
\text { minimize } F(\boldsymbol{x}), \quad \boldsymbol{x} \in \mathrm{IR}^{\mathrm{n}}
$$

subject to

$$
\begin{aligned}
& \mathbf{h}_{\mathbf{k}}(\mathbf{x})=0, \text { for } \mathbf{k}=1 \ldots, \mathrm{m}_{\mathrm{e}} \\
& \mathbf{g}_{\mathbf{j}}(\mathbf{x}) \geq 0, \text { for } j=1 \ldots \ldots, \mathrm{m} \\
& \mathbf{x}_{\mathbf{l}} \leq \mathbf{x} \leq \mathbf{x}_{\mathrm{u}},
\end{aligned}
$$

the successive quadratic programming (SQP) algorithm was rated as the best with regard to efficiency (11). The range of $\mathbf{x}$ are defined by its lower $\mathbf{x}_{1}$ and upper $\mathbf{x}_{u}$ bound limits. In order to keep under consideration the curvature of the objective equation $F(x)$, the equality $h_{k}(x)$ and the inequality $\boldsymbol{g}_{\mathbf{j}}(\mathbf{x})$ constraints, a Lagrangian $L(\mathbf{x}, \mathbf{u}, \mathbf{v})$ is formulated (Eq. 10). The $v_{k}$ and $u_{j}$ are the Lagrange 
multipliers for equality and inequality constraints respectively.

$$
L(\mathbf{x}, \mathbf{u}, \boldsymbol{v})=F(\mathbf{x})+\sum \nabla_{k} \mathbf{h}_{\mathbf{k}}(\mathbf{x})+\sum \mathbf{u}_{j} \boldsymbol{g}_{j}(\mathbf{x})
$$

Lagrange multiplier is weight given to satisfy the constraints.

Determination of Search Direction (d)-The SQP algorithm assumes all the functions of the model to be continousiy differentiable. The SQP method is based on the iterative formulations and solutions of quadratic programming subproblems. The subproblem are obtained using a quadratic approximation of the Lagrangian $q(\boldsymbol{d} ; \boldsymbol{x})$ (Eq. II) and by linearizing the constraints (Eqs. 12-13).

Minimize $q(\mathbf{d} ; \mathbf{x}) \equiv \nabla F\left(\mathbf{x}^{(t)}\right)^{T} \mathbf{d}+1 / 2 \mathbf{d}^{T} \mathbf{H}^{(t)} \mathbf{d}$

subject to

$$
\begin{aligned}
& \mathbf{h}_{\mathbf{k}}(\mathbf{d} ; \mathbf{x}) \equiv \mathbf{h}_{\mathbf{k}}\left(\mathbf{x}^{(t)}\right)+\nabla \mathbf{h}_{\mathbf{k}}\left(\mathbf{x}^{(t)}\right)^{T} \mathbf{d}=0 \quad \mathbf{k}=1, \ldots, \mathbf{k} \\
& \mathbf{g}_{j}(\mathbf{d} ; \mathbf{x}) \equiv \mathbf{g}_{j}\left(\mathbf{x}^{(t)}\right)+\nabla \mathbf{g}_{j}\left(\mathbf{x}^{(t)}\right)^{T} \mathbf{d} \geq 0 \quad j=1, \ldots, J
\end{aligned}
$$

where $\mathbf{x}^{T}$ and $d^{T}$ represent the transpose of $\mathbf{x}$ and $\mathbf{d}$ respectively. The effectiveness of a numerical iterative technique often depends on a good initial estimate of the vector for the independent variables involved (11,15). The 
initial iteration requires a user supplied vector of independent variables as the starting point $\mathbf{x}_{0}$. For the initial iteration the program assigns Lagrange multipliers a value of zero and the variable metric, that is the Lagrangian hessian matrix $\mathrm{H}^{(t)}$ is set to identity matrix I. Therefore the initial search direction $d_{0}$ is the steepest descent direction for the objective function. For the subsequent $t^{\text {th }}$ iteration, the continuosly updated $\mathbf{x}_{t}$ vector is used to determine the gradient vector $\nabla F\left(\mathbf{x}^{(t)}\right)$ and the Lagrangian hessian matrix. The search direction $d_{t}$ is calculated such that it satisfies the resultant quadratic subproblem. Then the Lagrange multipliers for active equality and inequality constraints are calculated by equating them to the derivative of the quadratic approximation for the Lagrangian (Eq. 14).

$$
\nabla q(\mathbf{d} ; \mathbf{x})=\mathbf{\nabla} \mathbf{h}(\mathbf{d} ; \mathbf{x})+\mathbf{u} \nabla \mathbf{g}(\mathbf{d} ; \mathbf{x})
$$

For inactive constraints the Lagrange multipliers are equal to zero.

Selection of Step Size Along Search Direction-To move a step closer toward optimum from poor initial values of the $\mathbf{z}_{0}$ vector, we also need a value of step length $\alpha$. Therefore, in order to force convergence toward optimum, we formulate a penalty function $P(\mathbf{x}, \mathbf{u}, \mathbf{v})$, which would minimize the objective function and also satisfy the constraints. By 
definition this penalty function is a non-differentiable function (Eq. 15).

$$
P(\mathbf{x}, \mathbf{u}, \mathbf{v})=F(\mathbf{x})+\sum_{\mathrm{k}=1}^{K} \mathbf{u}_{\mathbf{k}}\left|\mathbf{h}_{\mathbf{k}}(\mathbf{x})\right|-\sum_{j=1}^{J} \boldsymbol{\sigma} \min \left(0, \mathbf{g}_{j}(\mathbf{x})\right)
$$

For the initial iteration, the penalty parameters are the absolute values of the lagrange multipliers.

$$
u_{k}=\left|v_{k}\right| \quad \sigma=\left|u_{j}\right|
$$

For the $t^{t h}$ iteration, the penalty parameters $\left(u_{k}^{(t)}, \sigma_{j}^{(t)}\right)$ are selected according to the conditions (Eqs. 16-17) that ensure that convergence can be obtained.

$$
\begin{aligned}
& u_{k}^{(t)}=\max \left\{\left|v_{k}^{(t)}\right|, \quad 1 / 2\left(u_{k}^{(t-1)}+\left|v_{k}^{(t)}\right|\right)\right\} \\
& \sigma_{j}^{(t)}=\max \left\{\left|u_{j}^{(t)}\right|, 1 / 2\left(\sigma_{j}^{(t-1)}+\left|u_{j}^{(t)}\right|\right)\right\}
\end{aligned}
$$

A line search using quadratic interpolation is done to obtain the step length $\alpha$, where $0 \leq \alpha \leq 1$. The step length a is obtained such that penalty function value at the current point $\mathbf{x}_{t+1}$ as obtained by (Eq. 18)

$$
\mathbf{x}_{t+1}=\mathbf{x}_{t}+\alpha d_{t}
$$


is less than the penalty function value at previous point $\mathbf{x}_{t}$. This ensures that over $n$ iterations the point $\mathbf{x}_{n}$ will be such that the active constraint are satisfied so that the penalty terms become zero and thereby achieving the minimization of the orignal function.

Check for Convergence Criteria-At this point the optimal solution is printed if the convergence criteria (11) of the SQP algorithm are satisfied. Otherwise the Lagrangian hessian matrix $\mathbf{H}^{(t)}$ is updated.

Broydon-Fletcher-Goldfarb-Shano (BFGS) Method for Jpdating the Lagrangian Hessian Matrix-The update of the Lagrangian hessian matrix $H^{(t+1)}$ using BFGS algorithm is such that it approaches $B^{-1}$ of the orignal function as with the Newton method. Thus the whole process starts with the steepest descent method and in the limit becomes the Newton method. The update of the Lagrangian hessian matrix $\mathbf{H}^{(t+1)}$ depends on the closeness to the optimum solution, as indicated by the:

(a) difference between current and the previous first derivatives of Lagrangian (Eq. 19)

$$
\left.y=\nabla_{\mathbf{x}^{L}} \mathbf{u} \mathbf{x}^{(t+1)}, \mathbf{u}^{(t+1)}, \mathbf{v}^{(t+1)}\right)-\nabla_{\mathbf{x}} \mathbf{L}\left(\mathbf{x}^{(t)}, \mathbf{u}^{(t+1)}, \mathbf{v}^{(t+1)}\right)
$$

(b) difference between current and the previous search positions (Eq. 20) 


$$
z=\mathbf{x}^{(t+1)}-\mathbf{x}^{(t)}
$$

and (c) the previous Lagrangian hessian matrix $\mathbb{H}^{(t)}$. The value of $\mathbf{z}^{\mathrm{T}} \mathrm{y}$ (where $\mathbf{z}^{\mathrm{T}}$ represents the transpose of $\mathbf{z}$ ) is used for obtaining the value of $\theta$ according to the following conditions (Eq. 21-22),

$$
\theta=I \quad \text { if } \quad \mathbf{z}^{\mathrm{T}} \mathrm{y} \geq 0.2 \mathbf{z}^{\mathrm{T}} \mathbf{H}^{(\mathrm{t})} \mathbf{z}
$$

otherwise

$$
\theta=\left(0.8 \mathbf{z}^{T} \mathbf{H}^{(t)} \mathbf{z}\right) /\left(\mathbf{z}^{\mathrm{T}} \mathbf{H}^{(t)} \mathbf{z}-\mathbf{z}^{\mathrm{T}} \mathbf{y}\right) .
$$

Next the value of $y$ is modified into w according to (Eq. 23)

$$
w=\theta y+(1-\theta) \mathbf{H}^{(t)} \mathbf{z}
$$

The constraints 0.2 and 0.8 are arbitary and choosen from numerical experience $(11,15)$. We then substitute these parameters into the BFGS updating formula (Eq. 24) to obtain the updated Lagrangian hessian matrix $\mathbf{H}^{(t+1)}$.

$\mathbf{H}^{(t+1)}=\left(\mathbf{H}^{(t)}-\mathbf{H}^{(t)} \mathbf{z}^{T} \mathbf{H}^{(t)}\right) /\left(\mathbf{z}^{\mathrm{T}} \mathbf{H}^{(t)} \mathbf{z}^{\mathrm{T}}\right)+\left(w w^{T} / \mathbf{z}^{T} w\right)$

Updating the Lagrangian hessian matrix helps to improve the search direction, since it converges to the hessian inverse as the optimum solution is approached. BFGS is the most 
successful quasi Newton method for keeping the Lagrangian hessian matrix positive definite for the minimization problem, provided the initial update matrix is also positive definite (11). Hence, SQP combines the advantages of variable metric methods for constrained optimization calculations with the fast convergence of Newton's method $(11,15)$.

\section{BXPBRIMENTAL SECTION}

Materials-The direct compression formulations had the following percentage (w/w) composition:

Theophylline $25.0 \%$ (Sigma Chemical, St. Louis, Missouri), Beaverwhite 300 talc 15.0\% (Cyprus Industrial Minerals Company, Mobile, Alabama), corn starch 3 to $4 \%$ (Sigma Chemical, St. Louis, Missouri) and direct tableting lactose 56 to 58\% (Scheffield Products, Norwich, New York).

Choices of Second Order Designs-The two factors equiradial designs requires fewer experimental runs than the central composite design, and gives improved design properties, see Table 1. The two independent variables studied consisted of a process variable (the compression force) and a formulation variable (the percent of disintegrant), all other processing and formulation variables were kept constant.

The effect of these two independent variable were studied 
Table 1-Properties of Second Order Design Requiring Same Number of Bxperimental Runs for Two Independent Variables.

\begin{tabular}{lccc} 
& \multicolumn{3}{c}{ Experimental Design } \\
Properties & Factorial & Composite Hexagon \\
\hline Runs & 9 & 9 & 9 \\
Redundancy & 1.5 & 1.5 & 1.5 \\
Orthogonal & Yes & No & No \\
Rotatable & No & Yes & Yes \\
Uniform & & & No \\
Precision & No & Nos & \\
\hline
\end{tabular}


using the uniform precision equiradial hexagonal experimental design as shown in Table 2.

Formulations and Preparation-The controlled conditions for material storage, processing and manufacturing were maintained at $24 \pm 2^{\circ} \mathrm{C}$ and at relative humidity of $26 \pm 3 \%$. All powders were sieved through sieve size of mesh size 20. The components of the various tablet formulations were mixed for 1.5 minutes in a WAB type T2C turbula mixer. The tablet formulations were compressed in a random order on the instrumented tablet press. An instrumented stokes B-2 rotary tablet press was used as described previously (16). The tooling consisted of a single standard concave set of punches of size $3 / 8$ inch and its die. The compression and the ejection forces data were collected for 30 tablets, at a rate of 10 tablets per run. No tablet capping or laminating problems occurred during tablet manufacture. All the tablets were manufactured on the same day. The tablets were stored under the conditions defined above, in plastic bottles with well closed lids wrapped in parafilm.

Determination of In Vitro Properties-Ten tablets were evaluated for crushing strength (Erweka Hardness Tester; Chemical and Pharmaceutical Industry, New York, New York). Six tablets were evaluated for friability, during which no tablet capping or lamination occurred (Erweka Friabilator; Chemical and Pharmaceutical Industry, New York, New York), 
Table 2-Bxperimental Design for Two factors

\begin{tabular}{|c|c|c|c|c|c|}
\hline \multirow{3}{*}{$\begin{array}{l}\text { Bxperimental } \\
\text { Unit }\end{array}$} & \multicolumn{2}{|l|}{ Random } & \multirow{2}{*}{$\begin{array}{l}\text { Factor } \\
\text { Form }\end{array}$} & \multicolumn{2}{|l|}{ levels } \\
\hline & Order & Coded & & \multicolumn{2}{|c|}{ Physical Units } \\
\hline & Number & $\mathbf{X 1}$ & $\mathrm{x} 2$ & $\mathrm{X} 1(\mathrm{BN}) \mathrm{X} 2$ & $(x w / w)$ \\
\hline 1 & 2 & 1.0 & 0.000 & $15.11(0.30)$ & 3 \\
\hline 2 & 5 & 0.5 & 0.866 & $13.38(0.31)$ & 4 \\
\hline 3 & 6 & -0.5 & 0.866 & $9.99(0.22)$ & 4 \\
\hline 4 & 8 & -1.0 & 0.000 & $8.45(0.18)$ & 3 \\
\hline 5 & 1 & -0.5 & -0.866 & $9.97(0.23)$ & 2 \\
\hline 6 & 9 & 0.5 & -0.866 & $13.58(0.35)$ & 2 \\
\hline 7 & 3 & 0.0 & 0.0 & $11.95(0.19)$ & 3 \\
\hline 8 & 4 & 0.0 & 0.0 & $11.84(0.27)$ & 3 \\
\hline 9 & 7 & 0.0 & 0.0 & $11.77(0.29)$ & 3 \\
\hline
\end{tabular}

Value in parenthesis are standard deviations 
Six tablets were evaluated for disintegration time using discs (USP Disintegration Time Tester, Vanderkamp; Van-Kel Industries, Chatham, New Jersey). The apparatus (Paddle method, USP; Vanderkamp; Van-kel Industries, Chatham, New Jersey), dissolution medium and procedure suggested in the in the USP were applied to three tablets per formulation. Dissolution samples of $10 \mathrm{ml}$ were withdrawn at $5,10,15$, $20,30,45$ minutes intervals. The dissolution medium volume was kept constant by adding the same volume of fresh dissolution medium kept at the temperature of $37^{\circ} \mathrm{C}$. Additionally, to ensure total release of drug, the agitation speed was increased to 150 R.P.M. for additional 45 minutes after all timed samples had been obtained, this sampling time is referred to as $T_{\infty}$. The samples were diluted and the concentration were measured on a Diode Array Spectrophotometer (Hewlett Packard; Loveland, Colarado) at the wavelengths of $272 \mathrm{~nm}$ as specified in the USP. The predicted formulation tablets were also analyzed similarly.

Analysis of Data-The dependent variables consisted of the response variables such as ejection force and the resultant drug delivery system characteristics such as tablet mean in vitro dissolution time (MDT in vitro), crushing strength, disintegration time and friability. All the statistical and regression analysis procedure on the dependent variables were performed using statistical 
analysis system (SAS) procedures. The dissolution data was fitted to Gompretz model (Eq. 23) (17), -using non-linear regression analysis technique (Nonlin, SAS).

$$
\omega=\alpha \exp \left\{-\beta e^{-k t}\right\}
$$

Where $\omega$ is the percent drug dissolved at time $t, \propto$ is the final value of percent drug dissolved, $\beta$ and $k$ are the roots of the Gompretz equation. The MDT in vitro was calculated using moment analysis; as the ratio of the area under dissolution rate-time curve and area under dissolution rate curve (18). The area under these curves were calculated by a computer using the trapezoidal rule. The response surface equations for MDT in vitro and friability were calculated using least squares multiple regression analysis (Reg, SAS). The least squares criteria for estimating coefficients for the equation emphasizes observed data points that have large residuals, which tend to have large sample variances, in order to minimize the sum of squares error. The reciprocal of the variance were used in the weighted least squares multiple regression analysis (17) (Reg, SAS) for ejection force, hardness, and disintegration time data. The weighted least squares emphasizes those points that have least sample variances and therefore overcomes the limitations of least squares method. The optimization was carried using International Mathematical 
and statistical libraries (IMSL) fortran subroutines. The characteristics of the tablet formulation was evaluated using principal component analysis (19) (Prin Comp, SAS). The simulation study was carried using a program written in SAS basic (20).

\section{RESULTS AND DISCUSSION}

Response Variables-The dissolution profiles for the tablets are shown Figures $1-3$, and the parameters for the Gompretz equation are shown in Table 3 . The tablet properties obtained from the experimental design are shown in Table 4.

Regression Models-The response surface equations (Table 5) for the MDT in vitro, the hardness, and disintegration time were linear, while those for ejection force and friability were non-linear and therefore the problem was solved by non-linear programming. The $P$ values indicated that the equations are highly statistically significant. The $R$ square and the $R$ square with adjusted degrees of freedom values, and the lack of fit test at $5 \%$ significance level for the regression equations indicate that the goodness of fit were satisfactory. The relationship between the response variable and the controllable variables were explored by means of three dimensional plots and the contour plots which show contour lines of equal response and the 


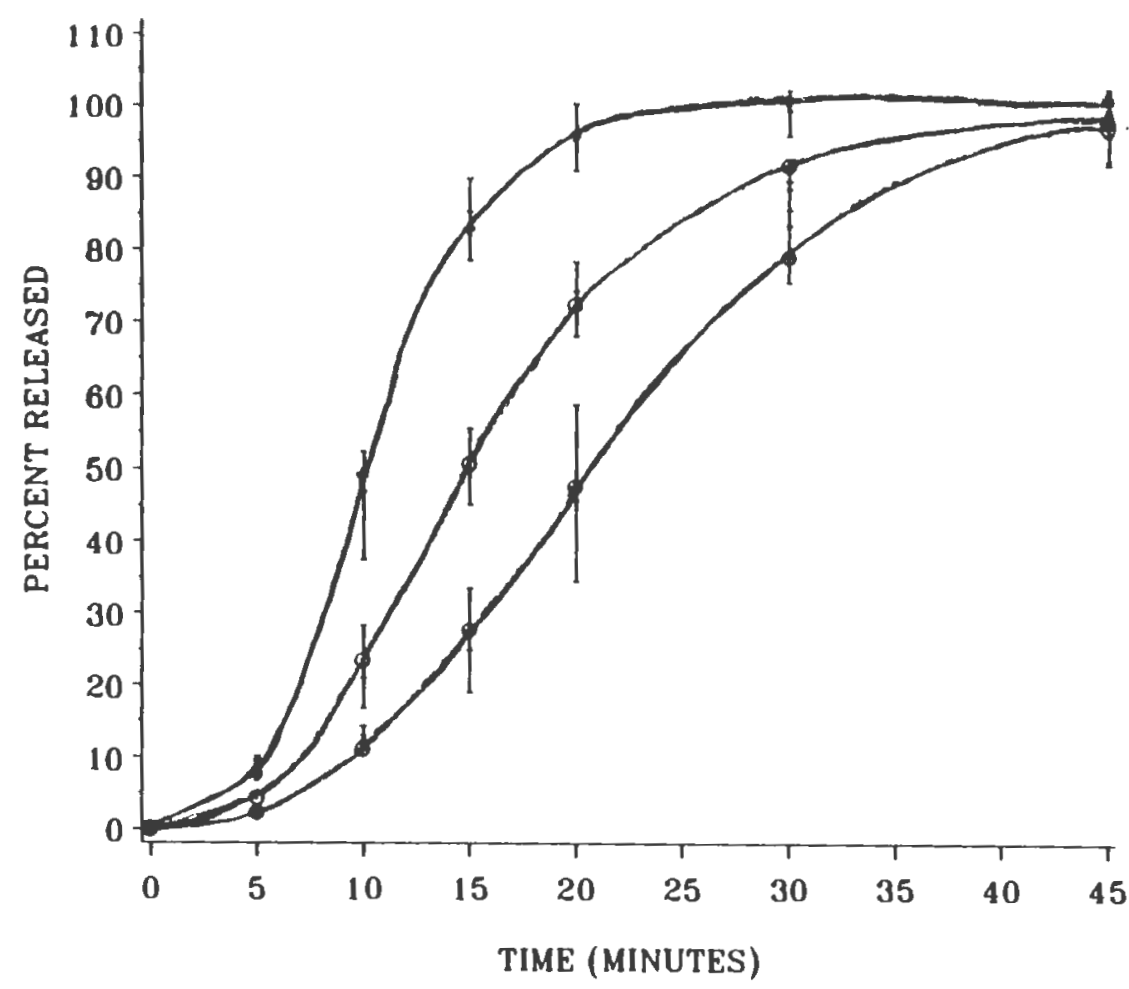

FIGURE 1: DISSOLUTION CURVES SIIOWING PERCENT OF THEOPIIYLLINE RELEASED FROM TABLETS OF FORMULATIONS $1\left({ }^{\circ}\right), 2(+), 3(0)$. THE BAR REPRESENTS RANGE OF $V$ ALUES. 


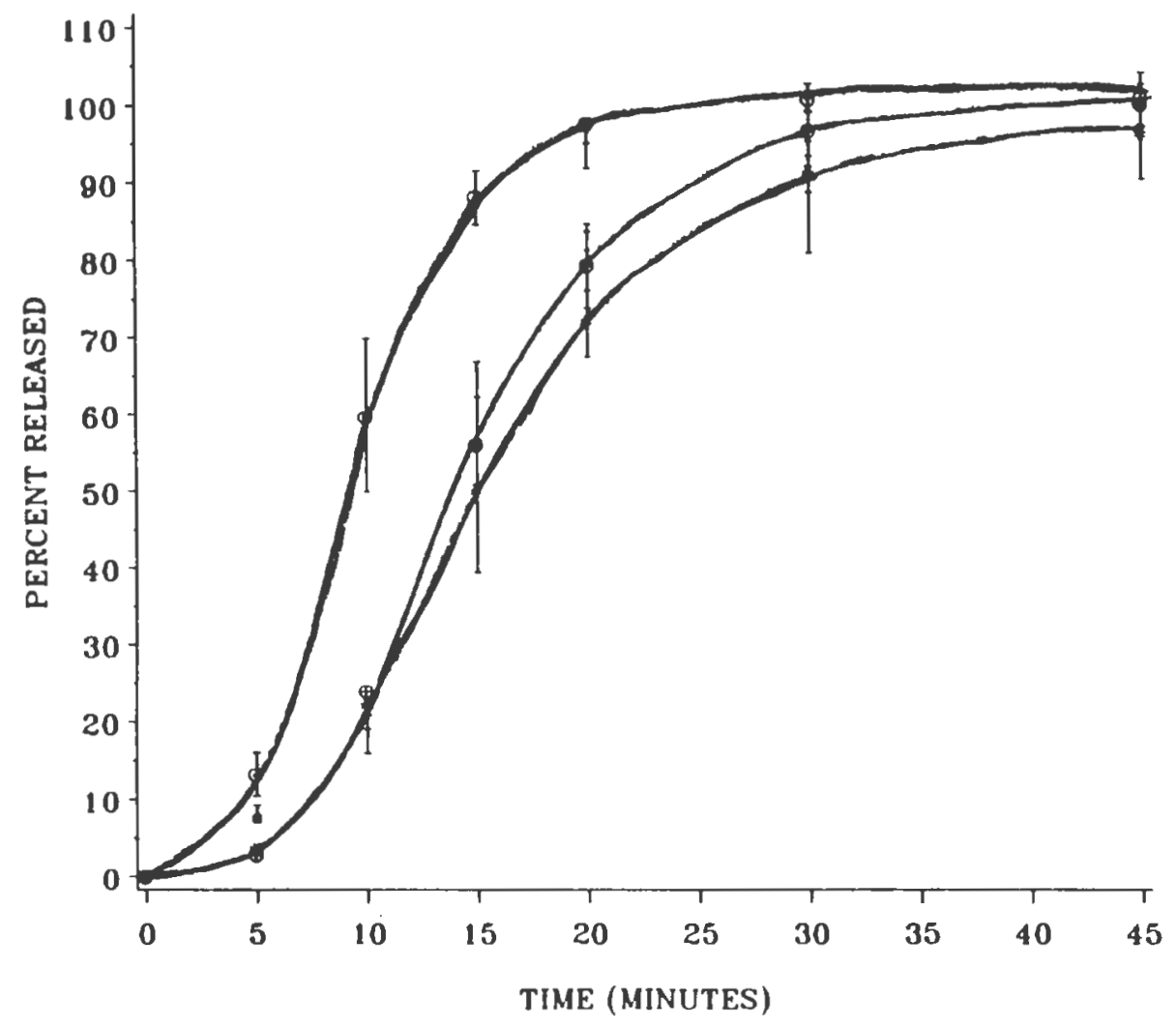

FIGURE 2: DISSOLUTION CURVES SIIOWING PERCENT OF THEOPIIYLLINE REIEASED FROM TABLETS OF FORMULATIONS $4\left({ }^{\circ}\right), 5(+), 6(0)$. THE BAR REPRESENTS RANGE OF VALUES. 


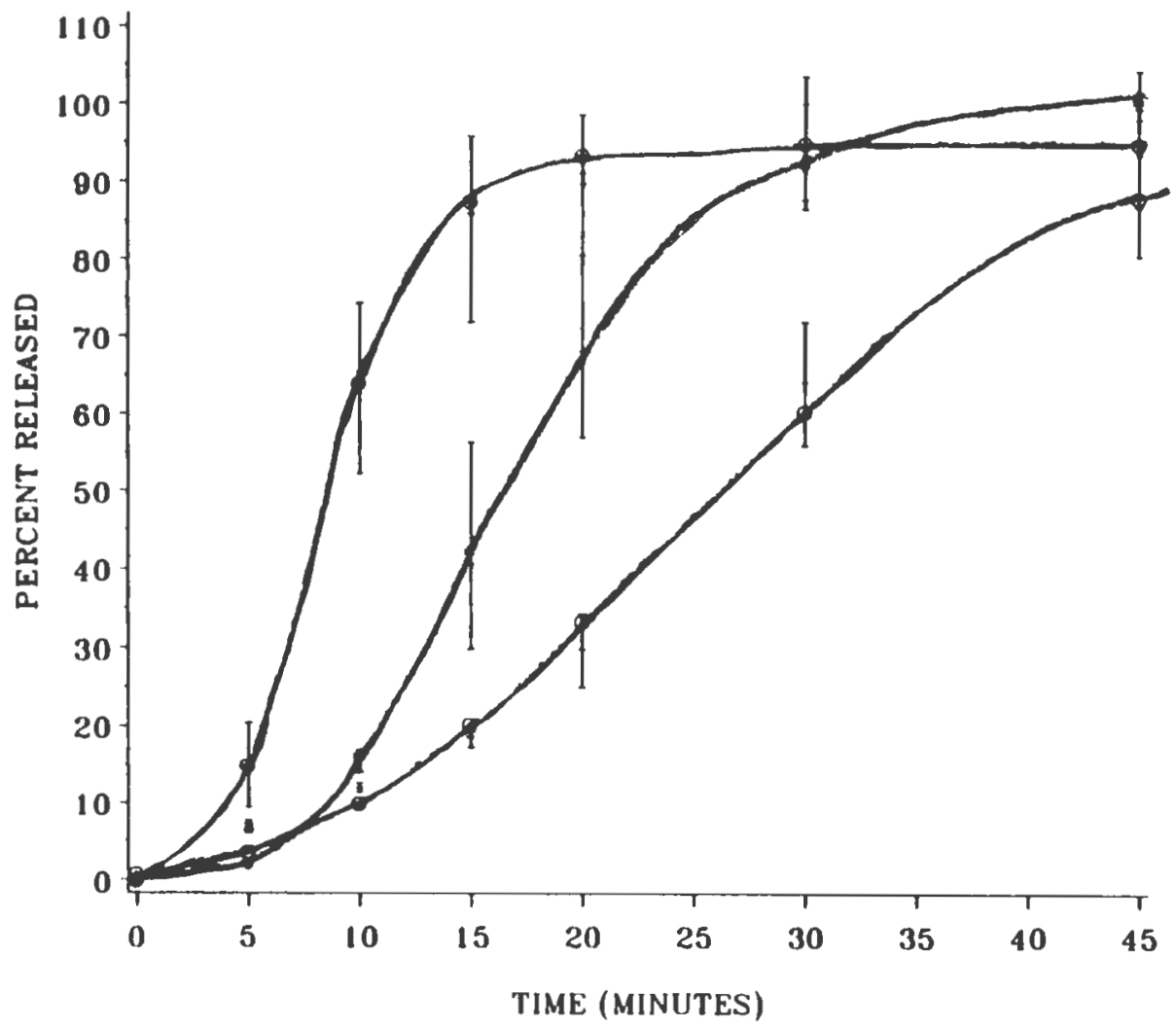

FIGURE 3: DISSOLUTION CURVES SHOWING PERCENT OF THEOPHYLLINE RELEASED FROM TABLETS OF FORMULATIONS $7(\bullet), 8(+), 9(0)$. THE BAR REPRESENTS RANGE OF VALUES. 
Table 3-The Parameters Obtained by Non-linear Regression Analysis.

\begin{tabular}{|c|c|c|c|c|}
\hline Formulation & Gompretz & Equation & Parameters & MDT in vitro \\
\hline Number & $\alpha$ & $\beta$ & $\mathbf{k}$ & (hours) \\
\hline 1 & 103.996 & 6.421 & 0.1054 & 0.3573 \\
\hline 2 & 100.657 & 8.748 & 0.1806 & 0.2536 \\
\hline 3 & 101.216 & 7.853 & 0.2700 & 0.1646 \\
\hline 4 & 95.206 & 8.705 & 0.3089 & 0.1496 \\
\hline 5 & 101.336 & 9.444 & 0.257 & 0.1847 \\
\hline 6 & 107.805 & 4.819 & 0.0707 & 0.4038 \\
\hline 7 & 98.001 & 6.771 & 0.1555 & 0.2652 \\
\hline 8 & 97.007 & 7.369 & 0.1607 & 0.2657 \\
\hline 9 & 101.767 & 8.078 & 0.1479 & 0.2963 \\
\hline Optimized & 95.242 & 5.249 & 0.1125 & 0.3154 \\
\hline
\end{tabular}


Table 4. Experimental Values of Response Varlables

\begin{tabular}{lllllll}
\hline $\begin{array}{l}\text { Experimental } \\
\text { Unit }\end{array}$ & $\begin{array}{l}\text { Ejection } \\
\text { Force (II) }\end{array}$ & $\begin{array}{l}\text { Weight } \\
\text { XRSD }\end{array}$ & $\begin{array}{l}\text { Hardness } \\
(\text { Y.g })\end{array}$ & $\begin{array}{l}\text { Percent } \\
\text { Friability }\end{array}$ & $\begin{array}{l}\text { Disintegration } \\
\text { Timinutes) }\end{array}$ & $\begin{array}{l}\text { MDT } \\
(\mathrm{hr})\end{array}$ \\
\hline & & & & & & \\
1 & $613.2(10.8)$ & 0.3531 & $12.48(1.58)$ & 0.294 & $8.63(0.28)$ & 0.3573 \\
2 & $581.2(26.7)$ & 0.4224 & $11.82(1.32)$ & 0.344 & $6.01(0.30)$ & 0.2536 \\
3 & $450.5(18.6)$ & 0.4066 & $8.99(0.90)$ & 0.419 & $3.44(0.09)$ & 0.1646 \\
4 & $397.1(21.8)$ & 0.3674 & $7.65(0.66)$ & 0.496 & $3.37(0.15)$ & 0.1496 \\
5 & $462.8(21.8)$ & 0.3633 & $8.97(0.69)$ & 0.422 & $5.44(0.21)$ & 0.1847 \\
6 & $603.9(14.3)$ & 0.4045 & $12.27(1.70)$ & 0.291 & $9.13(0.48)$ & 0.4038 \\
7 & $542.4(27.7)$ & 0.3042 & $10.67(1.37)$ & 0.353 & $6.07(0.35)$ & 0.2652 \\
8 & $533.5(28.9)$ & 0.4072 & $10.71(1.01)$ & 0.296 & $5.68(0.31)$ & 0.2657 \\
9 & $533.0(30.2)$ & 0.3616 & $10.25(1.34)$ & 0.328 & $6.53(0.21)$ & 0.2963
\end{tabular}

Value in parenthesis are standard devlations

MDT is mean in vitro dissolution time 
Table 5. Multiple Regression Analysis Equation for Each Response Variable

\begin{tabular}{|c|c|c|c|c|c|}
\hline $\begin{array}{l}\text { Parameters/ } \\
\text { Summary }\end{array}$ & $\begin{array}{l}\text { Ejection } \\
\text { Force (N) }\end{array}$ & $\begin{array}{l}\text { Hardness } \\
(\mathrm{Kg})\end{array}$ & $\begin{array}{l}\text { Percent } \\
\text { Friability }\end{array}$ & $\begin{array}{l}\text { Disintegration } \\
\text { Time (minutes) }\end{array}$ & $\begin{array}{l}\text { MDT } \\
(h r)\end{array}$ \\
\hline 80 & 537.838 & 10.596 & 0.3395 & 6.0105 & 0.2601 \\
\hline $\mathrm{Bl}(\mathrm{y} .1)$ & 118.262 & 3.039 & -0.1017 & 2.7426 & 0.1206 \\
\hline $\mathrm{B} 2(\times 2)$ & - & - & - & -1.3497 & -0.0492 \\
\hline $\mathrm{B} 11(\times 1 * \times 1)$ & -38.780 & - & 0.0624 & - & - \\
\hline $\mathrm{B} 22(\times 2 * \times 2)$ & - & - & - & - & - \\
\hline $\mathrm{B} 12(\mathrm{xI} \times \mathrm{x} 2)$ & - & - & - & - & - \\
\hline R Square & 0.9774 & 0.9739 & 0.8888 & 0.9812 & 0.8693 \\
\hline ADJ $R-S Q$. & 0.9699 & 0.9702 & 0.8518 & 0.9749 & 0.8257 \\
\hline F Value & 130.038 & 261.544 & 23.989 & 156.586 & 19.945 \\
\hline Prob $>F$ & 0.0001 & 0.0001 & 0.0014 & 0.0001 & 0.0022 \\
\hline
\end{tabular}

MDT is mean in vitro dissolution time. 
direction in which the gradient has steeper value are shown in Figure 4-11. In general, the MDT in vitro is widely used as a dissolution index for comparison of dissolution behaviour.

Optimization-The MDT in vitro as the objective function was minimized so as to obtain rapid dissolution rate. The constraints used were that tablet hardness should be $\geq 12$ kg, the disintegration time should be $\leq 7.5$ minutes, the friability be $\leq 0.3$ percent, and the ejection force should be $\leq 605$ Newtons. Additional constraints were the experimental limits placed on values of $\bar{x}_{1}$ and $\bar{x}_{2}$. The optimum solution values for the independent variables satisfied all the constraints simultaneously and provided an optimal value for the objective function.

Optimal Solution-The formulation according to the optimal solution was prepared as shown in Table 6 . The comparison of predicted and experimental values for optimum formulation showed very good agreement and are shown in Table 7. A model is valid if despite its inexactness in representing the system, it can give a reasonable prediction of a systems performance.

Sensitivity Analysis-Sensitivity analysis in the vicinity of the optimal solution was performed in order to monitor change in response to minor modifications in the values of the constraints. The objective function of the 


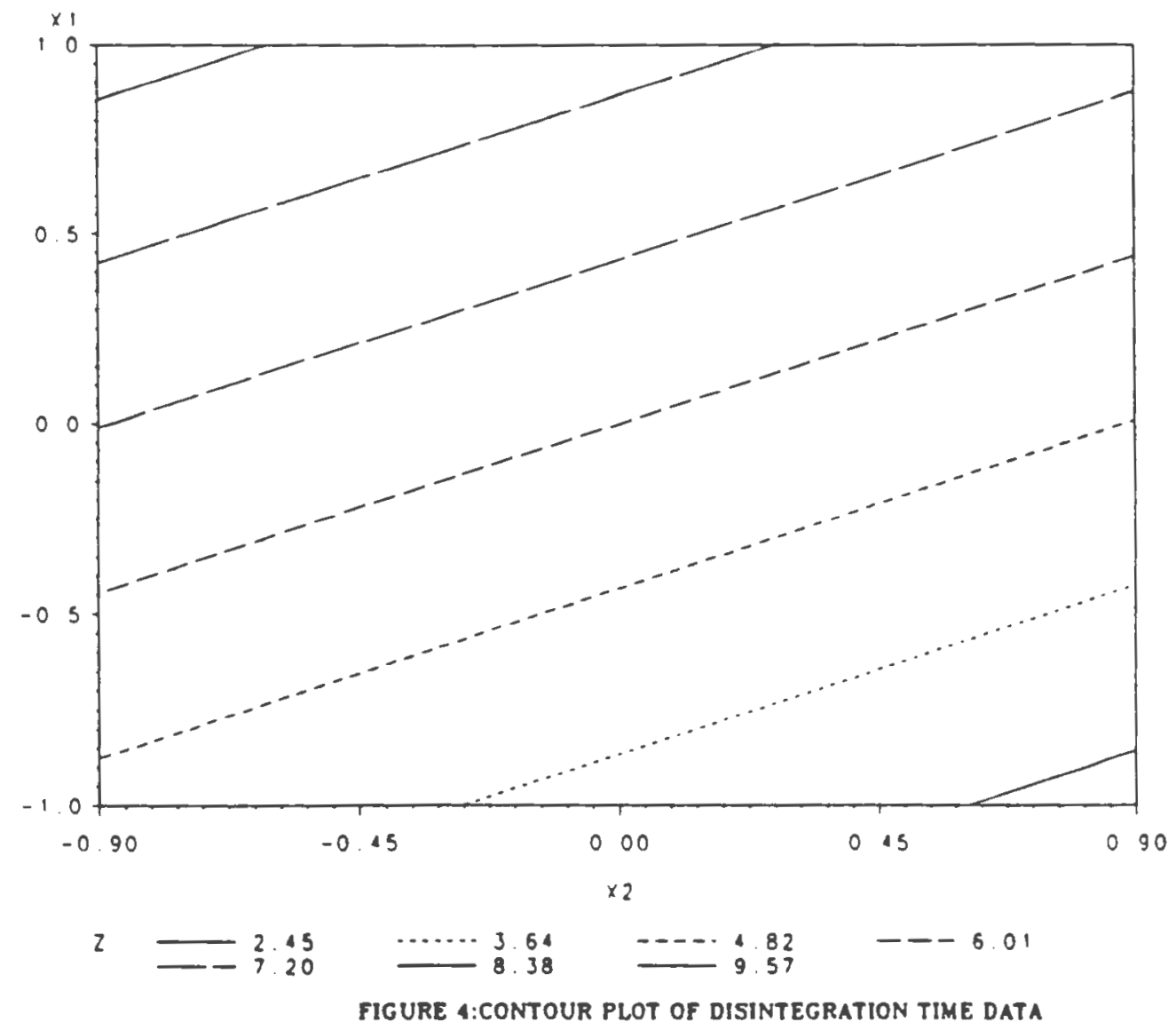

118 


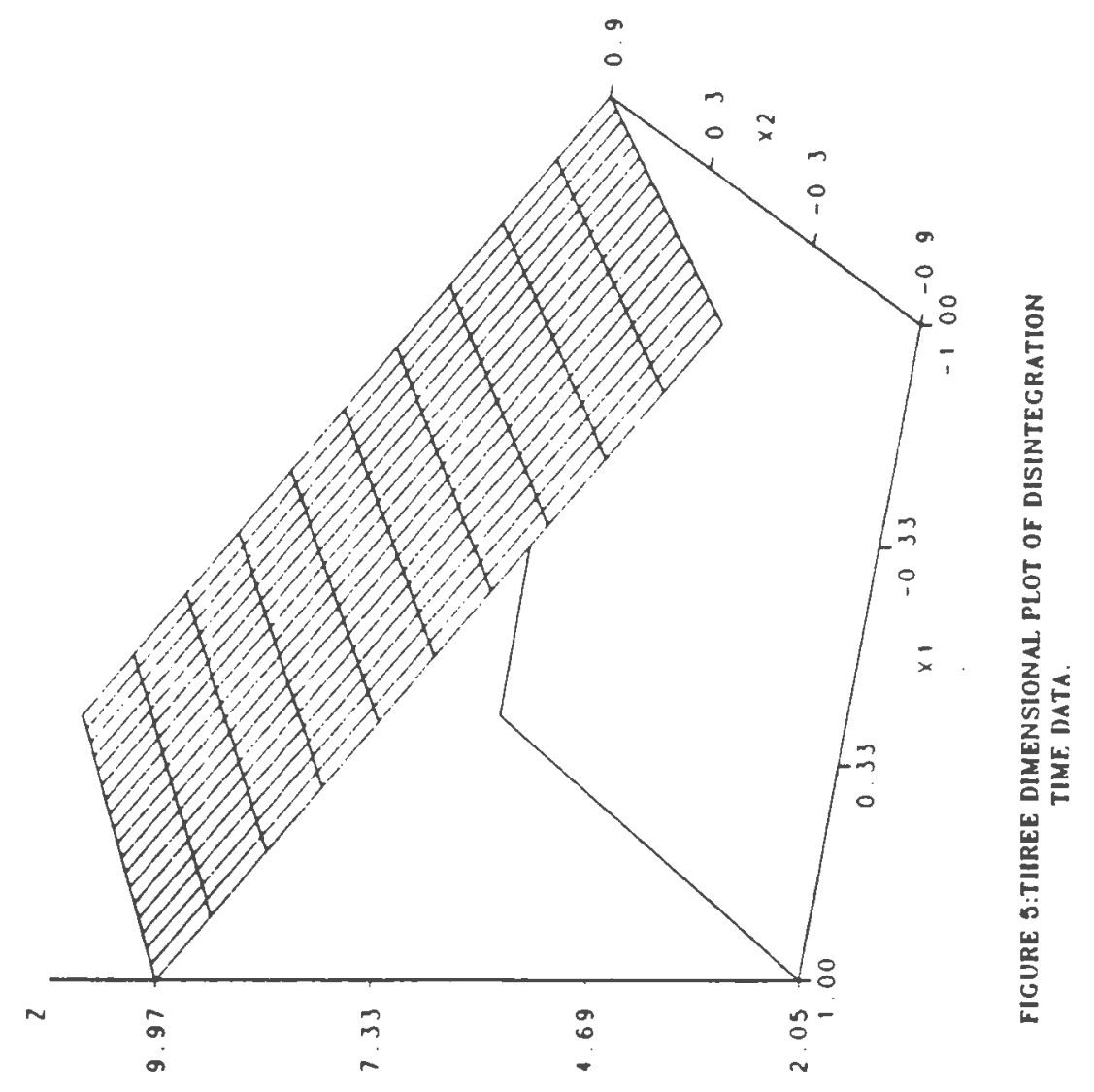




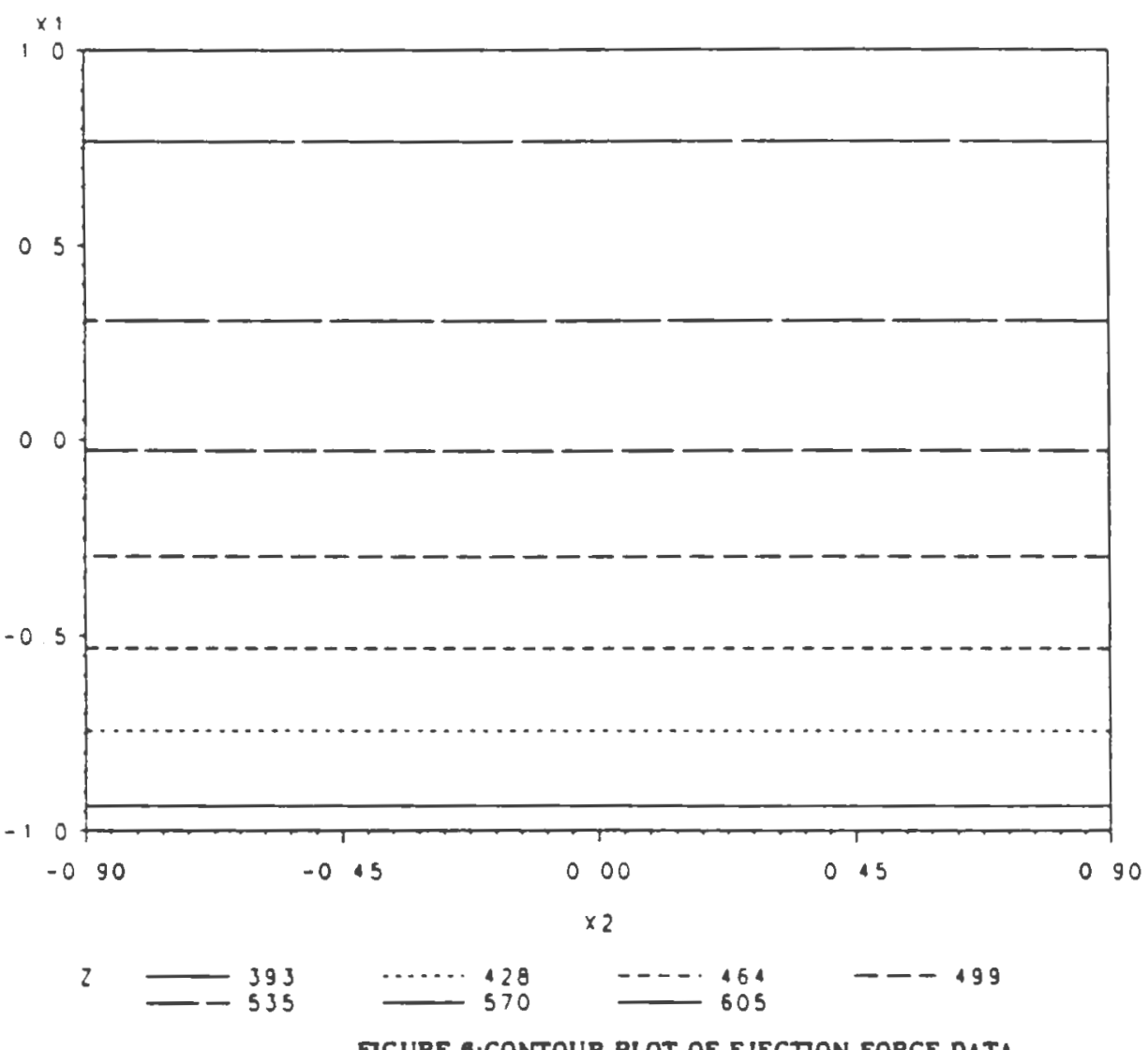

FGURE 6:CONTOUR PLOT OF EJECTION FORCE DATA 


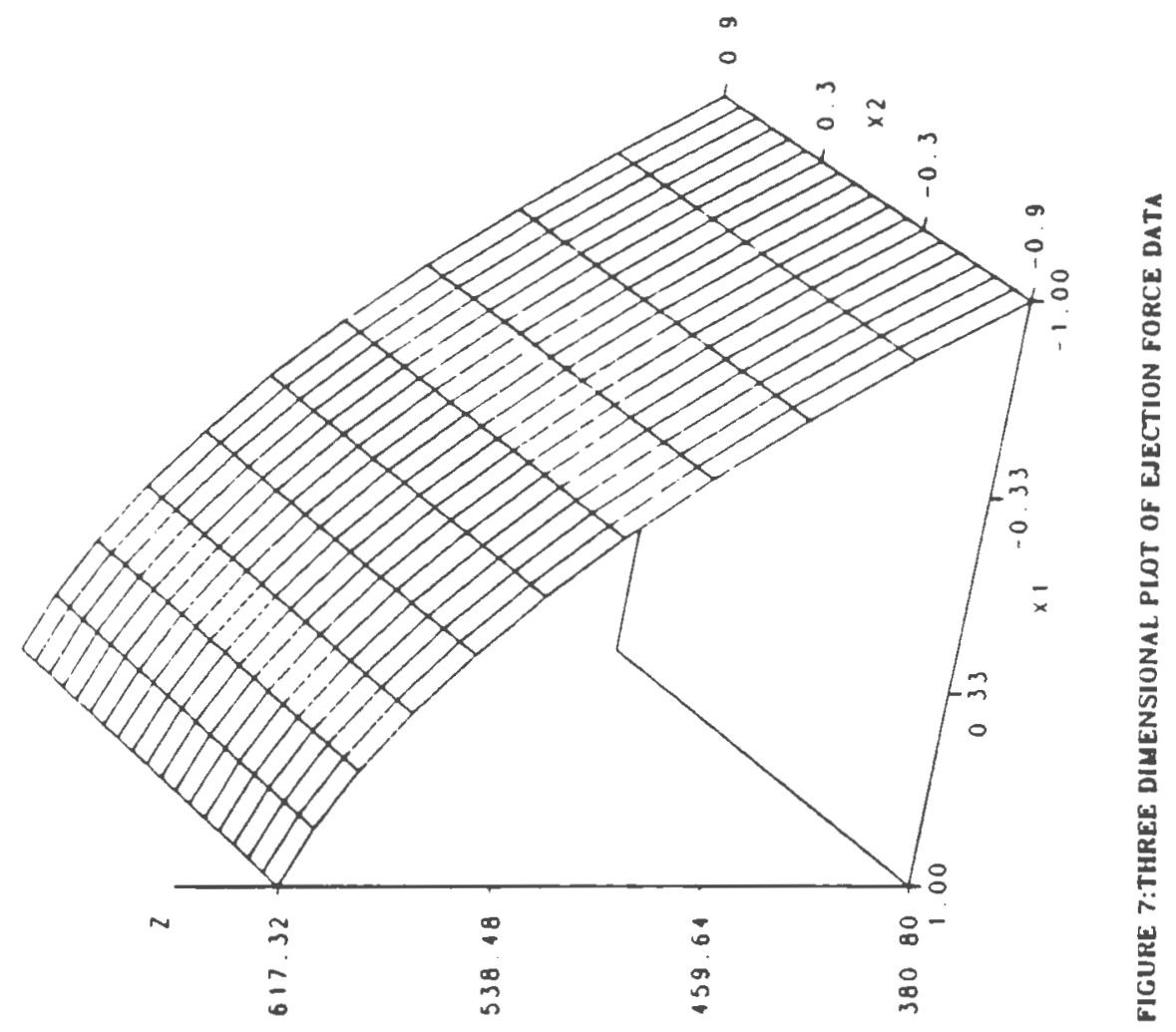




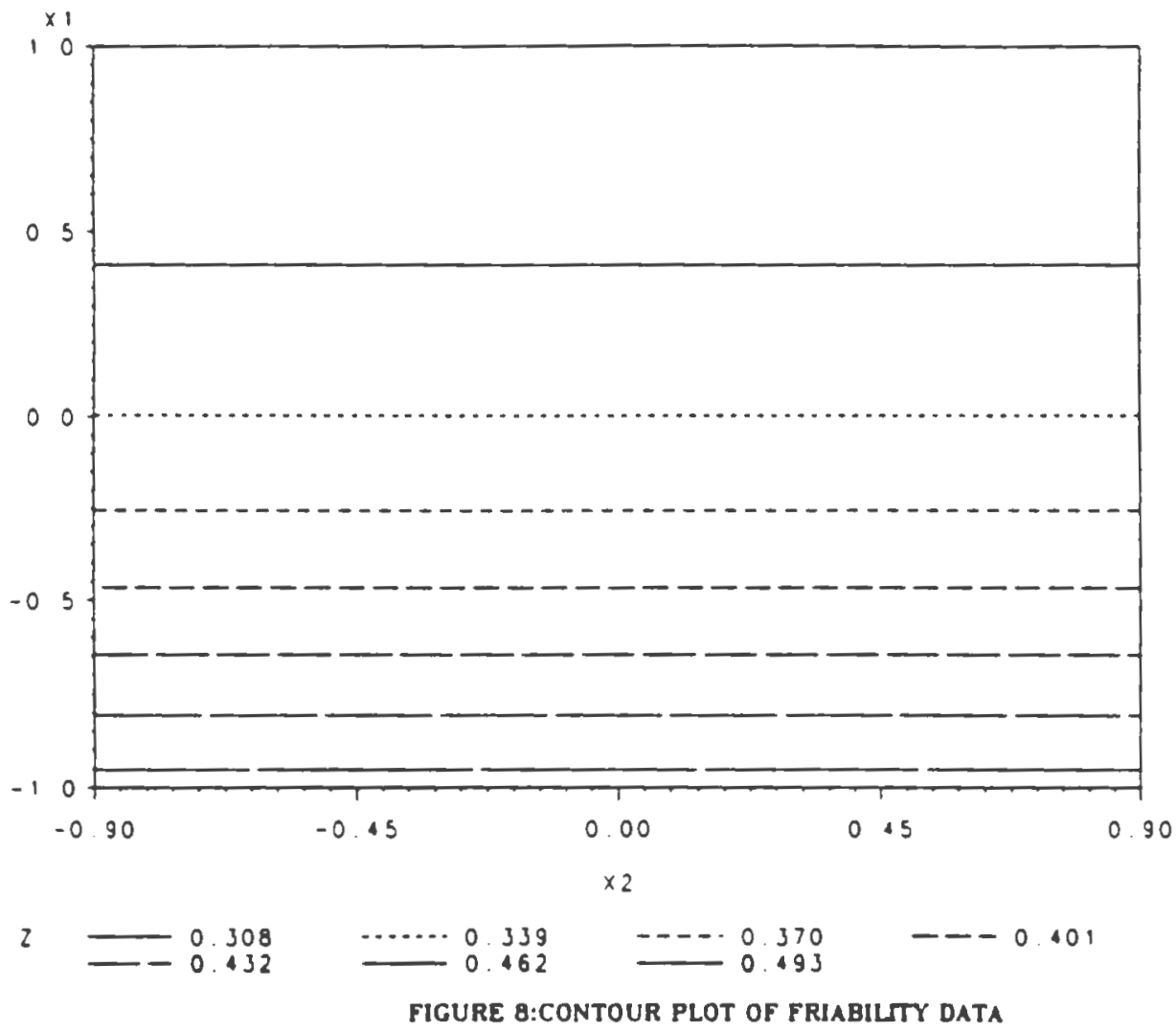




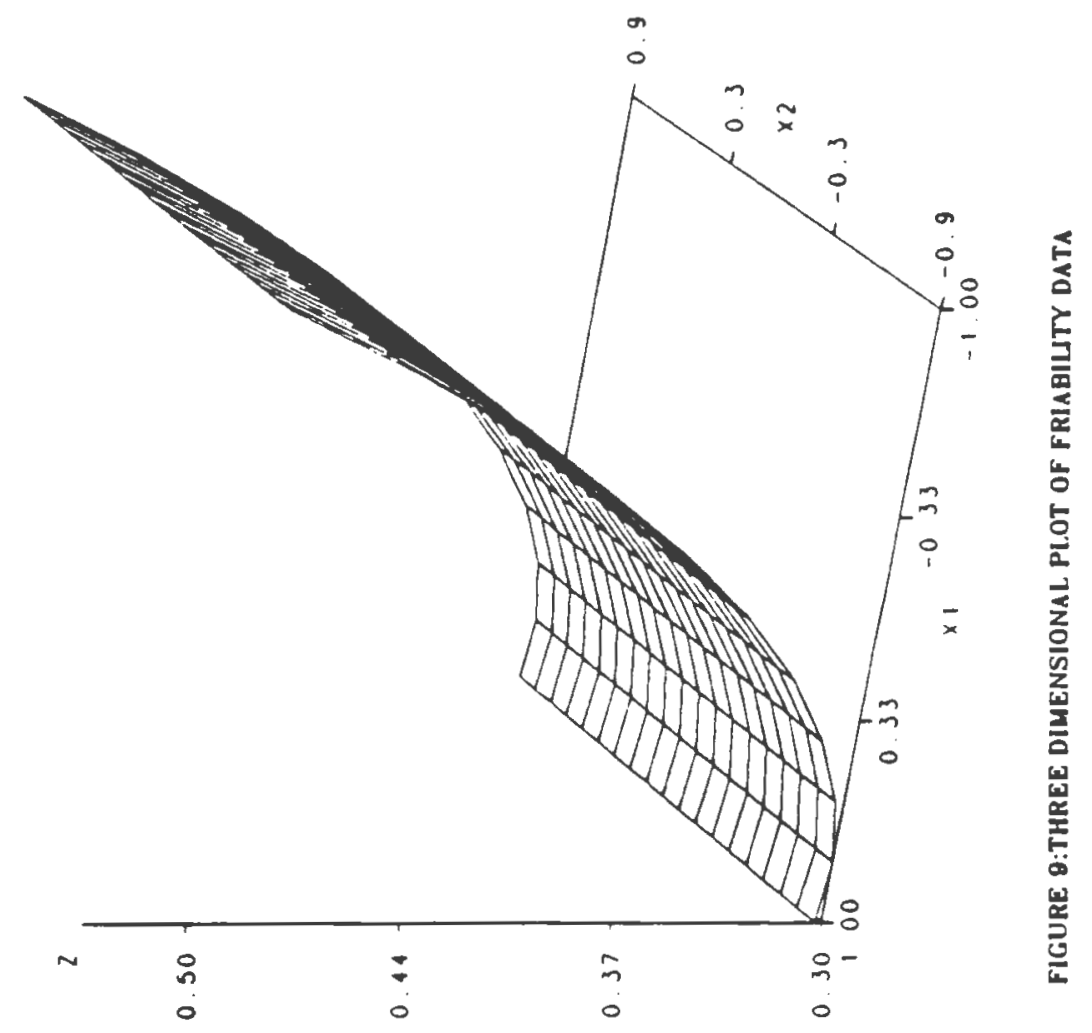




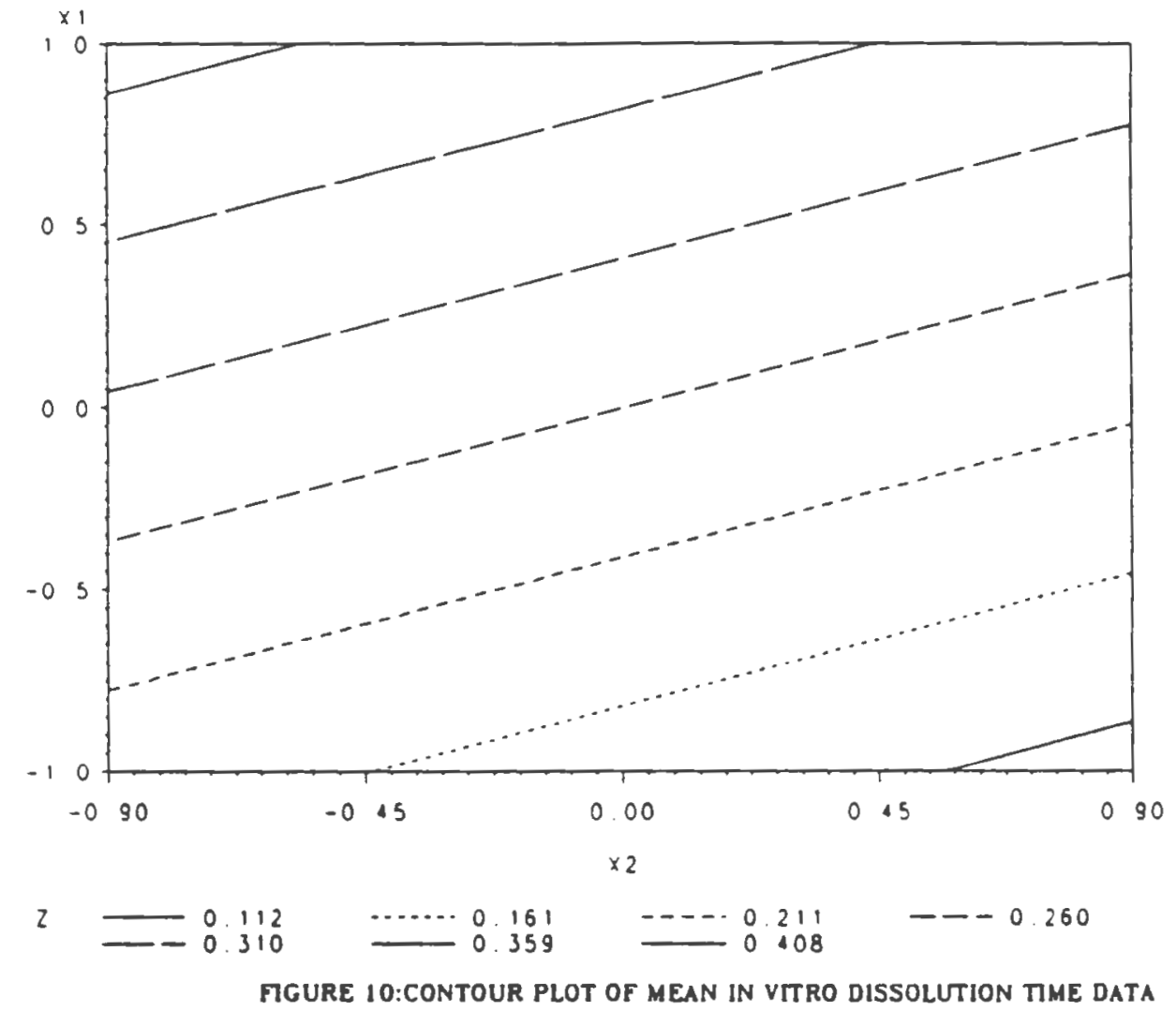




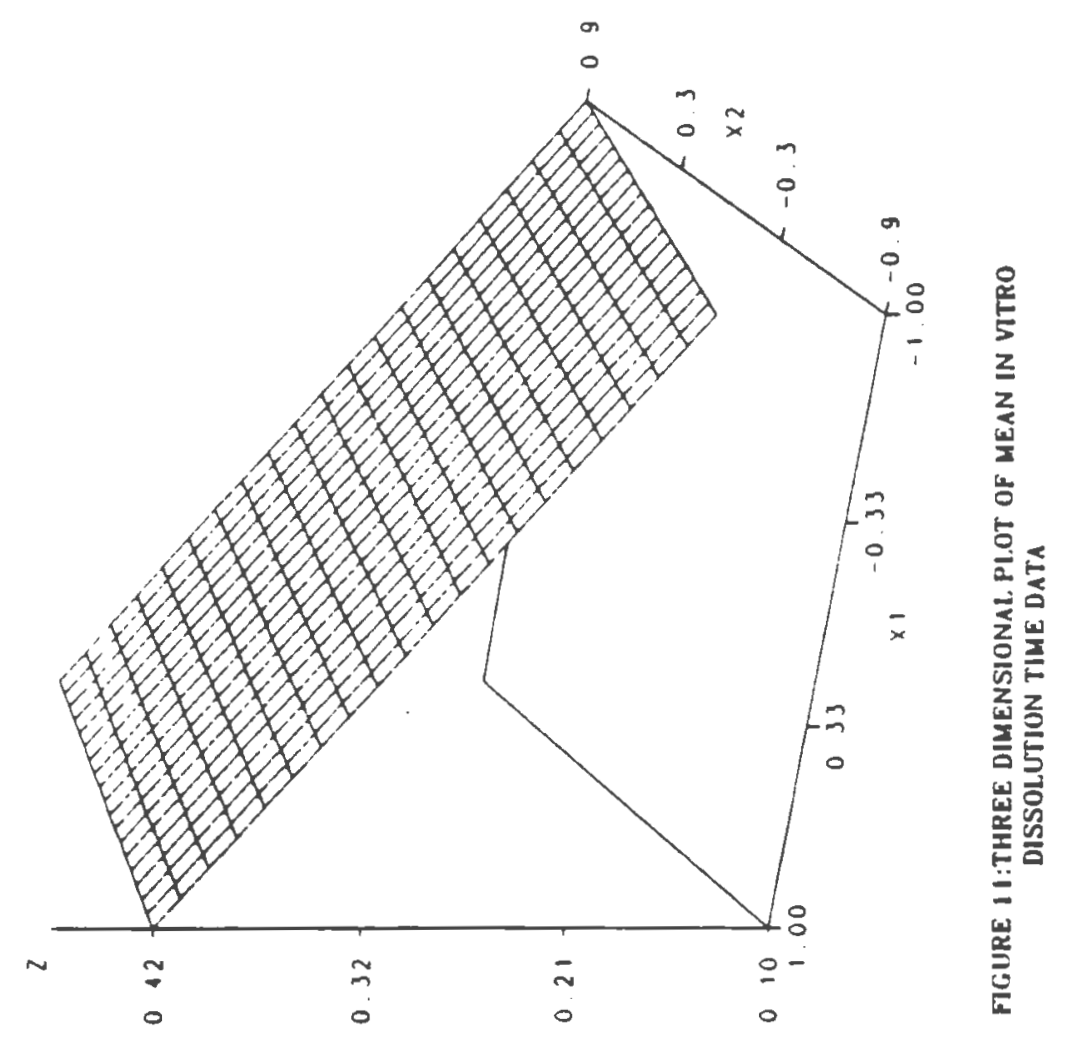


MDT in vitre was minimized by the SQP, after modifying the intercept of the constraint being evaluated. Sensitivity analysis for each constraint was performed while all other constraints were maintained unchanged. The resulting $\mathrm{X}_{1}$ and $\mathrm{x}_{2}$ values obtained were used to calculate the new MDT in vitro. For hardness the values altered ranged from 12.54 to $12.85 \mathrm{~kg}$ and values below $12.54 \mathrm{~kg}$ did not alter $\mathrm{x}_{1}$ and $\mathrm{x}_{2}$. For disintegration the values below 6.593 minutes produced infeasible solution, values above 6.593 minutes produced no change in $\mathbb{X}_{1}$ and $\mathbb{X}_{2}$ solution. For ejection force values below 597.55 Newtons produced infeasible solution, while values above 597.55 Newtons produced no change in $X_{1}$ and $X_{2}$. For friability the values altered ranged from 0.3060 to 0.2984. Friability values below 0.2984 produced infeasible solution, while values above 0.3060 produced no further change in $X_{1}$ and $X_{2}$. The sensitivity of the optimal solution to the changes in the constraints are shown in Figure 12 and 13. A one percent change in the hardness and the friability values resulted in $1.53 \%$ and $4.31 \%$ change in MDT in vitro time respectively. The sensitivity coefficients for the optimal solution values for hardness and friability were derived using rate method. The sensitivity coefficients were found to be 1.02 and -1.43 with respect to hardness and friability respectively. From these results it is clear that the MDT in vitre is more 
Table 6-Optimum Formulation at Compression

$$
\text { Force of } 13.91(0.29) \mathrm{KN}
$$

Ingredients

Percent $w / w$

Theophyline

25.0

Beaverwhite 300

15.0

Corn Starch

4.0

Lactose

56.0

Value in parenthesis is standard deviation. 
Table 7-Comparison of Predicted and Experimental Values of Response Varlables for Optimum Formulation.

\begin{tabular}{|c|c|c|c|c|c|c|c|}
\hline $\begin{array}{l}\text { Opt Imum } \\
\text { Formulation }\end{array}$ & $\begin{array}{l}\text { Ejection } \\
\text { Force (II) }\end{array}$ & $\begin{array}{l}\text { Weight } \\
x \text { RSD }\end{array}$ & $\begin{array}{l}\text { Hardness } \\
(\text { K.g })\end{array}$ & $\begin{array}{l}\text { Per } \\
\text { Fr } 1\end{array}$ & $\begin{array}{l}\text { cent } \\
\text { abl11ty }\end{array}$ & $\begin{array}{l}\text { Disintegrat!on } \\
\text { Time (minutes) }\end{array}$ & $\begin{array}{l}\text { MDT } \\
(\mathrm{hr})\end{array}$ \\
\hline Constraints & $\leq 605$ & $x$ & $\geq 12$ & & 0.3 & $\leq 7.5$ & \\
\hline Predi=ted & 597.55 & 0.3531 & 12.54 & & 0.2393 & 6.593 & 0.2345 \\
\hline Experimental & $584.15(17.93)$ & 0.2994 & $12.27(1$. & 441 & 0.2323 & $6.57(0.23)$ & 0.3154 \\
\hline
\end{tabular}

Value in parenthesis are standard deviations.

MDT is mean in vitre dissolution time. 
sensitive to changes in friability compared to hardness. The negative sign of the sensitivity coefficient indicated that increase in friability results in decreased MDT in Vitro, while increase in tablet hardness increases the MDT in vitre as expected.

Principal Component Analysis-Principal component analysis was performed using standardized scores to determine the principal factors that characterize the tablet formulation. The first principal component explained 92.8\% of the total standardized variance as shown in Table 8 . The remaining principal components did not greatly help to explain the standardized variance and therefore were not considered any further. All the tablet properties show approximately equal correlation coefficient with the first principal component as shown in Table 9 . Therefore the first principal component represents the overall tablet physical properties. In other words measurements of all these tablet properties are of approximately equal importance in defining the characteristic of the formulated tablet. The information from all these measured variables would explain $92.5 \%$ of the characteristics of the formulated tablet.

Simulation of Variations in Compression PorcesRegression analysis by least squares method used for estimating response surface model coefficients rest on two 


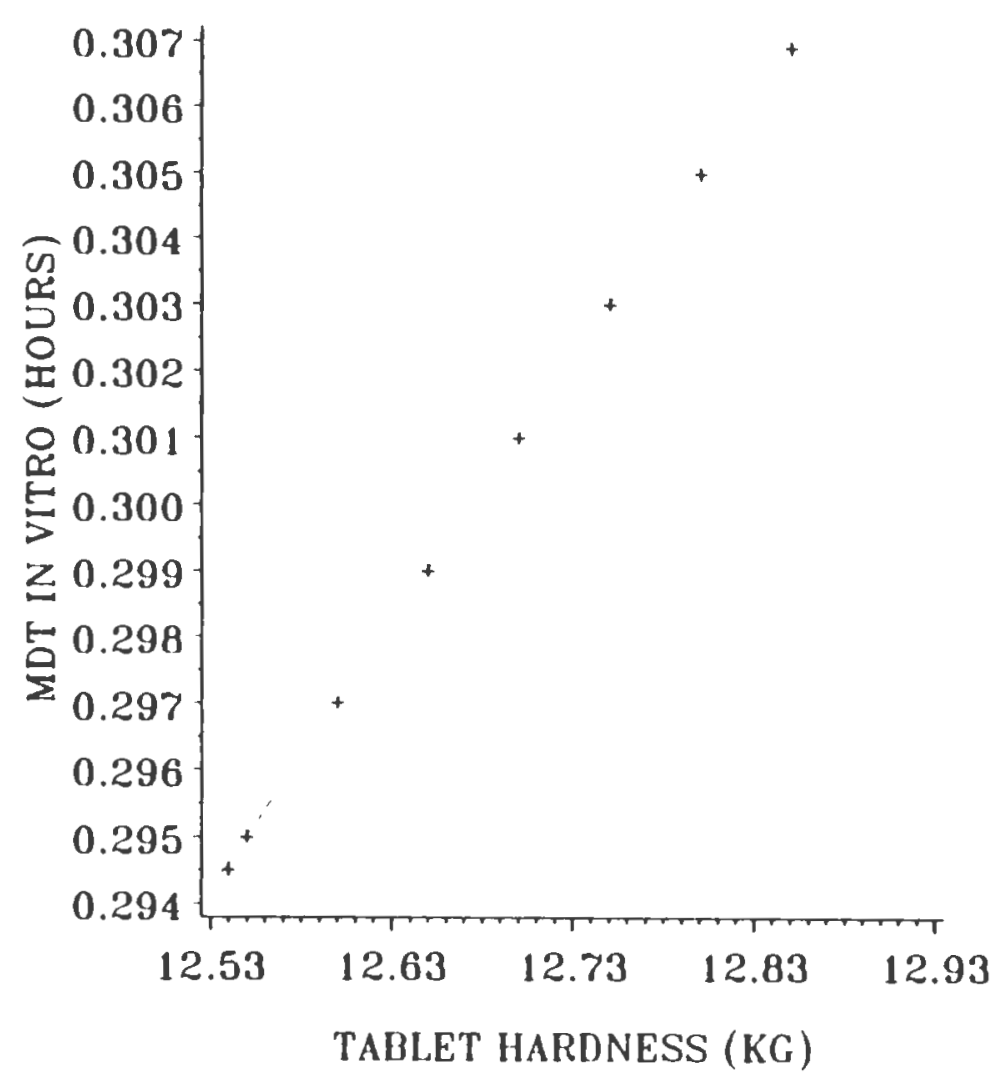

FIGURE 12: OPTIMUM MDT IN VITRO AS FUNCTION OF HARDNESS CONSTRAINT 


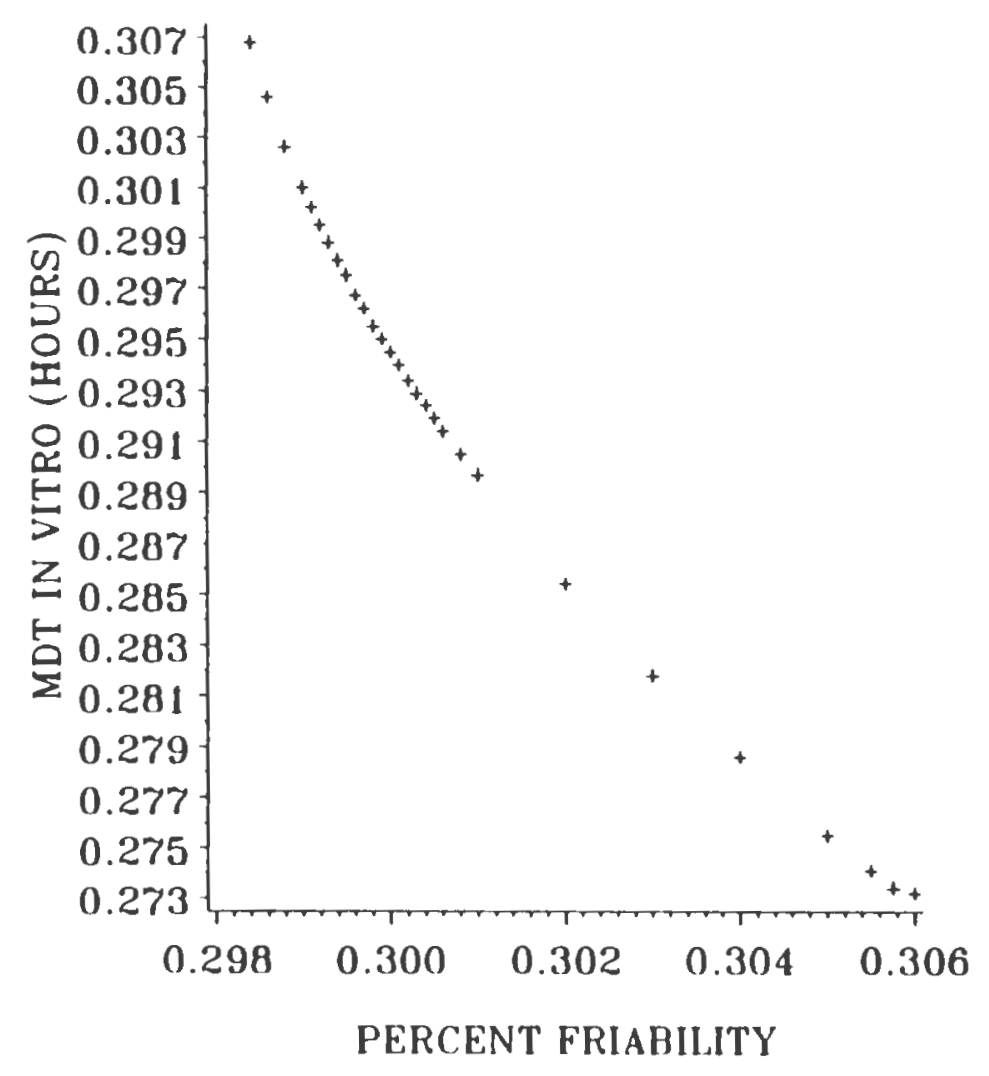

FIGURE 13: OPTIMUM MDT IN VITRO AS FUNCTION OF PERCENT FRIABILTY 
Table 8-Variance Analysis of the First Four Principal Componets.

\begin{tabular}{llll}
\hline $\begin{array}{l}\text { Principal } \\
\text { Components }\end{array}$ & Eigenvalues & Proportion & Cumulative \\
& & & \\
1 & 3.71034 & 0.927587 & 0.92759 \\
2 & 0.18140 & 0.045350 & 0.97294 \\
3 & 0.08344 & 0.020861 & 0.99380 \\
4 & 0.02481 & 0.006202 & 1.00000 \\
\hline
\end{tabular}

Total Variance 3.99999

Total \% Relative Information 100.0 
Table 9-Coefficients of Bigenvectors Associated with First Two Principal Components.

\begin{tabular}{lrc} 
Tablet & & Principal \\
Properties & $\begin{array}{c}\text { Component } \\
2\end{array}$ \\
\hline & & \\
Hardness & 0.502862 & 0.035710 \\
Friability & -0.485033 & 0.819638 \\
Disintegration Time & 0.502054 & 0.524148 \\
MDT in vitro & 0.509720 & 0.228447 \\
\hline
\end{tabular}


main assumptions that a cause and effect relationship exist between independent variables $\left(\mathbb{x}_{1}, \ldots \bar{x}_{k}\right)$ and dependent variable ( $Y$ ) measured with experimental error, and that the independent variable values can be measured without error. Since compression force values have standard deviations we randomly perturbed $\mathbb{x}_{1}$ values to see its effects on the values of response surface equations coefficients in a simulation study (20). Hence, the coefficients of the response surfaces were obtained using simulation for changes according to the experimentally observed standard deviation in compression force values. If the optimum value is unaffected by changes in neighbourhood of a parameter, then that parameter has low sensitivity, and therefore having a precise value for that parameter will not be crucial to finding the true optimum (20). The equations obtained from simulation study have the coefficients in close agreement with those actually obtained from experiment. The coefficient values obtained from the simulation experiment are shown in Table 10. Furthermore, these equations were used for obtaining the optimal solution using same constraints as with actual experiment. The optimal solution obtained was very similar, suggesting the use of $4 \%$ corn starch and $14.21 \mathrm{KN}$ of compression force. This suggests that the response surface model generated by uniform precision hexagonal design is a robust one. 
Table 10-Simulation Generated Coefficlents of the Response Surfaces.

\begin{tabular}{|c|c|c|c|c|c|}
\hline $\begin{array}{l}\text { Parameters } \\
\text { Summary }\end{array}$ & $\begin{array}{l}\text { Ejection } \\
\text { Force }(N)\end{array}$ & $\begin{array}{l}\text { Hardness } \\
(\mathrm{Kg})\end{array}$ & $\begin{array}{l}\text { Percent } \\
\text { Friability }\end{array}$ & $\begin{array}{l}\text { Disintegration } \\
\text { Time (minutes) }\end{array}$ & $\begin{array}{l}\text { MDT } \\
(\mathrm{hr})\end{array}$ \\
\hline BO & $533.556(5.173)$ & $10.604(0.090)$ & $0.3388(0.004)$ & $6.0186(0.087)$ & $0.2605(0.003)$ \\
\hline $\mathrm{BI}(\mathrm{XI})$ & $115.335(4.621)$ & $3.006(0.127)$ & $-0.0999(0.005)$ & $2.7268(0.124)$ & $0.1202(0.005)$ \\
\hline $\mathrm{B} 2(\mathrm{X} 2)$ & - & - & - & $-1.3578(0.159)$ & $-0.0494(0.005)$ \\
\hline $\operatorname{B11}(X 1 * X 1)$ & $-31.423(8.220)$ & - & $0.0635(0.011)$ & - & - \\
\hline $\mathrm{B} 22(\mathrm{X} 2 * \times 2)$ & - & - & - & - & - \\
\hline $\mathrm{B} 12(\mathrm{XI} * \mathrm{X} 2)$ & - & - & - & - & - \\
\hline R Square & 0.9798 & 0.9648 & 0.8859 & 0.9791 & 0.8719 \\
\hline ADJ R-SQ. & 0.9731 & 0.9598 & 0.8479 & 0.9721 & 0.8292 \\
\hline F Value & 179.772 & 218.890 & 24.209 & 166.417 & 21.203 \\
\hline Prob>F & 0.0001 & 0.0001 & 0.0016 & 0.0001 & 0.0023 \\
\hline
\end{tabular}


The computer search method has the disadvantage of frequently giving a plural solution for suitable formulations (10). With the classical Lagrangian method, it can become difficult to solve the resultant set of simultaneous equations especially for nonlinear problems. Therefore a numerical method such as successive unconstrained optimization technique (SUMT) or SQP must be used to locate the optimal solution point. The SQP method is more efficient and robust compared to previously published optimization techniques including SUMT (11). The SQP method can also be used to obtain solution to the problems solved by the previously published optimization methods.

\section{CONCLOSIONS}

A mathematical optimization technique novel to the pharmaceutical sciences has been applied to obtain an optimum formulation of conventional theophylline tablets. The uniform precision hexagonal experimental design provided a robust response surface model. The constrained nonlinear optimization problem was efficiently optimized by use of the SQP algorithm. Properties of the optimal formulation agreed well with the predicted profile. Sensitivity analysis performed showed that the optimal solution was sensitive to changes in hardness and friability. 


\section{REFERENCES}

1. Schwartz, J. B.; Flamholz, J. R.; Press, R. H. J. Pharm. Sci. 1973, 62, 1165-1170.

2. Schwartz, J. B.; Flamholz, J. R.; Press, R. H. J. Pharm. Sci. 1973, 62, 1518-1519.

3. Down. J. R. B.; Miller. R.A.; Chopra. S. R.; Millar. J. F. Drug Dev. Indus. Pharm. 1980, 6, 311-330.

4. Bohidar, N. R.; Bavitz, J. F.; Shiromani, P. R. Drug Dev. Indus. Pharm. 1986, 12, 1503-1510.

5. Takayama. R.; Nambu. N.; Nagai. T. Chem. Pharm. Bull. $1983,31,4496-4450$.

6. Takai. T.; Takayama. K.; Nambu. N.; Nagai. T. Chem. Pharm. Bull. 1984, 32, 1942-1947.

7. Shek, E.; Ghani, M.; Jones, R. E. J. Pharm. Sci. 1980, $69,1135-1142$.

8. Dincer. S.; Ozdurmus. S. J. Pharm. Sci. 1977, 67, $1070-1073$.

9. Fonner,Jr., D. E.; Buck. J. R.; Banker, G. S. J. Pharm. Sci. 1970, 59, 1587-1596.

10. Takayama. B.; Imaizumi. H.; Nambu. N.; Nagai. T. Chem. Pharm. Bull. 1985, 33, 292-300.

11. Reklatis. G. V.; Ravindran. A.; Ragsdell. B. M. Engineering Optimization: Methods and Applications; John Wiley and Sons, Inc. New York, New York, p.438$458,1983$.

12. Box. G. E. P.; Draper. N. R.; Smith. H. Empirical 
Model Building and Response Surface; John Wiley and

Sons, Inc. New York, New York, p.508-515, 1987.

13. Biles. W. E.; Swain. J. J. Optimization and Industrial Experimentation; John Wiley and Sons, Inc. New York, New York, p.135-147, 1980.

14. Myers. R. H. Response Surface Methodology. Allyn and Bacon, Boston Massachusetts, p.126-173, 1971.

15. Powell. M. J. D. A Fast Algorithm for Nonlinearly Constrained Optimization Calculations in Numerical Analysis, Dundee 1977 (G.A Watson, Ed.), Lecture Notes in Mathematics No. 630, Springer-Verlag, New York, 1978.

16. Dawoodbhai. S.; Chueh. H. R.; Rhodes. C. T. Drug Dev. Indus. Pharm. 1987, 13, 2441-2457.

17. Draper. N. R.; Smith. H. Applied Regression Analysis; John Wiley and Sons, Inc. New York, New York, p.108$111,511-512,1980$.

18. Tanigawara. Y.; Yamaoka. R.; Nakagawa. T.; Uno. T. Chem. Pharm. Bull. 1982, 30, 1088-1090.

19. Bohidar, N. R.; Schwartz, J. B.;Restaino, F. A. J. Pharm. Sci. 1975, 64, 966-969.

20. Chatterjee. S.; Hadi. A.S. Sensitivity Analysis in Linear Regression; John Wiley and Sons, Inc. New York, New York, p.261-262, 1988. 
Section III. 
Appendix A: General and Analytical Data. 


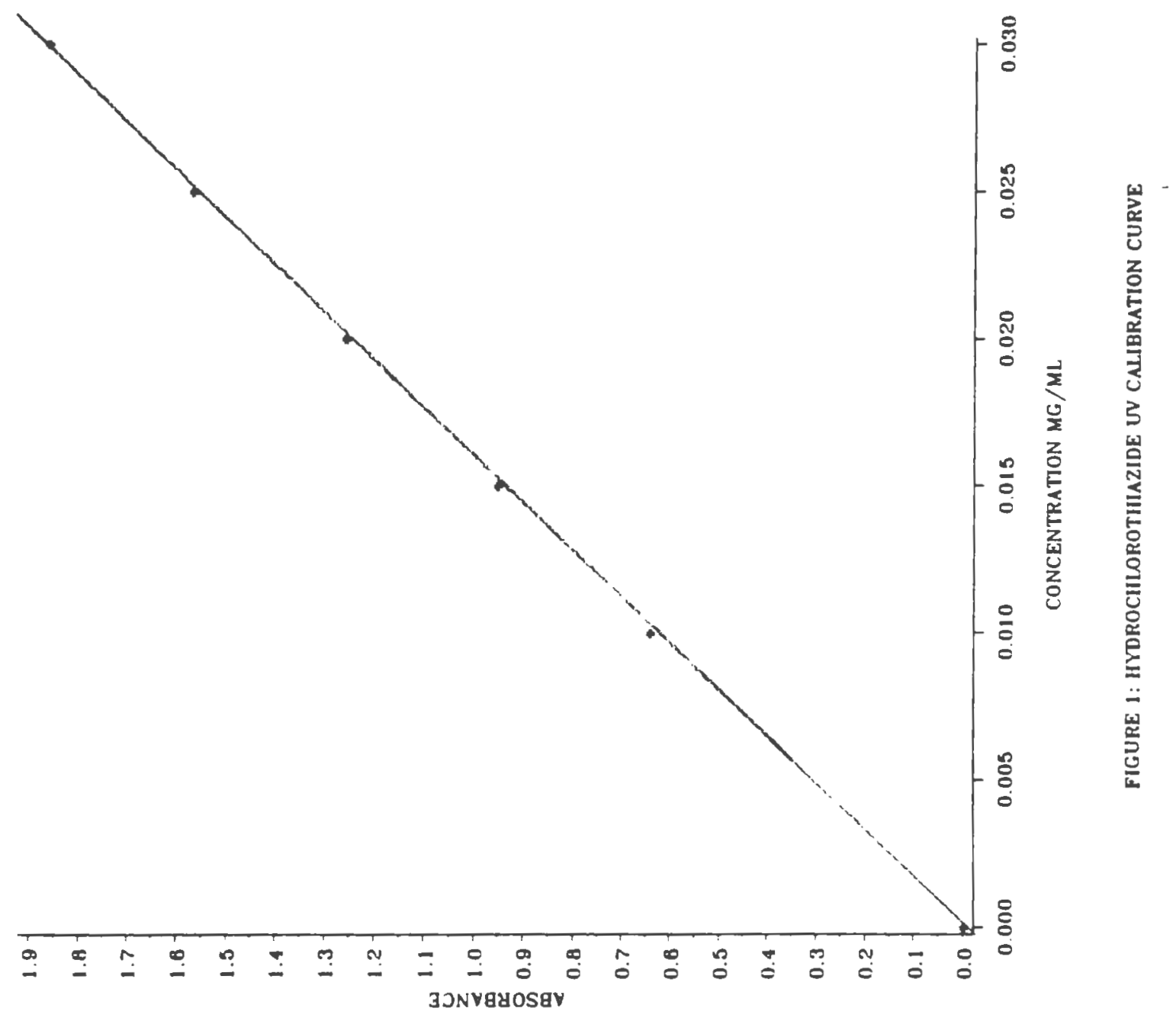




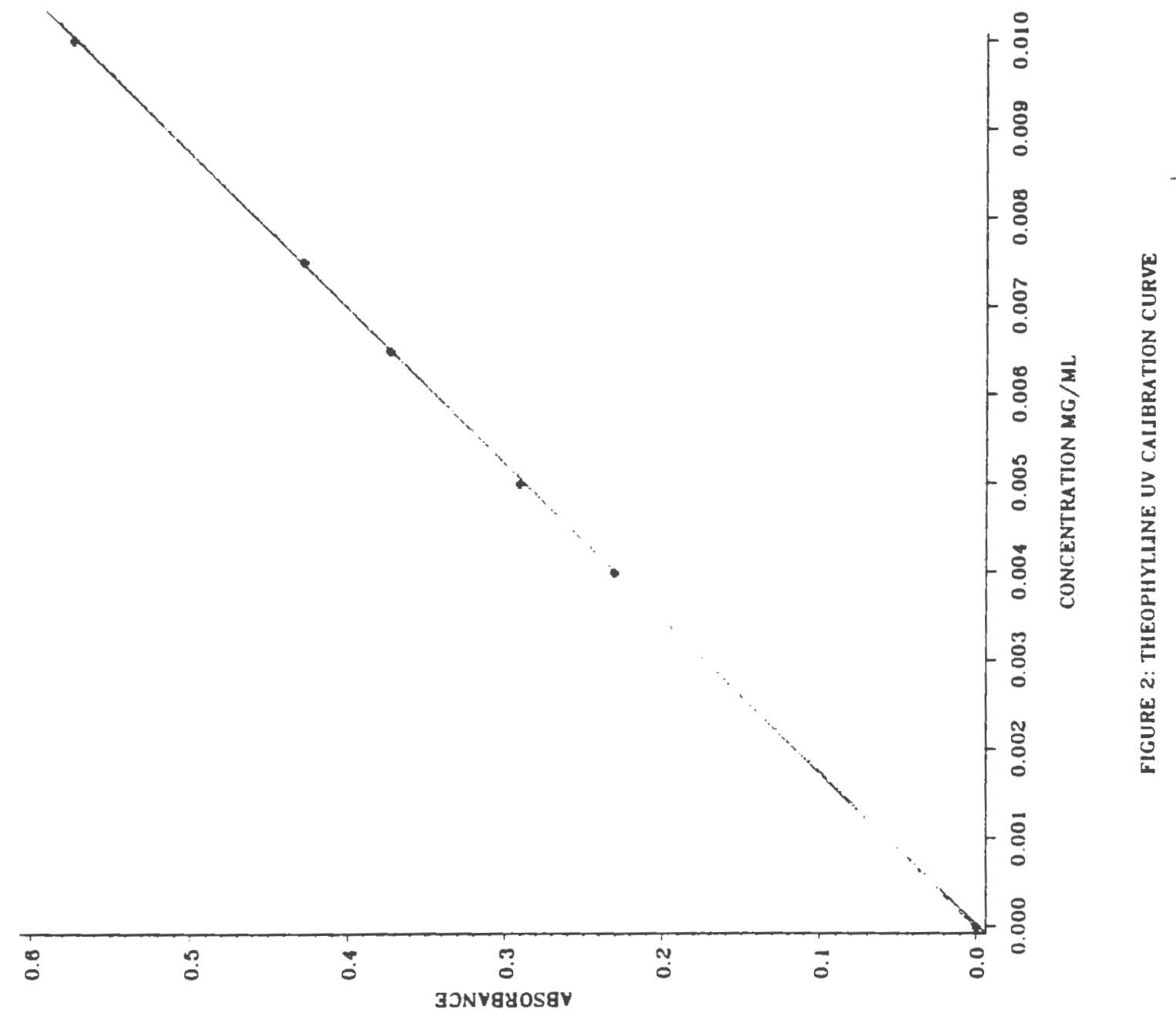




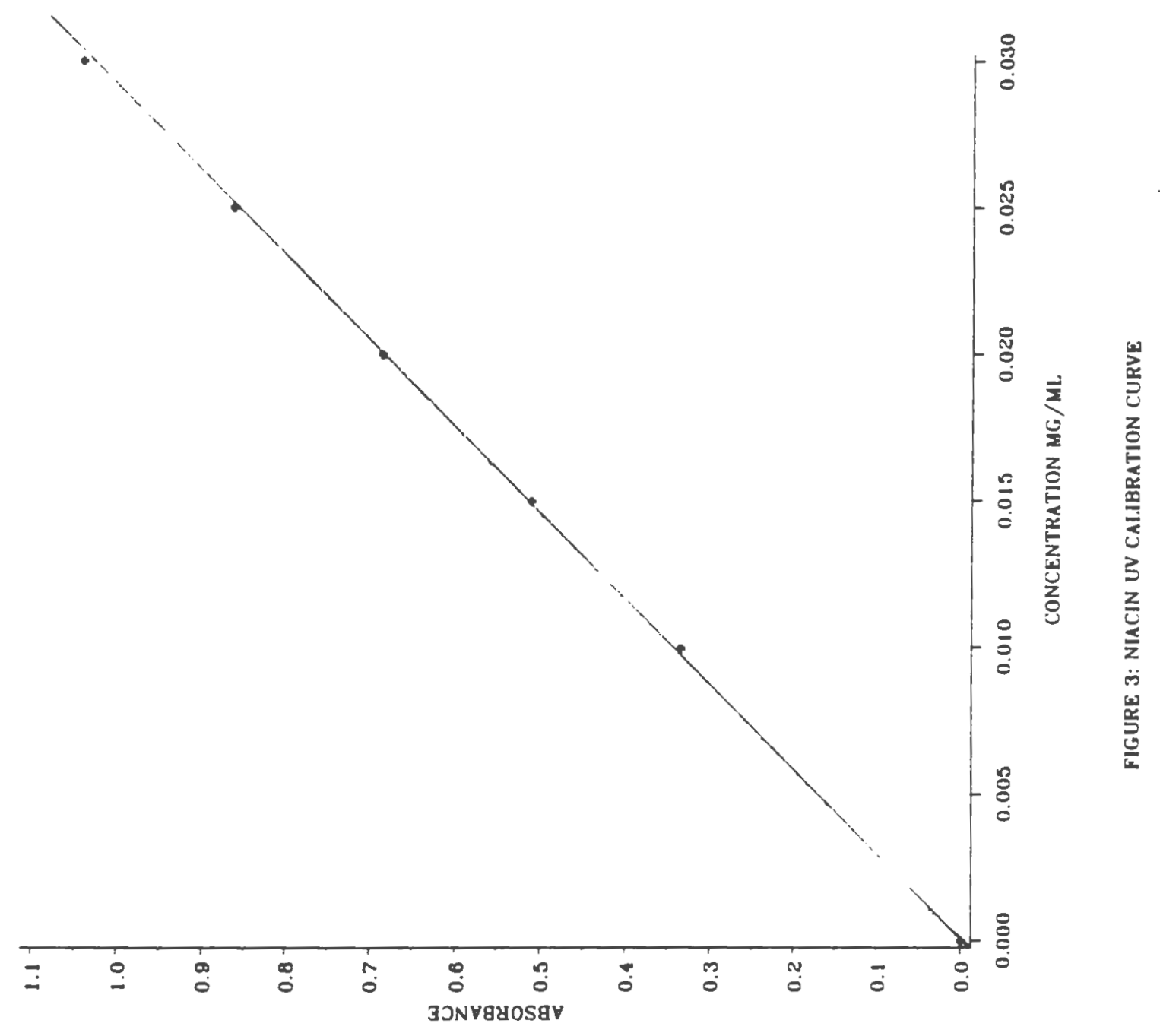




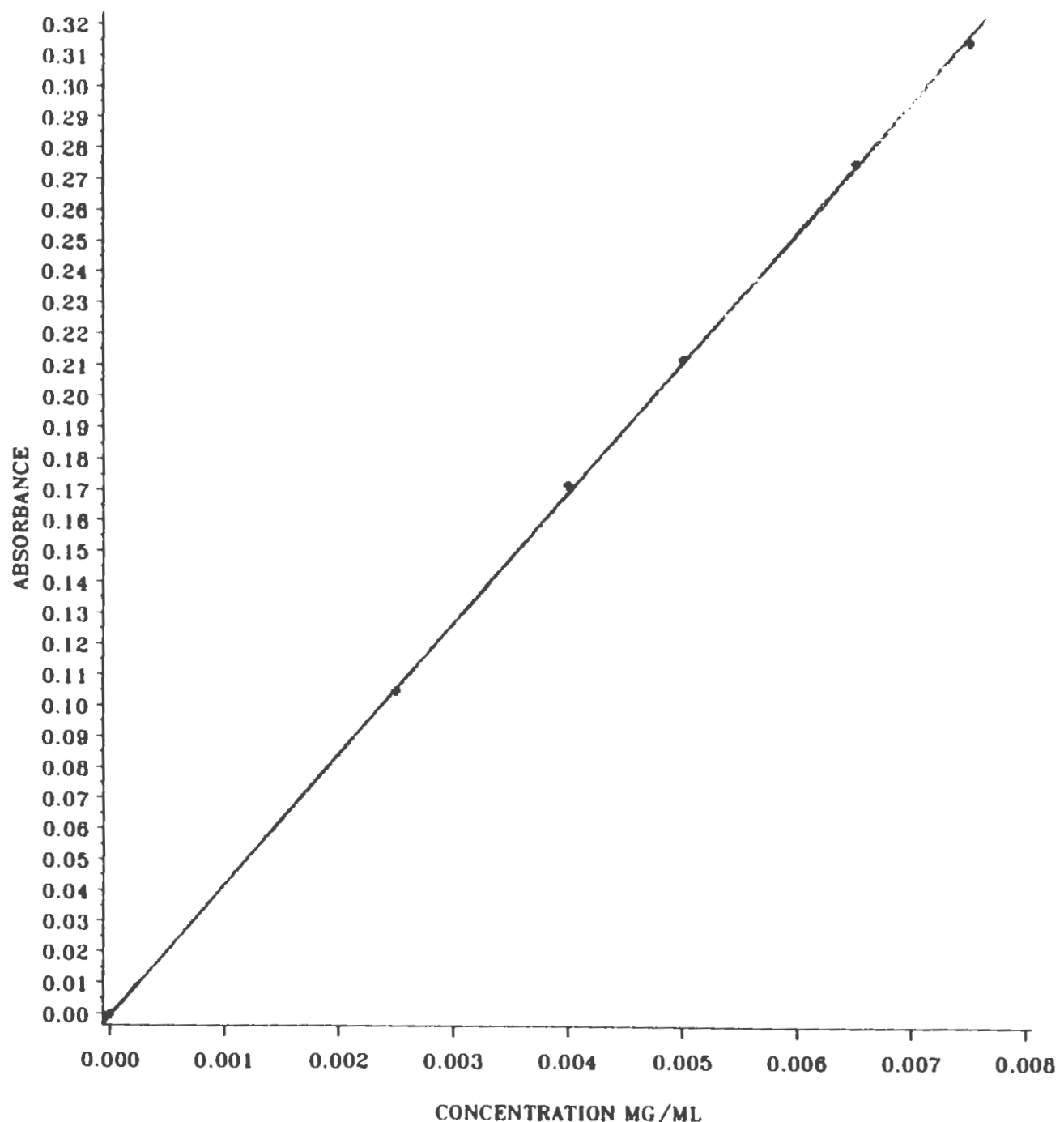

FIGURE 4: PHENYLPROPANOLAMINE UV CALJGRATION CURVE 
Table 1.0

Dissolution Method in Matrix and Lubricant Study.

\begin{tabular}{l} 
Dissolution ${ }^{*}$ Agitation \\
Mrug \\
\hline
\end{tabular}

$\begin{array}{llllr}\text { Niacin } & \text { Water } & 900 \mathrm{ml} & \text { Paddle } & 75 \\ \text { Hydrochlorothiazide } & \text { O.lN Hcl } & 900 \mathrm{ml} & \text { Basket } & 150 \\ \text { Phenylpropanolamine } & \text { Water } & 500 \mathrm{ml} & \text { Paddle } & 50 \\ \text { Theophylline } & \text { Water } & 900 \mathrm{ml} & \text { Paddle } & 50\end{array}$

*Double distilled and deionized water, freshly de-aerated. 
Table 2

Ultra-Violet Analysis of Dissolution Sample in Matrix and Mbricant Study

\begin{tabular}{|c|c|c|c|c|}
\hline Druģ & $\begin{array}{l}\text { Uv Have- } \\
\text { Jength }(\mathrm{nm})\end{array}$ & $\begin{array}{l}\text { Fxtinction } \\
\text { Literature }\end{array}$ & $\begin{array}{l}\text { Coeffjcient } \\
\text { Ohserved }\end{array}$ & $\begin{array}{l}\text { Correlation } \\
\text { Coefficient }\end{array}$ \\
\hline Niacin & 262 & $22.31^{*}$ & 34.85 & 0.9998 \\
\hline Hydrochlorothiazide & 272 & 64.50 & 61.64 & 0.9938 \\
\hline Phenyl propanolamine & 201 & - & 42.28 & 0.9938 \\
\hline Theophylline & 272 & 53.00 & 57.03 & 0.9998 \\
\hline
\end{tabular}

"Units : mg/(ml c.m)

* " In methanol 
The Tables 3 and 4 are Purt of the Manucript II

Table 3

Formulations and Tableting Data of Lubricant Study for Hydrochlorothiazide (10.0\%)

\begin{tabular}{|c|c|c|c|c|c|}
\hline Lubricant & & $\begin{array}{l}\text { Inesium } \\
\text { earate }\end{array}$ & $\begin{array}{l}\text { Matrix } \\
\text { Avicel PH-102 }\end{array}$ & $\begin{array}{l}\text { Compression } \\
\text { Force }(\mathrm{kN})\end{array}$ & $\begin{array}{l}\text { Ejection } \\
\text { Force }(\mathrm{N})\end{array}$ \\
\hline Altalc 300 & $(1.0 \%)$ & $0.2 \%$ & $88.80^{\circ}$ & $5.60(0.09)$ & $55.80(2.22)$ \\
\hline Altalc 400 & $(1.0 \%)$ & $0.2 \%$ & $88.80 \%$ & $4.97(0.08)$ & $52.63(1.67)$ \\
\hline Alababama 300 & $(1.0 \%)$ & $0.2 \%$ & $88.80 \%$ & $5.12(0.06)$ & $52.40(1.93)$ \\
\hline Alababama 400 & $(1.0 \%)$ & $0.2 \%$ & $88.80^{\circ}$ & $5.12(0.06)$ & $53.15(0.67)$ \\
\hline Supra & $(1.0 \%)$ & $0.2 \%$ & $88.80^{\circ}$ & $5.19(0.06)^{\circ}$ & $50.75(2.48)$ \\
\hline Magnesium ste & arate & $2.0 \%$ & $88.00 \%$ & $6.10(0.08)$ & $47.28(1.38)$ \\
\hline
\end{tabular}

** Values in parenthesis are standard deviations. 
Table 4

Formulations and Tableting Data of Lubricant Study for Acetaminophen ( $5.0 \%)$

\begin{tabular}{llllll}
\hline & & $\begin{array}{l}\text { Magnesium } \\
\text { Lubricant }\end{array}$ & $\begin{array}{l}\text { Satrix } \\
\text { Avicel PH-102 }\end{array}$ & $\begin{array}{l}\text { Compression } \\
\text { Force (KN) }\end{array}$ & $\begin{array}{l}\text { Ejection } \\
\text { Force (N) }\end{array}$ \\
\hline Altalc 300 & $(1.0 \%)$ & $0.25 \%$ & $93.75 \%$ & $7.72(0.08)$ & $70.4(5.9)$ \\
Altalc 400 & $(1.0 \%)$ & $0.25 \%$ & $93.75 \%$ & $7.85(0.09)$ & $82.6(6.5)$ \\
Alababama $300(1.0 \%)$ & $0.25 \%$ & $93.75 \%$ & $7.66(0.10)$ & $80.6(7.0)$ \\
Alababana $400(1.0 \%)$ & $0.25 \%$ & $93.75 \%$ & $8.25(0.10)$ & $91.9(7.4)$ \\
Supra & $(1.0 \%)$ & $0.25 \%$ & $93.75 \%$ & $7.02(0.07)$ & $69.1(6.3)$ \\
1.tagnesium stearate & $2.00 \%$ & $91.50 \%$ & $8.73(0.09)$ & $72.8(6.7)$ \\
\hline
\end{tabular}

** Values in parenthesis arc stariand acviations. 
Tables 5 to 13 are Unpublished Additional Data for the Wanuscript II study.

Table 5

Formulations and Tableting Data of Lubricant Study for Hydrochlorothiazide (10.0\%)

\begin{tabular}{|c|c|c|c|c|c|}
\hline Lubricant ${ }^{*}$ & & $\begin{array}{l}\text { Disintegrant } \\
\text { Primogel }\end{array}$ & $\begin{array}{l}\text { Watrix } \\
\text { Avicel PH-102 }\end{array}$ & $\begin{array}{l}\text { Compression } \\
\text { Force (kJ) }\end{array}$ & $\begin{array}{l}\text { Ejection } \\
\text { Force (N) }\end{array}$ \\
\hline Beaverwhite 300 & $(1.0 \%)$ & $1.0 \%$ & $87.80 \%$ & $5.30(0.09)$ & $65.89(5.26)$ \\
\hline Beaverwhite 400 & $(1.0 \%)$ & $1.0 \%$ & $87.80 \%$ & $5.34(0.08)$ & $72.86(7.61)$ \\
\hline Beaverwhite 500 & $(1.0 \%)$ & $1.0 \%$ & $87.80^{\circ}$ & $5.27(0.09)$ & $74.47(6.25)$ \\
\hline Supra & $(1.0 \%)$ & $1.0 \%$ & $87.80_{N}^{N}$ & $5.50(0.09)$ & $66.48(5.38)$ \\
\hline Untraglide 325 & $(1.0 \%)$ & $1.0 \%$ & $87.80^{\circ}$ & $5.46(0.08)$ & $70.90(5.08)$ \\
\hline Alabama 500 & $(1.0 \%)$ & $1.0 \%$ & $87.80 \%$ & $5.31(0.08)$ & $69.39(5.04)$ \\
\hline
\end{tabular}

* Plus Mafnesium stearate $0.2^{\mathrm{N}}$.

** values in parenthesis are standard deviations. 
Table 6

Formulations and Tableting Data of Lubricant Study for Viacin, Phenylpropanolamine and Theophyl.tine

\begin{tabular}{|c|c|c|c|c|c|}
\hline Drug & Lubricant & $\begin{array}{l}\text { Disintegrant } \\
\text { Primogel }\end{array}$ & $\begin{array}{l}\text { Matrix } \\
\text { Avicel PH-102 }\end{array}$ & $\begin{array}{l}\text { Compression } \\
\text { Force ( } \mathrm{BN})\end{array}$ & $\begin{array}{l}\text { Ejection } \\
\text { Force }(\mathrm{N})\end{array}$ \\
\hline Niacin (10.0\%) & $\begin{array}{l}\text { Beaverwhite } 300 \text { (1.0\%) } \\
\text { Beaverwhite } 500 \text { (1.0\%) }\end{array}$ & $\begin{array}{l}1.0 \% \\
1.0 \%\end{array}$ & $\begin{array}{l}91.55 \% \\
91.55 \%\end{array}$ & $\begin{array}{l}5.61(0.12) \\
5.52(0.09)\end{array}$ & $\begin{array}{l}71.77(2.94) \\
72.68(3.04)\end{array}$ \\
\hline $\begin{array}{l}\text { Phenylpropanol- } \\
\text { amine ( } 20.0 \%)\end{array}$ & $\begin{array}{l}\text { Beaverwhite } 400(1.0 \%) \\
\text { Beaverwhite } 500(1.0 \%)\end{array}$ & - & $\begin{array}{l}78.80 \% \\
78.80 \%\end{array}$ & $\begin{array}{l}6.28(0.11) \\
6.14(0.10)\end{array}$ & $\begin{array}{l}344.62(23.66) \\
337.26(17.31)\end{array}$ \\
\hline $\begin{array}{l}\text { Theophylline } \\
(40.0 \%)\end{array}$ & $\begin{array}{l}\text { Beaverwhite } 300 \text { (1.0\%) } \\
\text { Beaverwhite } 400 \text { (1.0\%) }\end{array}$ & $\begin{array}{l}1.0 \% \\
1.0 \%\end{array}$ & $\begin{array}{l}57.80 \% \\
57.80 \%\end{array}$ & $\begin{array}{l}5.32(0.15) \\
5.29(0.15)\end{array}$ & $\begin{array}{l}155.37(4.43) \\
149.52(4.21)\end{array}$ \\
\hline
\end{tabular}

*Plus Magnesium Stearate 0.2\%.

* values in parenthesis are standard deviations. 
Table 7

Baseline Formulations and Tableting Data for Lubricant Study Using Magnesium Stearate as Lubricant.

\begin{tabular}{|c|c|c|c|c|c|}
\hline Drug & $\begin{array}{l}\text { Matrix } \\
\text { Avicel PH-102 }\end{array}$ & $\begin{array}{l}\text { Magnesium } \\
\text { Stearate }\end{array}$ & $\begin{array}{l}\text { Disintegrant } \\
\text { Primogel }\end{array}$ & $\begin{array}{l}\text { Compression } \\
\text { Force (KN) }\end{array}$ & $\begin{array}{l}\text { Ejection } \\
\text { Force (KN) }\end{array}$ \\
\hline $\begin{array}{l}\text { Niacin } \\
(10.0 \%)\end{array}$ & $87.0 \%$ & $2.0 \%$ & $1.0 \%$ & $5.12(0.07)$ & $60.83(7.12)$ \\
\hline $\begin{array}{l}\text { Hydrochlorothiazide } \\
(10.0 \%)\end{array}$ & $87.0 \%$ & $2.0 \%$ & $1.0 \%$ & $5.49(0.08)$ & $45.53(3.76)$ \\
\hline $\begin{array}{l}\text { Phenyl propaholamine } \\
(20.0 \%)\end{array}$ & $78.8 \%$ & $2.0 \%$ & - & $6.02(0.08)$ & $70.74(4.24)$ \\
\hline $\begin{array}{l}\text { Theopłlylline } \\
(40.0 \%)\end{array}$ & $58.0 \%$ & $1.0 \%$ & $1.0 \%$ & $5.06(0.11)$ & $90.28(4.95)$ \\
\hline
\end{tabular}

\footnotetext{
** Values in parenthesis are standard deviations.
} 
Table 8

Properties of Hydrochlorothiazide Tablets Prepared in Lubricant St uly.

\begin{tabular}{|c|c|c|c|c|c|c|}
\hline & Tablet ${ }^{\mathrm{a}}$ & Haidness ${ }^{\mathrm{b}}$ & Percent $^{\mathrm{C}}$ & Cumparti- & Percent & Disintegrationd \\
\hline Lubricant & Weight (mg) & $(\mathrm{kg})$ & Mardus & bility & Friability & Time (secs) \\
\hline
\end{tabular}

\begin{tabular}{lllllll}
\hline Beaverwhite \#300 & $250.2(0.32)$ & $4.2(0.2)$ & 112.5 & 0.80 & 0.016 & $14-16$ \\
Beaverwhite \#100 & $251.2(0.31)$ & $3.8(0.1)$ & 100.0 & 0.70 & 0.012 & $14-15$ \\
Beaverwhite \#500 & $249.9(0.31)$ & $4.2(0.2)$ & 114.7 & 0.79 & 0.040 & $14-16$ \\
Supra & $251.9(0.30)$ & $4.2(0.2)$ & 110.9 & 0.76 & 0.012 & $13-17$ \\
Ultraglide \#325 & $252.0(0.23)$ & $4.4(0.2)$ & 116.8 & 0.80 & 0.036 & $16-18$ \\
Altalc \#500 & $251.0(0.24)$ & $4.4(0.2)$ & 116.3 & 0.82 & 0.044 & $15-17$ \\
Magnesium Stearate & $250.6(0.26)$ & $0.9(0.2)$ & -- & 0.16 & 0.96 & $30-45$
\end{tabular}

\footnotetext{
avalues in parenthesis are relative standard deviations.

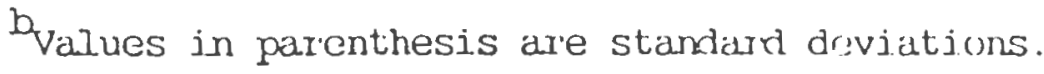

Using hardness value of Beaverwhite $\$ 400$ tablets as $100 \%$.

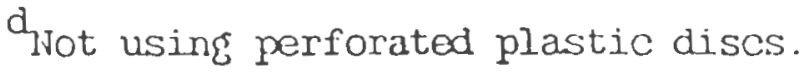


Table 9

Dissolution Properties of Hydrochlorothiazide Tablets Lubricated with Talc and Magnesium Stearate Combination as Compared tó Magnesium Stearate Only

\begin{tabular}{|c|c|c|c|}
\hline \multirow{2}{*}{$\begin{array}{l}\text { Lubricant } \\
\text { Beaverwhite } \# 300\end{array}$} & \multicolumn{3}{|c|}{$\begin{array}{l}\text { Percent Drug Dissolvod } \\
\text { Tine (Winutes) }\end{array}$} \\
\hline & $90.6(5.3)$ & $92.3(4.5)$ & $99.4(1.8)$ \\
\hline Beaverwhite $\# 400$ & $99.6(2.9)$ & $102.1(2.4)$ & $104.9(0.7)$ \\
\hline Beaverwhite $\# 500$ & $91.2(1.9)$ & $94.4(1.5)$ & $97.2(2.5)$ \\
\hline $\begin{array}{l}\text { Magnesium Stearate } \\
\text { (Baseline) }\end{array}$ & $85.5(6.2)$ & $90.4(4.9)$ & $100.9(1.5)$ \\
\hline
\end{tabular}

Qvalues in parenthesis are stariard deviations.

potal possible release of drug from tablet.

as at time equal to infinity. 
Table 10

Properties of Niacin. Theophylline and Phenylpropanolamine Tablets

Prepared in the Lubricant Study

$\begin{array}{lccl}\text { Diug and } & \text { Tablet }^{\mathrm{a}} & \text { Hardness }^{\mathrm{b}} \text { Percent }^{\mathrm{c}} \text { Compac- } & \text { Peroent Disintegration } \\ \text { Lubricant } & \text { Wt. (mg) } & (\mathrm{kg}) & \text { Harder tibility Friability Time (sec) }\end{array}$

\section{Niacin}

Beaverwhite \#300

Beaverwhite $\# 500$

$249.7(0.40) \quad 5.6(0.3) 100.0$

$250.0(0.32) \quad 5.7(0.5) 100.9$

1.01

0.12

$7-9$

Magnesium Stearate

$250.0(0.26) \quad 3.3(0.3)$

1.03

0.11

$8-10$

Phenylpropanolamine

Beaverwhite \#400

Beaverwhite \#500

$250.8(0.44) \quad 4.3(0.2) 102.9$

0.64

0.33

$13-17$

Magnesium Stearate

$250.1(0.21) \quad 4.1(0.2) 100.0$

0.68

0.09

0.67

0.07

16-19

$252.0(0.23) \quad 1.5(0.3)$ -

0.26

0.56

$16-19$

Theophylline

Beaverwhite \#300

Beaverwhite \#400

$\begin{array}{lll}251.5(0.59) & 5.4(0.3) & 100.0\end{array}$

1.01

$251.5(0.54) \quad 5.4(0.2) \quad 100.9$

1.02

0.05

$250.1(0.40)$

$3.4(0.1)$

0.66

0.05

0.12

$6-8$

6-8

$8-10$

avalues in parenthesis are relative standard deviations.

$\mathrm{b}_{\text {values in }}$ parenthesis are standard deviations.

Gsing the lower hardness value of tablet for a drug as $100 \%$.

alot using perforated plastic discs. 
Table 11

Dissolution Properties of Tablets Containing Niacin.

\begin{tabular}{llccc}
\hline Study & Lubricant & \multicolumn{3}{c}{$\begin{array}{c}\text { Percent Drug Dissolved } \\
\text { Time (Minutes) }\end{array}$} \\
& & 5 & 10 & $\mathrm{~T}_{\infty}^{\mathrm{b}}$ \\
\hline Lubricant & Beaverwhite \#300 & $101.7(3.2)$ & $105.8(0.6)$ & $107.4(1.0)$ \\
& Beaverwhite \#500 & $103.4(1.8)$ & $105.4(0.6)$ & $107.4(1.8)$ \\
Exaseline & Magnesium Stedrate & $94.3(2.1)$ & $96.5(1.9)$ & $97.3(1.9)$ \\
& & & &
\end{tabular}

avalues in parenthesis are standard deviations.

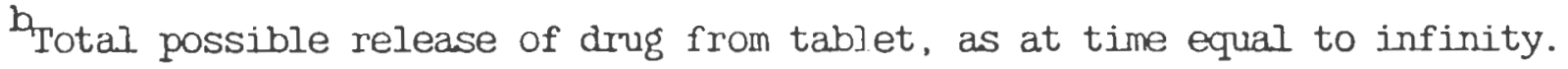

With Lactose instead Avicel PH-102. 
Table 12

Dissolution Properties of Tablets Containing Theophylline

\begin{tabular}{llccc}
\hline Study & Lubricant & \multicolumn{2}{c}{$\begin{array}{c}\text { Percent Drug Dissolved } \\
\text { Time (Minutes) }\end{array}$} \\
& & 30 & 45 & $\mathrm{~T}_{\infty}^{\mathrm{b}}$ \\
\hline Lubricant & Beaverwhite \#300 & $93.9(3.6)$ & $96.6(2.5)$ & $100.0(1.2)$ \\
& Beaverwhite \#400 & $91.9(3.0)$ & $96.7(1.6)$ & $97.7(0.8)$ \\
Biaseline & Magnesium Stearate & $95.2(1.2)$ & $97.7(0.9)$ & $98.6(0.5)$ \\
& & & & \\
\hline
\end{tabular}

avalues in parenthesis are standard deviations.

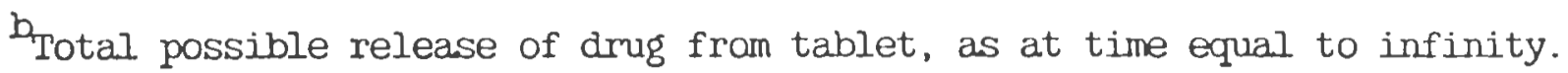


Table 13

Dissolution Properties of Tablets Containing Phenylpropanolamine

\begin{tabular}{llccc} 
& Talc & \multicolumn{3}{c}{$\begin{array}{c}\text { Percent Drug Dissolved } \\
\text { Time (Minutes) }\end{array}$} \\
& & 5 & 10 & $\mathrm{~T}_{\infty}^{\mathrm{b}}$ \\
\hline Lubricant & Beaverwhite $\# 400$ & $64.5(9.1)$ & $80.8(8.2)$ & $100.0(1.7)$ \\
& Beaverwhite $\$ 500$ & $76.0(11.6)$ & $90.4(5.9)$ & $100.0(1.1)$ \\
& Magnesium Stearate & $85.1(10.5)$ & $93.9(6.7)$ & $100.0(4.0)$. \\
\hline
\end{tabular}

avalues in parenthesis are standard deviations.

$\mathrm{b}_{\text {Total }}$ possible release of drug from tablet, as at time equal to infinity. 


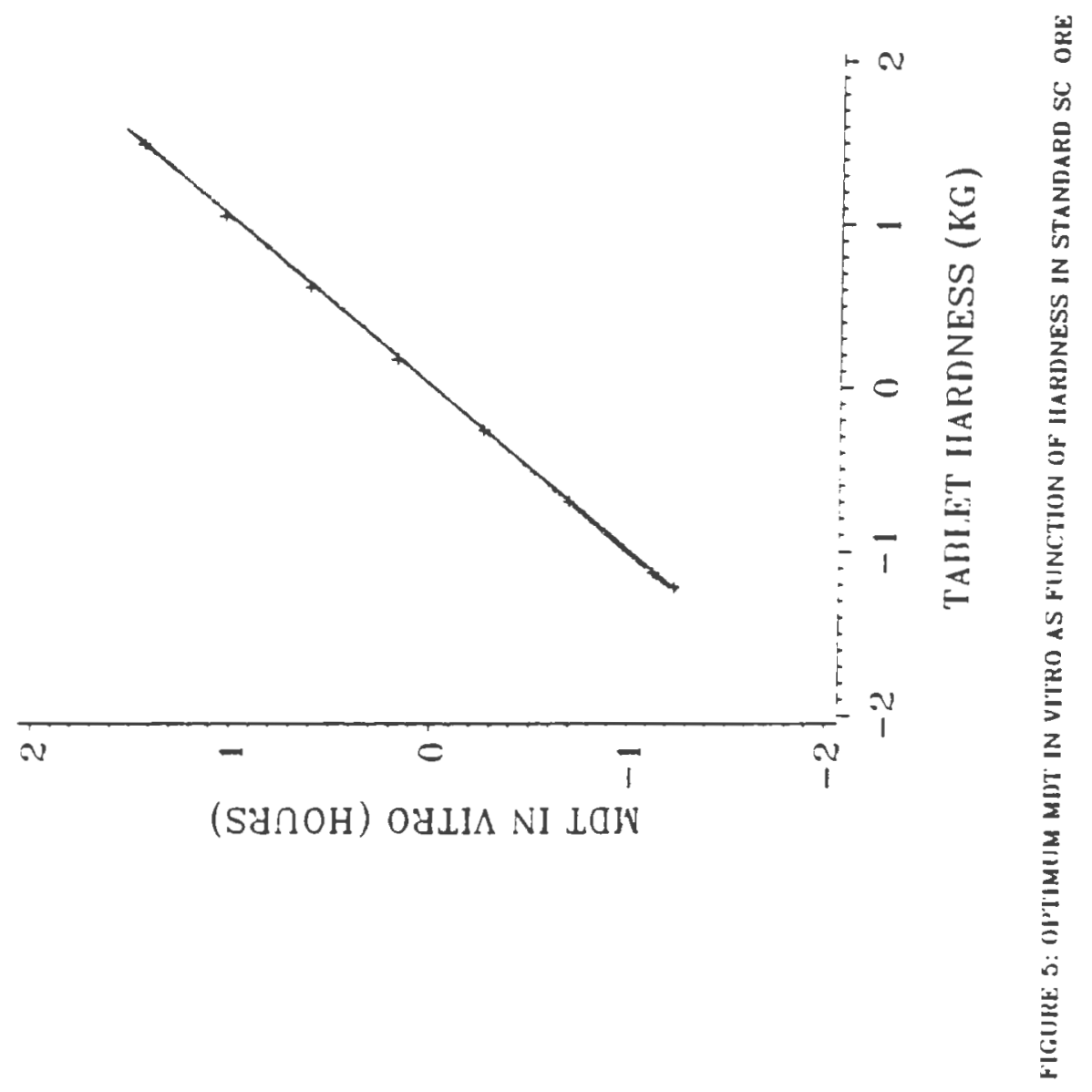




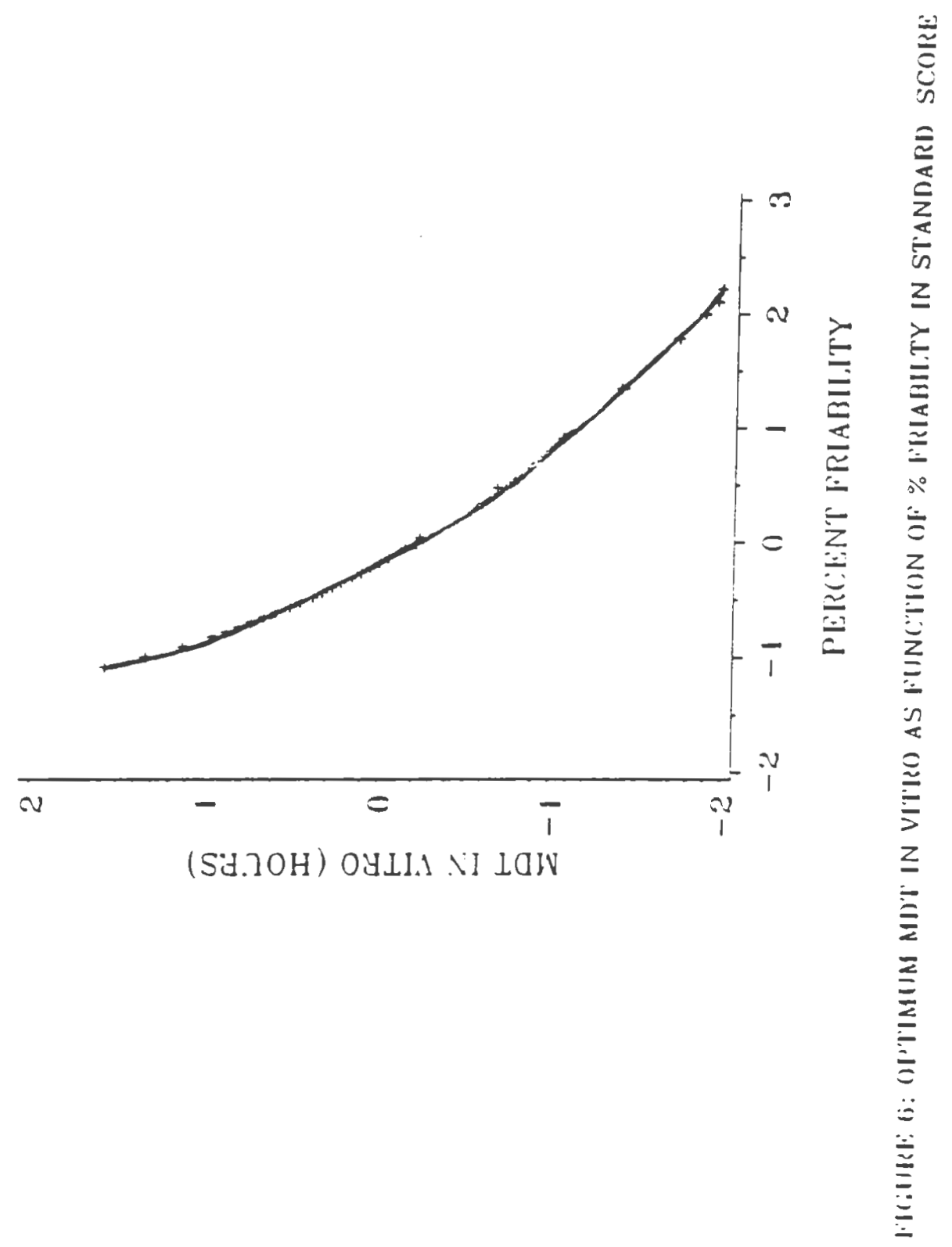




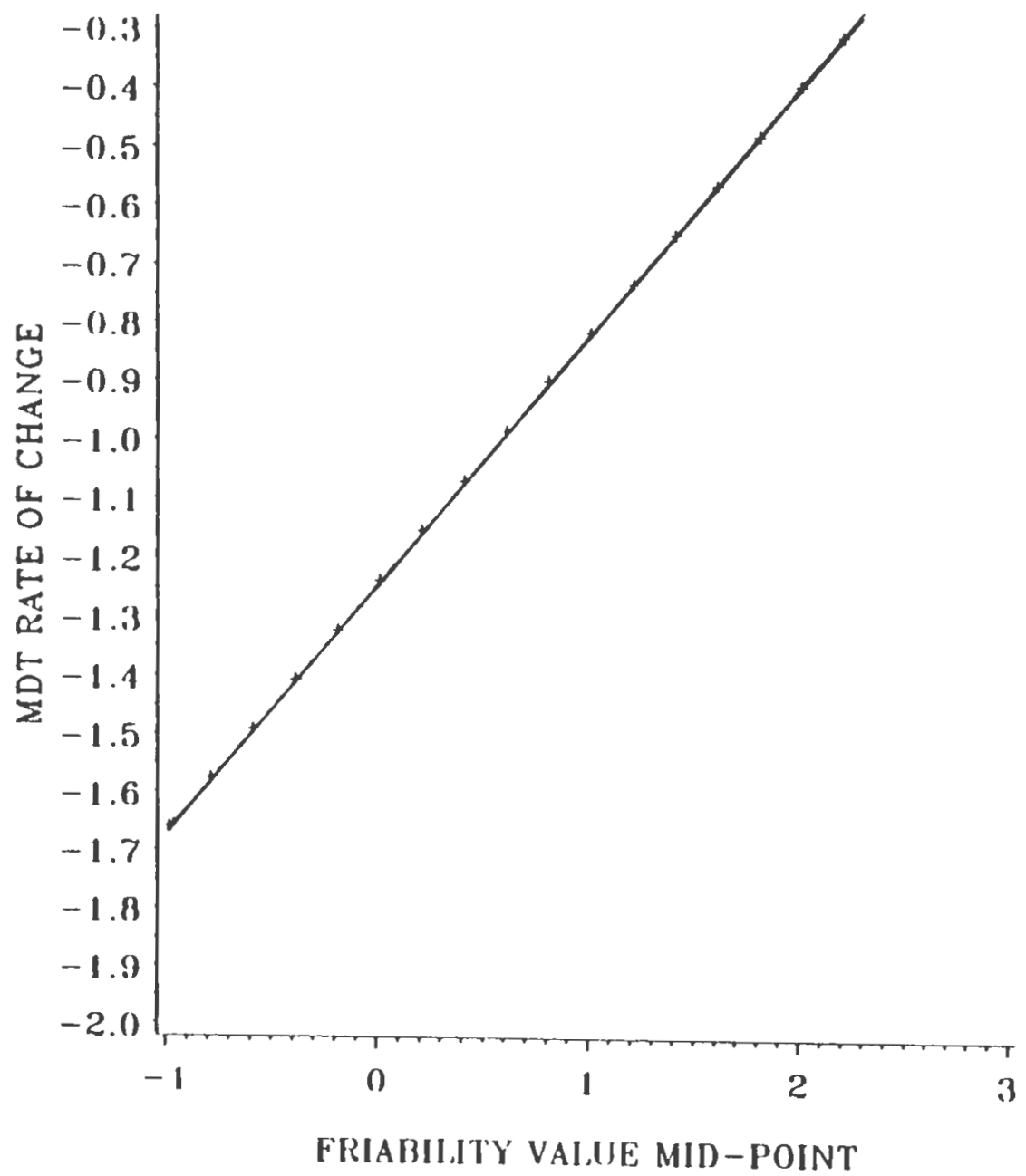

FIGURE: 7: RATE PIOT OF MDT IN VITRO AS A FUNCTION OF FRIABIIITY 


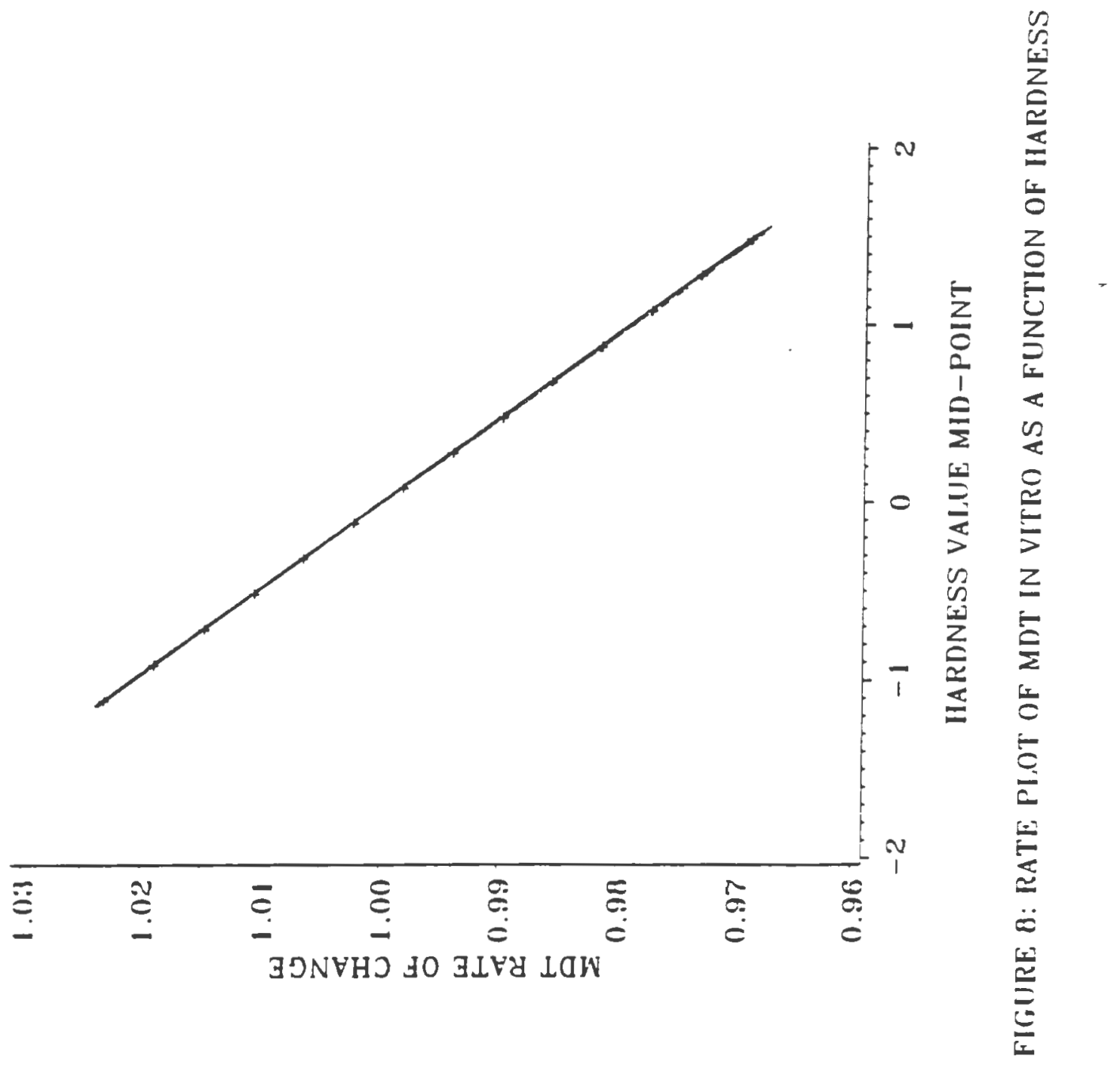


Appendix B: Patent 
PHARMACEUTICAL TABLET MATRIX

CONTAINING TALC AS AS A MAJOR COMPONENT

\section{BACKGRQUND OF THE INVENTION}

The present invention relates to pharmaceutical

5 compounds in tablet form. More particularly, the invention relates to pharmaceutical compounds tableted by a direct-compression process in which talc is present as a major component of the tablet matrix.

In the production of tableted pharmaceutical

10 compounds the active substances are normally combined with auxillary agents, termed "matrix ingredients" herein, the quantity of which is often greater than that of the active substances. The matrix ingredients generally comprise diluent and binding substances,

15 disintegrants and lubricants, including, for example, as a diluent, sugar or the like; as a binder, cellulose, cellulose derivatives, such as the microcrystalline cellulose, Avicel PH-102, or lactose; as a disintegrator, modified starches, such as Primogel; and 20 as lubricants, talc or magnesium stearate. The formulation of pharmaceutical tablet compositions must be such as to enable the economic production of tablets having the desired properties of, inter alia, hardness, friability, appearance, 25 disintegration and tablet weight control. In the past 
the aforementioned properties have been derived largely from the proper selection of binder materials among which cellulose and cellulose derivative materials have been prominent. However, since such binder materials

5 are relatively expensive, it is desirable for economic considerations, to reduce to a minimum the amount required for obtaining the foregoing desirable properties.

It is to the achievement of these ends, therefore,

10 that the present invention is directed.

\section{SUMMARY OF THE INVENTION}

Stated briefly, the present invention provides novel matrix compositions for pharmaceutical compounds that are particularly adapted for tableting by direct

15 compression processes, characterized by being high in talc content. It now has been discovered that binary mixtures of talc and binders, particularly microcrystalline cellulose or lactose, can be used to make excellent tablets for commonly used drugs and

20 vitamins. Such compositions will contain up to 40 weight percent talc.

It is, accordingly, an object of the invention to reduce the cost of pharmaceutical compounds that are tableted by direct compression processes. 
It is further object of the invention to provide a novel matrix composition for tableted pharmaceutical compounds produced by a direct compression process wherein talc is employed, not only as a lubricant and 5 glidant, but also as a bulk-contributing component and as a supplement to bonding agents.

Other objects, aspects and advantages of the invention will become apparent from a considerations of the specification and claims that follow.

Talc is a material designated "generally regarded as safe" by the U.S. Food and drug Administration. It has been widely used in the pharmaceutical industry as a glidant or lubricant in tablets, as a filler in hard

15 gelatin capsules, as a tablet coating, and as a major component of many topically applied powders. Where used as a glidant or lubricant in a compressed tablet, talc is incorporated into the formulation at relatively low levels, normally very much less than ten percent. When

20 used as a filler, diluent or bulking agent in hard gelatin capsule, somewhat higher concentrations, e.g., up to twenty percent, may be used.

It has now been discovered that talc, which is a relatively inexpensive material, can be combined in 25 significantly large amounts with known, more expensive 
matrix materials to produce by direct compression methods tablets having the desirable characteristics of reduced cost, improved hardness, improved friability, excellent tablet weight control, improved appearance and

5 rapid disintegration. Moreover, because of the presence of talc, no seperate glidant or lubricant is required for production purposes so that the economics of the product are still further enhanced.

Tablet formulations according to the invention

10 comprise matrix materials in preponderant amount, i.e., at least 75 percent by weight. The matrix materials are mixtures of lubricant and binder in which the lubricant component is essentially talc in amounts ranging from 10.0 to about 40.0 weight percent, preferably from about

1520.0 to about 25.0 percent. The binder component may be a conventional binder material, for example, microcrystalline cellulose, or lactose.

In order that those skilled in the art can more fully understand the invention, the following examples 20 are set forth. These examples are provided solely for purpose of illustration, and should not be taken as expressing limitations on the invention unless so confirmed by appended claims. All parts and percentages given hereinafter are by weight, unless otherwise 25 stated. 
The procedure followed in preparing the constituent ingredients for the respective examples was essentially uniform. The ingredients as listed in each example, were mixed in particulate form in a Turbula

5 mixer and, thereafter, compressed in a stokes B-2 rotary press into tablets, each weighing a nominal $400 \mathrm{mg}$. The compression and ejection forces generated in the press were measured by piezo-electric transducers located in the press eyebolt and in the ejection cam,

10 respectively. The tablets were compressed at a fixed press setting for each formulation with the press speed set at 25 revolutions per minute and the die fill adjusted to obtain tablets of the desired weight. In all cases the respective talcs utilized were those

15 provided by, and bearing the designations of Cyprus Industrial Minerals Company, Denver, Colarado. The results reported reflect the properties of tablets produced by such talcs in various particle sizes. Talcs identified by the size designation, "300", for example,

20 have a median particle size of 6 um. and size distribution in which $95 \%$ of the particles are finer than $20 \mathrm{um}$. and $12 \%$ are finer than $1 \mathrm{um}$. The size designation, "400", indicate a talc having a median particle size of $4 \mathrm{um}$. and size distribution in which $2599 \%$ of the particles are finer than $45 \mathrm{um}$. and $16 \%$ are finer than $1 \mathrm{um}$. The size designation, "500", indicate 
a talc having a median particle size of 3 um. and size distribution in which $95 \%$ of the particles are finer than $10 \mathrm{um}$. and $18 \%$ are finer than $1 \mathrm{um}$.

In the examples, Alabama tales were compared using

5 niacin formulations; Alabama, Altalc \& Beaverwhite talcs were compared using hydrochlorothiazide formulations; and Beaverwhite 300 talc was used for formulations of the phenylpropanolamine and the theophylline tablets.

The following tests were performed to evaluate the

10 in vitro propeties of the tablets:

\section{Tablet Appearance}

Five randomly selected tablets were examined with a magnifying glass and the presence or abscence of the following relevant characteristics were observed: texture uniformity, e.g., absence of mottling, smoothness of surface or abscence of pitted surfaces, presence of black specks or lines; surface finish, e.g., shining or matt look; and chipping or cracking at the tablet edge.

\section{Tablet Weight Uniformity}

Twenty tablets were weighed on an electronic mettler analytical balance and the relative weight deviation observed. 


\section{Tablet Crushing Strength (Hardness)}

The crushing strength values of ten tablets were determined on an Erweka Hardness Tester. Since formulation compactibility is the ratio of tablet

5 hardness to compression pressure and, since the surface of the testing element is constant throughout the tests, compactibility was calculated as the ratio of hardness to compression force.

Tablet Friability

10 Ten tablets were dedusted and their initial collective weight determined. The tablets were then tumbled in a Roche-type friabilator for four minutes at 25 revolutions per minute after which the final collective weight was determined and the percent

15 friability computed using the formula:

Percent Friability = Initial Weight - Final Weight * 100 Initial Weight

\section{Tablet Disintegration Times}

The disintegration times of six tablets were 20 determined using the USP method of disintegration. While the usual procedure required the placement of plastic caps above the tablets, such caps were not employed where the tablets disintegrated rapidly. 
Examples 1 to 16

The compositions of the formulations tested and the press forces employed in the direct compression tableting procedures with respect to each respective

5 formulation are as shown in Table I. Baseline formulations (see Table II) in which magnesium stearate, a commonly employed tableting lubricant, was used in place of talc in the matrix, were prepared for the compilation of comparative data. In the baseline

10 formulation, as reported in Table II, tablets of $400 \mathrm{mg}$. weight were prepared by the same direct compression process employed for preparing the tablets of the invention; however, the tablets of Niacin, Avicel PH-102 and magnesium stearate were only $375 \mathrm{mg}$. weight due to

15 limitations by the then existing press setting.

Comparisons of the properties of the respective tablets produced in accordance with the invention against those of the baseline tablets are reported in Table III. 
TABILI: I

WRKMLIATION ANT) TAIBIIET (XMPACTION IMTA

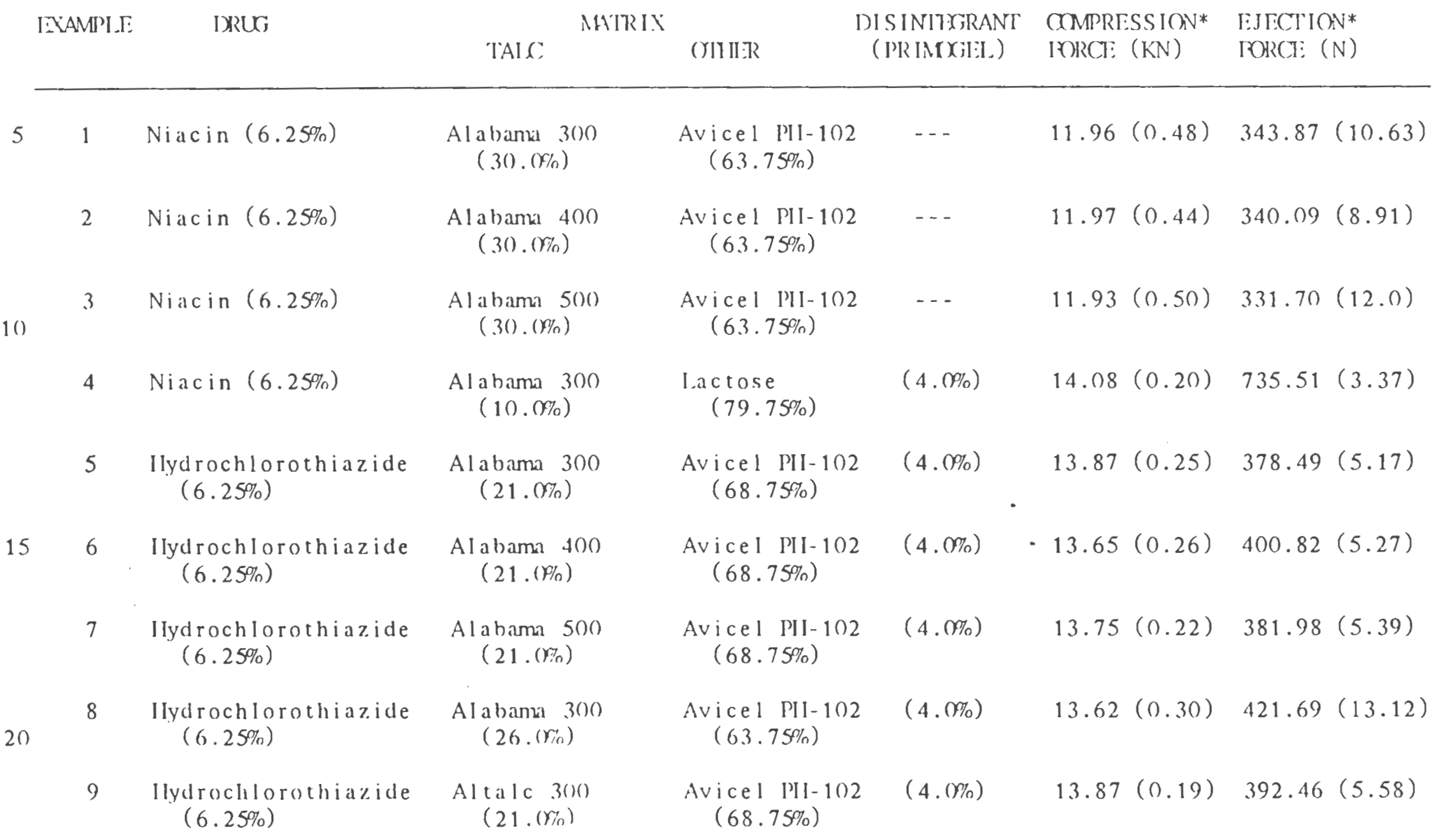


TABI.I: I $\left(\operatorname{con} \operatorname{t}^{\prime} \mathrm{d}\right)$

IXIRULTATION ANT TABBLET OOMPACTION IATA

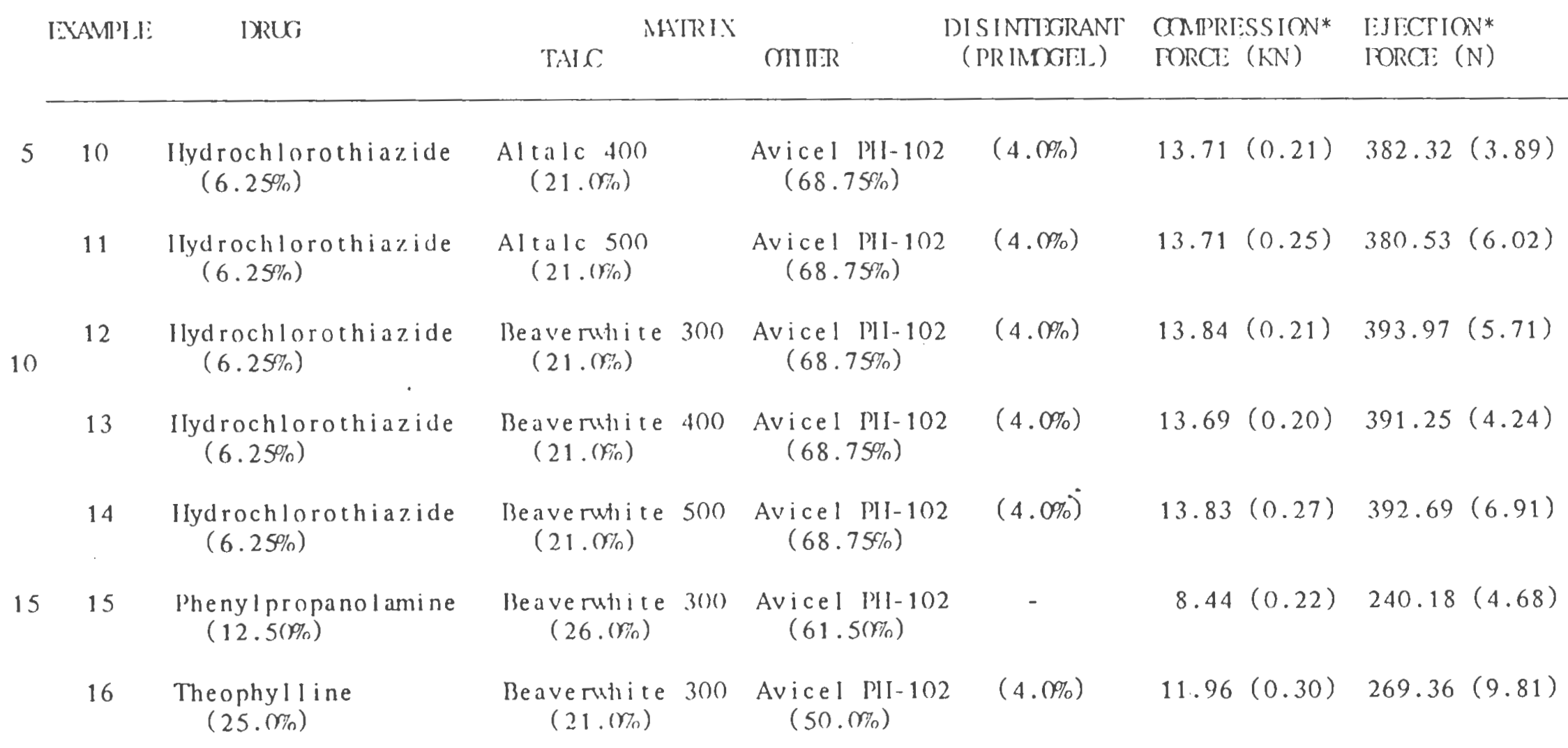

*Values in parenthesis are standard deviations. 
TABII: II

IMASIEI INI: IRKMU ATIONS ANI) TAIBIIITING IHTA USING NAGNIESIUM STTAARATT: AS I.UIRICANT

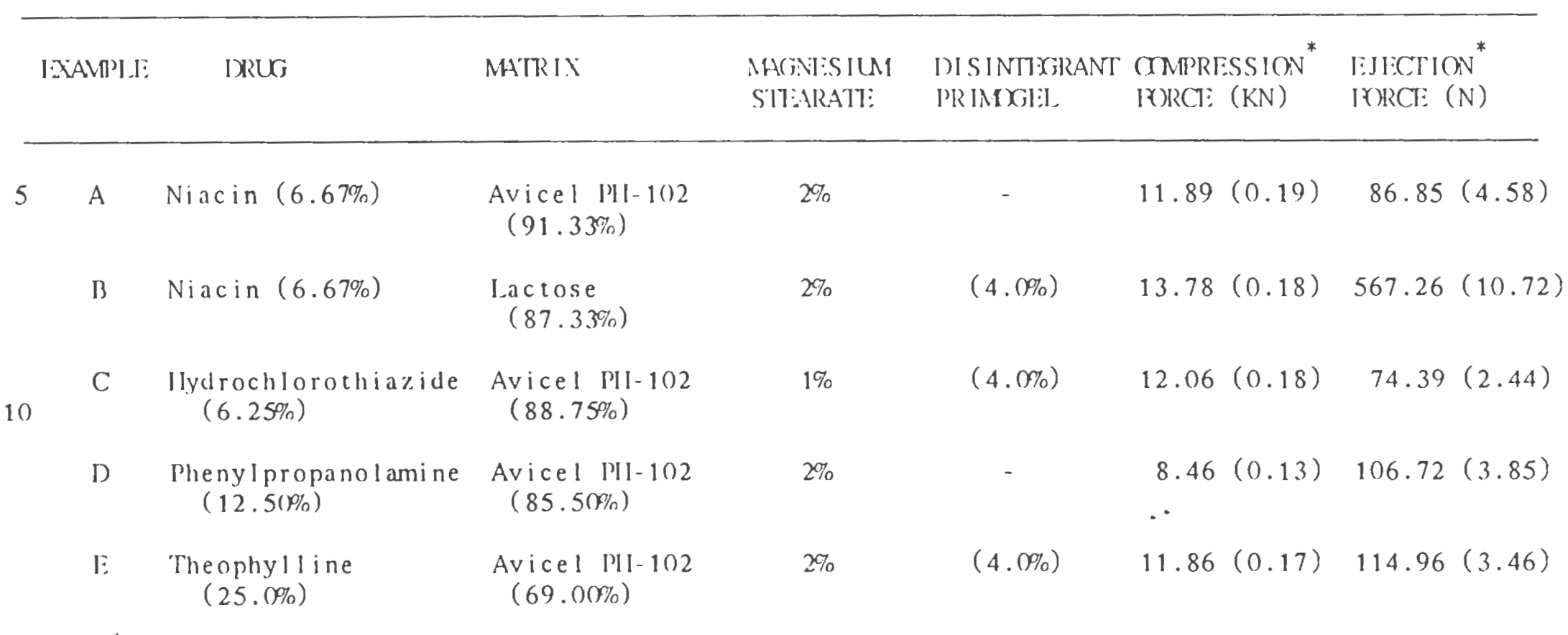

15 *Values in parenthesis are standard deviations 
TABBI: II I

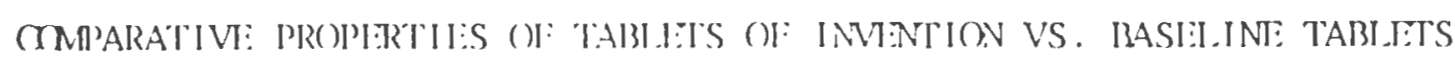

\begin{tabular}{|c|c|c|c|c|c|c|}
\hline & EXAMI'IE & $\begin{array}{l}\text { IIARDNT:SS } \\
\left(K^{\prime}(j)\right.\end{array}$ & $\begin{array}{l}\text { PI:RCINT } \\
\text { IIARIH:R }\end{array}$ & CARACTIBILITY & $\begin{array}{l}\text { PIRCTNT } \\
\text { IRIABII.I'TY }\end{array}$ & $\begin{array}{l}\text { DI S INITGRATION } \\
\text { TIMI: ( } \mathrm{SI}: \mathrm{C} .)\end{array}$ \\
\hline \multirow[t]{5}{*}{5} & 1 & $11.8(1.1)$ & 111.3 & 0.98 & 0.26 & $24-48$ \\
\hline & 2 & $11.3(0.3)$ & 106.6 & 0.94 & 0.28 & $24-48$ \\
\hline & 3 & $10.6(0.6)$ & $100.0^{(2)}$ & 0.89 & 0.25 & $24-48$ \\
\hline & BASIIIINI: A & $11.5(0.8)$ & - & 0.97 & 0.14 & $36-54$ \\
\hline & 4 & $11.7(1.2)$ & - & 0.83 & 0.26 & $216-252$ \\
\hline \multirow[t]{5}{*}{10} & BASEIIINE B & $8.9(1.5)$ & - & 0.65 & 0.26 & $450-540$ \\
\hline & 5 & $12.4(0.5)$ & 124.0 & 0.90 & 0.08 & $26-30$ \\
\hline & 6 & $11.5(0.5)$ & 115.0 & 0.84 & 0.12 & $21-23$ \\
\hline & 7 & $10.8(0.4)$ & 108.0 & 0.78 & 0.07 & $21-22$ \\
\hline & 8 & $6.6(0.7)$ & - & 0.48 & 0.34 & $23-26$ \\
\hline \multirow[t]{3}{*}{15} & 9 & $14.3(0.5)$ & 143.0 & 1.03 & 0.17 & $20-23$ \\
\hline & 10 & $11.2(0.3)$ & 112.0 & 0.81 & 0.17 & $20-23$ \\
\hline & 11 & $10.0(0.8)$ & $100.0^{(3)}$ & 0.72 & 0.19 & $22-24$ \\
\hline
\end{tabular}


TABHI: $111\left(\operatorname{con}{ }^{\prime} t\right)$

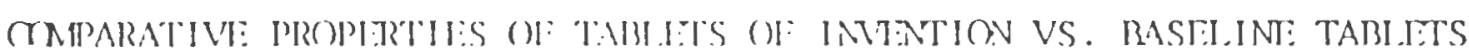

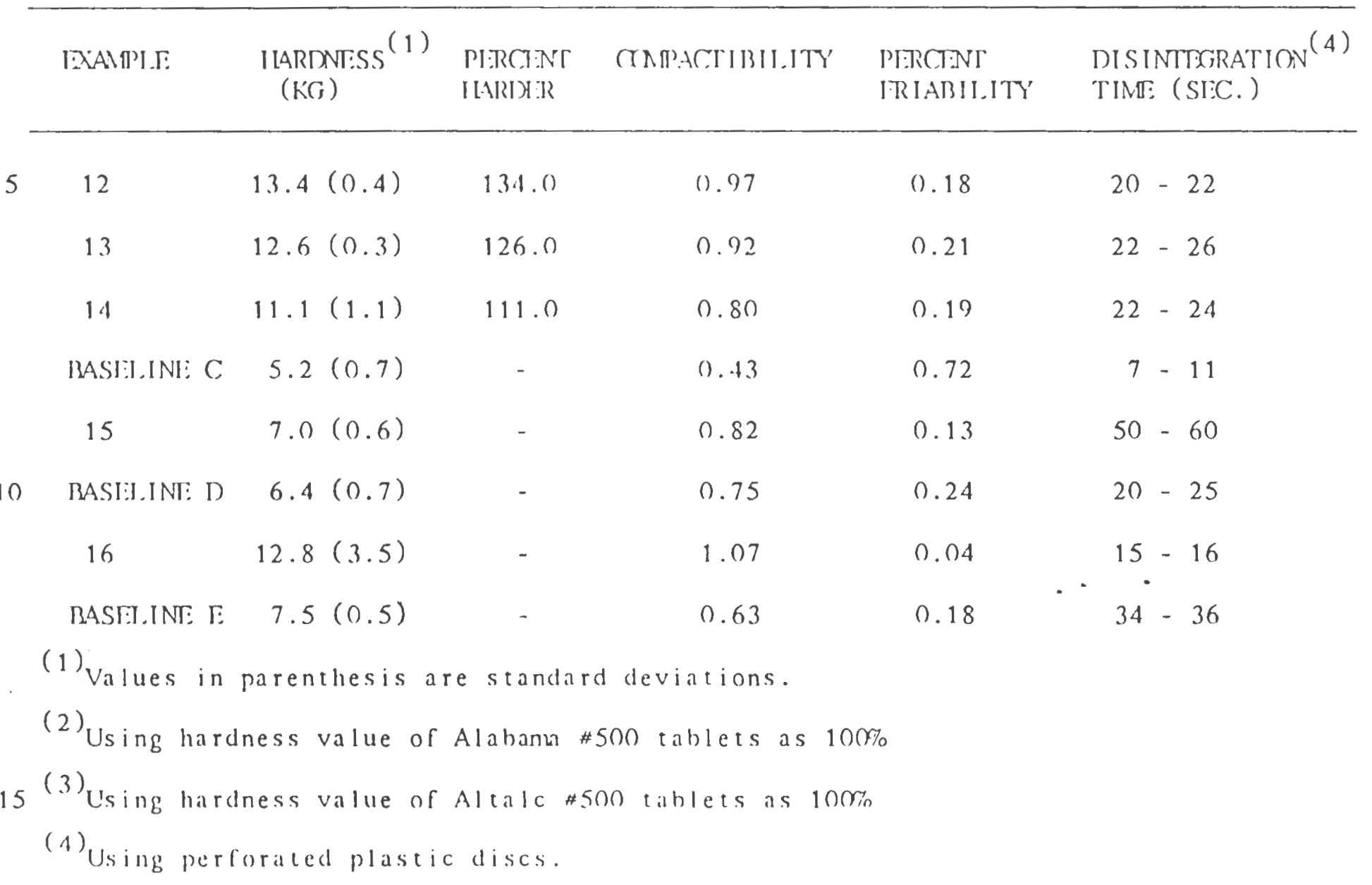


With particular reference to the data reported in Table III as to Tablet Hardness, niacin tablets having Avicel PH-102 plus Alabama 300 or Alabama 400 talcs were statistically significantly harder as compared to those

5 in which Alabama 500 was matrix element. The hardness values of niacin tablets employing Alabama 300 or Alabama 400 talcs were similar to those of tablets containing the baseline formulation.

For hydrochlorothiazide, all of the various talcs

10 tested showed considerably greater hardness as compared to the concerned baseline formulation. Tablets containing Altalc 300 as the matrix component were statistically significantly harder than those employing Beaverwhite 300 , which are, in turn, significantly

15 harder than tablets containing either Alabama 300 or Beaverwhite 400 talc in the matrix. Slightly less hard hydrochlorothiazide tablets were obtained from formulations containing either Alabama 400, Alabama 500 , Altalc 400 or Beaverwhite 500 talcs in their matrices.

20 No statistically significant differences exist among these latter mentioned talcs. The tablets exhibiting the lowest hardness values are those containing Altalc 500 in the matrix. For phenylpropanolamine and, similarly, for theophylline, talc-containg matrices 25 generally produced statistically significantly harder 
tablets compared with those containing the respective baseline formulations.

As regards Tablets Friability, for niacin the tablet formulations containing talc and Avicel PH-102 have a percent friability that is about twice that of

5 the baseline formulation. Those formulated with talc and lactose had the same percent friability as the baseline formulation. For hydrochlorothiazide, tablets produced with Alabama talcs had the lowest friability, 10 while those produced with Altalc and Beaverwhite had similar friability characteristics. The percent friability for all tablets produced in accordance with the invention was a mere fraction of those having the baseline formulation.

15 The percent friability of phenylpropanolamine and theophyline tablets made with talc is two to four times lower than tablets produced with their respective baseline formulations.

As regards Tablet Disintegration, the

20 disintegration times of the niacin and theophylline tablets containing talc in their matrices were about half the disintegration times for their respective baseline formulations. The talc-containing tablets including hydrochlorothiazide and phenypropanolamine as

25 active ingredients disintegrated in about three times as their respective baseline formulations. 
From the foregoing it will be appreciated that - pharmaceutical tablets having an elevated concentration of talc in their matrix exhibit highly beneficial properties. They are relatively inexpensive to produce,

5 have a pharmaceutically elegant appearance, exhibit good hardness or crushing strength.

While the foregoing description is directed primarily to the preferred embodiments and practices of the invention, it will be apparent to those skilled in

10 the art that changes and modifications of the described concepts can readily be made without departing from the spirit and scope of the invention as defined by the following claims.

\section{CLAIMS}

1. A pharmaceutical composition in compressed tablet form comprising a pharmaceutically active ingredient contained in a tablet matrix comprising at least about 10 weight percent talc, said matrix comprising a preponderance of the total weight of said tablet.

2. A tablet as recited in claim 1 in which said matrix comprises at least about 75 percent of the total weight of said tablet. 
3. A tablet as recited in claim 1 in which talc is present in the matrix in an amount of- from about 10 to about 45 weight percent based upon the total weight of said matrix.

4. A tablet as recited in claim 3 in which said matrix comprises at least about 50 weight percent of microcrystalline cellulose or lactose as a binder material, based on the total weight of the matrix.

5. A tablet as recited in claim 4 in which the binder material is present in the matrix in an amount of from about 75 to about 95 percent by weight based on the total weight of said matrix.

6. A tablet as recited in claim 5 in which the binder material is microcrystalline cellulose.

7. A tablet as recited in claim 5 in which the binder material is lactose.

8. A pharmaceutical composition in compressed tablet form comprising a dosage portion of active ingredient including from about 10 up to 40 weight percent talc, and the remainder including pharmaceutical diluent and binder materials. 
9. The pharmaceutical composition as recited in nlaim 8 having a matrix containing said talc said binder material.

10. The pharmaceutical composition as recited in claim 9 in which said diluent and binder materials include microcrystalline cellulose, lactose and starch.

11. The pharmaceutical composition as recited in claim 10 in which said talc has a median particulate 淮e of from about 3 to about 6 microns.

12. The pharmaceutical composition as recited in either claim 10 or claim 11 in which the matrix composition is about 21 weight percent talc and about 68.75 weight percent microcrystalline cellulose.

13. The pharmaceutical composition as recited in claim 12 including starch as a disintegrant.

14. The pharmaceutical composition as recited in either claim 10 or claim 11 in which the matrix composition is about 10 weight percent talc and about 80 weight percent lactose. 
15. The pharmaceutical composition as recited in 14 including starch as a disintegrant.

\begin{abstract}
ABSRTRACT
Pharmaceutically acceptable tablets in which talc in amounts from about 10 to about 40 weight percent exists together with a binding agent in the matrix.
\end{abstract}


Appendix C: Software. 


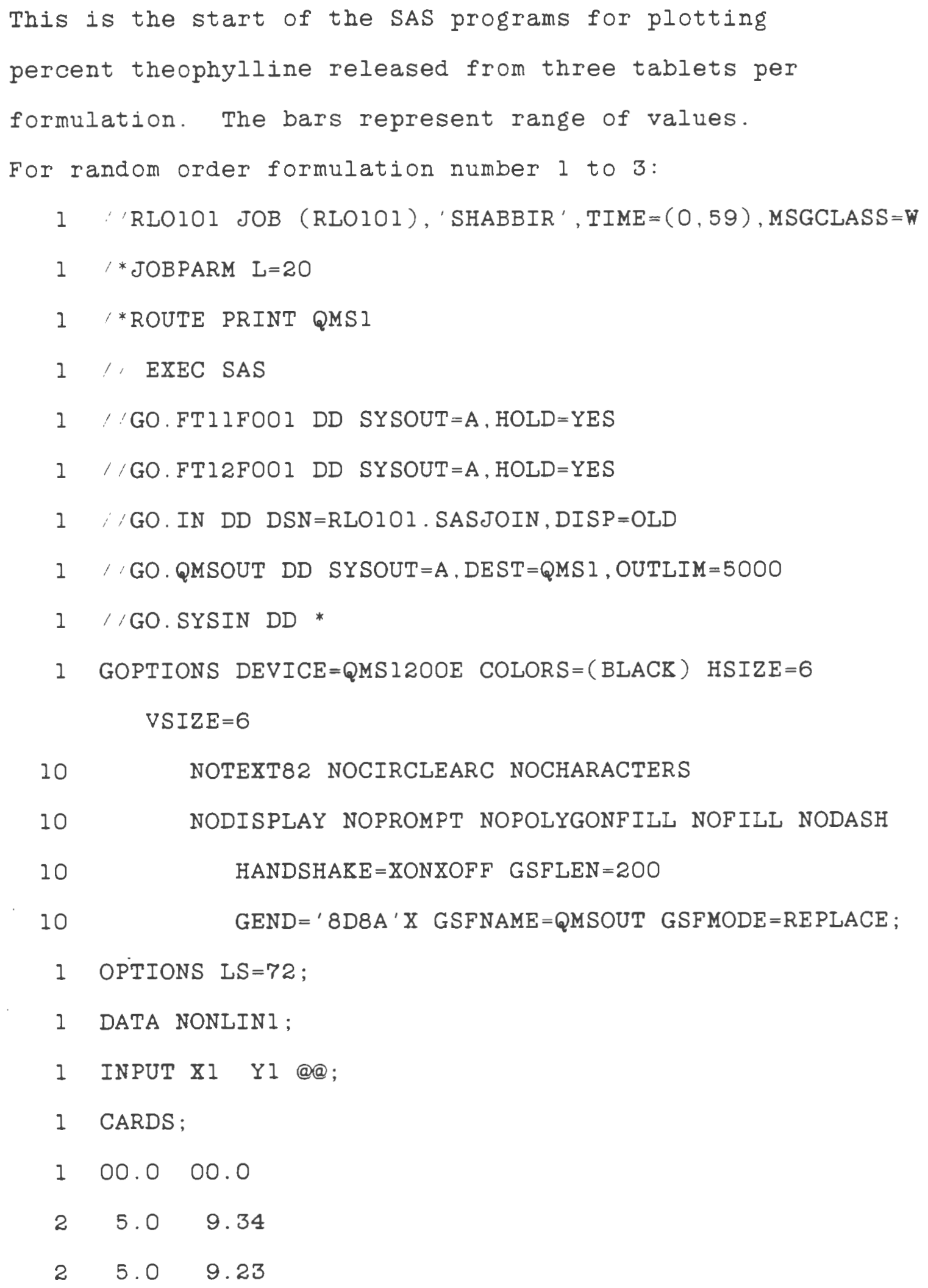




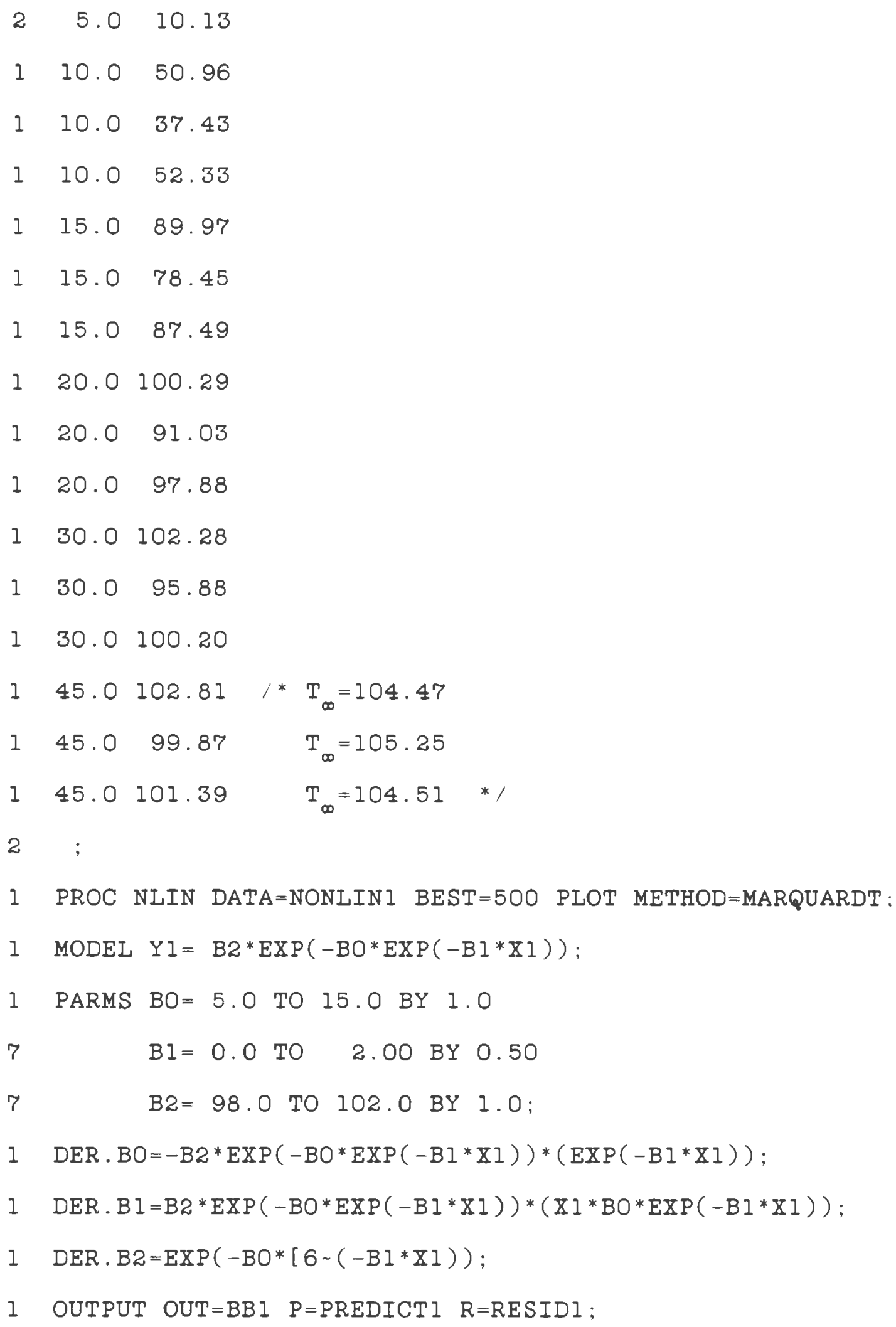




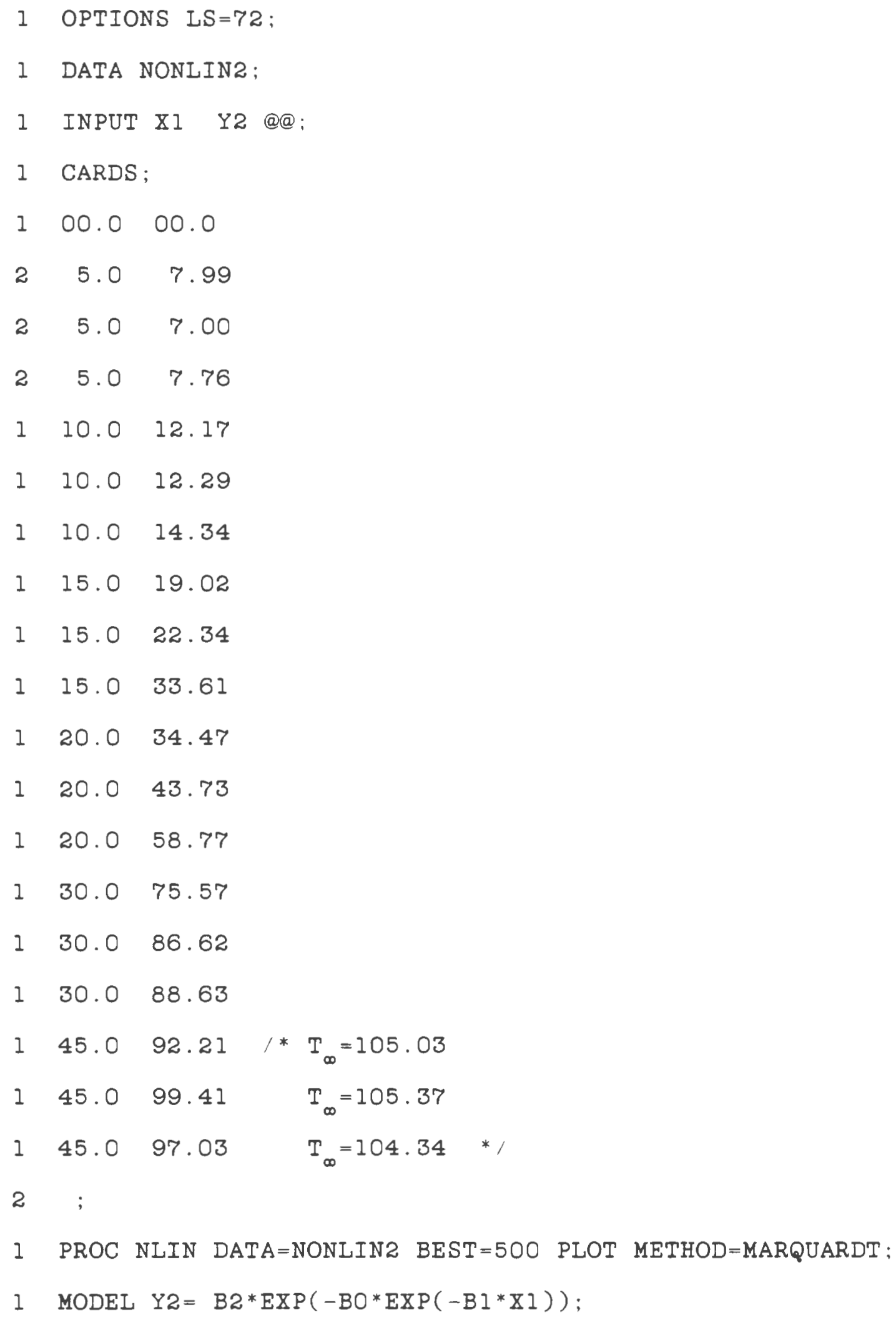




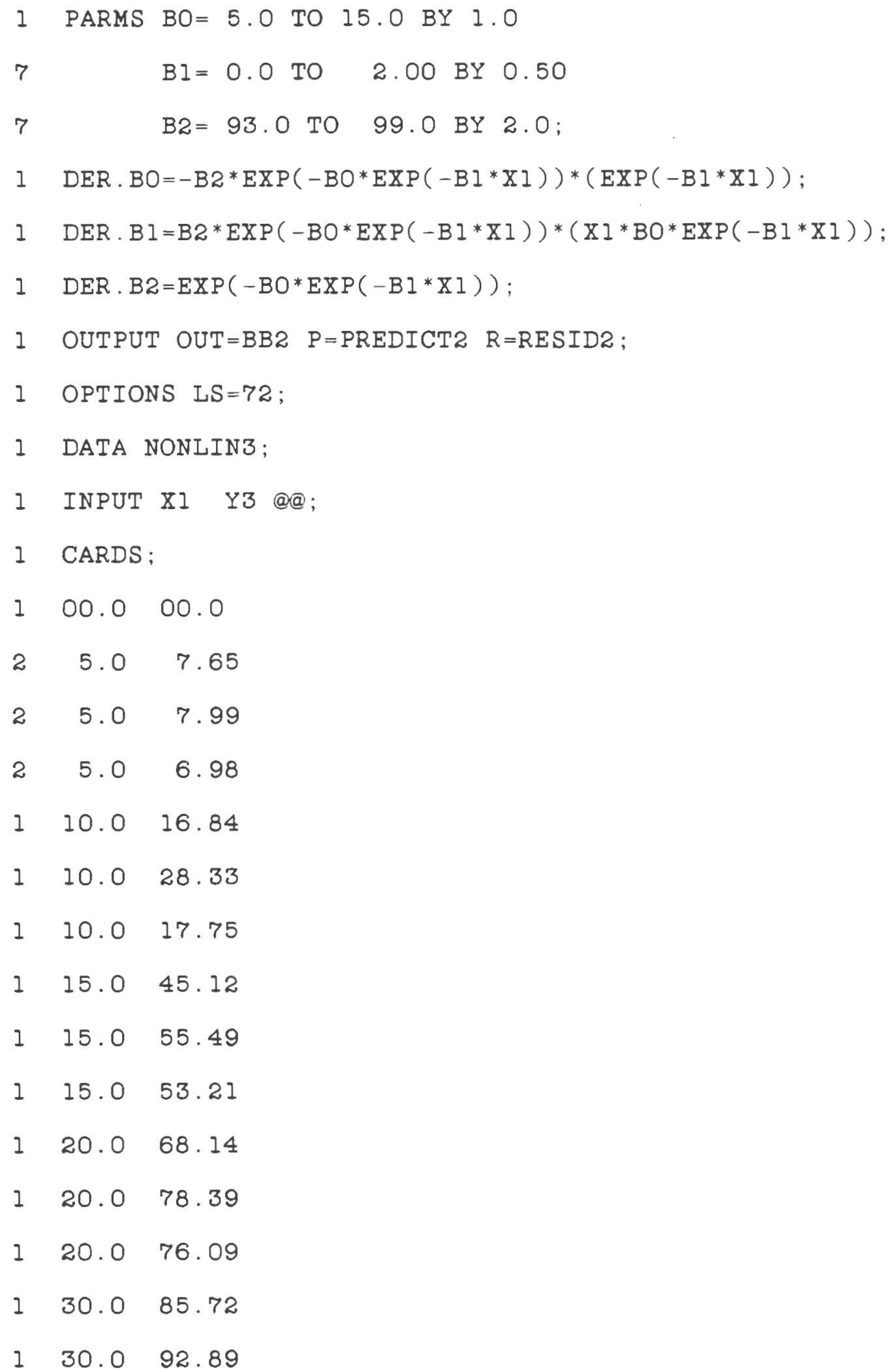




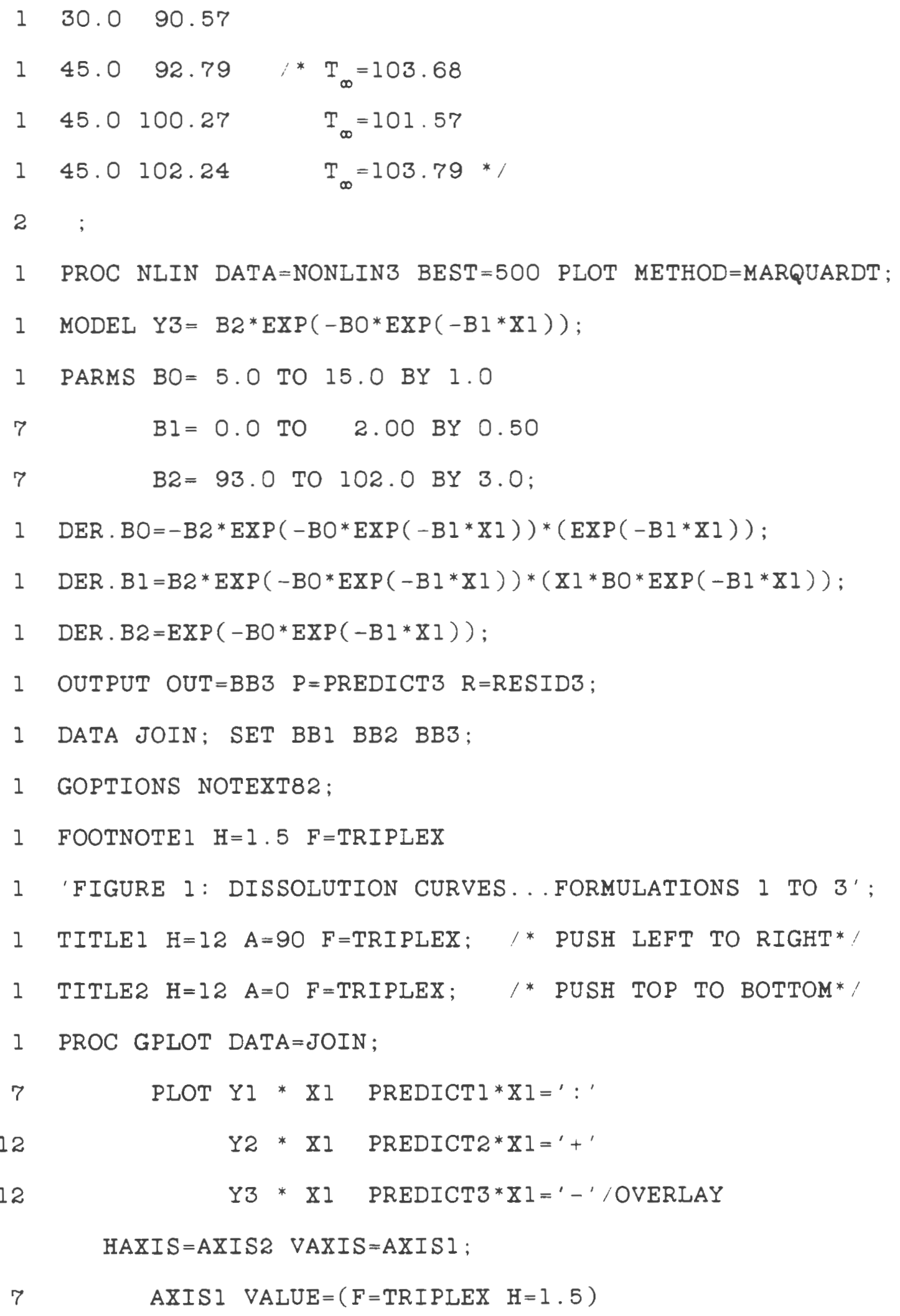

AXISI VALUE $=(F=T R I P L E X \quad H=1.5)$ 


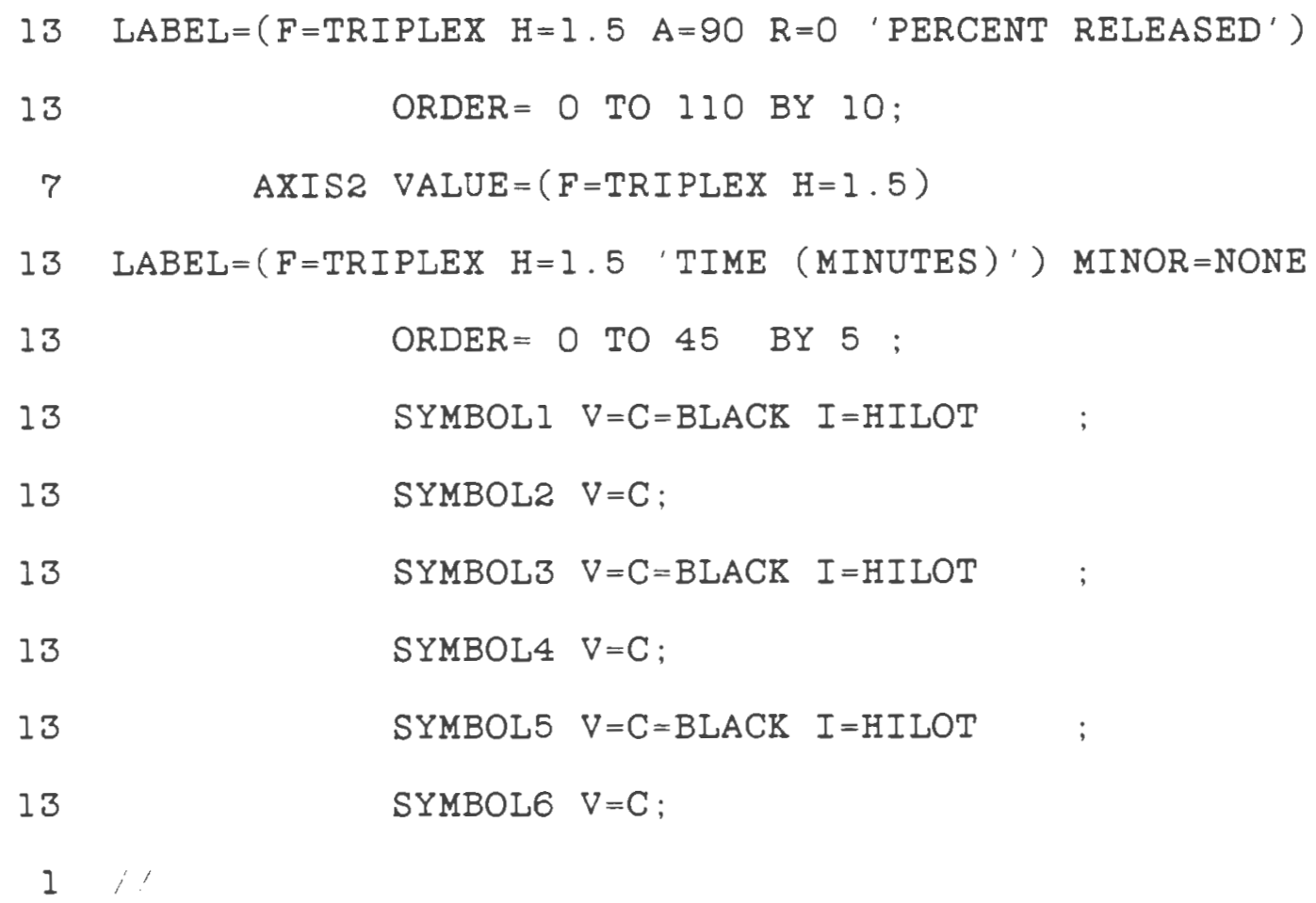




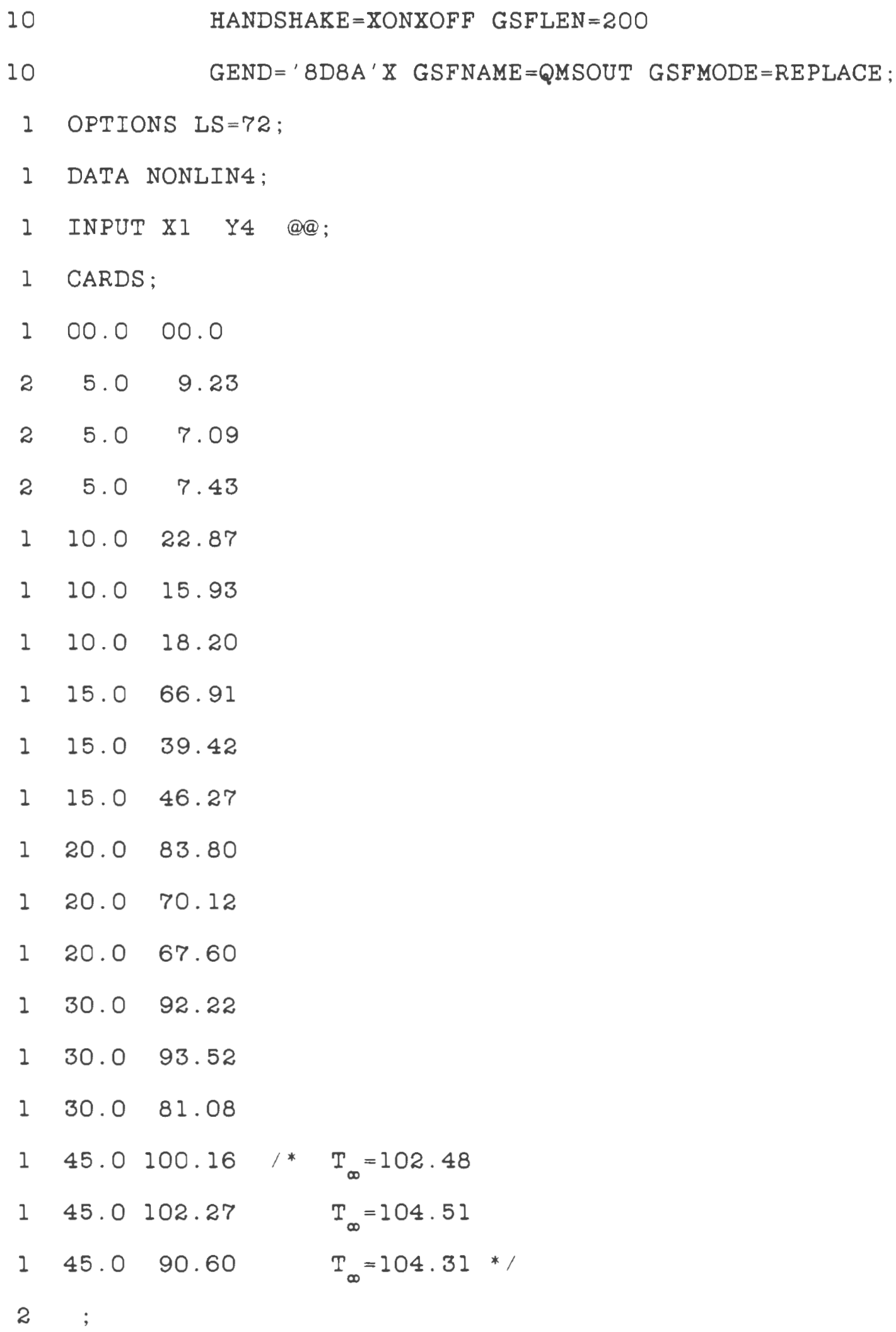


1 PROC NLIN DATA=NONLIN4 BEST=500 PLOT METHOD=MARQUARDT;

1 MODEL $Y 4=B 2 * \operatorname{EXP}(-B O * \operatorname{EXP}(-\mathrm{BI} * \mathrm{XI}))$;

1 PARMS $B O=5.0$ TO 10.0 BY 1.0

$7 \quad B I=0.0$ TO 2.00 BY 0.50

$7 \quad$ B2 $=91.0$ TO 102.0 BY $3.0 ;$

$1 \quad \mathrm{DER} \cdot \mathrm{BO}=-\mathrm{B} 2 * \operatorname{EXP}(-\mathrm{BO} * \operatorname{EXP}(-\mathrm{BI} * \mathrm{XI})) *(\operatorname{EXP}(-\mathrm{BI} * \mathrm{XI}))$;

$1 \mathrm{DER} \cdot \mathrm{BI}=\mathrm{B} 2 * \operatorname{EXP}(-\mathrm{BO} * \operatorname{EXP}(-\mathrm{BI} * \mathrm{XI})) *(\mathrm{XI} * \mathrm{BO} * \operatorname{EXP}(-\mathrm{BI} * \mathrm{XI}))$;

$1 \mathrm{DER} \cdot \mathrm{B} 2=\operatorname{EXP}(-\mathrm{BO} * \operatorname{EXP}(-\mathrm{B} I * \mathrm{XI}))$;

1 OUTPUT OUT=BB4 P=PREDICT4 R=RESID4;

1 OPTIONS LS=72;

1 DATA NONLIN5;

IINPUT XI Y5 @@;

1 CARDS ;

100.000 .0

$2 \quad 5.0 \quad 7.76$

$25.0 \quad 7.43$

$25.0 \quad 7.20$

$1 \quad 10.0 \quad 20.82$

$1 \quad 10.0 \quad 23.09$

$1 \quad 10.0 \quad 21.50$

$1 \quad 15.050 .85$

$1 \quad 15.0 \quad 62.25$

$1 \quad 15.0 \quad 54.96$

$120.0 \quad 76.10$

$120.0 \quad 83.30$

$120.0 \quad 84.79$ 
$1 \quad 30.0 \quad 92.28$

$130.0 \quad 99.22$

$130.0 \quad 95.05$

$145.099 .88 / * T_{\infty}=105.38$

$145.0102 .00 \quad T_{\infty}=104.68$

$145.099 .94 \quad T_{\infty}=105.10 * !$

$2 \quad ;$

1 PROC NLIN DATA=NONLIN5 BEST=500 PLOT METHOD=MARQUARDT;

1 MODEL Y5 $=\mathrm{B} 2 * \operatorname{EXP}(-\mathrm{BO} * \operatorname{EXP}(-\mathrm{BI} * \mathrm{XI}))$;

1 PARMS $\mathrm{BO}=5.0$ TO $10.0 \mathrm{BY} 1.0$

7

$\mathrm{BI}=0.0$ TO $2.00 \mathrm{BY} 0.50$

$7 \quad$ B2 $=98.0$ TO 102.0 BY 1.0 ;

$1 \quad \mathrm{DER} \cdot \mathrm{BO}=-\mathrm{B} 2 * \operatorname{EXP}(-\mathrm{BO} * \operatorname{EXP}(-\mathrm{B} 1 * \mathrm{XI})) *(\operatorname{EXP}(-\mathrm{BI} * \mathrm{X} 1))$;

$1 \mathrm{DER} \cdot \mathrm{BI}=\mathrm{B} 2 * \operatorname{EXP}(-\mathrm{BO} * \operatorname{EXP}(-\mathrm{BI} * \mathrm{X} 1)) *(\mathrm{XI} * \mathrm{BO} * \operatorname{EXP}(-\mathrm{BI} * \mathrm{X} 1))$;

$1 \quad \mathrm{DER} \cdot \mathrm{B} 2=\operatorname{EXP}(-\mathrm{BO} * \operatorname{EXP}(-\mathrm{BI} * \mathrm{X} 1))$;

1 OUTPUT OUT=BB5 P=PREDICT5 R=RESID5;

1 OPTIONS LS $=72$;

1 DATA NONLIN6;

1 INPUT XI Y6 @@;

1 CARDS;

$100.0 \quad 00.0$

$25.0 \quad 10.46$

$2 \quad 5.0 \quad 15.98$

$2 \quad 5.0 \quad 12.04$

$1 \quad 10.0 \quad 49.94$

110.060 .40 


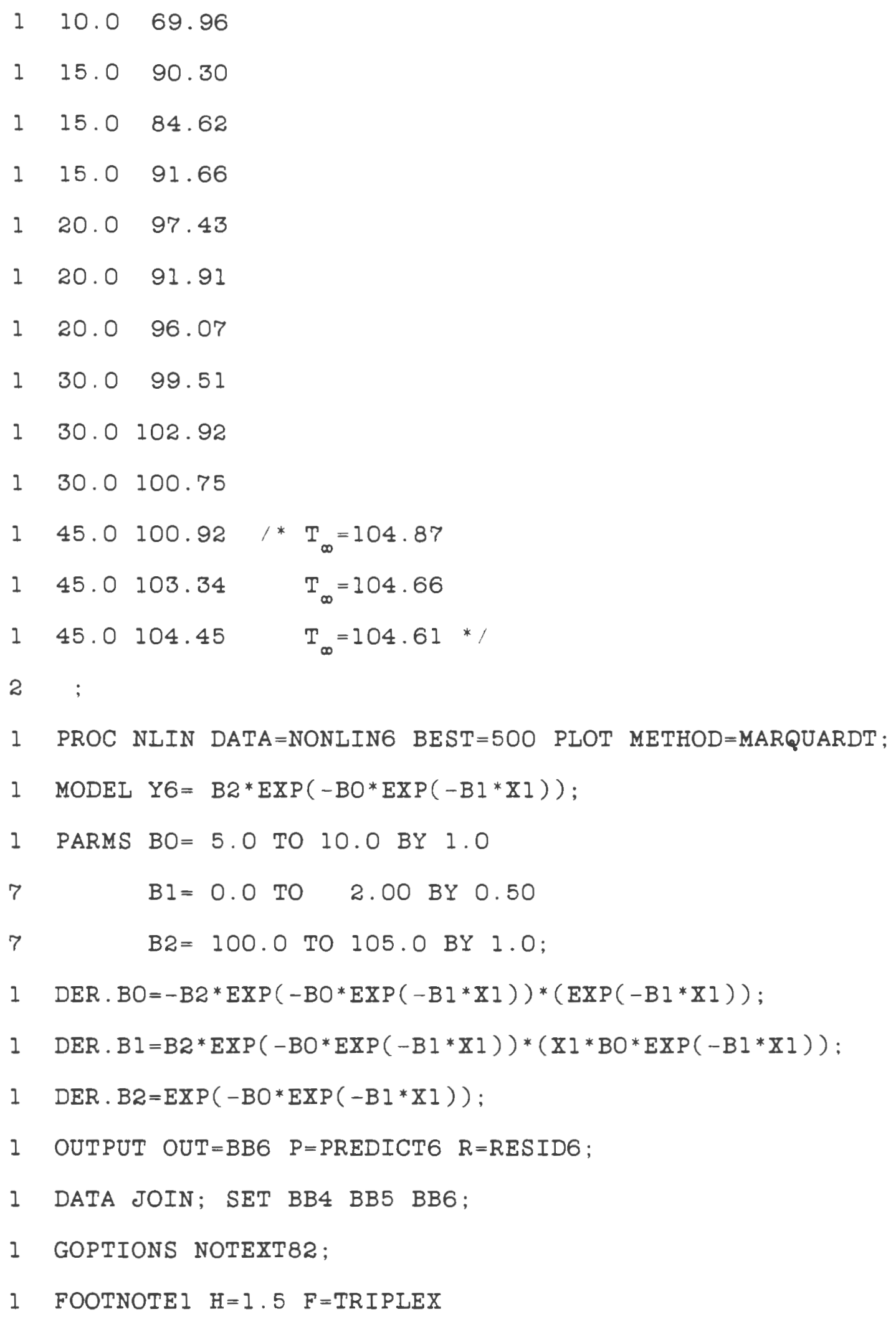


1 'FIGURE 2: DISSOLUTION CURVES...FORMULATIONS 4 TO 6';

1 TITLEI $\mathrm{H}=14 \mathrm{~A}=90 \mathrm{~F}=\mathrm{TRIPLEX} ;$ / * PUSH LEFT TO RIGHT*

1 TITLE2 H=14 A=O F=TRIPLEX; ; * PUSH TOP TO BOTTOM*/

$1 \quad$ PROC GPLOT DATA $=$ JOIN;

$7 \quad$ PLOT $Y 4 * X I \quad$ PREDICT $4 * X 1={ }^{*}: '$

12

12 $\mathrm{Y5} * \mathrm{X} 1$ PREDICT5*X1 ${ }^{\prime}{ }^{\prime}+{ }^{\prime}$

Y6* XI PREDICT6*X1='-' OVERLAY

HAXIS=AXIS2 VAXIS=AXISI;

AXISI VALUE $=(F=$ TRIPLEX $\mathrm{H}=1.5)$

13 LABEL=(F=TRIPLEX H=1.5 A=90 R=0 'PERCENT RELEASED')

$$
\text { ORDER = O TO } 110 \text { BY } 10 ;
$$

AXIS2 VALUE $=(F=$ TRIPLEX $H=1.5)$ ORDER $=0$ TO 45 BY 5 ; SYMBOLI $V=C=B L A C K \quad I=H I L O T \quad$; SYMBOL2 $\mathrm{V}=\mathrm{C}$; SYMBOL3 $V=C=B L A C K \quad I=H I L O T \quad$;

SAS programs for random order formulation number 7 to 9.

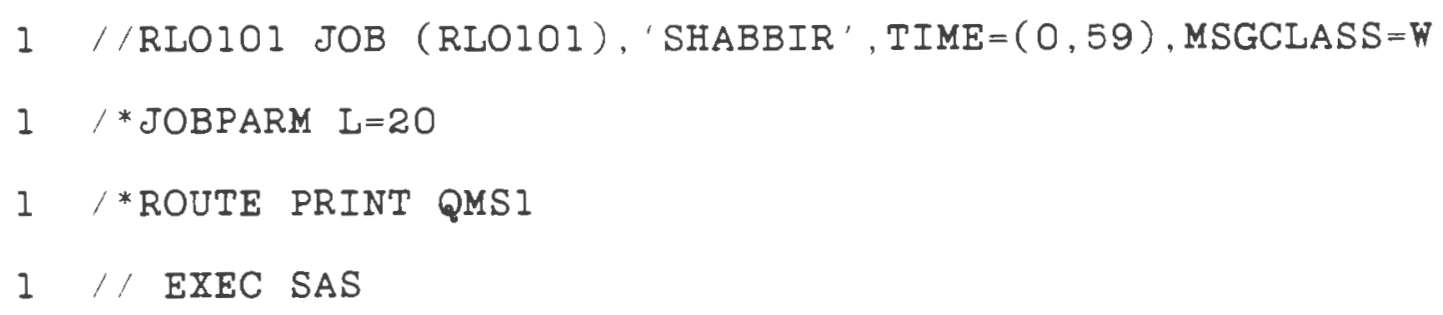




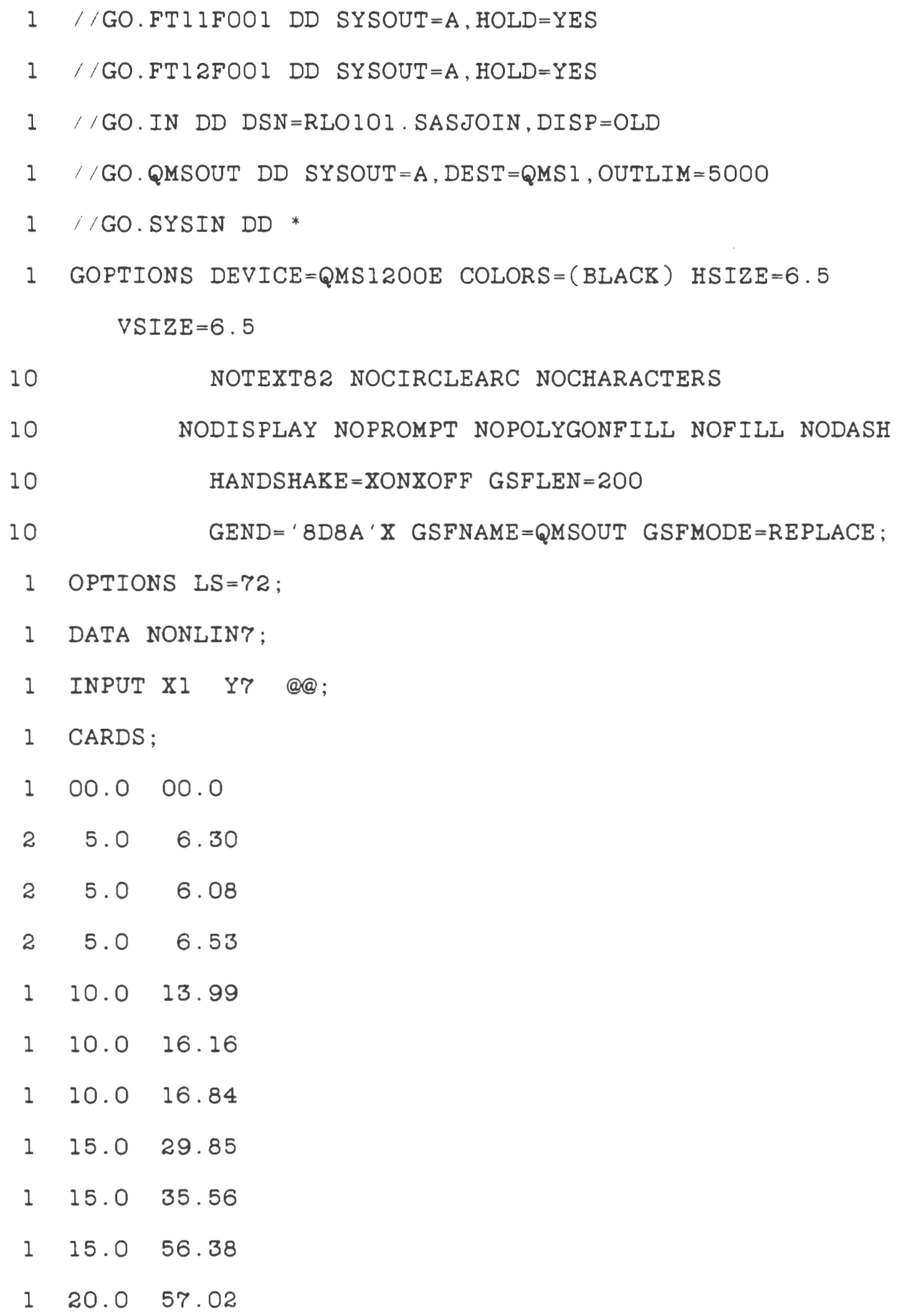




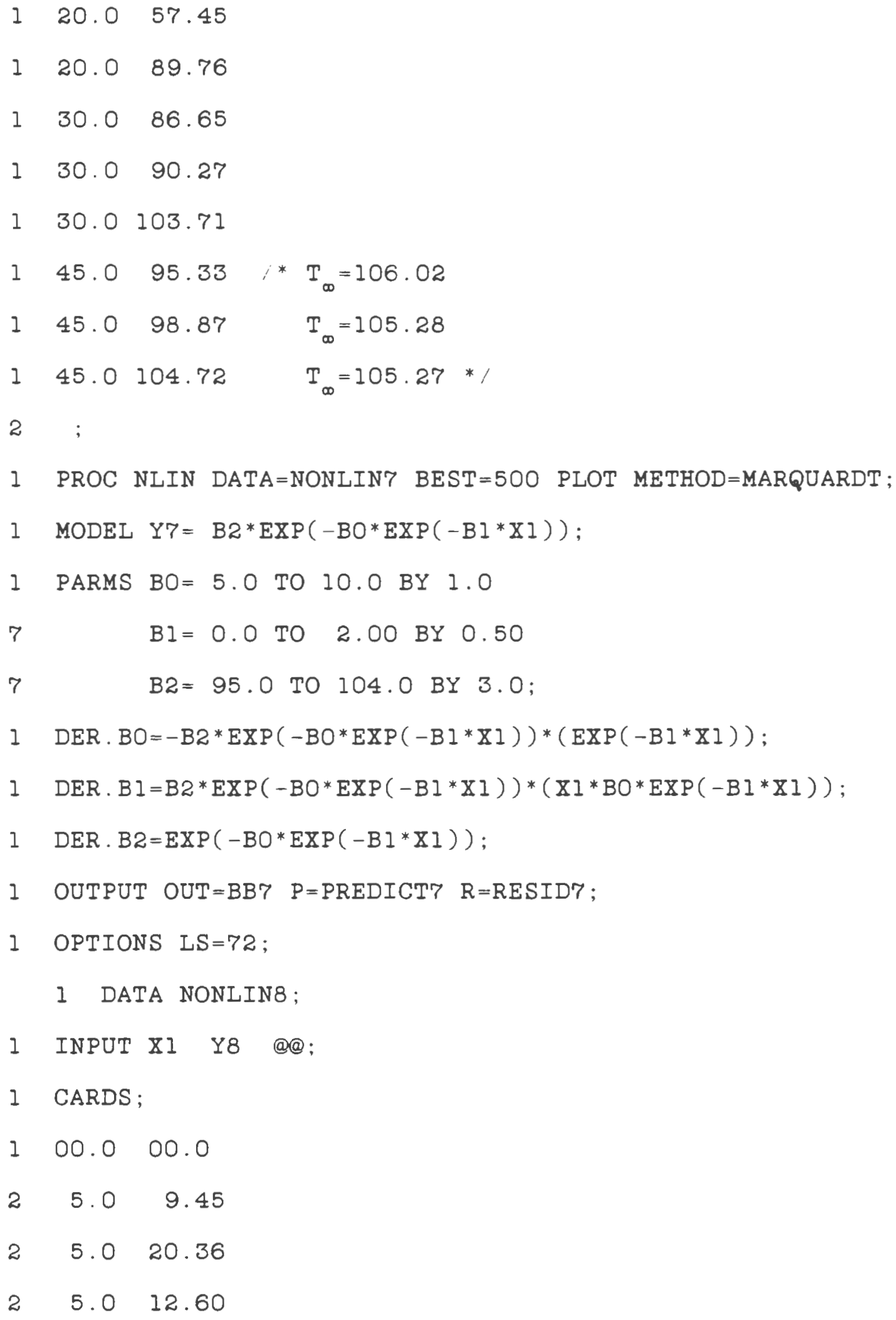




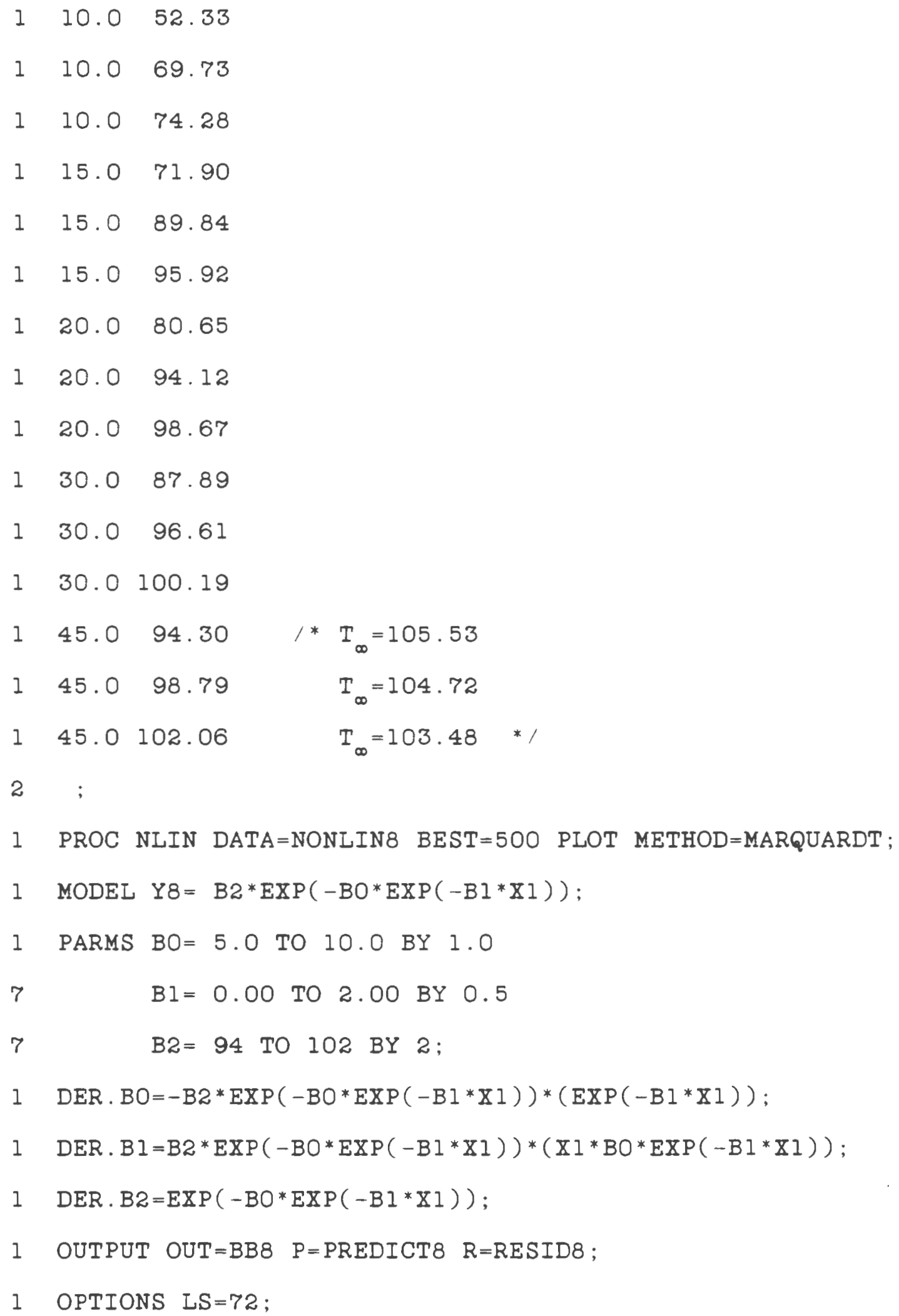


1 DATA NONLIN9;

1 INPUT $\mathrm{XI}$ Y9@;

1 CARDS ;

100.000 .0

$2 \quad 5.0 \quad 7.09$

$2 \quad 5.06 .75$

$2 \quad 5.0 \quad 7.65$

$110.0 \quad 11.95$

$1 \quad 10.0 \quad 11.38$

$1 \quad 10.0 \quad 12.52$

$1 \quad 15.0 \quad 19.36$

$1 \quad 15.0 \quad 17.19$

$1 \quad 15.0 \quad 19.14$

$1 \quad 20.0 \quad 34.36$

$120.0 \quad 25.00$

$120.0 \quad 30.16$

$130.0 \quad 64.65$

$130.0 \quad 56.10$

$130.0 \quad 72.01$

$145.086 .63 / * T_{\infty}=103.83$

$145.0 \quad 80.72 \quad T_{\infty}=103.21$

$145.0 \quad 93.84 \quad \mathrm{~T}_{\infty}=104.52 * 1$

2 ;

1 PROC NLIN DATA=NONLIN9 BEST=500 PLOT METHOD=MARQUARDT;

1 MODEL $Y 9=B 2 * \operatorname{EXP}(-\mathrm{BO} * \operatorname{EXP}(-\mathrm{B} 1 * \mathrm{X} 1))$;

1 PARMS $B O=5.0$ TO $10.0 \mathrm{BY} 1.0$ 


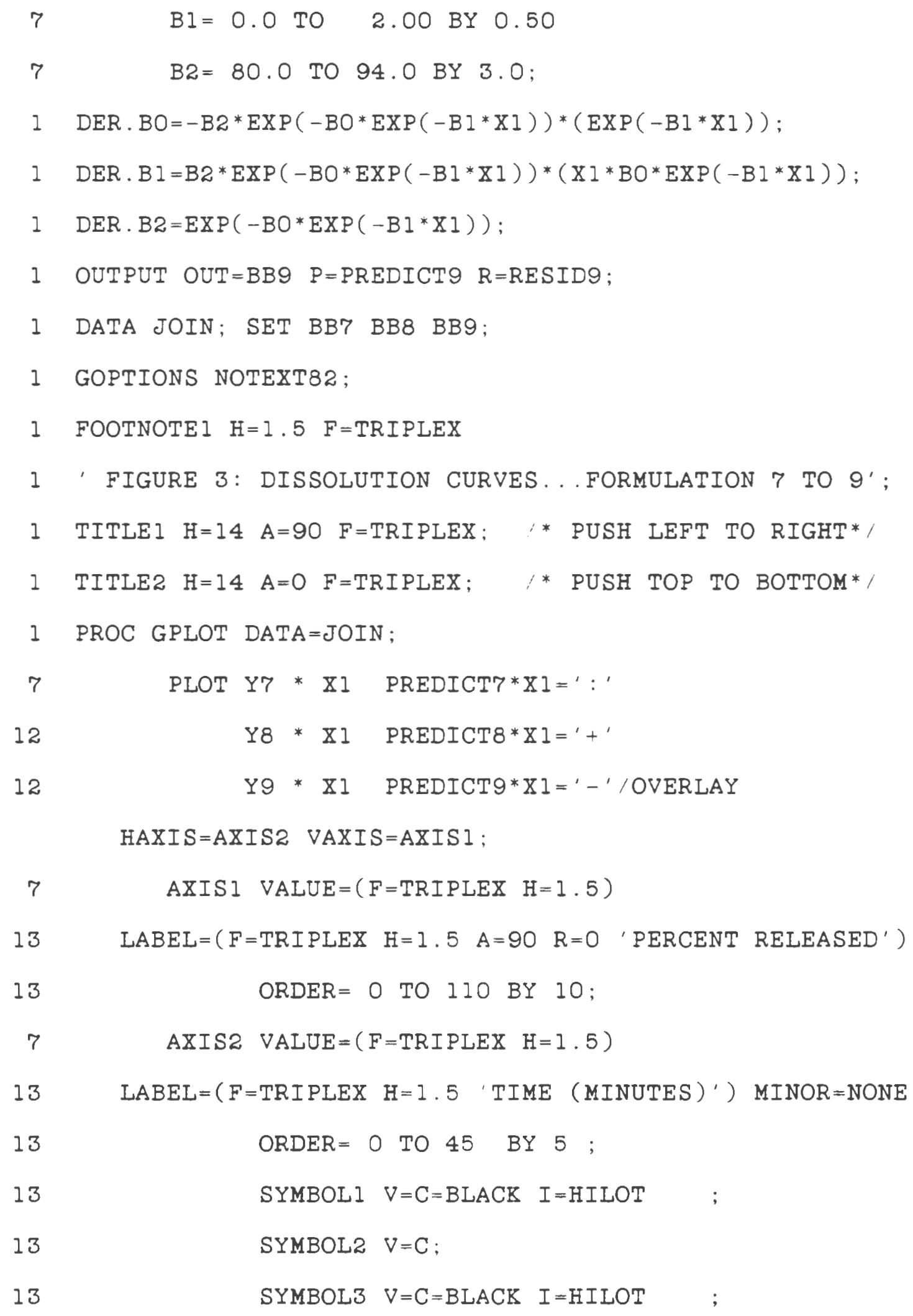




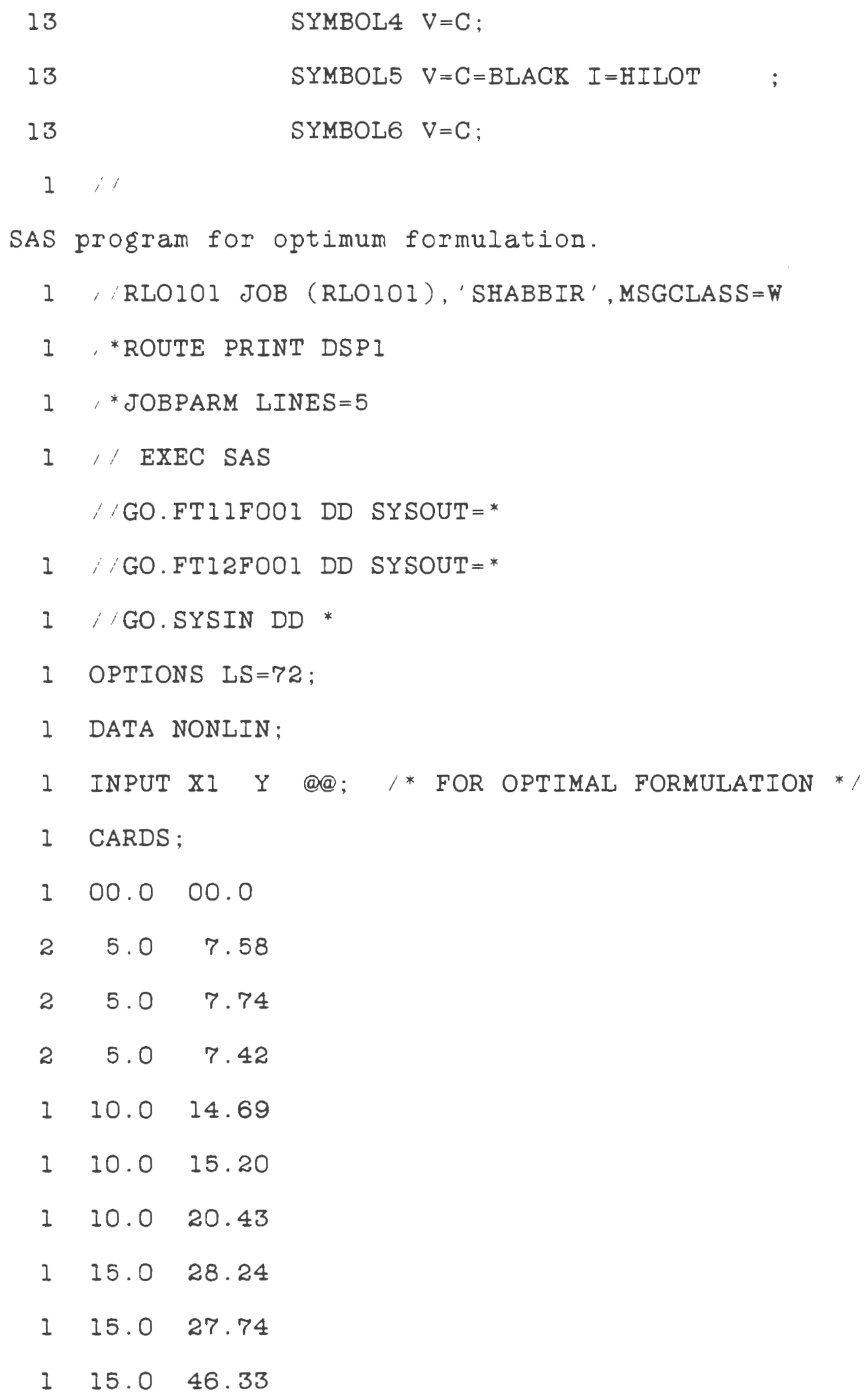




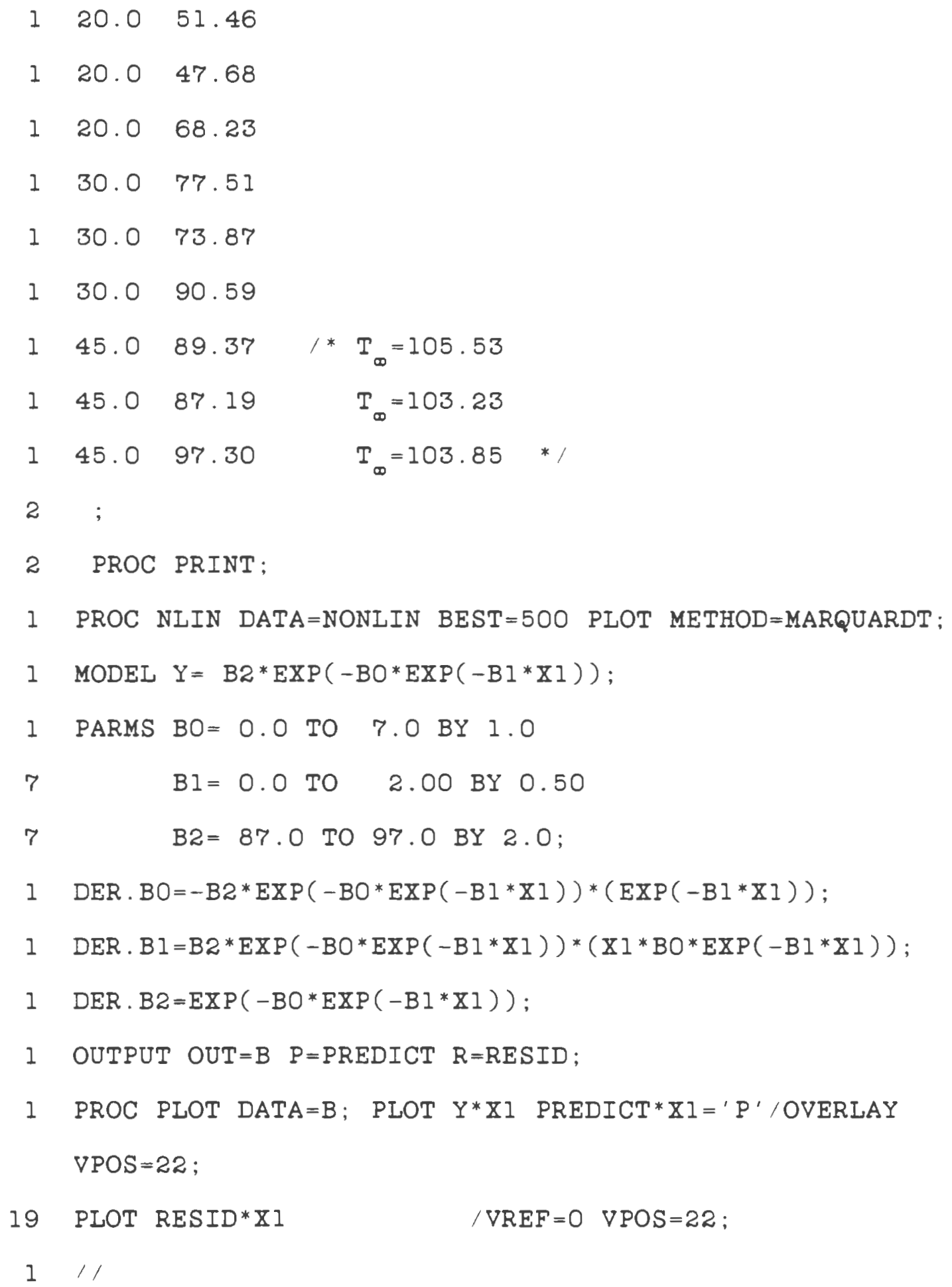


This is the start of the SAS program for plotting disintegration time data, for three dimensional and contour plots.

$1 / /$ RLO101 JOB (RLO101), 'SHABBIR', TIME $=(0,59)$, MSGCLASS $=W$

$1 / *$ JOBPARM $L=20$

I / ROUTE PRINT QMSI

$1 / /$ EXEC SAS

$1 / /$ GO.FTIIFOOI DD SYSOUT $=A$, HOLD $=$ YES

$1 / /$ GO.FTI2FOOI DD SYSOUT $=A$, HOLD $=$ YES

$1 / /$ GO. IN DD DSN=RLOIO1. SASJOIN, DISP=OLD

$1 / /$ GO. QMSOUT DD SYSOUT =A,DEST $=$ QMS 1 , OUTLIM $=5000$

1 //GO.SYSIN DD *

1 GOPTIONS DEVICE $=$ QMS $1200 E$ COLORS $=($ BLACK $)$ HSIZE $=6.3$ $\operatorname{VSIZE}=6.3$ NOTEXT82 NOCIRCLEARC NOCHARACTERS NODISPLAY NOPROMPT NOPOLYGONFILL NOFILL NODASH HANDSHARE $=$ XONXOFF GSFLEN $=200$ GEND $=$ ' 8D8A' $\square$ GSFNAME $=$ QMSOUT GSFMODE $=$ REPLACE ;

1 GOPTIONS NOTEXT82;

1 OPTIONS LS $=72$;

1 DATA HARDNESS;

1 INPUT XI X2 Y;

$1 \quad \mathrm{XISQR}=\mathrm{XI} * \mathrm{XI}$;

$1 \quad \mathrm{X} 2 \mathrm{SQR}=\mathrm{X} 2 * \mathrm{X} 2$; 


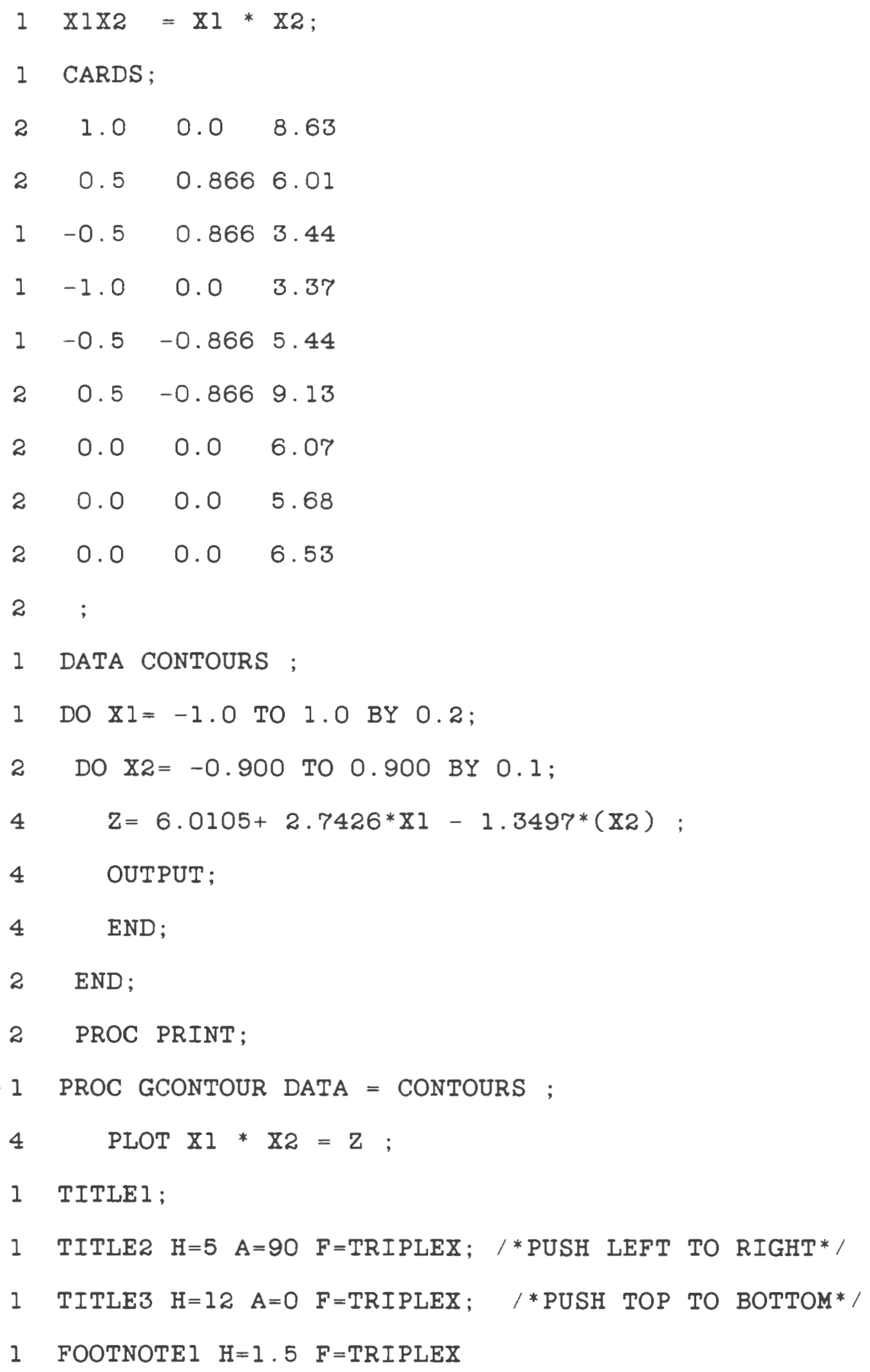




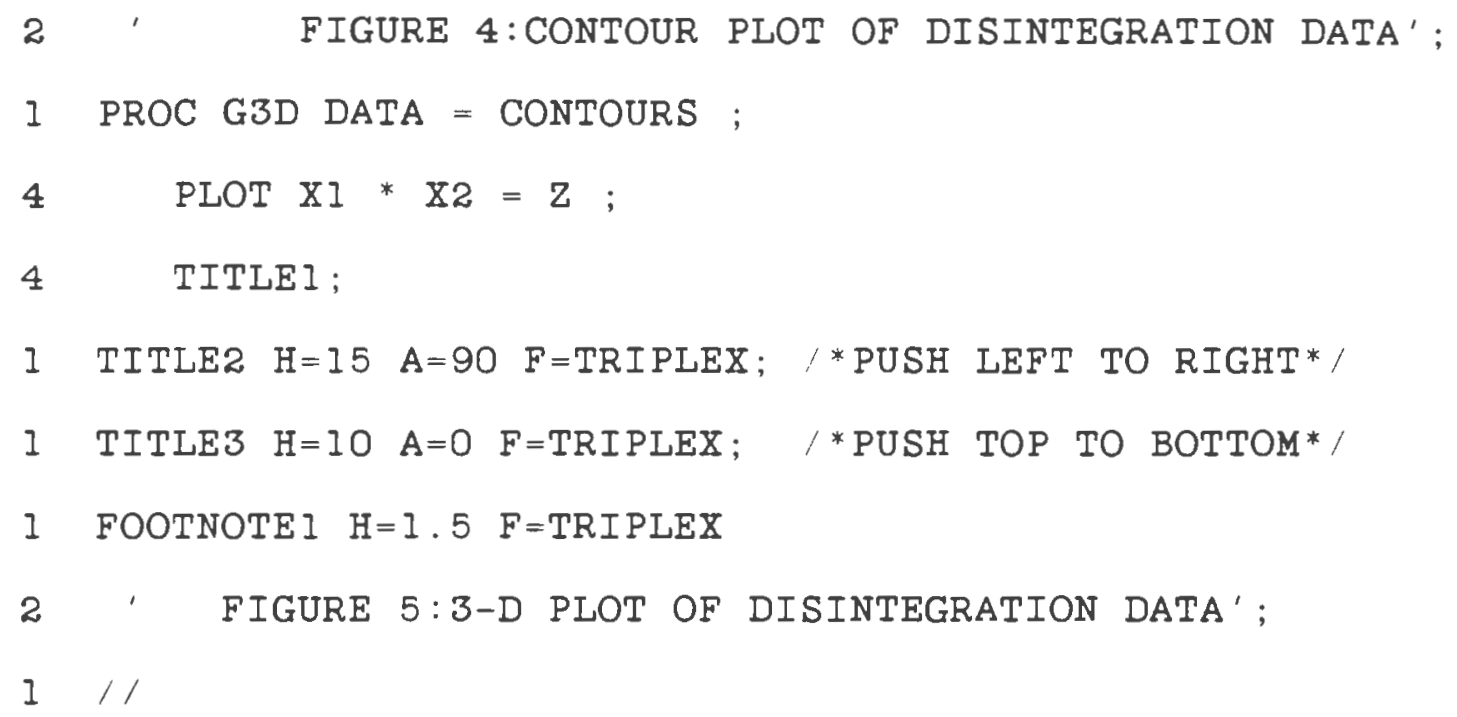




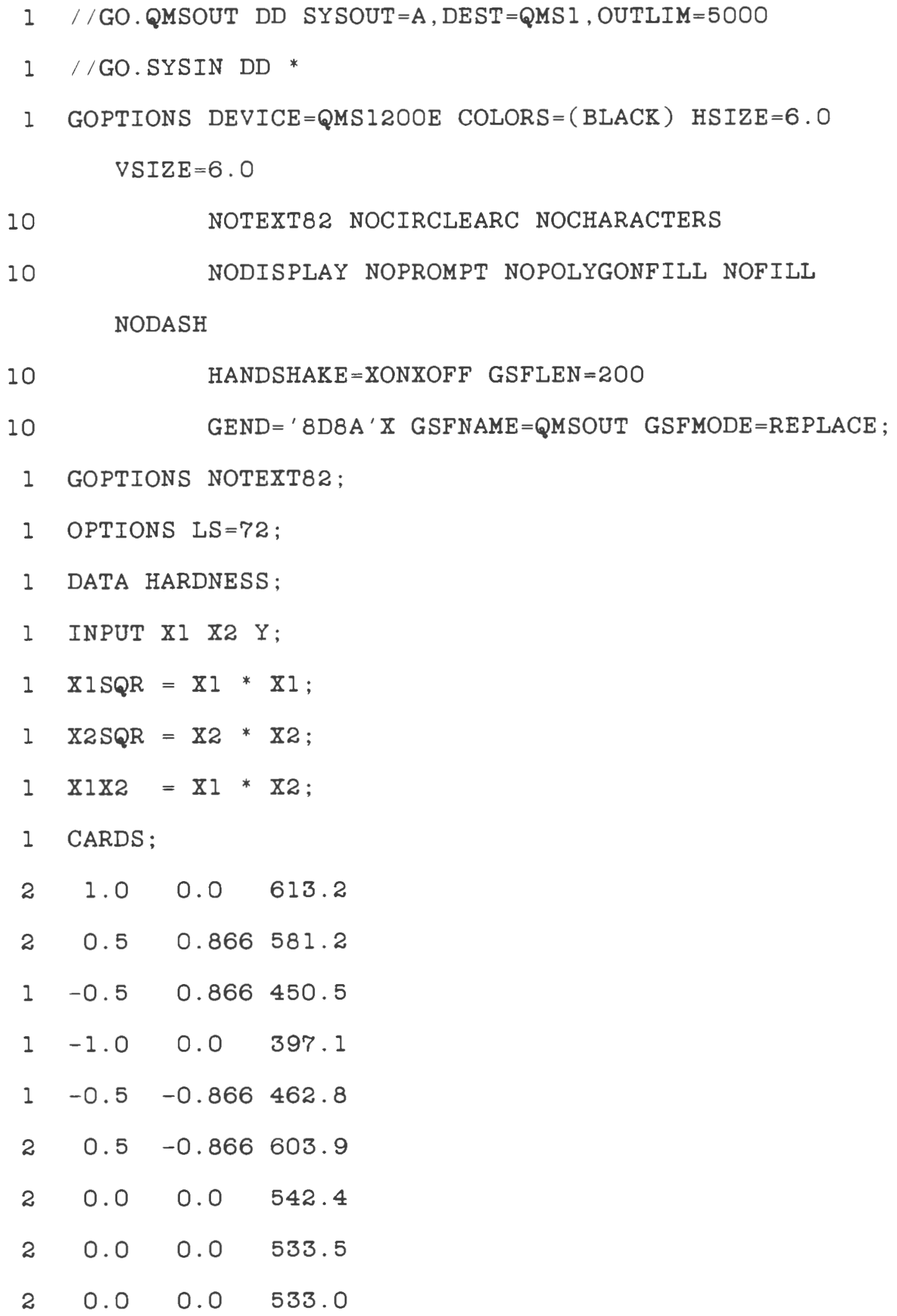




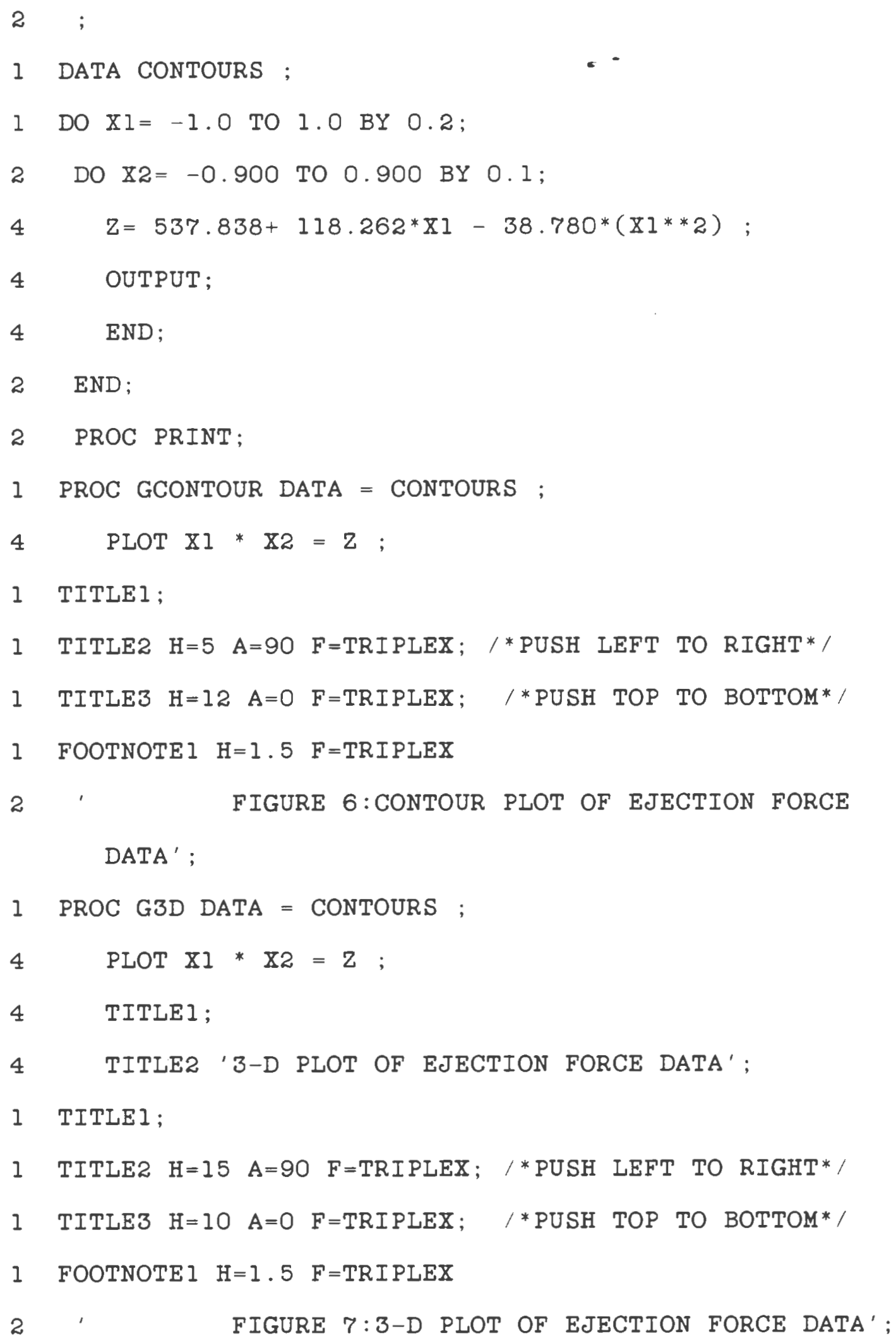


This is the end of the SAS program for plotting ejection force data, for three dimensional and contour plots.

This is the start of the SAS program for plotting friability data, for three dimensional and contour plots.

$1 / /$ RLOIO1 JOB (RLO101), 'SHABBIR', TIME $=(0,59)$, MSGCLASS $=W$

$1 /$ * JOBPARM L $=20$

$1 / *$ ROUTE PRINT QMSI

$1 / /$ EXEC SAS

$1 / /$ GO.FTIIFOOI DD SYSOUT=A, HOLD=YES

$1 / /$ GO.FT12FOO1 DD SYSOUT=A, HOLD=YES

$1 / /$ GO. IN DD DSN=RLOIO1. SASJOIN, DISP=OLD

$1 / /$ GO.QMSOUT DD SYSOUT $=\mathrm{A}, \mathrm{DEST}=\mathrm{QMSI}$, OUTLIM $=5000$

$1 / /$ GO.SYSIN DD *

1 GOPTIONS DEVICE $=$ QMSI2OOE COLORS $=($ BLACK $)$ HSIZE $=6.0$ VSIZE $=6.0$ NOTEXT82 NOCIRCLEARC NOCHARACTERS 


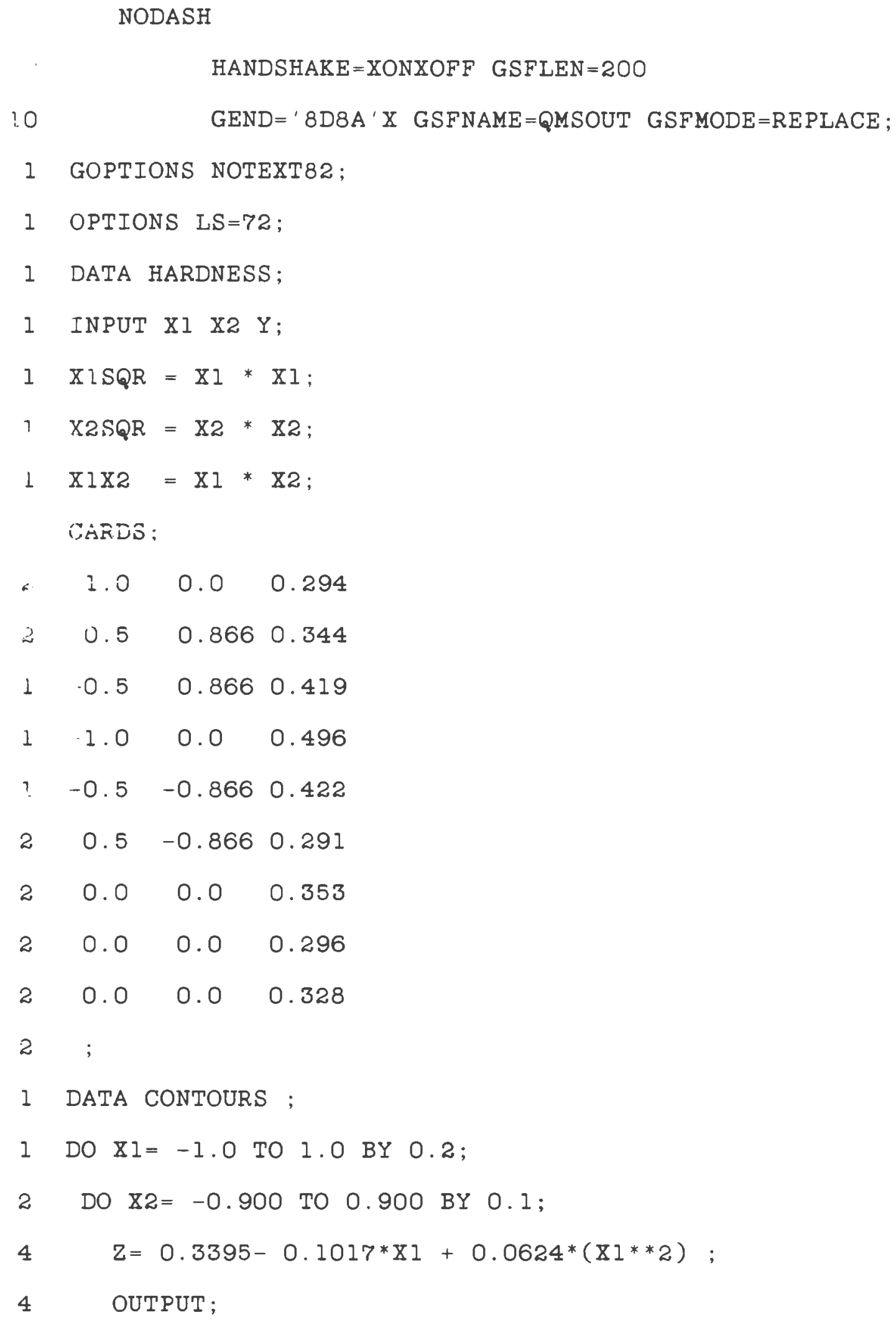




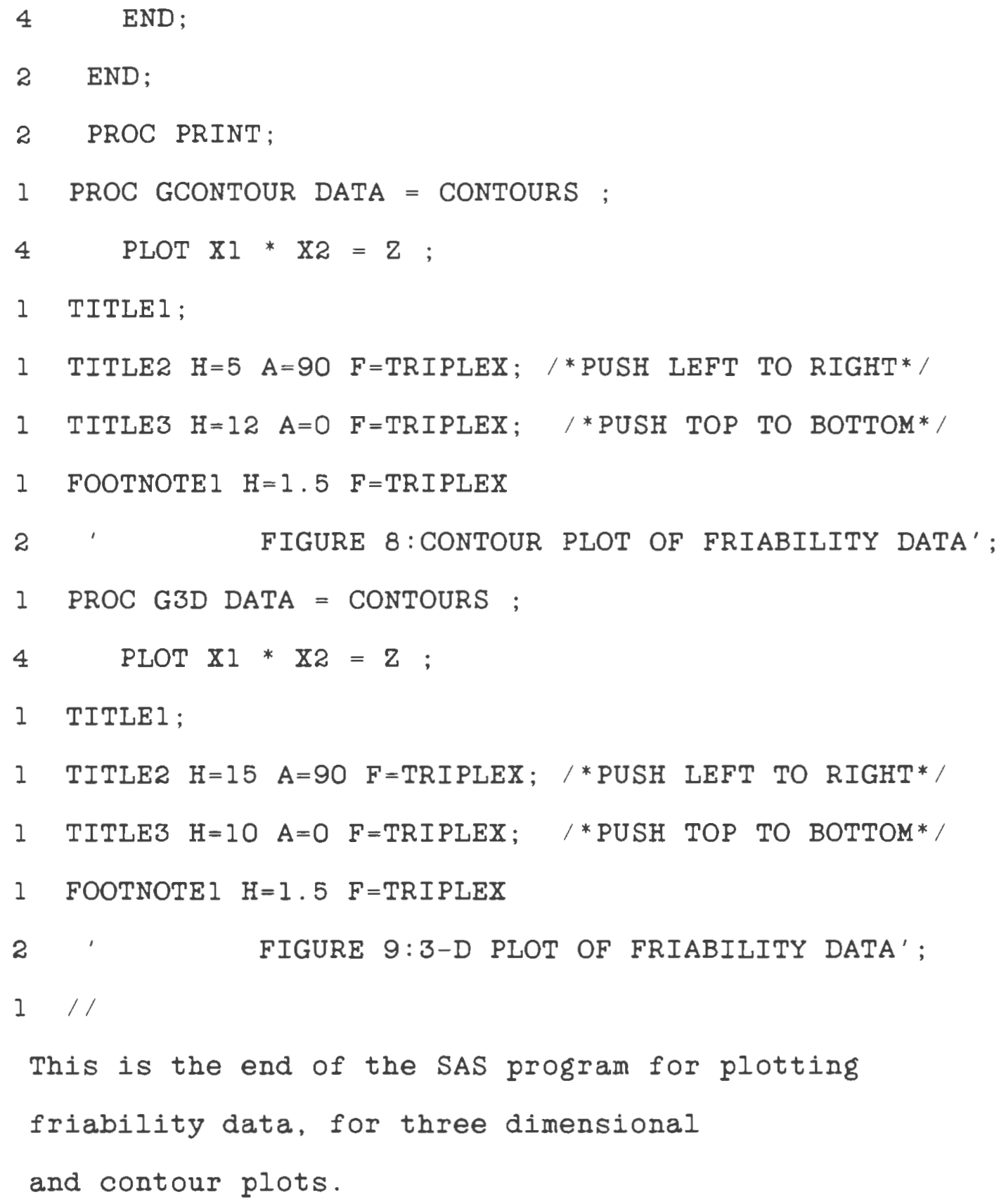




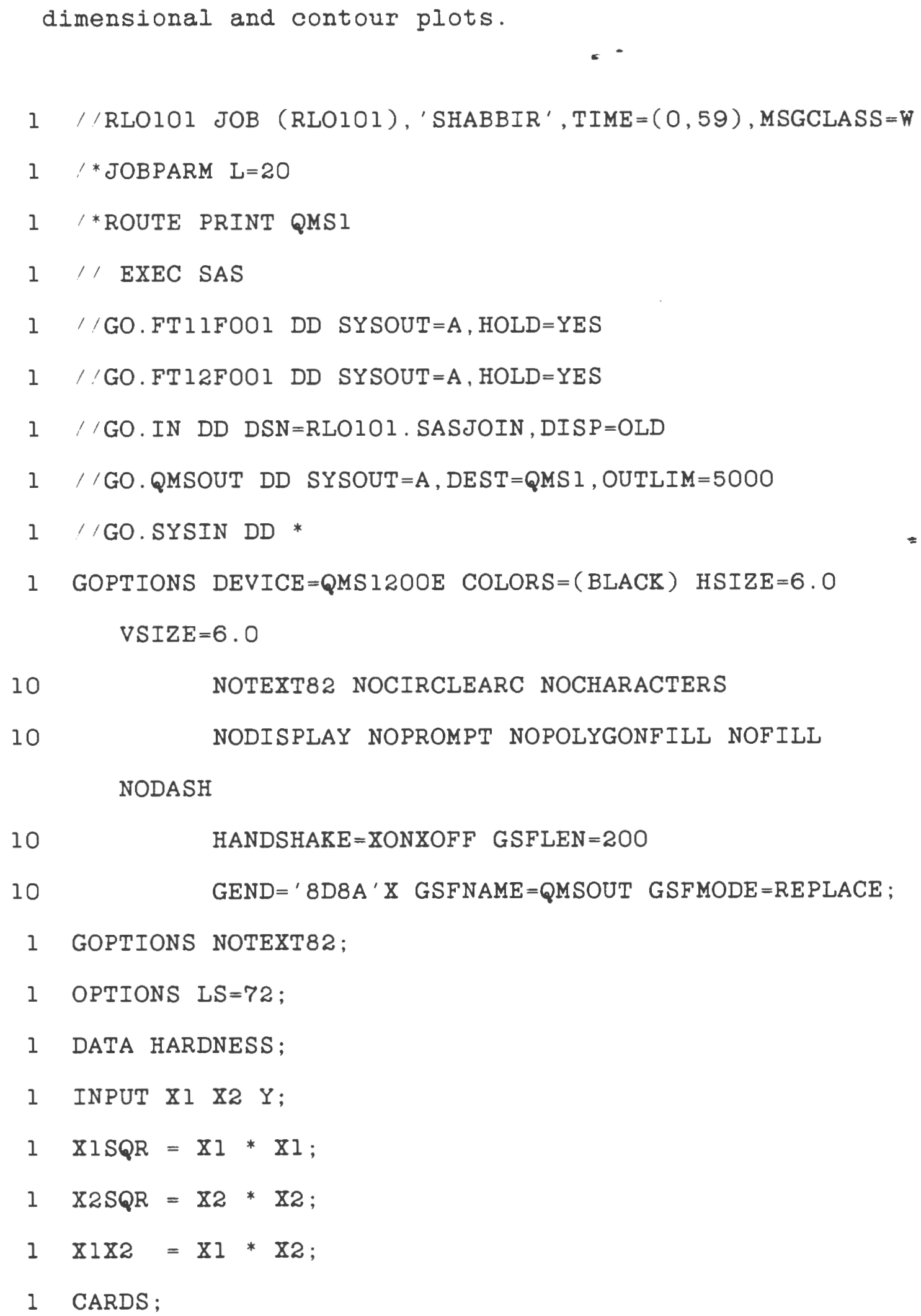




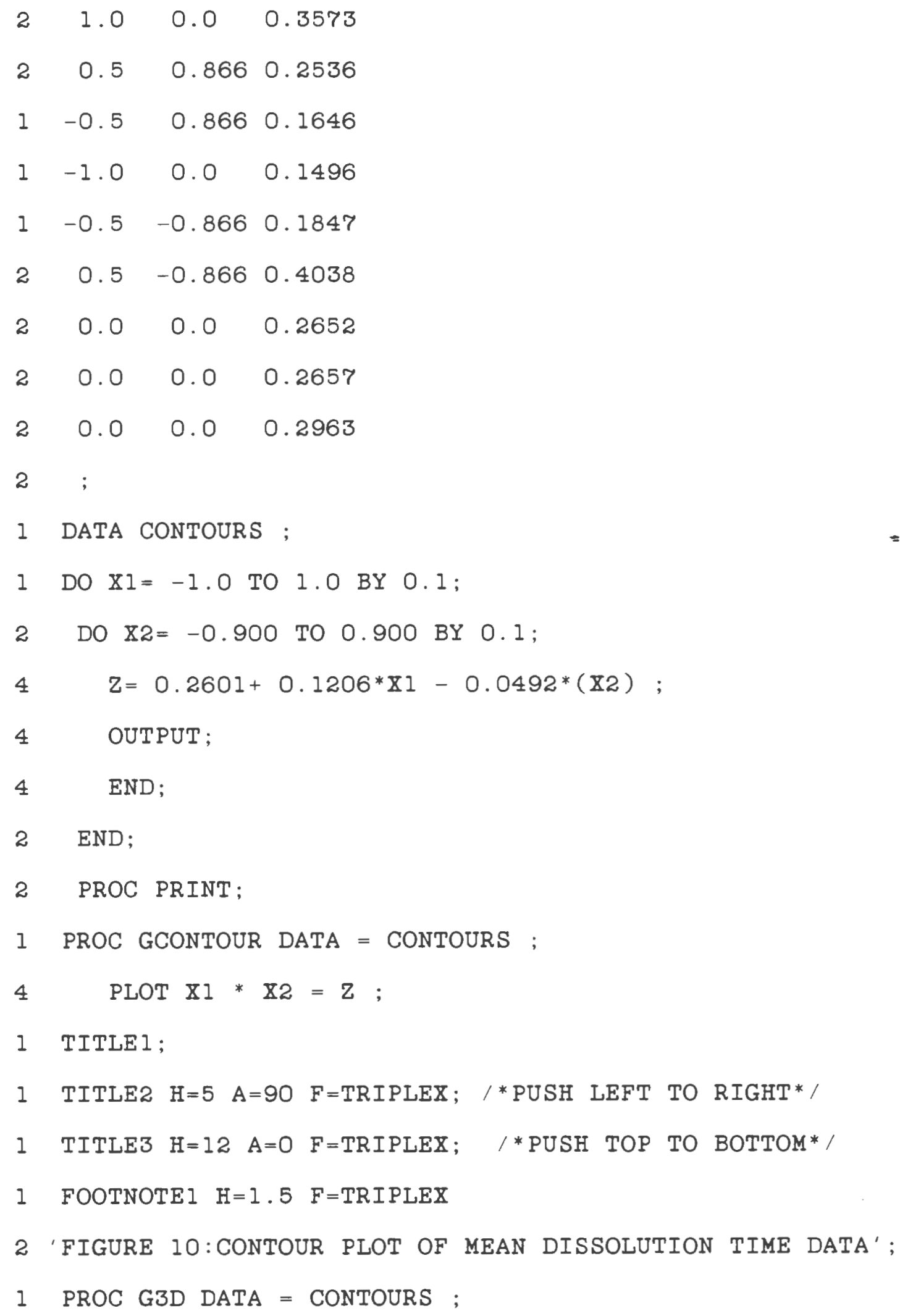




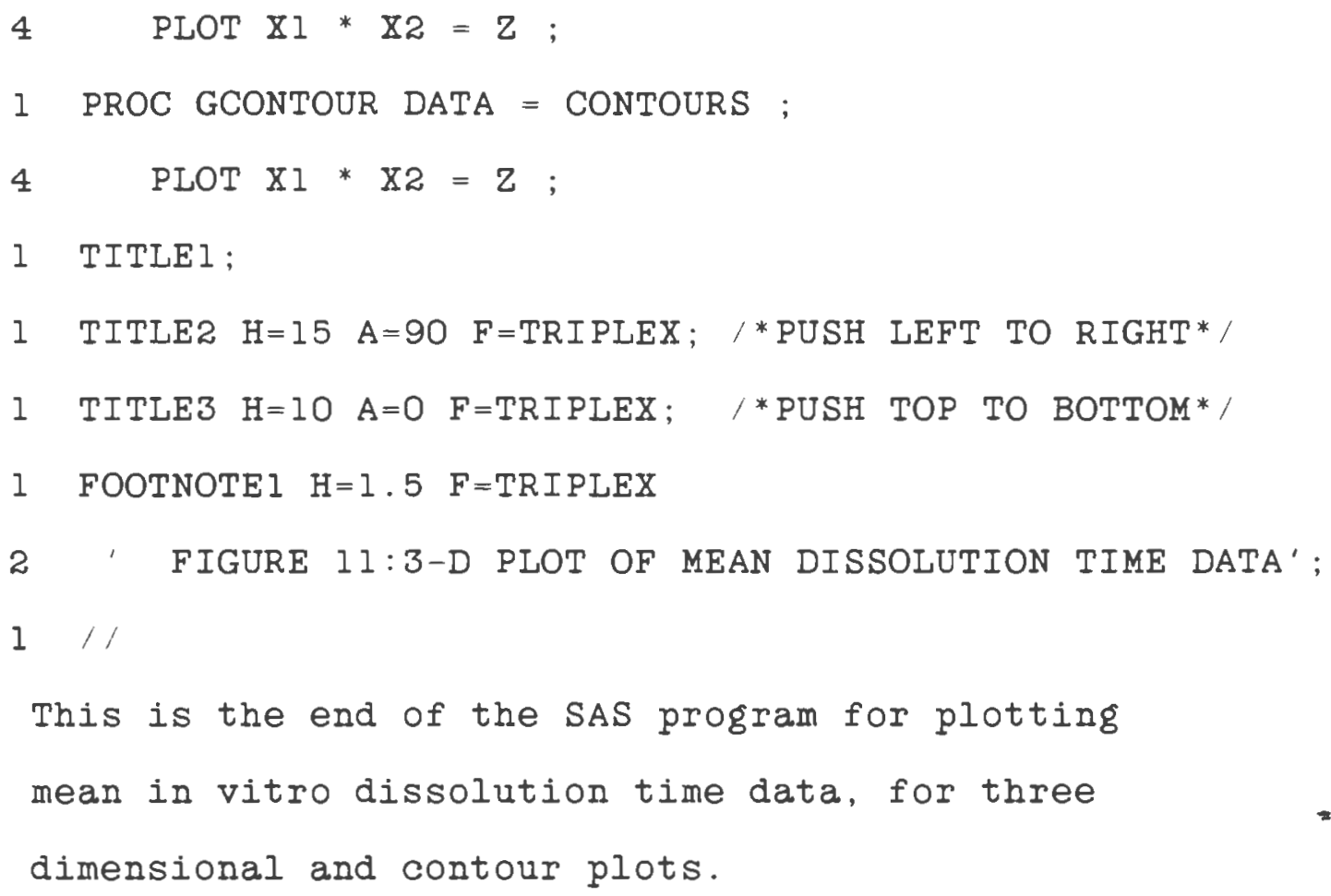


$1 / /$ GO.QMSOUT DD SYSOUT $=\mathrm{A}, \mathrm{DEST}=\mathrm{QMS} 1$, OUTLIM $=5000$

$1 / /$ GO.SYSIN DD *

1 GOPTIONS DEVICE $=$ QMSI2OOE COLORS $=($ BLACK $)$ HSIZE $=6$

VSIZE $=6$

10

NOTEXT82 NOCIRCLEARC NOCHARACTERS

10

NODISPLAY NOPROMPT NOPOLYGONFILL NOFILL

NODASH

10

HANDSHAKE $=$ XONXOFF GSFLEN $=200$

10

GEND=' 8D8A' X GSFNAME=QMSOUT GSFMODE=REPLACE ;

1 OPTIONS LS $=72$;

1 DATA ALLHARD;

1 INPUT HD MDI ;

$1 \mathrm{HDl}=(\mathrm{HD}-12.680) / 0.1149$;

$1 \quad M D 11=(M D 1-0.3002) / 0.0046$;

$1 \mathrm{HDISQR}=\mathrm{HDI} * \mathrm{HDI}$;

1 CARDS ;

$2 \quad 12.540 .2945$

$2 \quad 12.550 .2950$

$\begin{array}{lll}2 & 12.6 & 0.2970\end{array}$

$2 \quad 12.650 .2990$

$2 \quad 12.7 \quad 0.3010$

$2 \quad 12.750 .3030$

$\begin{array}{lll}2 & 12.8 & 0.3050\end{array}$

$2 \quad 12.850 .3069$

2 ;

1 DATA ALLFR; 


\begin{tabular}{|c|c|c|}
\hline 1 & \multicolumn{2}{|c|}{ INPUT FR MD4 ; } \\
\hline 1 & \multicolumn{2}{|c|}{$F R I=(F R-0.3009) / 0.0023$; } \\
\hline 1 & \multicolumn{2}{|c|}{ MD4 $1=(M D 4-0.2919) / 0.0095 ;$} \\
\hline 1 & $F R I S Q R=F R I$ & * FRI; \\
\hline 1 & CARDS ; & \\
\hline 5 & 0.2984 & 0.3068 \\
\hline 5 & 0.2986 & 0.3046 \\
\hline 5 & 0.2988 & 0.3026 \\
\hline 5 & 0.2990 & 0.3010 \\
\hline 5 & 0.2991 & 0.3002 \\
\hline 5 & 0.2992 & 0.2995 \\
\hline 5 & 0.2993 & 0.2988 \\
\hline 5 & 0.2994 & 0.2981 \\
\hline 5 & 0.2995 & 0.2975 \\
\hline 5 & 0.2996 & 0.2967 \\
\hline 5 & 0.2997 & 0.2962 \\
\hline 5 & 0.2998 & 0.2955 \\
\hline 5 & 0.2999 & 0.2950 \\
\hline 5 & 0.3000 & 0.2945 \\
\hline 5 & 0.3001 & 0.2940 \\
\hline 5 & 0.3002 & 0.2934 \\
\hline 5 & 0.3003 & 0.2929 \\
\hline 5 & 0.3004 & 0.2924 \\
\hline 5 & 0.3005 & 0.2919 \\
\hline 5 & 0.3006 & 0.2914 \\
\hline 5 & 0.3008 & 0.2905 \\
\hline
\end{tabular}




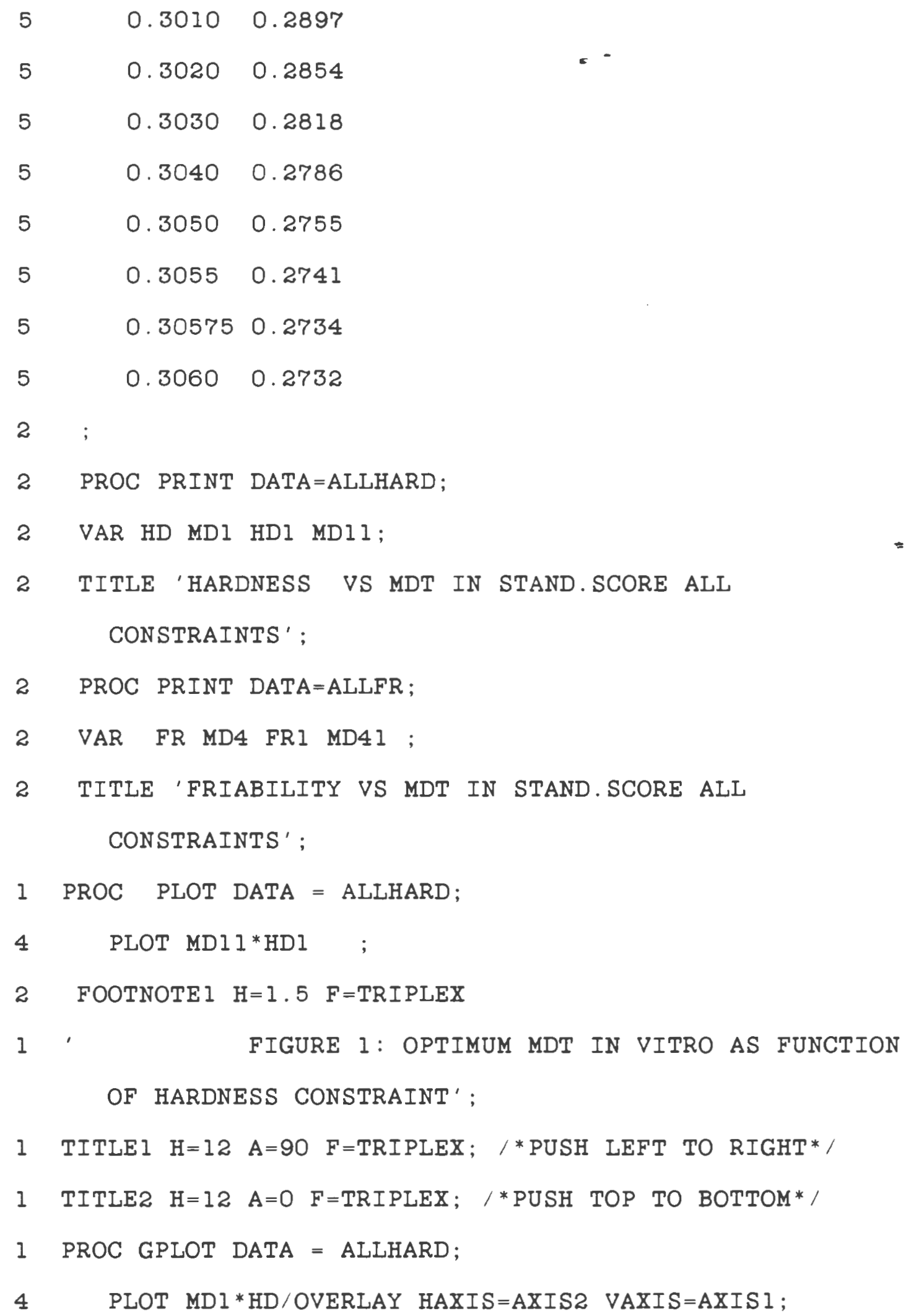




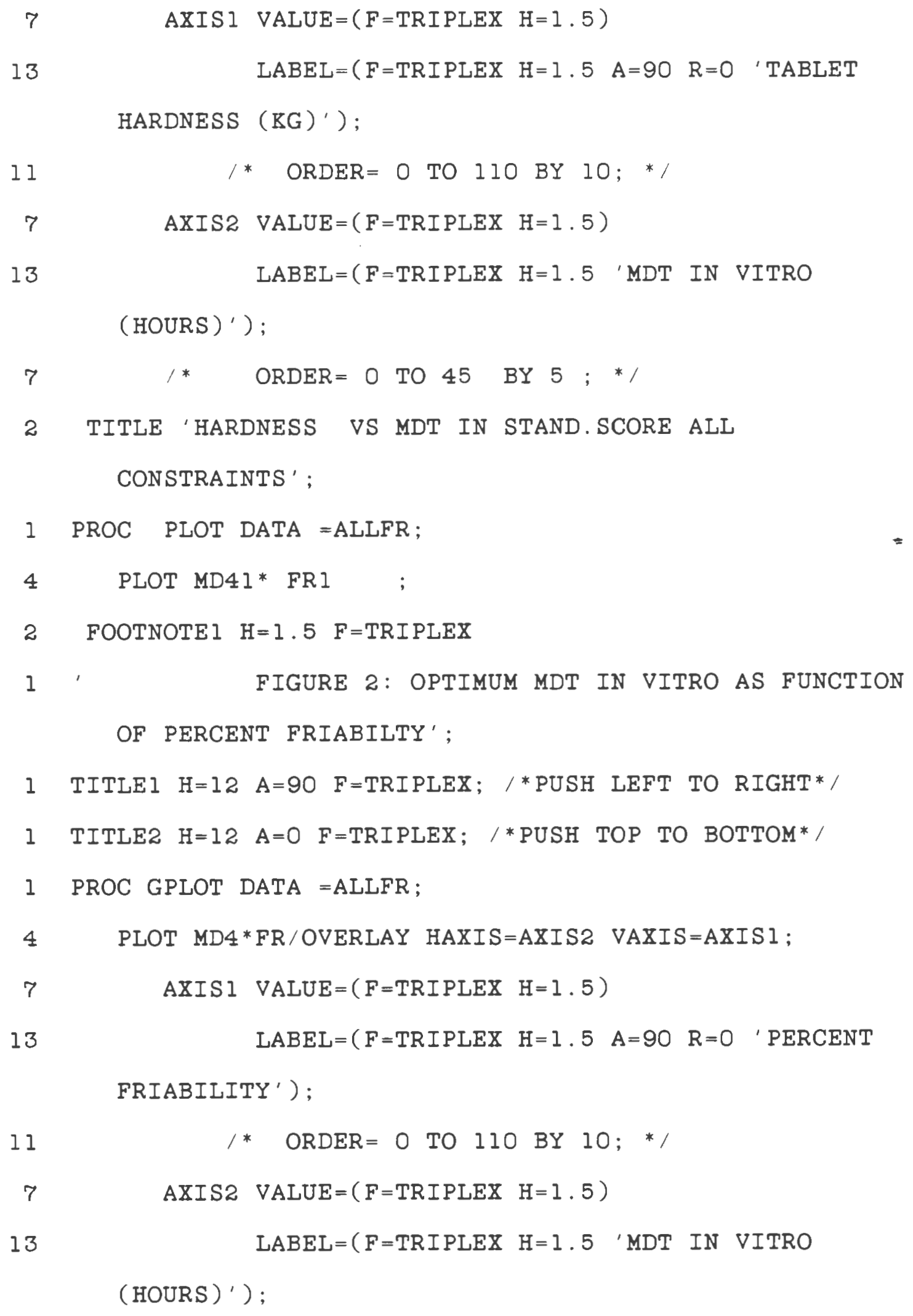


$2 / *$ TITLE 'FRIABILITY VS MDT IN STAND. SCORE ALL CONSTRAINTS'; */

2 PROC STEPWISE DATA=ALLHARD;

2 MODEL MDI I=HDI HDISQR/STEPWISE MAXR DETAILS;

$2 / * T I T L E$ 'HARDNESS VS MDT IN STAND. SCORE ALL CONSTRAINTS' ; */

2 PROC STEPWISE DATA=ALLFR;

2 MODEL MD4I=FRI FRISQR / STEPWISE MAXR DETAILS;

$2 / * T I T L E$ 'FRIABILITY VS MDT IN STAND.SCORE ALL CONSTRAINTS'; */

$1 / 1$

This is the end of the SAS programs for plotting optimum mean in vitro dissolution time as a function of hardness and friability constraints.

This is the start of the SAS program for calculating the response surface equation for crushing strengths of the tablets obtained from nine formulations of the optimization study. The weights used are the 
reciprocal of the variance of each tablet formulation mean.

$1 / / R L O 101$ JOB (RLO1O1), 'SHABBIR', NOTIFY=RLO1OI, MSGCLASS $=W$

$1 /$ *ROUTE PRINT DSPI

$1 / *$ JOBPARM LINES $=5$

$1 / /$ EXEC SAS

$1 / /{ }^{*}$ O.FTIIFOOI DD DSN=URI.RLOIO1.RESULT1, DISP=OLD

$1 / / * O . F T 12 F 001$ DD DSN=URI. RLOIOI. RESULT2, DISP=OLD

$1 / /$ GO.FTIIFOOI DD SYSOUT $=*$

$1 / /$ GO.FT12FOOI DD SYSOUT $=*$

$1 / /$ GO.SYSIN DD *

1 OPTIONS LS=72;

1 DATA HARDNESS;

1 INPUT XI Z2 YI W:

$1 \mathrm{XISQR}=\mathrm{XI} * \mathrm{X} 1$;

$1 \quad \mathrm{X} 2 \mathrm{SQR}=\mathrm{X} 2 * \mathrm{X} 2$;

$1 \mathrm{X} 1 \mathrm{X} 2=\mathrm{X} 1 * \mathrm{X} 2$;

1 CARDS ;

$\begin{array}{lllll}2 & 1.0 & 0.0 & 13.475 & 0.3996\end{array}$

$\begin{array}{llllll}2 & 0.5 & 0.866 & 11.820 & 0.5739\end{array}$

$\begin{array}{lllll}1 & -0.5 & 0.866 & 8.985 & 1.2291\end{array}$

$\begin{array}{lllll}1 & -1.0 & 0.0 & 7.655 & 2.2957\end{array}$ 


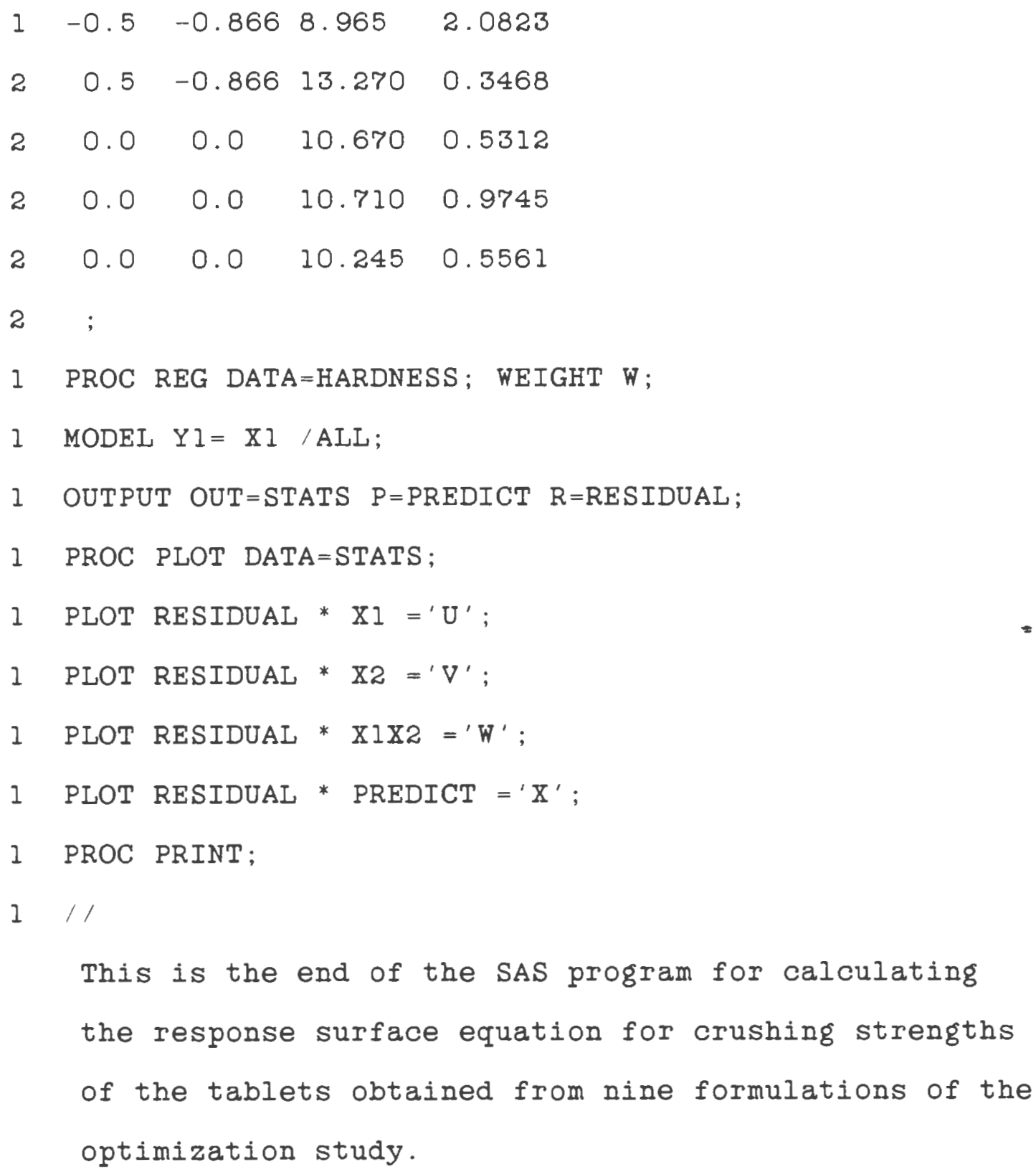

This is the end of the SAS program for calculating the response surface equation for crushing strengths of the tablets obtained from nine formulations of the optimization study.

This is the start of the SAS program for calculating the response surface equation for disintegration time data of the tablets obtained from nine formulations 
of the optimization study. The weights used are the reciprocal of the variance of each tablet formulation mean.

1 //RLO1O1 JOB(RLO1O1), 'SHABBIR', NOTIFY=RLO101, MSGCLASS $=\mathbb{W}$

$1 / *$ ROUTE PRINT DSPI

$1 /$ * JOBPARM LINES $=5$

$1 / /$ EXEC SAS

$1 /{ }^{*}$ O.FTIIFOOI DD DSN=URI.RLOIOI.RESULTI, DISP=OLD

$1 / /{ }^{*}$ O.FTI2FOOI DD DSN=URI.RIOIO1.RESULT2, DISP=OLD

$1 / /$ GO.FTIIFOOI DD SYSOUT =*

$1 / /$ GO.FTI2FOOI DD SYSOUT $=*$

$1 / /$ GO.SYSIN DD *

1 OPTIONS LS=72;

1 DATA HARDNESS;

1 INPUT XI X2 YI W;

$1 \mathrm{XISQR}=\mathrm{XI} * \mathrm{XI}$;

$1 \mathrm{X} 2 \mathrm{SQR}=\mathrm{X} 2 * \mathrm{X} 2$;

$1 \mathrm{X} 1 \mathrm{X} 2=\mathrm{X} 1 * \mathrm{X} 2$;

1 CARDS ;

$\begin{array}{lllll}2 & 1.0 & 0.0 & 8.625 & 12.398\end{array}$

$\begin{array}{lllll}2 & 0.5 & 0.866 & 6.014 & 11.261\end{array}$

$\begin{array}{llllll}1 & -0.5 & 0.866 & 3.444 & 132.118\end{array}$

$\begin{array}{lllll}1 & -1.0 & 0.0 & 3.367 & 45.043\end{array}$

$\begin{array}{lllll}1 & -0.5 & -0.866 & 5.439 & 22.461\end{array}$ 


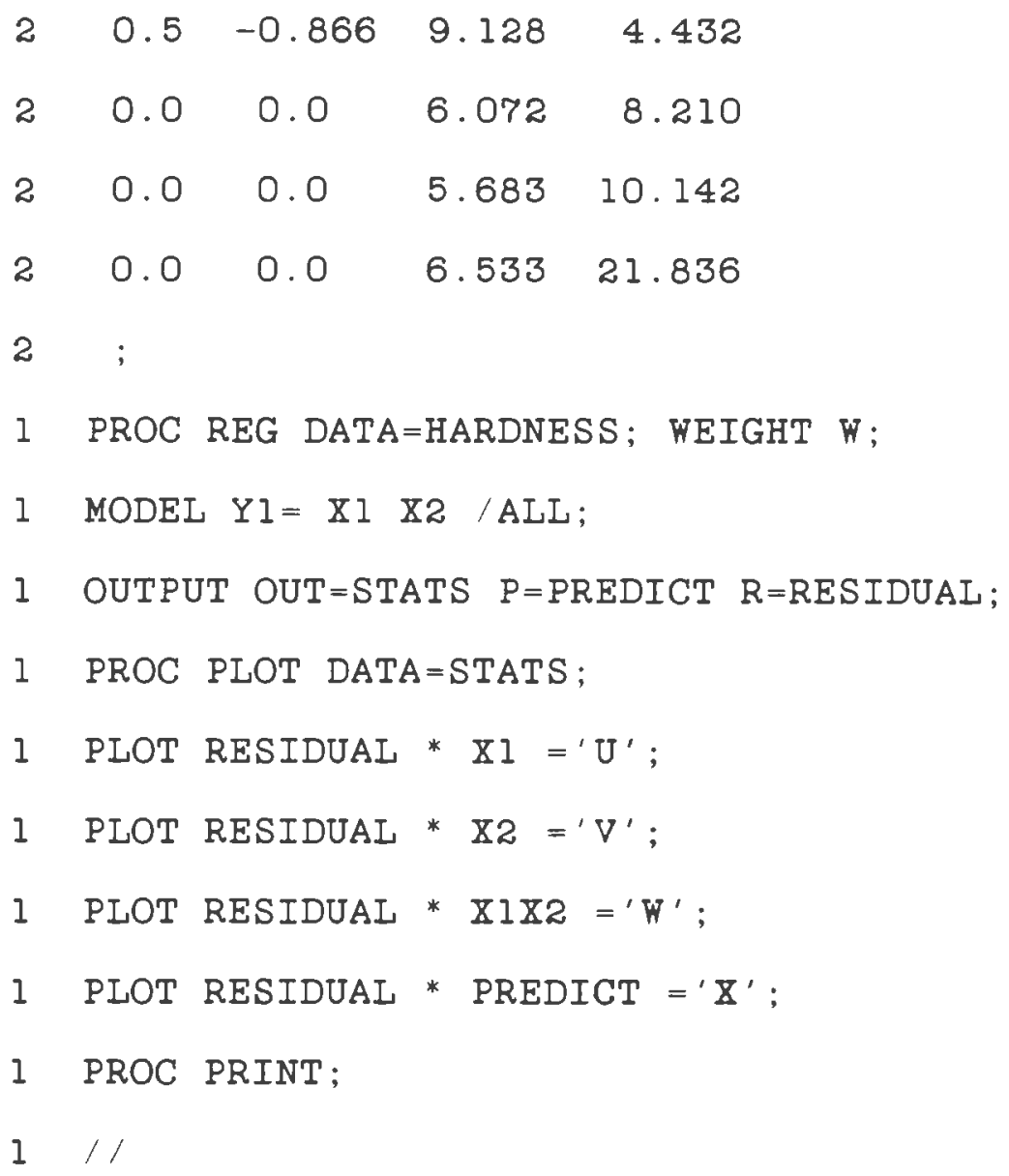

This is the end of the SAS program for calculating the response surface equation for disintegration time data of the tablets obtained from nine formulations of the optimization study.

This is the start of the SAS program for calculating the response surface equation for ejection force data of the tablets obtained from nine formulations of the 
optimization study. The weights used are the reciprocal of the variance of each tablet formulation mean .

$1 / /$ RLOIOI JOB(RLO1O1), 'SHABBIR', NOTIFY=RLOIOI, MSGCLASS $=W$

$1 /{ }^{*}$ ROUTE PRINT DSPI

$1 / *$ JOBPARM LINES $=5$

$1 / /$ EXEC SAS

$1 / / * O . F T 11 F 001$ DD DSN=URI.RLOIOI.RESULTI, DISP=OLD

$1 / / * O . F T 12 F 001$ DD DSN=URI.RLOIOI.RESULT2, DISP=OLD

$1 / /$ GO.FTIIFOOI DD SYSOUT $=*$

$1 / / \mathrm{GO} . \mathrm{FTI} F O O 1$ DD SYSOUT $=$ *

$1 / /$ GO.SYSIN DD *

1 OPTIONS LS $=72$;

1 DATA HARDNESS;

1 INPUT XI X2 YI W;

$1 \quad Y 1=Y 1 / 1000$;

$1 \quad \mathrm{XISQR}=\mathrm{XI} * \mathrm{XI}$;

$1 \mathrm{X} 2 \mathrm{SQR}=\mathrm{X} 2 * \mathrm{X} 2 ;$

$I X 1 X 2=X 1 * X 2$;

1 CARDS;

$\begin{array}{lllll}2 & 1.0 & 0.0 & 613.17 & 8573.4\end{array}$

$\begin{array}{lllll}2 & 0.5 & 0.866 & 581.18 & 1402.7\end{array}$

$\begin{array}{lllll}1 & -0.5 & 0.866 & 450.53 & 2890.5\end{array}$

$\begin{array}{lllll}1 & -1.0 & 0.0 & 397.05 & 2104.2\end{array}$ 


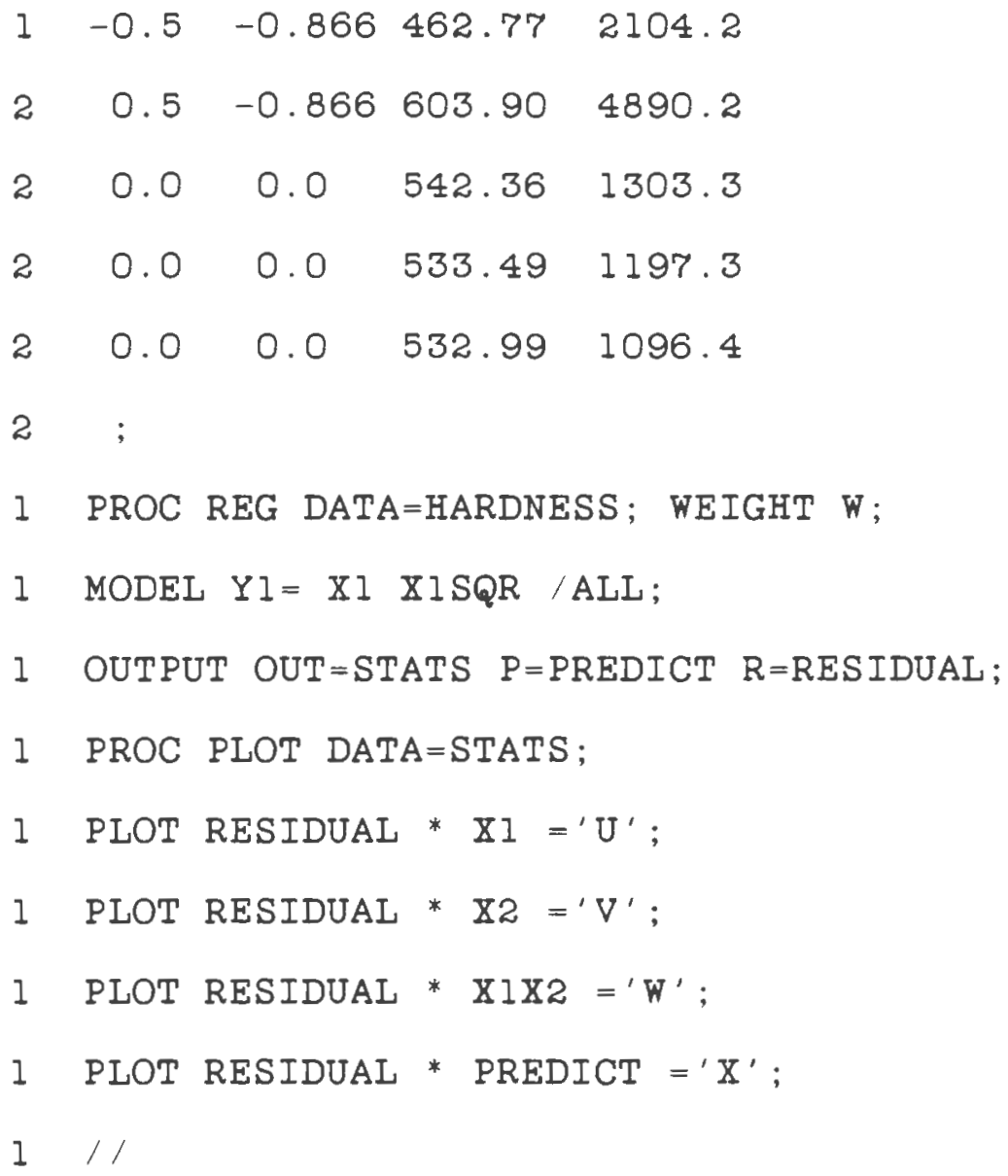

This is the end of the SAS program for calculating the response surface equation for ejection force data of the tablets obtained from nine formulations of the optimization study.

This is the start of the SAS program for calculating the response surface equation for percent friability data of the tablets obtained from nine formulations of the optimization study. 
1 / /RLO1O1 JOB(RLO101), 'SHABBIR', NOTIFY=RLO101, MSGCLASS $=W$

$1 /$ *ROUTE PRINT DSPI

1 * JOBPARM LINES $=5$

$1 /$ EXEC SAS

$1: / * O . F T 11 F 001$ DD DSN=URI.RLO101.RESULTI, DISP=OLD

$1 /{ }^{*}$ O.FT12F0O1 DD DSN=URI. RLO101. RESULT2, DISP=OLD

$1 / / G O . F T I I F O O 1$ DD SYSOUT $=*$

1 /:GO.FT12FOO1 DD SYSOUT $=*$

$1 / /$ GO.SYSIN DD *

1 OPTIONS LS=72;

1 DATA HARDNESS;

1 INPUT XI X2 YI;

$1 \quad \mathrm{XISQR}=\mathrm{XI} * \mathrm{XI}$;

$1 \quad \mathrm{X} 2 \mathrm{SQR}=\mathrm{X} 2 * \mathrm{X} 2 ;$

$1 \mathrm{X} 1 \mathrm{X} 2=\mathrm{X} 1 * \mathrm{X} 2$;

1 CARDS ;

$2 \quad 1.0 \quad 0.0 \quad 0.294$

$\begin{array}{llll}2 & 0.5 & 0.866 & 0.344\end{array}$

$\begin{array}{llll}1 & -0.5 & 0.866 & 0.419\end{array}$

$\begin{array}{llll}1 & -1.0 & 0.0 & 0.496\end{array}$

$\begin{array}{lllll}1 & -0.5 & -0.866 & 0.422\end{array}$

$2 \quad 0.5 \quad-0.866 \quad 0.291$

$\begin{array}{llll}2 & 0.0 & 0.0 & 0.353\end{array}$

$\begin{array}{llll}2 & 0.0 & 0.0 & 0.296\end{array}$

$\begin{array}{llll}2 & 0.0 & 0.0 & 0.328\end{array}$ 


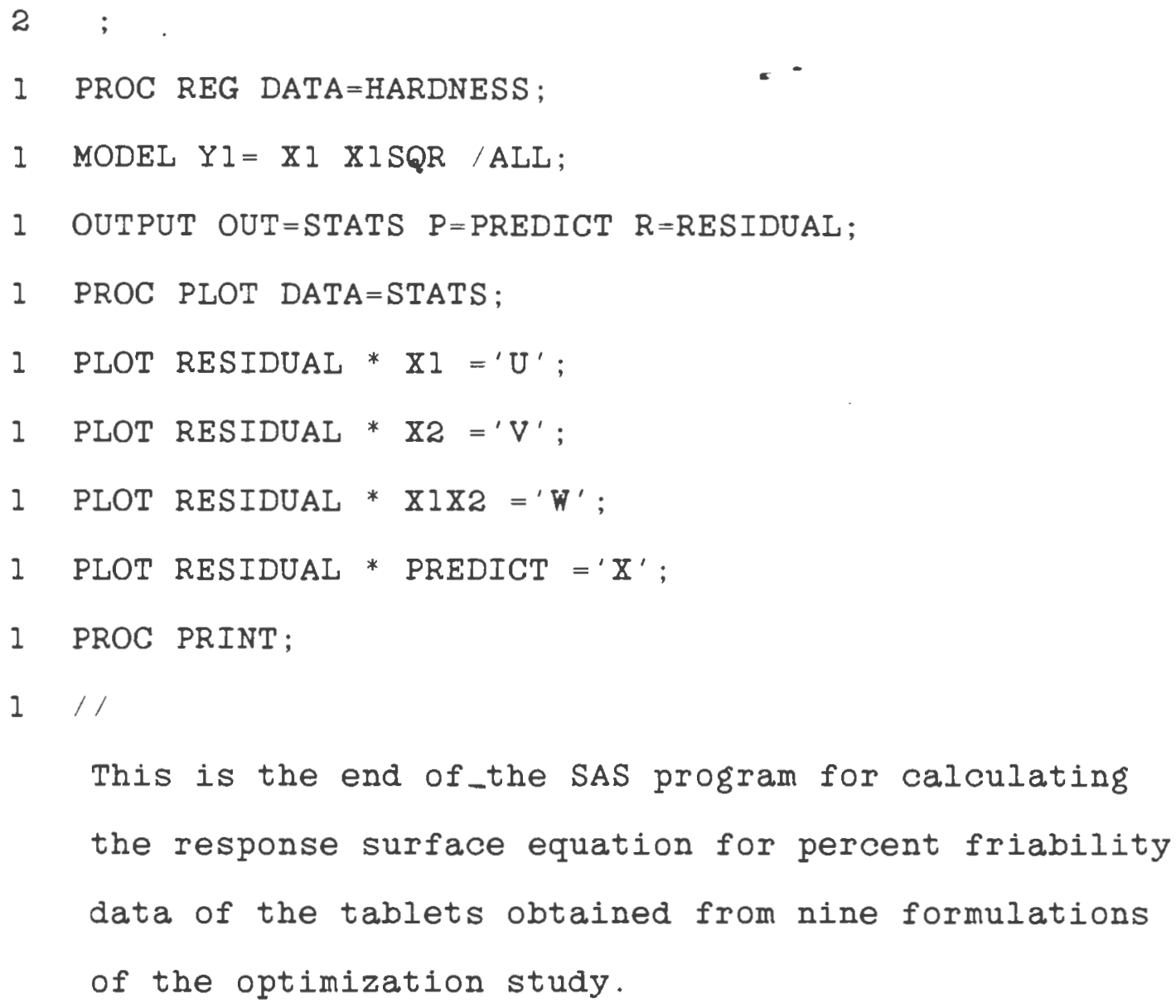

This is the start of the SAS program for calculating the response surface equation for mean in vitro dissolution data of the tablets obtained from nine formulations of the optimization study.

1 //RLO1O1 JOB(RLO1O1), 'SHABBIR', NOTIFY=RLO101, MSGCLASS $=$ W 


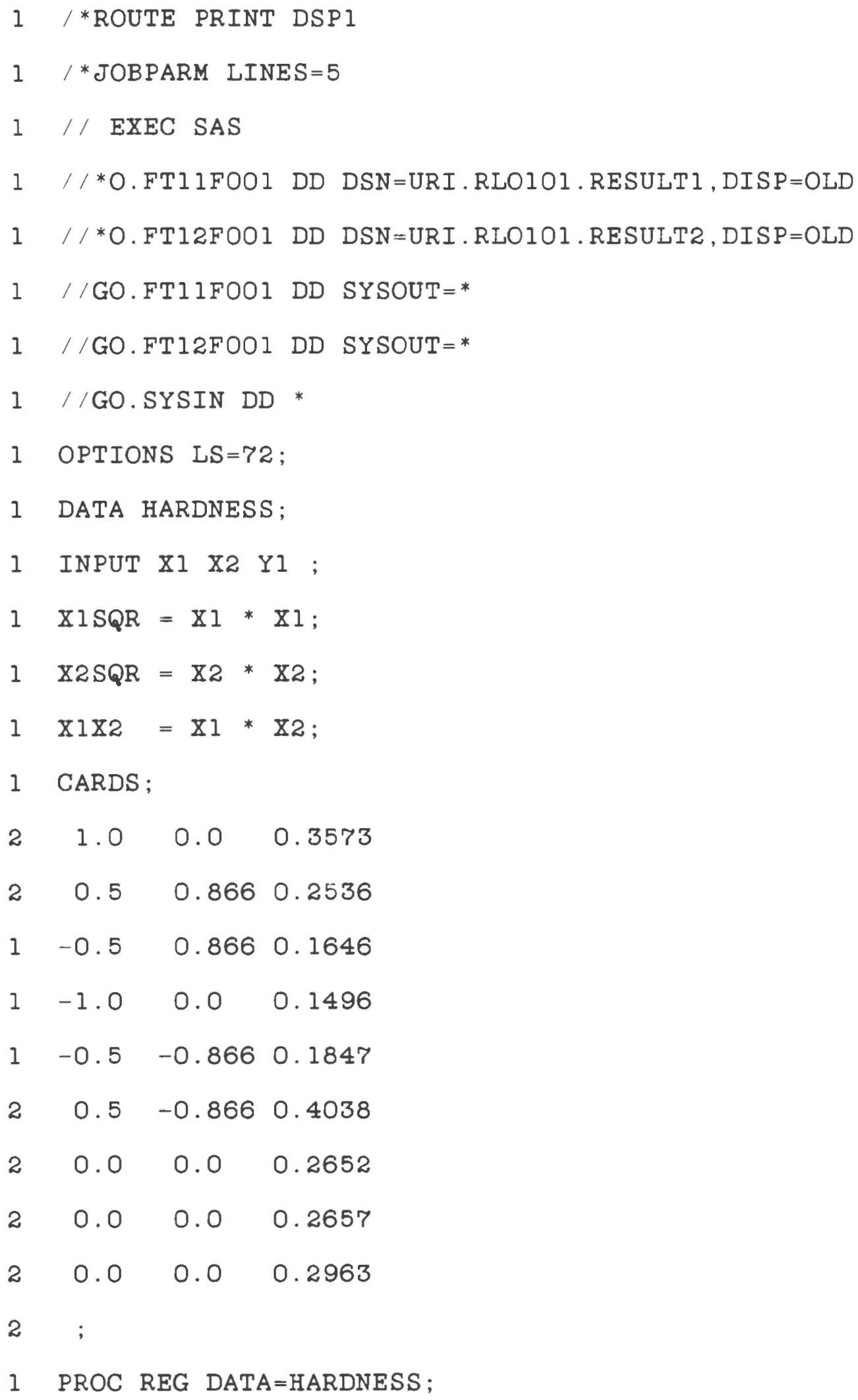




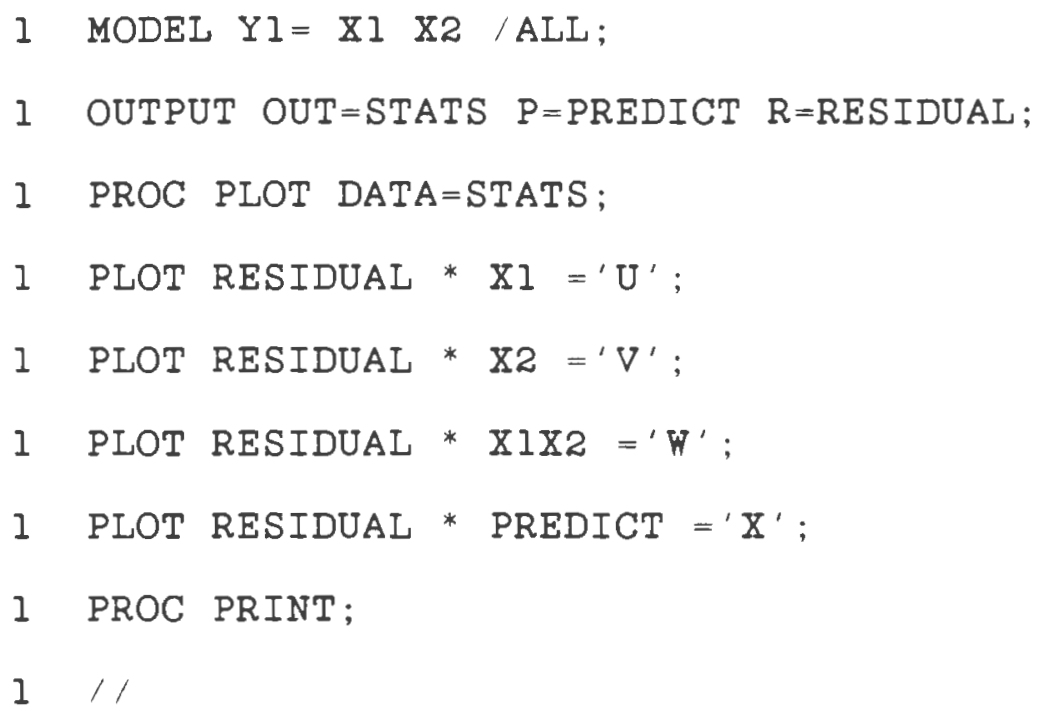

This is the start of the SAS programs for performing the principal component analysis, for the nine tablet formulations in the optimization study.

1 //RLO101 JOB(RLO101), 'SHABBIR', NOTIFY=RLO101, MSGCLASS $=W$

$1 /{ }^{*}$ ROUTE PRINT PRO

$1 / *$ JOBPARM LINES $=5$

1 / / EXEC SAS, PLOTDSN='RLOIO1. PLOTFILE', REWIND=YES

$1 / / * 0 . F T 11 F 001$ DD DSN=URI.RLOIO1.RESULTI, DISP=OLD 


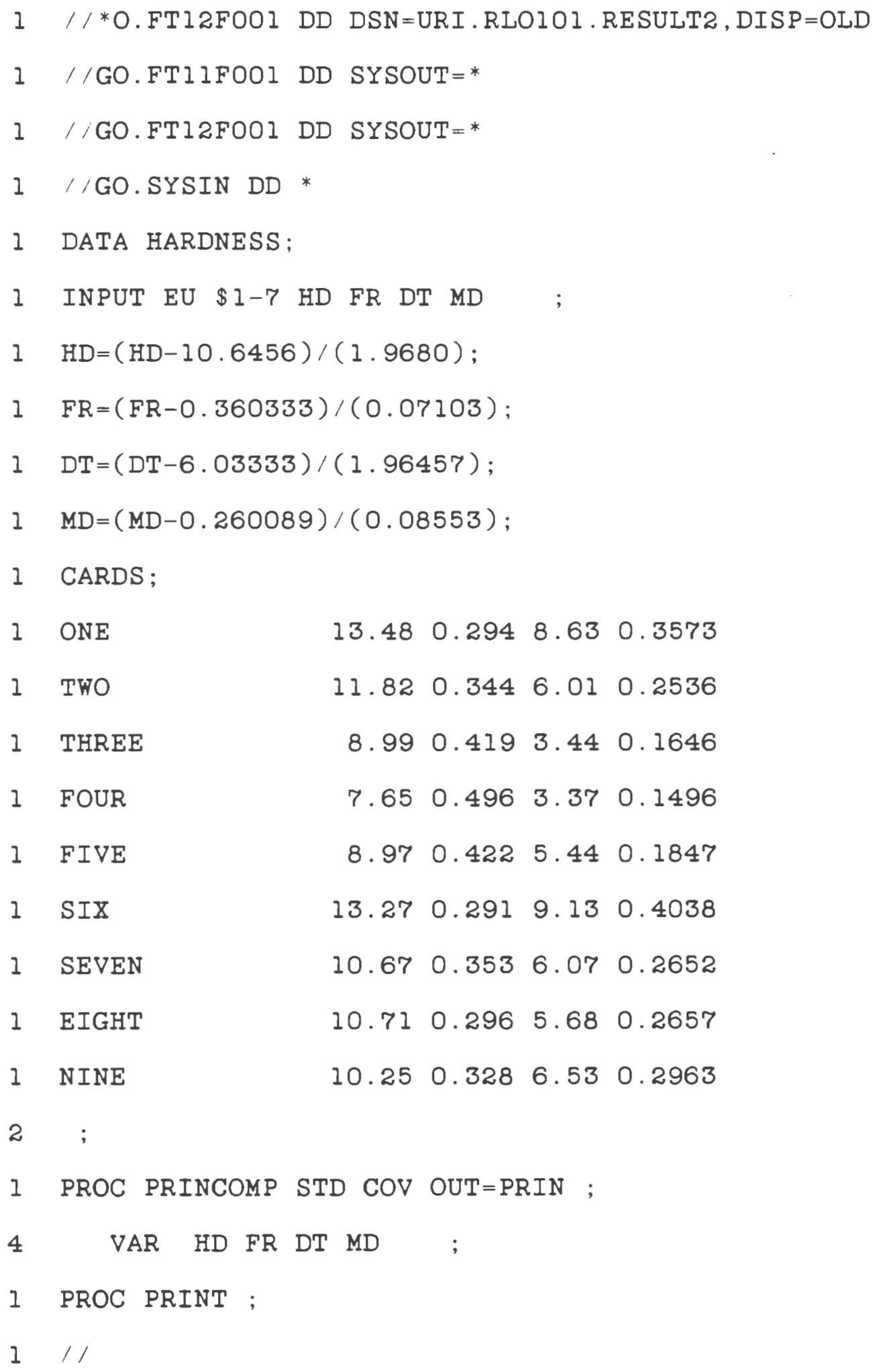


This is the end of the SAS programs for performing the principal component analysis, for the nine tablet formulations in the optimization study.

This is the start of the SAS program for formating and printing the simulation results.

1 / /RLO1O1M JOB(RLO1O1), 'SHABBIR', NOTIFY=RLO101, MSGCLASS $=W$, TIME $=(0,59)$

$1 /{ }^{*}$ ROUTE PRINT DSPI

$1 / *$ JOBPARM LINES $=10$

$1 / /$ EXEC SAS

$1 / / G O . F T I I F O O I$ DD SYSOUT =*

$1 / /$ GO.FTI2FOOI DD SYSOUT $=*$

1 / /GO.DATAIN DD DSN=RLOIOI.P,DISP=OLD

$1 / /$ GO.SYSIN DD *

1 OPTIONS NOCENTER;

1 DATA ONE; INFILE DATAIN; INPUT \# I CHAR \$CHAR8O.;

$1 \mathrm{DEP}=\operatorname{SUBSTR}(\mathrm{CHAR}, 2,3)$;

1 MODEL $=\operatorname{SUBSTR}($ CHAR, 10, 5);

1 RSQUARE =SUBSTR ( CHAR , 40, 8);

1 DATA T ; SET ONE;

4 IF $D E P=' D E P '$ THEN DO; 


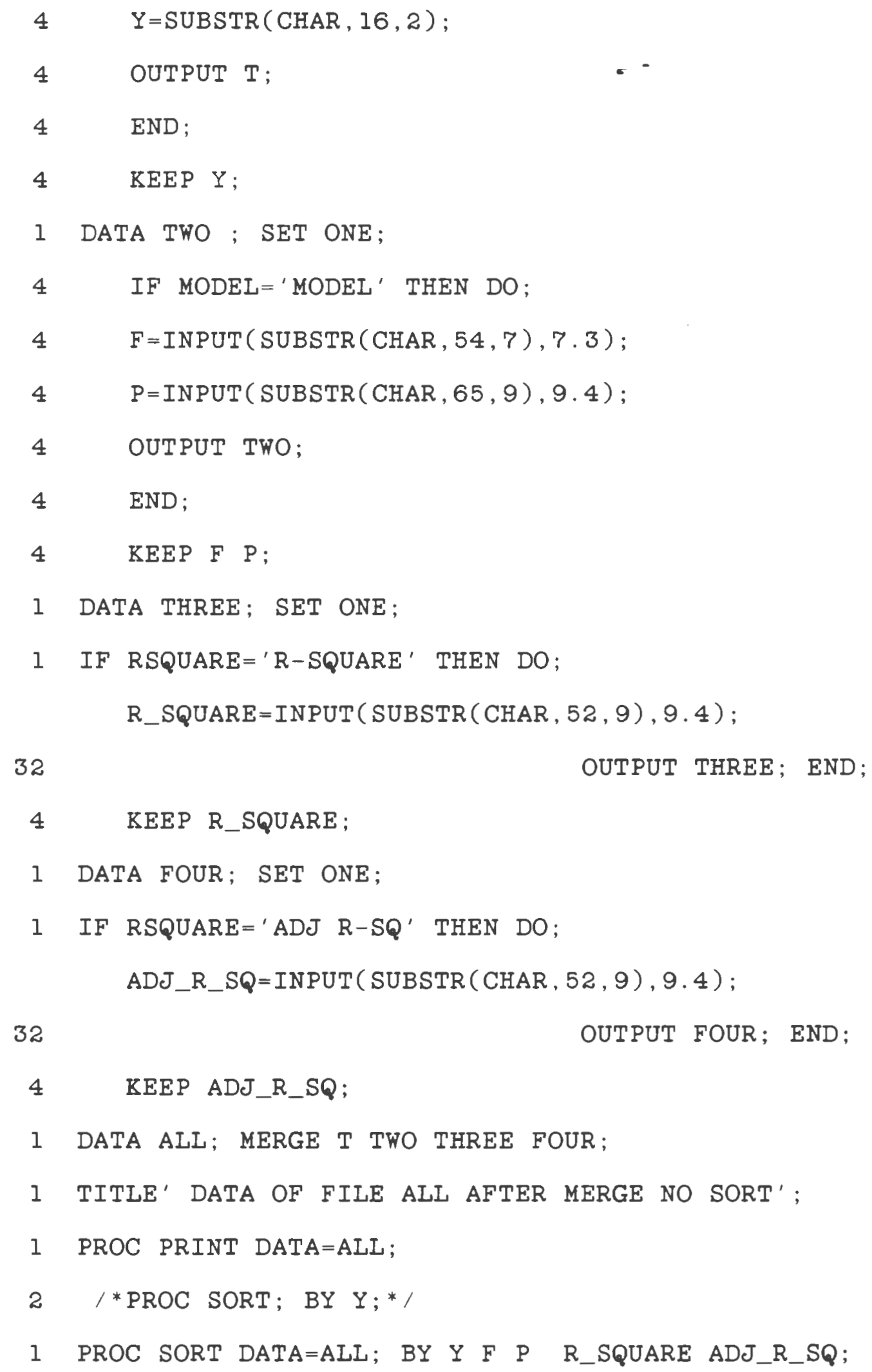




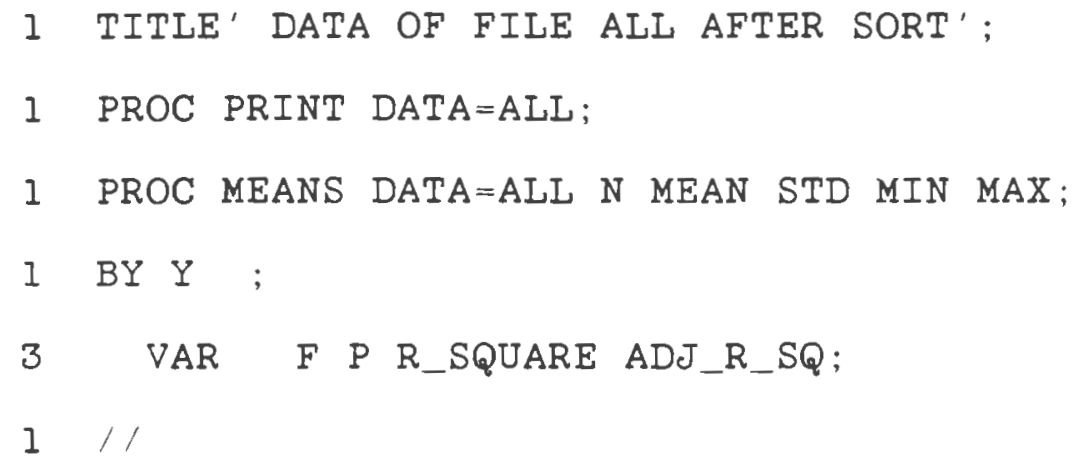

This is the start of the SAS program for simulating new compression force values within the standard deviations limits and obtaining the response surface equations for mean values of tablet in vitro properties as orignally obtained for the nine formulations of the optimization study.

1 //RLO1O1 JOB(RLO101), 'SHABBIR', NOTIFY=RLO101, MSGCLASS $=$ W, TIME $=4$

$1 / *$ ROUTE PRINT LOCAL

$1 / *$ JOBPARM LINES $=10$

$1 / /$ EXEC SAS

$1 / /^{*}$ O.FTI1FOO1 DD DSN=URI.RIOIO1.RESULTI, DISP=OLD

$1 / / * O . F T 12 F O O 1$ DD DSN=URI.RLO101.RESULT2, DISP=OLD 
$1 / /$ GO.FTIIFOOI DD SYSOUT $=*$

I //GO.FTI2FOOI DD SYSOUT=*

I //GO.SYSIN DD *

1 OPTIONS $\mathrm{LS}=72$;

1 DATA HARDNESS;

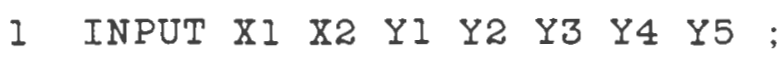

$I X I S Q R=X I * X I$;

$1 \mathrm{X} 2 \mathrm{SQR}=\mathrm{X} 2 * \mathrm{X} 2$;

$1 \mathrm{X} 1 \mathrm{X2}=\mathrm{X} 1 * \mathrm{X} 2$;

1 CARDS;

$\begin{array}{llllllll}2 & 1.0 & 0.0 & 0.3573 & 8.63 & 0.294 & 13.48 & 613.2\end{array}$

$\begin{array}{lllllllll}2 & 0.5 & 0.866 & 0.2536 & 6.01 & 0.344 & 11.82 & 581.2\end{array}$

$\begin{array}{lllllllll}1 & -0.5 & 0.866 & 0.1646 & 3.44 & 0.419 & 8.99 & 450.5\end{array}$

$\begin{array}{lllllllll}1 & -1.0 & 0.0 & 0.1496 & 3.37 & 0.496 & 7.66 & 397.1\end{array}$

$\begin{array}{lllllllll}1 & -0.5 & -0.866 & 0.1847 & 5.44 & 0.422 & 8.97 & 462.8\end{array}$

$\begin{array}{lllllllll}2 & 0.5 & -0.866 & 0.4038 & 9.13 & 0.291 & 13.27 & 603.9\end{array}$

$\begin{array}{llllllll}2 & 0.0 & 0.0 & 0.2652 & 6.07 & 0.353 & 10.67 & 542.4\end{array}$

$\begin{array}{llllllll}2 & 0.0 & 0.0 & 0.2657 & 5.68 & 0.296 & 10.71 & 533.5\end{array}$

$\begin{array}{llllllll}2 & 0.0 & 0.0 & 0.2963 & 6.53 & 0.328 & 10.25 & 533.0\end{array}$

$2 \quad ;$

2 DATA NEW;

1 DO $M=1$ TO 30 ;

I *------STARTING VALUES FOR ENDOGENOUS------;

$2 \quad Y I=0 ; Y 2=0 ; Y 3=0 ; Y 4=0 ; Y 5=0 ;$

I $\mathrm{DO} \mathrm{N}=1$ TO 9 ;

$2 \quad Y 1=0 ; Y 2=0 ; Y 3=0 ; Y 4=0 ; Y 5=0 ;$ 


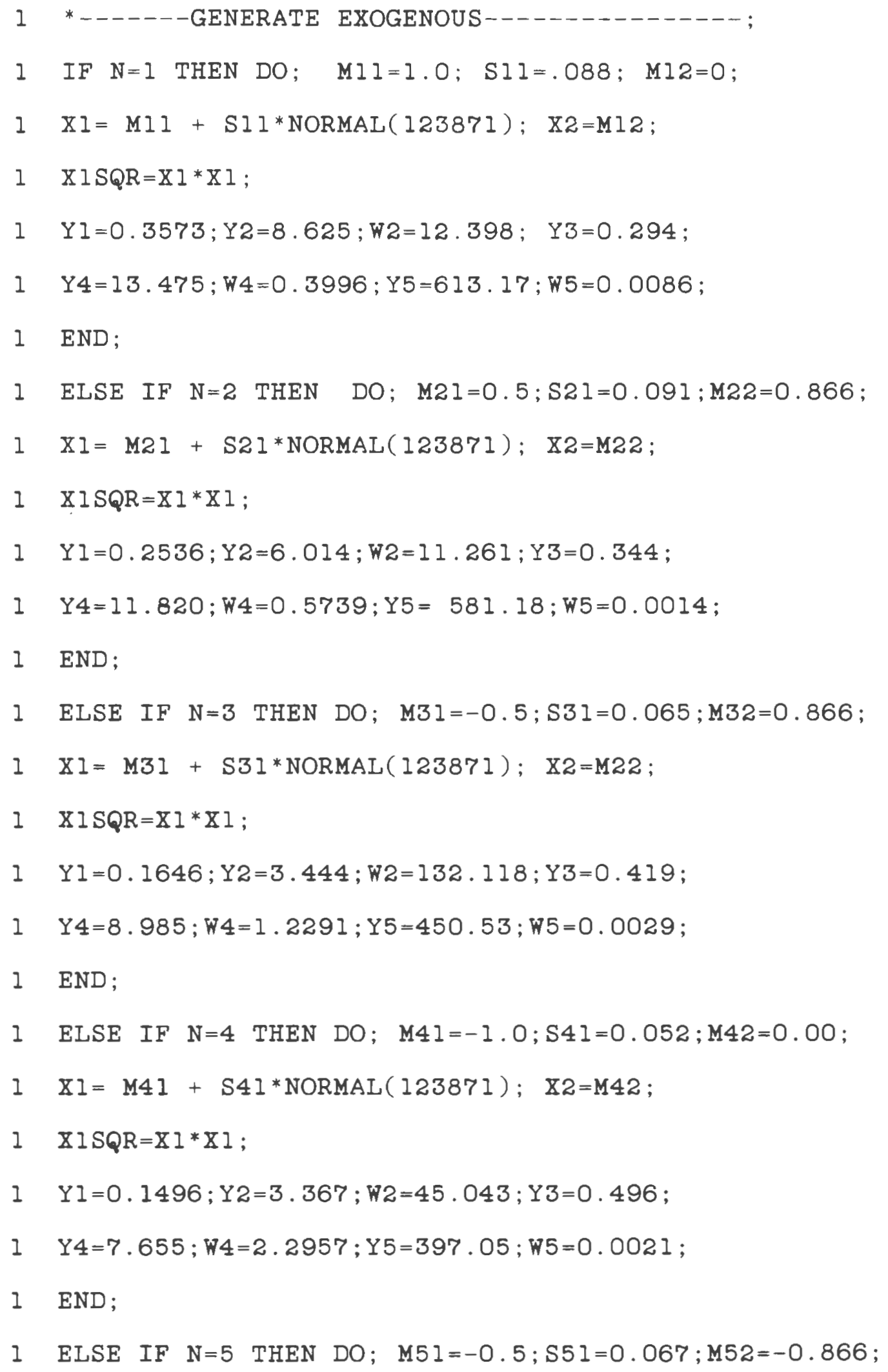


I XI $\quad \mathrm{M} 51+\mathrm{S} 51 * \operatorname{NORMAL}(123871) ; \mathrm{X} 2=\mathrm{M} 52 ;$

$1 \quad \mathrm{XISQR}=\mathrm{XI} I \mathrm{XI}$;

$1 \quad Y 1=0.1847 ; Y 2=5.439 ; W 2=22.461 ; Y 3=0.422 ;$

$1 \quad Y 4=8.965 ; W 4=2.0823 ; Y 5=462.77 ; W 5=0.0021 ;$

1 END;

1 ELSE IF $\mathrm{N}=6$ THEN DO; $\mathrm{M} 61=0.5 ; \mathrm{S} 61=0.102 ; \mathrm{M} 62=-0.866$;

$1 \quad \mathrm{XI}=\mathrm{M} 61+\mathrm{S} 61 *$ NORMAL $(123871) ; \mathrm{X} 2=\mathrm{M} 62 ;$

$1 \quad \mathrm{X} I S Q R=\mathrm{X} I * \bar{X} I$;

$1 \quad Y 1=0.4038 ; Y 2=9.128 ; พ 2=4.432 ; Y 3=0.291$;

$1 \quad Y 4=13.270 ; W 4=0.3468 ; Y 5=603.90 ; W 6=0.0049$;

1 END;

1 ELSE IF $N=7$ THEN DO; M71=0.0; S71=0.056;M72=0.0;

$1 \quad \mathrm{XI}=\mathrm{M} 71+$ S71*NORMAL $(123871) ; \mathrm{X} 2=\mathrm{M} 72 ;$

$1 \quad X I S Q R=X I * X I$;

$1 Y I=0.2652 ; Y 2=6.072 ; W 2=8.210 ; Y 3=0.353$;

$1 Y 4=10.670 ; W 4=0.5312 ; Y 5=542.36 ; W 5=0.0013$;

1 END;

1 ELSE IF $N=8$ THEN DO; $M 81=0.0 ; S 81=0.079 ; M 82=0.0$;

$1 \quad \mathrm{X} 1=\mathrm{M} 81+\mathrm{S} 81 *$ NORMAL $(123871) ; \mathrm{X} 2=\mathrm{M} 82 ;$

$1 \quad X I S Q R=X I * X I$;

$1 Y 1=0.2657 ; Y 2=5.683 ; \mathrm{WL}=10.142 ; Y 3=0.296$;

$1 \quad Y 4=10.710 ; W 4=0.9745 ; Y 5=533.49 ; W 5=0.0012 ;$

1 END;

1 ELSE IF $\mathrm{N}=9$ THEN DO;M9I=0.0;S91=0.085;M92=0.0;

$1 \mathrm{X} 1=\mathrm{M} 91+\mathrm{S} 91 *$ NORMAL $(123871) ; \mathrm{X} 2=\mathrm{M} 92 ;$

$1 \quad \mathrm{XISQR}=\mathrm{XI} * \mathrm{XI}$; 


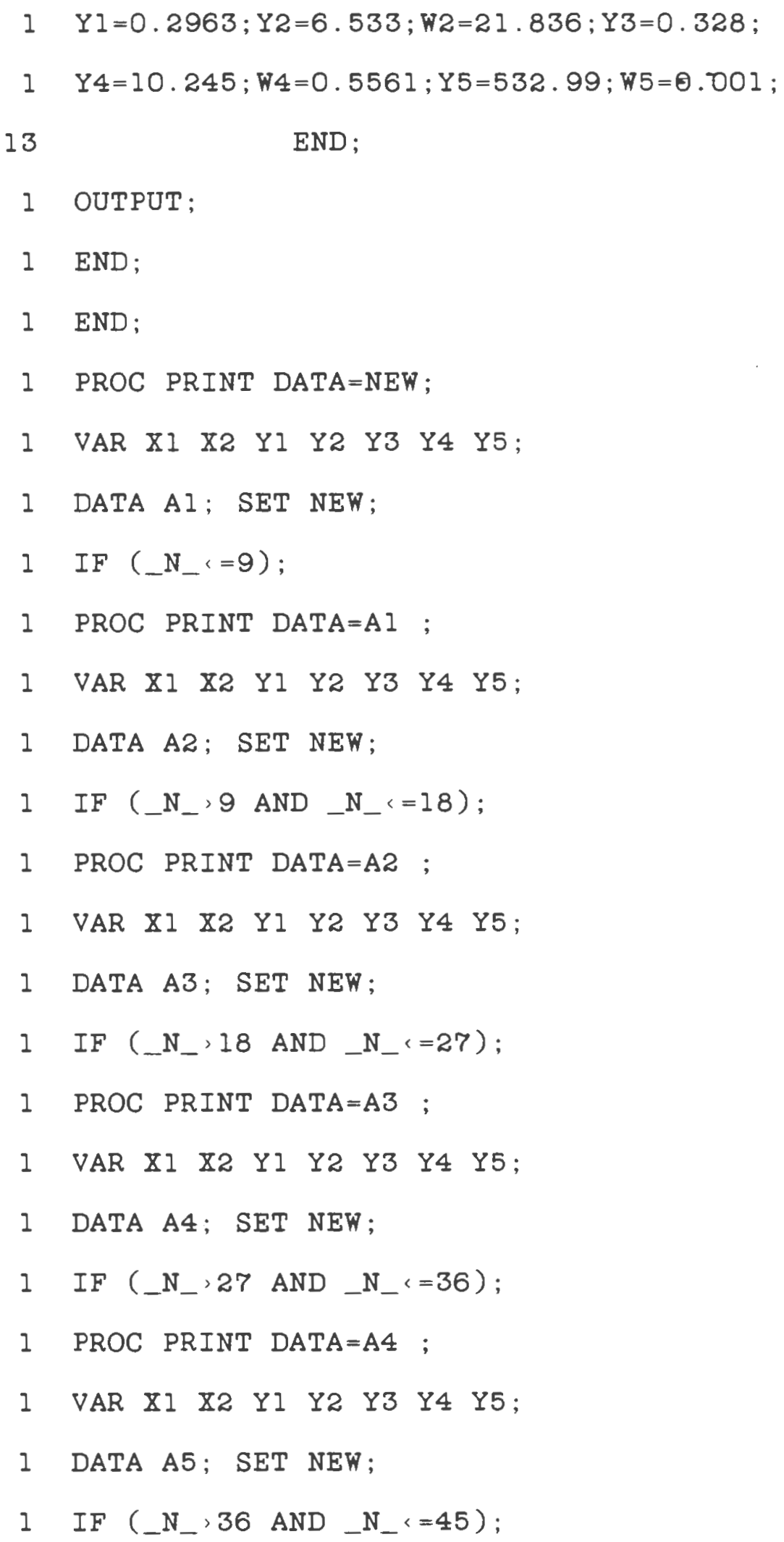


1 PROC PRINT DATA=A5 ;

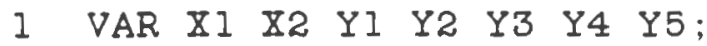

1 DATA A6; SET NEW;

1 IF ( $N_{-}>45$ AND $\left.N_{-}=54\right)$;

1 PROC PRINT DATA=A6 ;

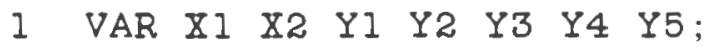

1 DATA A7; SET NEW;

1 IF (_N_.54 AND _N $\left.\mathrm{N}_{-}=63\right)$;

1 PROC PRINT DATA=A7 ;

1 VAR X1 X2 Y1 Y2 Y3 Y4 $Y 5$;

1 DATA A8; SET NEW;

1 IF ( _N , 63 AND $\left.N_{-}<=72\right)$;

1 PROC PRINT DATA=A8 ;

$\begin{array}{lllllllll}1 & V A R & X 1 & X 2 & Y 1 & Y 2 & Y 3 & Y 4 & Y 5 ;\end{array}$

1 DATA A9; SET NEW;

1 IF ( $\mathrm{N}_{-}, 72$ AND $\left.\mathrm{N}_{-}<=81\right)$;

1 PROC PRINT DATA=A9;

$\begin{array}{llllllllll}1 & V A R & X 1 & \mathrm{X} 2 & Y 1 & Y 2 & Y 3 & Y 4 & Y 5 ;\end{array}$

1 DATA AIO; SET NEW;

1 IF ( $N_{-}, 81$ AND $\left.N_{-}<=90\right)$;

1 PROC PRINT DATA=AIO;

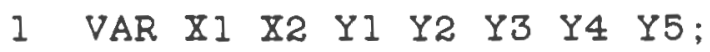

I DATA AII; SET NEW;

1 IF ( $N_{-}, 90$ AND $\left.N_{-}<=99\right)$;

1 PROC PRINT DATA=AII;

$\begin{array}{lllllllll}1 & V A R & X 1 & X 2 & Y 1 & Y 2 & Y 3 & Y 4 & Y 5 ;\end{array}$ 
1 DATA AI2; SET NEW;

1 IF (_N_,99 AND _N_< $=108$ );

1 PROC PRINT DATA=Al2 ;

1 VAR X1 X2 Y1 Y2 Y3 Y4 Y5;

1 DATA AI3; SET NEW;

1 IF (_N_'108 AND _N_< $=117$ );

1 PROC PRINT DATA=Al3 ;

1 VAR X1 X2 Y1 Y2 Y3 Y4 Y5;

1 DATA A14; SET NEW;

1 IF (_N_, 117 AND _N_c $=126$ );

1 PROC PRINT DATA=A14 ;

1 VAR XI X2 Y1 Y2 Y3 Y4 Y5;

1 DATA AI5; SET NEW;

1 IF (_N_'126 AND_N_c=135);

1 PROC PRINT DATA=AI5 ;

1 VAR X1 X2 Y1 Y2 Y3 Y4 Y5;

1 DATA A16; SET NEW;

1 IF (_N_>135 AND _N_s=144);

1 PROC PRINT DATA=Al6 ;

1 VAR X1 X2 Y1 Y2 Y3 Y4 Y5;

1 DATA AI7; SET NEW;

1 IF (_N_' 144 AND _N_c $=153$ );

1 PROC PRINT DATA=AI7;

1 VAR XI X2 Y1 Y2 Y3 Y4 Y5;

1 DATA Al8; SET NEW;

1 IF (_N_>153 AND _N_s $=162$ ); 
1 PROC PRINT DATA=AI8;

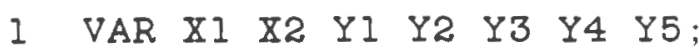

I DATA Al9; SET NEW;

1 IF (_N_>162 AND _N_'=171);

1 PROC PRINT DATA=AI9 ;

$\begin{array}{llllllllll}1 & V A R & X 1 & X 2 & Y 1 & Y 2 & Y 3 & Y 4 & Y 5 ;\end{array}$

I DATA A2O; SET NEW;

1 IF ( $N_{-}>171$ AND $\left.N_{-}<=180\right)$;

I PROC PRINT DATA=A2O;

$\begin{array}{lllllllll}1 & \text { VAR } & X 1 & X 2 & Y 1 & Y 2 & Y 3 & Y 4 & Y 5 ;\end{array}$

I DATA A21; SET NEW;

1 IF ( $N_{-}>180$ AND $\left.N_{-}=189\right)$;

1 PROC PRINT DATA=A21;

$\begin{array}{llllllllll}1 & V A R & X 1 & \text { X2 } & Y 1 & Y 2 & Y 3 & Y 4 & Y 5 ;\end{array}$

I DATA A22; SET NEW;

1 IF (_N_, I89 AND_N_s=198);

1 PROC PRINT DATA=A22;

1 VAR XI X2 YI Y2 Y3 Y4 Y5;

I DATA A23; SET NEW;

1 IF ( $N_{-}>198$ AND _N_c=207);

1 PROC PRINT DATA=A23;

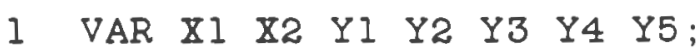

I DATA A24; SET NEW;

1 IF (_N_>207 AND_N_<=216);

1 PROC PRINT DATA=A24 ;

$\begin{array}{llllllllll}1 & V A R & Y 1 & X 2 & Y 1 & Y 2 & Y 3 & Y 4 & Y 5 ;\end{array}$ 
DATA A25; SET NEW;

1 IF $\left(\mathrm{N}_{-}, 216\right.$ AND $\mathrm{N}_{-}(=225)$;

1 PROC PRINT DATA $=$ A25 ;

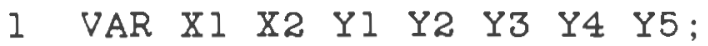

1 DATA A26; SET NEW;

1 IF $\left(\mathrm{N}_{-}>225\right.$ AND $\mathrm{N}_{-}(=234)$;

1 PROC PRINT DATA=A26 ;

$\begin{array}{llllllllll}1 & \text { VAR } & \mathrm{XI} & \mathrm{X} 2 & \mathrm{YI} & \mathrm{Y} 2 & \mathrm{Y} 3 & \mathrm{Y} 4 & \mathrm{Y5}\end{array}$

1 DATA A27; SET NEW;

1 IF ( $N_{-}, 234$ AND $\left.N_{-}<=243\right)$;

? DROC PRINT DATA=A27 ;

I VAR XI X2 Y1 Y2 Y3 Y4 Y5;

1 DATA A28; SET NEW;

1 IF ( $N_{-}, 243$ AND $\left.N_{-}<=252\right)$;

1 PROC PRINT DATA=A28;

1 VAR XI X2 Y1 Y2 Y3 Y4 Y5;

1 DATA A29; SET NEW;

1 IF $\left(N_{-}>252\right.$ AND $\left.N_{-}=261\right)$;

1 PROC PRINT DATA=A29;

1 VAR X1 X2 Y1 Y2 Y3 Y4 Y5;

I DATA A3O; SET NEW;

1 IF ( $N_{-}>261$ AND _N_' $\left.=270\right)$;

1 PROC PRINT DATA=A30;

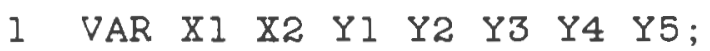

1 PROC REG DATA=AI OUTEST=AO11;

1 MODEL $Y 1=X 1 \quad X 2$; 
1 PROC REG DATA=Al OUTEST=AO12; WEIGHT W2;

1 MODEL Y2=X1 X2 ;

1 PROC REG DATA $=\mathrm{Al}$ OUTEST=AO13;

1 MODEL $Y 3=X 1$ XISQR;

1 PROC REG DATA=AI OUTEST=AO14; WEIGHT W4;

1 MODEL $Y 4=\mathrm{X} 1$;

1 PROC REG DATA=AI OUTEST=AO15; WEIGHT W5;

1 MODEL Y5=XI XISQR;

1 TITLE 'END OF SIMULATION \# 1';

1 PROC REG DATA=A2 OUTEST=AO21;

1 MODEL $Y 1=\mathrm{X} 1 \mathrm{X} 2$;

1 PROC REG DATA=A2 OUTEST=AO22; WEIGHT W2;

1 MODEL $Y 2=\mathrm{X} 1 \mathrm{X} 2$;

1 PROC REG DATA=A2 OUTEST=AO23;

1 MODEL Y3=XI XISQR;

1 PROC REG DATA=A2 OUTEST=AO24; WEIGHT $\$ 4$;

1 MODEL Y4=XI;

1 PROC REG DATA=A2 OUTEST=AO25; WEIGHT W5;

1 MODEL $Y 5=X I \quad X I S Q R$;

1 TITLE 'END OF SIMULATION \#2' ;

1 PROC REG DATA=A3 OUTEST=AO3I;

1 MODEL YI=XI X2 ;

1 PROC REG DATA=A3 OUTEST=AO32; WEIGHT W2;

1 MODEL $Y 2=X 1 \quad \mathrm{X} 2$;

1 PROC REG DATA=A3 OUTEST=AO33;

1 MODEL $Y 3=X 1$ XISQR; 
1 PROC REG DATA=A3 OUTEST=AO34; WEIGHT W4;

1 MODEL $Y 4=X I$;

I PROC REG DATA=A3 OUTEST=AO35; WEIGHT \%5;

1 MODEL Y5=XI XISQR;

1 TITLE 'END OF STMULATION \#3' ;

1 PROC REG DATA=A4 OUTEST=AO41;

1 MODEL $Y I=X 1 \quad X 2$;

I PROC REG DATA=A4 OUTEST=A042; WEIGHT W2;

1 MODEL Y2=XI X2 ;

I PROC REG DATA=A4 OUTEST=A043;

1 MODEL $Y 3=X I$ XISQR;

I PROC REG DATA=A4 OUTEST=AO44; WEIGHT W4;

1 MODEL $Y 4=X I$;

1 PROC REG DATA=A4 OUTEST=AO45; WEIGHT W5;

1 MODEL Y5=XI XISQR;

1 TITLE 'END OF SIMULATION \#4' ;

1 PROC REG DATA=A5 OUTEST=AO5I;

1 MODEL $Y I=X I \quad X 2$;

1 PROC REG DATA=A5 OUTEST=A052; WEIGHT W2;

1 MODEL $Y 2=X I$ X2 ;

1 PROC REG DATA=A5 OUTEST=A053;

1 MODEL Y3=XI XISQR;

I PROC REG DATA=A5 OUTEST=A054; WEIGHT W4;

1 MODEL $Y 4=X I$;

1 PROC REG DATA=A5 OUTEST=AO55; WEIGHT W5;

I MODEL Y $5=\mathrm{X} I$ XISQR; 
1 TITLE 'END OF SIMULATION \#5' ;

1 PROC REG DATA $=$ A6 OUTEST $=A 061$;

1 MODEL YI=X1 X2 ;

1 PROC REG DATA=A6 OUTEST=A062; WEIGHT W2;

1 MODEL $Y 2=\mathrm{X} 1 \mathrm{X} 2$;

1 PROC REG DATA=A6 OUTEST=A063;

1 MODEL Y3=XI XISQR;

1 PROC REG DATA=A6 OUTEST=A064; WEIGHT W4;

1 MODEL $Y 4=X I$;

1 PROC REG DATA=A6 OUTEST=A065; WEIGHT W5;

1 MODEL Y5=XI XISQR;

1 TITLE 'END OF SIMULATION \#6' ;

1 PROC REG DATA=A7 OUTEST=AO71;

1 MODEL $Y 1=\mathrm{X} I \quad \mathrm{X} 2$;

1 PROC REG DATA=A7 OUTEST=A072; WEIGHT W2;

1 MODEL $Y 2=\mathrm{X} 1 \mathrm{X2}$;

1 PROC REG DATA=A7 OUTEST $=$ A073;

1 MODEL Y3=XI XISQR;

1 PROC REG DATA=A7 OUTEST=A074; WEIGHT W4;

1 MODEL $Y 4=\mathrm{XI}$;

1 PROC REG DATA=A7 OUTEST=A075; WEIGHT W5;

1 MODEL Y5=XI XISQR;

1 TITLE 'END OF SIMULATION \#7';

1 PROC REG DATA=A8 OUTEST=AO81;

1 MODEL $Y I=X I \quad X 2$;

1 PROC REG DATA=A8 OUTEST=AO82; WEIGHT W2; 
1 MODEL $Y 4=\mathbb{Z} 1$;

1 PROC REG DATA=A10 OUTEST=A105; WEIGHT W5;

1 MODEL Y5=XI XISQR;

1 TITLE 'END OF SIMULATION \#10';

1 PROC REG DATA=AII OUTEST=AIII;

1 MODEL $Y 1=\mathrm{X} 1 \quad \mathrm{X} 2$;

1 PROC REG DATA=AlI OUTEST=Al12; WEIGHT W2;

1 MODEL $Y 2=\mathrm{X} 1 \mathrm{X} 2$;

1 PROC REG DATA=AII OUTEST=A113;

1 MODEL Y3=XI XISQR;

1 PROC REG DATA=A1I OUTEST=A114; WEIGHT W4;

1 MODEL $Y 4=\mathbb{X}$;

1 PROC REG DATA=AlI OUTEST=A115; WEIGHT 5 ;

1 MODEL Y5=XI XISQR;

1 TITLE 'END OF SIMULATION \#11';

1 PROC REG DATA=A12 OUTEST=A121;

1 MODEL $Y 1=X 1 \quad \mathrm{X} 2$;

1 PROC REG DATA=A12 OUTEST=A122; WEIGHT W2;

1 MODEL $Y 2=X 1 \quad \mathrm{X} 2$;

1 PROC REG DATA=A12 OUTEST=A123;

1 MODEL Y3=XI XISQR;

1 PROC REG DATA=AI2 OUTEST=A 124; WEIGHT W4;

1 MODEL $Y 4=\bar{I}$;

1 PROC REG DATA=A12 OUTEST=A125; WEIGHT W5;

1 MODEL $Y 5=X I$ XISQR;

1 TITLE 'END OF SIMULATION \#12' ; 
1 PROC REG DATA=AI3 OUTEST=A131;

1 MODEL YI=X1 X2 ;

1 PROC REG DATA=AI3 OUTEST=AI32; WEIGHT W2;

1 MODEL Y2=XI X2 ;

1 PROC REG DATA=A13 OUTEST=A133;

1 MODEL $Y 3=X 1$ XISQR;

1 PROC REG DATA=A13 OUTEST=A134; WEIGHT W4;

1 MODEL $Y 4=\mathrm{X} 1$;

1 PROC REG DATA=A13 OUTEST $=$ A135; WEIGHT W5;

1 MODEL Y $5=\mathrm{X} I$ XISQR;

1 TITLE 'END OF SIMULATION \#13';

1 PROC REG DATA=A14 OUTEST=A141;

1 MODEL $Y 1=X 1 \quad \mathrm{X} 2$;

1 PROC REG DATA=A14 OUTEST=A142; WEIGHT W2;

1 MODEL $Y 2=\mathrm{X} 1 \mathrm{X} 2$;

1 PROC REG DATA=AI4 OUTEST=A143;

1 MODEL Y3=XI XISQR;

1 PROC REG DATA=AI4 OUTEST=A 144; WEIGHT W4;

I MODEL $Y 4=X 1$;

1 PROC REG DATA=A14 OUTEST=A145; WEIGHT W5;

1 MODEL Y5=XI XISQR;

1 TITLE 'END OF SIMULATION \#14' ;

1 PROC REG DATA=AI5 OUTEST=A151;

1 MODEL YI=XI X2;

1 PROC REG DATA=AI5 OUTEST=AI52; WEIGHT W2;

1 MODEL $Y 2=\mathbb{Z} 1 \quad \mathrm{Z2}$; 
1 PROC REG DATA=A15 OUTEST=A153;

1 MODEL Y3=XI XISQR;

I PROC REG DATA=A15 OUTEST=A154; WEIGHT W4;

1 MODEL $Y 4=X 1$;

1 PROC REG DATA=AI5 OUTEST=A155; WEIGHT W5;

1 MODEL Y5=XI XISQR;

1 TITLE 'END OF SIMULATION \#15' ;

1 PROC REG DATA=A16 OUTEST=A161;

1 MODEL $Y 1=X 1 \quad X 2$;

1 PROC REG DATA=AI6 OUTEST=A162; WEIGHT W2;

1 MODEL Y2=XI X2 ;

1 PROC REG DATA=AI6 OUTEST=A163;

1 MODEL $Y 3=X I$ XISQR;

I PROC REG DATA=AI6 OUTEST=A164; WEIGHT W4;

1 MODEL $Y 4=\mathbb{X}$;

1 PROC REG DATA=A16 OUTEST=A165; WEIGHT W5;

1 MODEL Y5=XI XISQR;

1 TITLE 'END OF SIMULATION \#16';

1 PROC REG DATA=AI7 OUTEST=A171;

1 MODEL $Y 1=X 1$ X2 ;

1 PROC REG DATA=AI7 OUTEST=AI72; WEIGHT W2;

1 MODEL $Y 2=\mathrm{X} I \mathrm{X2}$;

1 PROC REG DATA=AI7 OUTEST=A173;

1 MODEL Y3=XI XISQR;

1 PROC REG DATA=AI7 OUTEST=A174; WEIGHT W4;

1 MODEL $Y 4=\mathrm{XI}$; 
1 PROC REG DATA=A17 OUTEST=A175; WEIGHT W5;

1 MODEL Y5=XI XISQR;

1 TITLE 'END OF SIMULATION \#17';

1 PROC REG DATA=A18 OUTEST=A181;

1 MODEL $Y 1=\mathrm{X} 1 \mathrm{X2}$;

1 PROC REG DATA=A18 OUTEST=A182; WEIGHT W2;

1 MODEL $Y 2=X 1 \quad \mathrm{X} 2$;

1 PROC REG DATA=A18 OUTEST=A183;

1 MODEL Y3=XI XISQR;

1 PROC REG DATA=Al8 OUTEST=A184; WEIGHT W4;

1 MODEL $Y 4=\mathrm{X} 1$;

1 PROC REG DATA=Al8 OUTEST=A185; WEIGHT W5;

1 MODEL Y5=XI XISQR;

1 TITLE 'END OF SIMULATION \#18';

1 PROC REG DATA=A19 OUTEST=A191;

1 MODEL $Y 1=\mathrm{X} 1 \mathrm{X} 2$;

1 PROC REG DATA=A19 OUTEST=A192; WEIGHT W2;

1 MODEL YZ=XI Z2 ;

1 PROC REG DATA=A19 OUTEST=A193;

1 MODEL Y3=XI XISQR;

1 PROC REG DATA=A19 OUTEST=A194; WEIGHT W4;

1 MODEL $Y 4=\mathrm{XI}$;

1 PROC REG DATA=A19 OUTEST=A195; WEIGHT W5;

1 MODEL Y5=XI XISQR;

1 TITLE 'END OF SIMULATION \#19';

1 PROC REG DATA=A2O OUTEST=A2O1; 
1 MODEL $Y I=X 1 \quad Z 2$;

1 PROC REG DATA=A2O OUTEST=A2O2; WEIGHT W2;

1 MODEL $Y 2=\mathrm{X} 1 \mathrm{X2}$;

1 PROC REG DATA=A2O OUTEST=A203;

1 MODEL Y3=XI XISQR;

1 PROC REG DATA=A2O OUTEST=A204; WEIGHT W4;

1 MODEL $Y 4=X I$;

1 PROC REG DATA=A2O OUTEST=A2O5; WEIGHT W5;

1 MODEL Y5=XI XISQR;

1 TITLE 'END OF SIMULATION \#20';

1 PROC REG DATA=A21 OUTEST=A211;

1 MODEL $Y 1=X 1$ X2 ;

1 PROC REG DATA=A2 I OUTEST=A2 12; WEIGHT W2;

1 MODEL $Y 2=X 1$ X2 ;

1 PROC REG DATA=A21 OUTEST=A213;

1 MODEL $Y 3=X I$ XISQR;

1 PROC REG DATA=A2I OUTEST=A2 14; WEIGHT W4;

1 MODEL $Y 4=X I$;

1 PROC REG DATA=A21 OUTEST=A2 15; WEIGHT W5;

1 MODEL Y $Y=X I$ XISQR;

1 TITLE 'END OF SIMULATION \#21' ;

1 PROC REG DATA=A22 OUTEST=A221;

1 MODEL YI=XI Z2;

1 PROC REG DATA=A22 OUTEST=A222; WEIGHT W2;

1 MODEL Y2=X1 X2;

1 PROC REG DATA=A22 OUTEST=A223; 
1 MODEL $Y 3=\mathbb{I}$ XISQR;

1 PROC REG DATA=A22 OUTEST=A224; WEIGHT W4;

1 MODEL $Y 4=\mathbb{X}$;

1 PROC REG DATA=A22 OUTEST=A225; WEIGHT W5;

1 MODEL Y5=X 1 XISQR;

1 TITLE 'END OF SIMULATION \#22' ;

1 PROC REG DATA=A23 OUTEST=A231;

1 MODEL $Y 1=X 1$ X2 ;

1 PROC REG DATA=A23 OUTEST=A232; WEIGHT W2;

1 MODEL $Y 2=X 1 \quad X 2$;

1 PROC REG DATA=A23 OUTEST=A233;

1 MODEL Y3=XI XISQR;

1 PROC REG DATA=A23 OUTEST=A234;WEIGHT W4;

$1 \quad$ MODEL $Y 4=\bar{X}$;

1 PROC REG DATA=A23 OUTEST=A235; WEIGHT W5;

1 MODEL Y5=XI XISQR;

1 TITLE 'END OF SIMULATION \#23' ;

1 PROC REG DATA=A24 OUTEST=A241;

1 MODEL $Y 1=X 1 \quad \mathrm{X} 2$;

1 PROC REG DATA=A24 OUTEST=A242; WEIGHT W2;

1 MODEL Y2=XI X2 ;

1 PROC REG DATA=A24 OUTEST=A243;

1 MODEL Y3=XI XISQR;

1 PROC REG DATA=A24 OUTEST=A244; WEIGHT W4;

1 MODEL $Y 4=\mathrm{X} 1$;

1 PROC REG DATA=A24 OUTEST=A245; WEIGHT W5; 
1 MODEL Y5=XI XISQR;

1 TITLE 'END OF SIMULATION \#24' ;

1 PROC REG DATA=A25 OUTEST=A251;

1 MODEL YI=XI X2 ;

1 PROC REG DATA=A25 OUTEST=A252; WEIGHT W2;

1 MODEL Y2=X1 X2 ;

1 PROC REG DATA=A25 OUTEST=A253;

1 MODEL Y3=XI XISQR;

1 PROC REG DATA=A25 OUTEST=A254; WEIGHT W4;

1 MODEL Y4=XI;

1 PROC REG DATA=A25 OUTEST=A255; WEIGHT W5;

1 MODEL Y5=XI XISQR;

1 TITLE 'END OF SIMULATION \#25' ;

1 PROC REG DATA=A26 OUTEST=A261;

1 MODEL YI $=X 1$ X2 ;

1 PROC REG DATA=A26 OUTEST=A262; WEIGHT W2;

1 MODEL Y2=X1 X2 ;

1 PROC REG DATA=A26 OUTEST=A263;

1 MODEL Y3=XI XISQR;

1 PROC REG DATA=A26 OUTEST=A264; WEIGHT W4;

1 MODEL $Y 4=\mathrm{X} 1$;

1 PROC REG DATA=A26 OUTEST=A265; WEIGHT W5;

1 MODEL Y5=XI XISQR;

1 TITLE 'END OF SIMULATION \#26' ;

1 PROC REG DATA=A27 OUTEST=A271;

1 MODEL $Y 1=X 1 \quad X 2$; 
1 PROC REG DATA=A27 OUTEST=A272; WEIGHT W2;

1 MODEL Y2=X1 X2 ;

I PROC REG DATA=A27 OUTEST=A273;

1 MODEL Y3 $=\mathrm{X} I$ XISQR;

1 PROC REG DATA=A27 OUTEST=A274; WEIGHT W4;

1 MODEL Y4=XI;

1 PROC REG DATA=A27 OUTEST=A275; WEIGHT W5;

1 MODEL Y $=\bar{X} 1$ XISQR;

1 TITLE 'END OF SIMULATION \#17';

1 PROC REG DATA=A28 OUTEST=A281;

1 MODEL Y1=X1 X2 ;

1 PROC REG DATA=A28 OUTEST=A282; WEIGHT W2;

1 MODEL Y2=X1 X2 ;

1 PROC REG DATA=A28 OUTEST=A283;

1 MODEL $Y 3=X I$ XISQR;

1 PROC REG DATA=A28 OUTEST=A284; WEIGHT W4;

1 MODEL $Y 4=\bar{X} 1$;

1 PROC REG DATA=A28 OUTEST=A285; WEIGHT W5;

1 MODEL Y5=XI XISQR;

1 TITLE 'END OF SIMULATION \#28' ;

1 PROC REG DATA=A29 OUTEST=A291;

1 MODEL $Y 1=X 1$ X2 ;

1 PROC REG DATA=A29 OUTEST=A292; WEIGHT W2;

1 MODEL $Y 2=\mathrm{X} 1 \mathrm{X2}$;

1 PROC REG DATA=A29 OUTEST=A293;

1 MODEL Y3=XI XISQR; 
1 PROC REG DATA=A29 OUTEST=A294; WEIGHT W4;

1 MODEL $Y 4=\mathrm{XI}$;

1 PROC REG DATA=A29 OUTEST=A295; WEIGHT W5;

1 MODEL Y5=XI XISQR;

1 TITLE 'END OF SIMULATION \#29';

1 PROC REG DATA=A3O OUTEST=A301;

1 MODEL Yl=X1 X2 ;

1 PROC REG DATA=A30 OUTEST=A302; WEIGHT W2;

1 MODEL Y2=X1 X2 ;

1 PROC REG DATA $=$ A3O OUTEST $=$ A303;

1 MODEL Y3=XI XISQR;

1 PROC REG DATA=A3O OUTEST=A304; WEIGHT W4;

1 MODEL Y $4=\bar{X}$;

1 PROC REG DATA=A30 OUTEST=A305; WEIGHT W5;

1 MODEL Y5=XI XISQR;

1 TITLE 'END OF SIMULATION \#30';

1 DATA JOINI;

1 SET AOll AO12 AO13 A014 A015 A021 A022 A023 A024 A025

$\begin{array}{llllllllllll}5 & A 031 & A 032 & A 033 & A 034 & A 035 & A 041 & A 042 & A 043 & A 044 & A 045\end{array}$

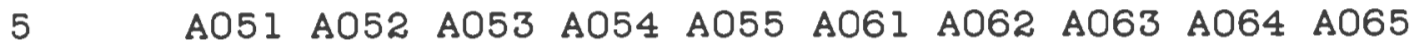

$5 \quad$ A071 A072 A073 A074 A075 A081 A082 A083 A084 A085

5 A091 A092 A093 A094 A095 Al01 Al02 Al03 Al04 Al05

5 All1 All2 All3 All4 All5 Al2l Al22 Al23 Al24 Al25

5 Al31 Al32 Al33 Al34 Al35 Al41 Al42 Al43 Al44 Al45

5 Al51 Al52 A153 A154 A155 Al61 A162 Al63 Al64 Al65

$5 \quad$ Al71 Al72 Al73 Al74 Al75 Al81 A182 Al83 Al84 Al85 
1 DATA JOIN2;

1 SET A211 A212 A213 A214 A215 A221 A222 A223 A224 A225

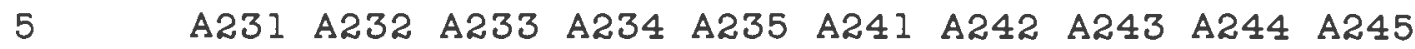

$\begin{array}{llllllllll}5 & \text { A251 } & \text { A252 } & \text { A253 A254 A255 A261 A262 A263 A264 A265 }\end{array}$

$5 \quad$ A27I A272 A273 A274 A275 A281 A282 A283 A284 A285

5 A291 A292 A293 A294 A295 A301 A302 A303 A304 A305;

1 DATA JOIN; SET JOINI JOIN2;

1 PROC PRINT DATA= JOIN ;

1 TITLE 'END OF SIMULATION PROGRAM REACHED';

1 PROC SORT DATA=JOIN;

1 BY Y1 Y2 Y3 Y4 Y5 INTERCEP XI X2 XISQR;

1 PROC MEANS DATA=JOIN;

$1 \quad$ BY Y1 Y2 Y3 Y4 Y5;

$1 / 1$

This is the end of the SAS program for simulating new compression force values within the standard deviations limits and obtaining the response surface equations for mean values of tablet in vitro properties as orignally obtained for the nine formulations of the optimization study.

This program calculates the mean in vitro dissolution time. The parameters for the equation should be entered 


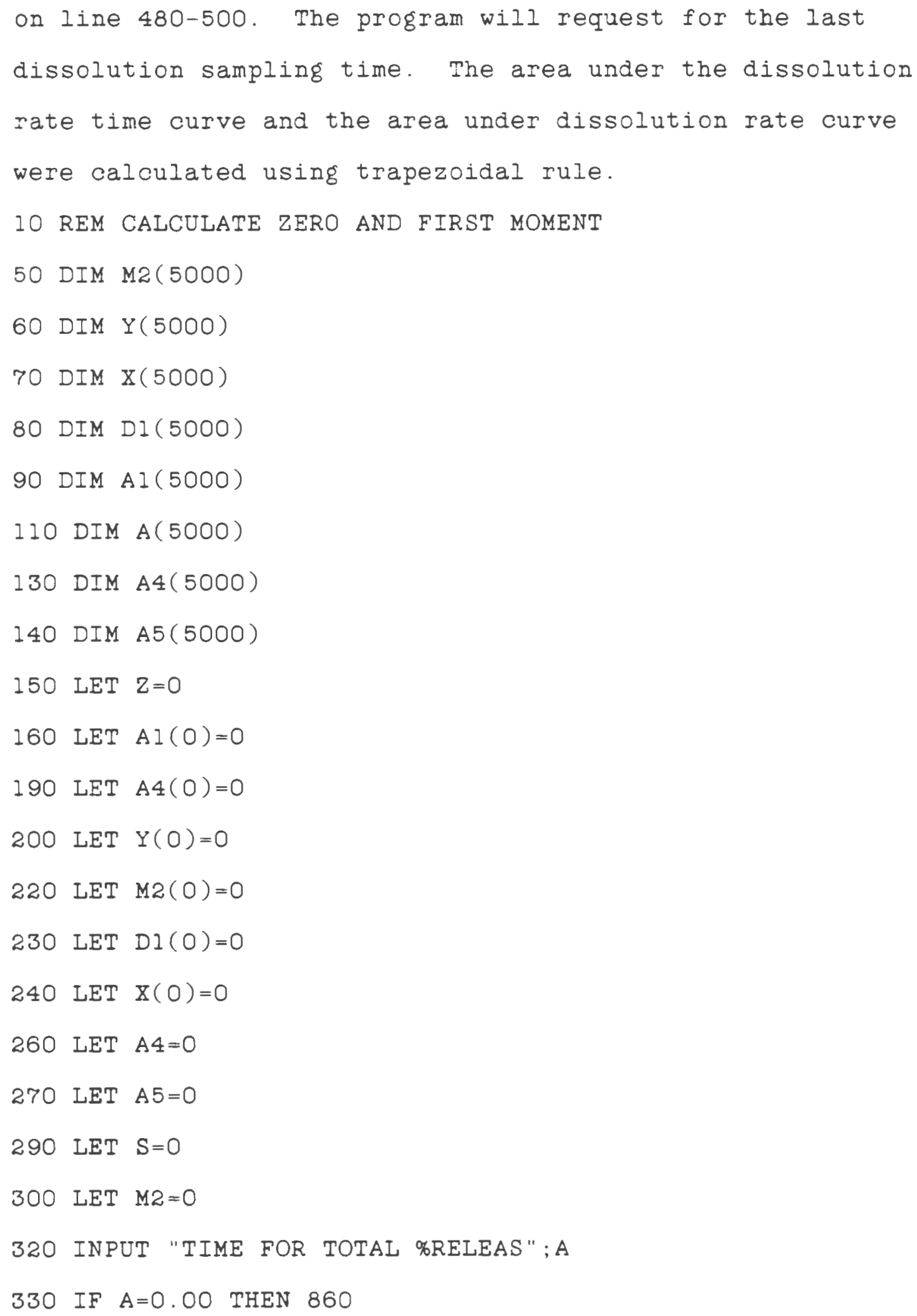




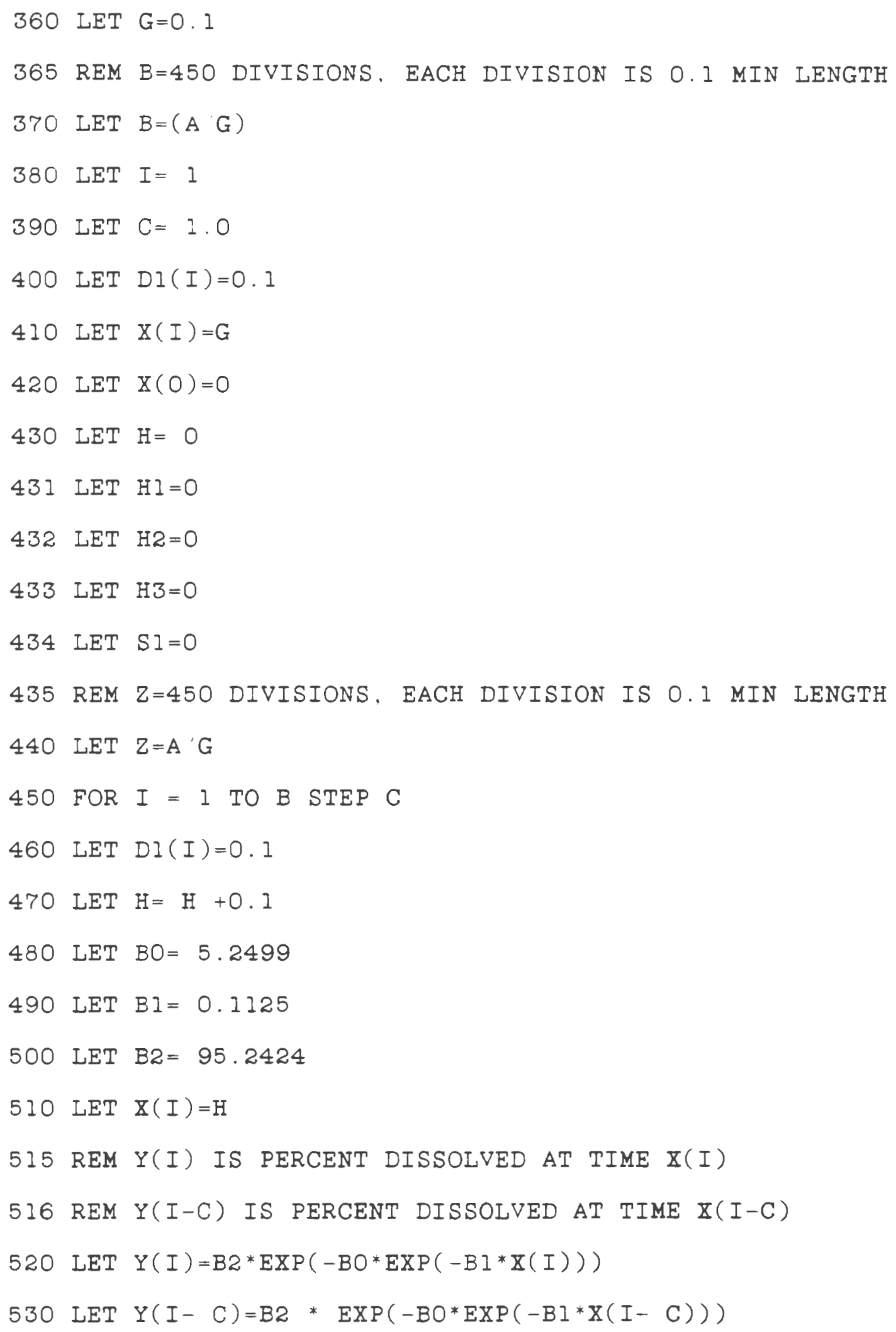




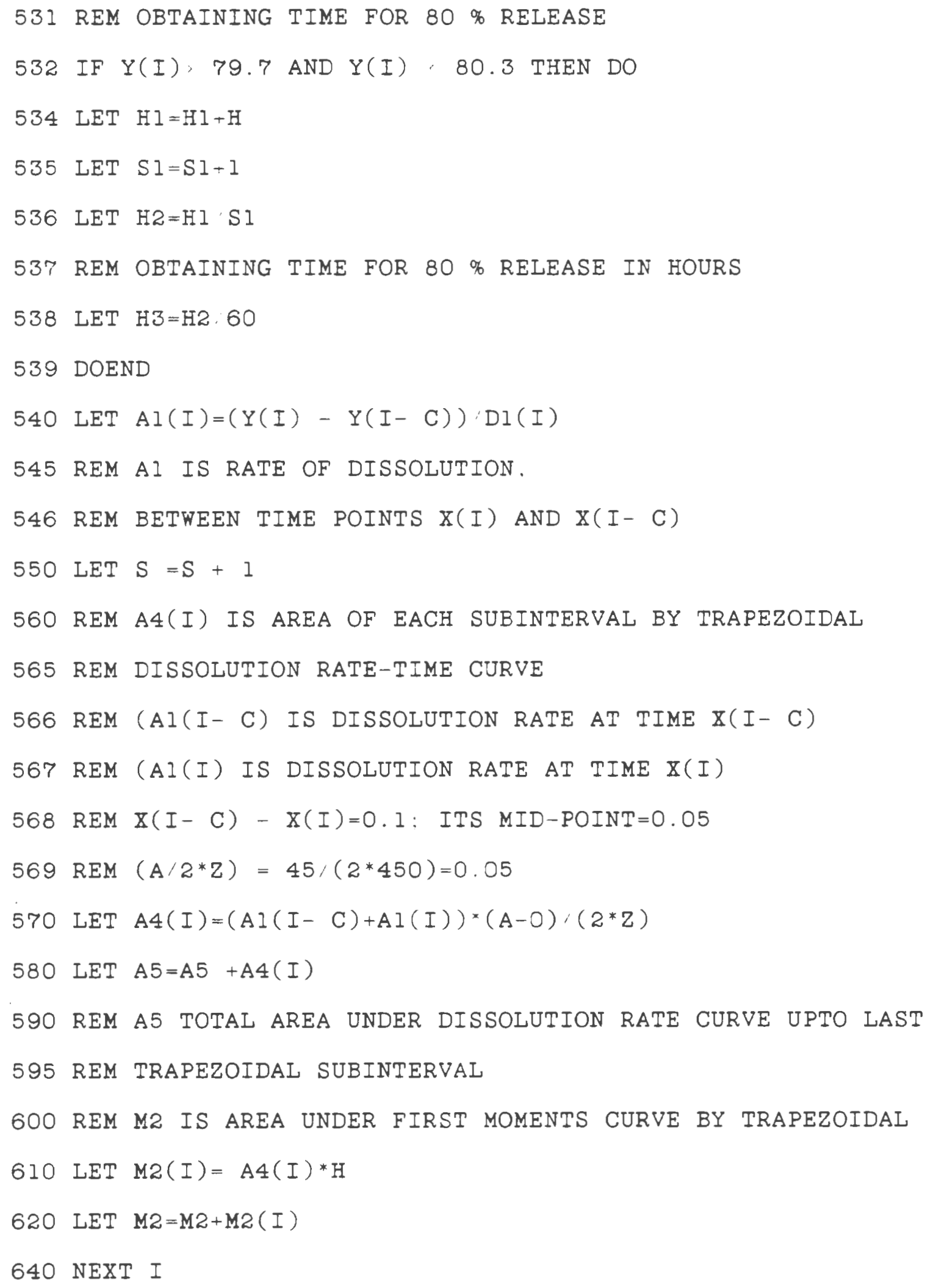




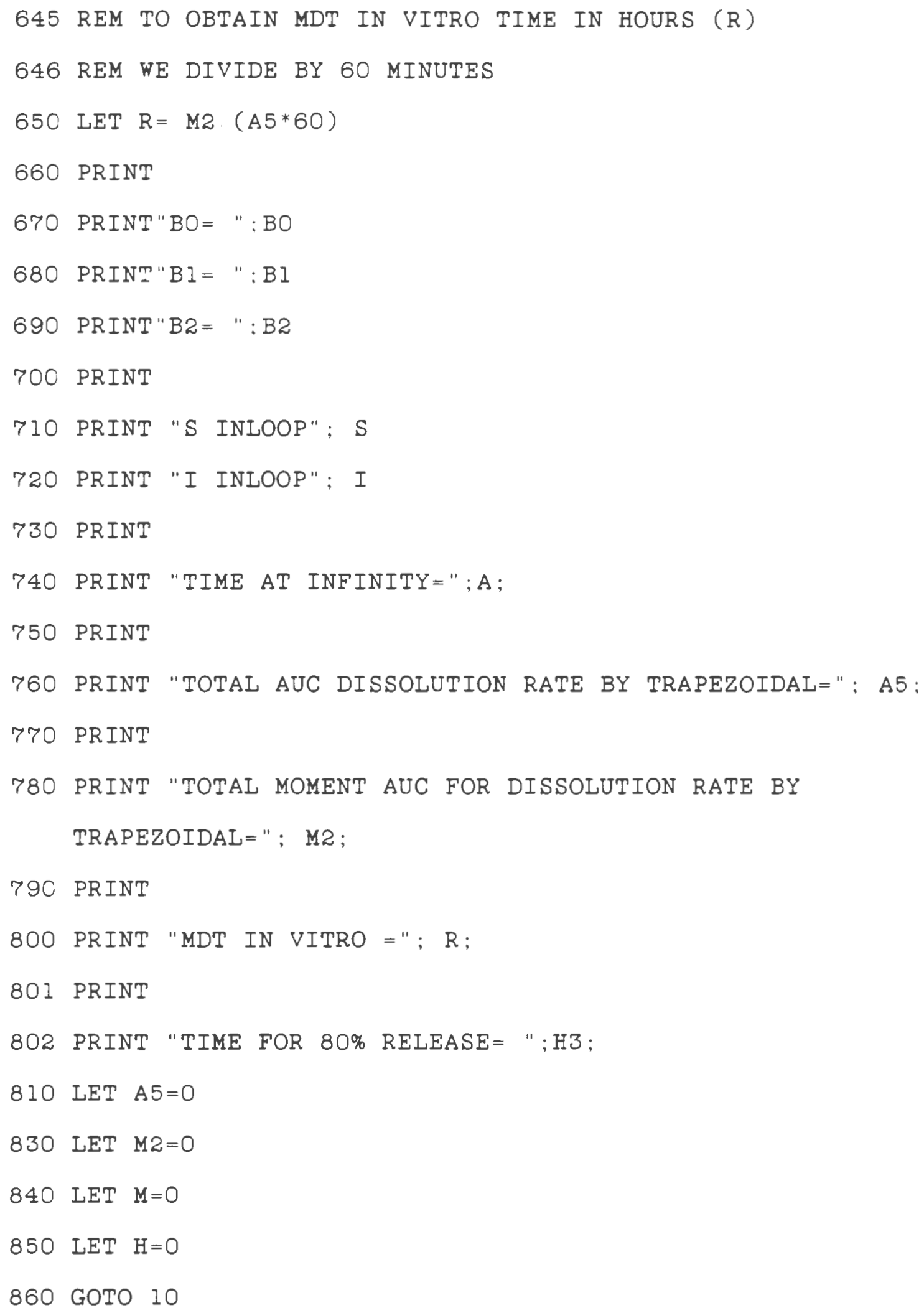


870 END

This is the end of the program that calculates the mean in vitro dissolution time.

THIS IS THE SUCCESSIVE QUADRATIC PROGRAMMING ALGORITHM FOR NONLINEARLY CONSTRAINED MINIMIZATION PROBIEM.

SOURCE: P. 899 , IMSL FORTRAN SUBROUTINES.

INTEGER IBTYPE, IPRINT, $M$, MAXINT, ME, $N$

$M E=$ TOTAL NO. OF EQUALITY CONSTRAINTS

PARAMETER (IBTYPE=0, IPRINT $=2, M=6, \quad$ MAXINT $=100, M E=0, N=2$ )

REAL FVALUE, $X(N), \quad \operatorname{XGUESS}(N), \quad X L B(N), \operatorname{XSCALE}(N), \operatorname{XUB}(N)$

EXTERNAL FCN, NCONF, WRRRN

DATA XGUESS, 0.50E0,0.850E0/, XSCALE:1.0,1.0,

DATA XLB;-1.OE6,-1.OE6/, XUB/1.OE6,1.OE6/

CALL NCONF (FCN, M, ME, N, XGUESS. IBTYPE, XLB, XUB,

XSCALE, IPRINT, MAXINT, X, FVALUE)

CALL WRRRN ('THE SOLUTION IS',N, I, X,N, O)

END

SUBROUTINE FCN ( $M, M E, N, X, A C T I V E, F, G)$

INTEGER $\mathrm{M}, \mathrm{ME}, \mathrm{N}$

REAL $\quad \mathrm{X}(*), \quad F, G(*)$

LOGICAL ACTIVE(*)

HIMMELBLAU PROBLEM I 


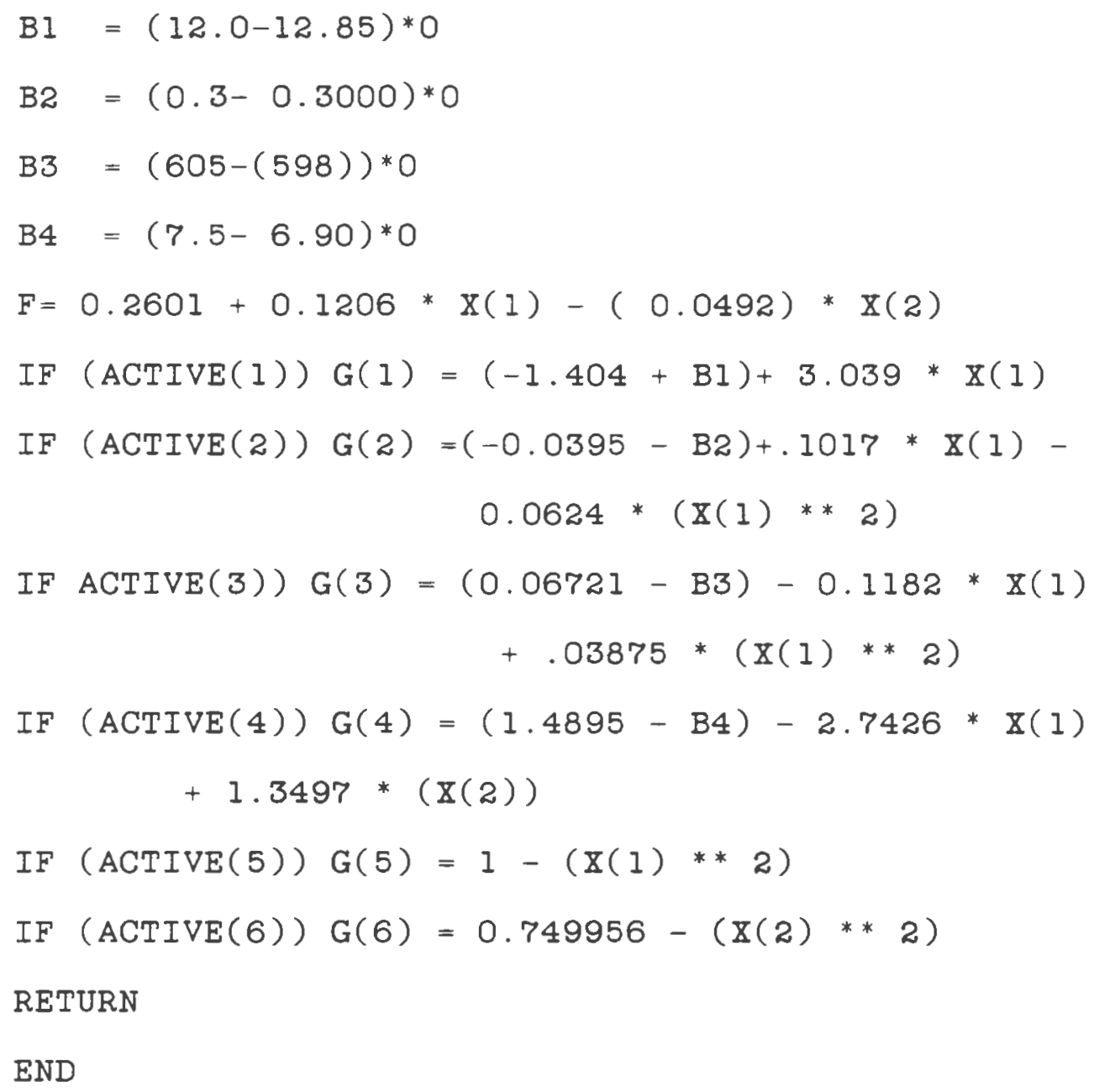


Appendix D: Manuscript V. 


\begin{abstract}
The Effect of Moisture on Powder Flow and on Compaction and Physical Stability of Tablets.

Shabbir Dawoodbhai and Christopher T. Rhodes Department of Pharmaceutics University of Rhode Island Kingston, RI 02881 .
\end{abstract}

\begin{abstract}
Introduction
Water vapor pressure in the atmosphere is quantified by the percent relative humidity. The moisture content at which a solid material produces a water vapour pressure equal to that of the surrounding environment is defined to be the equilibrium moisture content (EMC). The resultant weight gain of the solid is expressed as a percentage of its initial dry weight at a specified temperature and percent relative humidity.

The magnitude of the EMC depends on the percent relative humidity, temperature, binding site energy, surface area and the nature of the material. Certain materials have a low EMC such as non-porous talc, and kaolin. Conversely, organic sugars, hydrogen bonding polymers and crystal
\end{abstract}


hydrates have high a EMC. The EMC of starch, alginic acid, and tragacanth was reported to increase with increased percent relative humidity, but remained unaffected by increases in temperature (1). In contrast, increases in temperatures allowed the formation and deliquescence of hydrates to occur at lower percent relative humidity (1). However, lactose did not show deliquescence and its EMC increased only slightly even at $50 \mathrm{C}$ and $100 \%$ relative humidity ( 1 ).

The surface area of material also affects its EMC. Fine particle sizes of both sucrose and sodium chloride had higher EMC values compared to the coarse particles of these" materials (2). Most of the $4.8 \%$ of the moisture content usually present in microcrystalline cellulose is within the porous structure of its particles. The internal surface area represents $95 \%$ of the surface area of the microcrystalline cellulose particle that interacts with water vapor in the atmosphere ( 3 ).

Moisture in solids exists in several states. The adsorbed water vapor can become bound in the form of water of crystallization, for example, in the crystal hydrates of inorganic salts such as dibasic calcium phosphate dihydrate, and in organic sugars (lactose monohydrate). When the moisture is present in excess, as in the hygroscopic and deliquescent states, the water is said to exist in the unbound state. 
In amorphous solids, and in polymers such as starch and acacia, sorption of water proceeds beyond that required to satisfy all external particle surface area. Sorption of moisture also occurs within the amorphous solid, with the result that the mobility of moisture increases from tightly bound state to solvent like state. This is due to the lowering of the glass transition temperature by the moisture with the consequent increase in the free volume of individual molecules.

Effect of Moisture on The Flow of Powders.

The two fundamental forces that can affect the flow of powders are cohesion and friction. Cohesion is the mutual attraction, and resistance to seperation of contacting powder particles of a indentical material. Friction is the resistance exerted by one particle against the motion of another particle at the points of contact. The frictional forces act at a tangent to the contact point surface. The frictional force increases as the true (microscopic) contact area and as the average stress required to shear cold-welded junctions that form between contacting asperities of particles increases. The adsorbed moisture film lubricates the particles, and possibly prevents to some degree the cold welding of asperities, and thereby reduces the frictional force that opposes the relative motion of the particles. 
Cohesion in dry powder is a function of van der Waals forces, electrostatic forces and mechanical interlocking. The van der Waals forces increase as the particle diameter decreases. The electrostatic forces are influenced by the particulate nature, shape and the particle size distribution. Mechanical interlocking is a macroscopic phenomenon. It is more pronounced with particles of smaller size, which have a more irregular surface relative to diameter. Cohesion in moist powder involves liquid bridges and may also involve solid bridges, between particles. The liquid bridges connections depends on the percent of water and its distribution. The contributing factors are interfacial tension and capillary pressure. If the number of solid bridges increases it can result in increased cohesion and aggregation, and ultimately formation of a hard cake. Caking is the state in which the powder cannot be moved by vigorously shaking or tapping of the container. A parameter known as tensile strength of a powder bed, is obtained from measurements of the shear strength of a packed powder bed, with a shear cell. The influence of moisture content on the flow properties of powders has also been quantified by tensile strength values. Factors that influence tensile strength of powder bed include the nature of the material, percent moisture, particle size and the material packing density. Moisture significantly influenced the tensile strength of powders by formation of liquid 
bridges (4-6). At higher moisture content and at higher packing densities liquid bridges may progress from pendular to funicular bonds (4-6). Although the packing density of fine powder is less than that of coarse powder, the tensile strength of dry fine powder is greater than that of dry coarse powder. This is because of the greater number of contact points of fine powder particles (greater surface irregularity relative to diameter). This makes the particle-particle interaction forces greater than the mobilizing gravitational force. For coarse particles gravitational force exceeds interaction forces, leading to greater mobility $(5,6)$.

Increased packing density has been shown to increase the tensile strength for porous and non-porous, and also for cohesive and non-cohesive, powders (4-6). The nature of material and its particle size were important factors that influenced the tensile strength of powders. For a porous and cohesive powder (calcium phosphate), tensile strength was not changed because the moisture entered the intraparticulate voids and was therefore unable to accumulate on external surface to influence interparticulate forces by formation of liquid bridges (4). A non-porous and non-cohesive powder, the coarse fraction (32-75 um) of sodium chloride $(5,6)$, showed an increase in tensile strength with increase in moisture content up to about $4 \%$ because of the increase in the number of liquid bridges 
initially at points of actual contact (lower percent moisture) and eventually at points of near contact (at 4 percent moisture). Beyond a certain moisture content, the number of liquid bridges of both types remain constant. The forces of attraction of the liquid bridges at actual contact points are more powerful than at near contact points. However, with further increase in moisture content, the tensile strength reached a plateau because of the balance between increased net attractive forces at points of near contact and decreased attractive forces at points of actual contact, as the dimension of liquid bridges at points of actual contact increased $(4,5)$. Therefore, an increase in. moisture content can be expected to decrease the powder flow of both non-porous and non-cohesive materials.

With non-porous and cohesive powder such as fine sodium chloride particles there are more potential sites of contact compared to coarse particles $(5,6)$. A small initial increase in moisture content raised its tensile strength even further, due to increased particle-particle interactions. The combined effects of the number and attractive forces of the liquid bridges are similar as with coarse sodium chloride particles. However, with further increase in moisture content the particle-particle interaction decreased and became insignificant. As a result, the tensile strength exponentially decreased to a low level plateau value $(5,6)$. Therefore, increase in 
moisture cannot be expected to help improve the flow properties of already cohesive powder. Excessive moisture will further increase the tensile strength and may lead to caking of the powder. Caking has been observed at high percent relative humidity with several commonly used powder excipients including starch $(2,7,8)$. The occurrance of caking was suppressed by the addition of 0.25 to $0.5 \%$ magnesium oxide to starch, or by $1.0 \%$ of magnesium oxide to sugars and salts $(2,5)$. It was suggested that the fine plate shaped magnesium oxide particles adhered to the surfaces of caking material by van der Waals and electrostatic forces and that their presence reduced interparticulate cohesion by decreasing the number liquid bridges within caking material $(2,8)$.

\section{Effect of Moisture on Compaction of Powders.}

Compaction is a process by which powder particles are brought sufficiently close together so that the bonding forces between them are large enough to produce a strong compact. The necessity for the presence of moisture in formation of strong tablets was indicated by the fact that the crystal hydrates that inherently compressed well did not do so when their water of crystallization was removed e.g. ferrous sulphate heptahydrate (9). Moisture increases the compact strength by increasing the tensile strength of the powder bed, by increasing the contact area among the 
particles for bonding, by decreasing the variation of density within the tablet and by the récrystallization effect.

The reduced variation of density within the tablet was mainly attributed to the lubrication of the die walls (which allows a greater fraction of the applied force to be transmitted through the compact onto the lower punch, this is also known as the $R$ value) and only slightly attributed to the lubrication of powder particle surface (which facilitates rearrangement and repacking of particles) (1012). The adsorbed water film decreases the particle surface energy and thus decreases the adhesion of the tablet to the die wall. In addition, the expressed water film on the die wall during compaction functioned as a low viscosity lubricant (10-12). The increase in lubrication was indicated by the increase in the $R$ values, decrease in the ejection forces and decrease in the forces lost to the die wall (10-12).

Repacking and rearrangement of anhydrous dextrose and dextrose monohydrate increased with increasing percent moisture content as indicated by decrease of in situ porosity and decrease of yield force and by increased compact density (13). This presumably was due to interparticulate and die wall lubrication effects, and due to plasticizing effect of water, as the moisture content increased (13). With substances like microcrystalline 
cellulose, the moisture within its pores acts as an internal lubricant and facilitates the slippage and flow within individual microcrystals during compaction $(3,14)$. The moisture facilitates plastic deformation of microcrystals to allow close contact and hydrogen bonding between particles $(3,14)$. The moisture acted as a plasticizer, and thereby reduced the yield point and the elastic recovery during compaction $(3,14)$. Microcrystalline cellulose (14) and also soy protein (15) tablets, when directly compressed, showed increase in hardness as the percent moisture content increased and as the compression force increased until the true density of the material was reached. Either lack of moisture or insufficient moisture is one of the factors responsible for lamination of tablets since the yield force becomes high and the elastic recovery is increased. With crystalline, water soluble substances such as sodium chloride, the thin adsorbed layers of moisture increase the effective surface area for intimate contact (10-12). The phenomenon of recrystallization during compression will increase compact strength, when water is present as vapor in the pores of the particles. For anhydrous dextrose, with up to $8.9 \%$ moisture content the percent relative humidity is below the critical value of less than $81.3 \%$ (RHo), and therefore the moisture is present as vapor in the pores. The water vapor condenses on application of compression force and promotes the formation 
of a saturated solution which moves to the flaws within the particles or to the particle crystal contact points, mobilized in part by surface tension forces (13). Recrystallization upon decompression in these areas of weakness results in an increase in tensile strength (13). The presence of "excessive" moisture at moderate to high compression force decreases the compact strength, by decreasing the tensile strength of the powder bed, decreasing the microirregularities of the particles, by hydrodynamic resistance and by increased elastic recovery after ejection when compressed beyond true density.

The tensile strength of dextrose monohydrate tablets decreased with any increase of moisture content $(13,16)$, and the microcrystalline cellulose tablets capped in the presence of excessive moisture at high compression force (14), because of hydrodynamic resistance, together with increased elastic recovery after ejection. The tensile strength of anhydrous dextrose tablets decreased when made at moderate to high compression force in presence of excessive moisture due to hydrodynamic resistance of the liquid present in the voids of the compact (13).

Excessive moisture also produces the cappillary state of the powder aggregation and thereby the surface tension effect becomes insignificant in maintaining the high tensile strength of the powder bed. The moisture has a solvent effect of eliminating the surface cracks and 
irregularities in the crystals. This increases the crystals' resistance to fragmentation, and decreases the crystal surface energy, which therefore decreases adhesion between particles. The electrostatic charges of attraction also become dispersed (10-12). The hardness of lactose tablets containing naproxen at low and high compression force decreased as the moisture content increased beyond two percent (17).

Effect of Moisture on Physical stability.

Physical stability is the study of in vitro changes in a dosage form properties when subjected to physical stress and time. These in vitro changes may alter bioavailibility and therapeutic efficacy, even though the drug potency and purity appear unaltered.

Major changes in the physical stability of a compact can result from moisture gain and/or moisture loss at different points in time. The sorption of moisture by ingredients of tablets can result in formation of their solution for water soluble substances, with consequent crystal change and/or growth of crystalline substances or can manifest as swelling of polymeric materials.

\section{Moisture Gain.}

Changes in tablet appearance $(18,19)$ and increase in tablet volume $(14,18,20-23)$ as a result of moisture 
sorption was observed with several direct compression excipients. Amorphous or spray dried lactose tablet volume increased monotonously due to hygroscopic swelling at $35 \%$ relative humidity and $30 \mathrm{C}(21,23)$. No crystallization of lactose was detected because the amount of water sorbed was not sufficient for making super saturated solution of lactose $(21,23)$. At high percent relative humidity, the amorphous lactose tablet volume expansion was more rapid and extensive and, corresponded to rapid increase in crystalinity as the moisture content stabilized to a plateau level $(21,23)$. It was suggested that the water liberated from super-saturated amorphous lactose solution was due to decrease in surface area. This liberated water further promoted the formation of supersaturated amorphous lactose solution, and accelerated the autocatalytic crystallization into a-monohydrate and b-anhydrous lactose (21,23). Tablets containing hygroscopic materials such as docusate sodium, magnesium chloride, or potassium acetate and made up of crystalline water soluble excipients e.g. lactose or mannitol, showed crystal growth of these excipients when stored at high percent relative humidity at $37 \mathrm{C}$ for 4 months. The identity of these crystal growths was confirmed by DSC and TLC (18).

The crushing strength of tablets, made from crystalline substances or polymers, which are either water soluble or insoluble, will decrease when exposed to high 
percent relative humidity. Lactose tablets the with highest initial crushing strength underwent the greatest decrease in hardness, and vice versa, in a linear fashion $(24,26)$. With dibasic calcium phosphate dihydrate, the tablet hardness decrease was greater for tablets with lower initial moisture content compared to tablets with higher initial moisture content (25). Dibasic calcium phosphate dihydrate tablets made at an initial moisture content of $2.8 \%$ showed the least decrease in tablet hardness (25). The decrease in crushing strength of microcrystalline cellulose tablets was directly related to the amount of water sorbed (22).

The effect of moisture sorption on disintegration time depends on whether the tablet material is crystalline or polymeric. The disintegration time of microcrystalline cellulose tablets decreased more rapidly as the amount of sorbed moisture increased and as the exposure period to the high percent relative humidity increased (22). These tablets when evaluated after 202 days had the same hardness, thickness, and percent moisture content but shorter disintegration times, than those tablets evaluated after the 9 days. The change in the tablet internal structure was indicated by the abscence of fragments which disintegrated slowly from the tablets stored for 202 days (22). For tablets that contained lactose only and lactose plus naproxen there was a tendency for the disintegration time to slightly increase (25). For dibasic calcium phosphate 
dihydrate tablets prepared with an initial moisture content of 1.5 to $3.2 \%$ the disintegration time increased as the period of exposure to high humidity increased (25). For shorter periods of exposure the tablets with initial moisture content of 2.5 to $2.8 \%$ seemed to be least affected. However, with a prolonged period of exposure the disintegration time increased regardless of the initial moisture content (25).

After exposure to four humidity levels, the physical stability of the tablets were ranked using the criteria of minimum moisture uptake, minimum increase in volume of tablets and the retention of the maximum hardness and the minimum disintegration times. The excipients dibasic calcium phosphate dihydrate, and both hydrous and anhydrous lactose resulted in more physically stable tablets than did mannitol or monobasic calcium phosphate monohydrate. Sorbitol, dextrose and sucrose gave the least physically stable tablets (20).

The T50\% values for dissolution of naproxen from dibasic calcium phosphate increased as the period of exposure to high humidity increased (25). The T50\% values of naprozen from dibasic calcium phosphate dihydrate did not increase more significantly in the tablets with higher initial moisture content as compared to lower initial moisture content tablets for any given period of exposure to the high percent humidity (25). However, only a slight 
trend towards the decrease in dissolution rate of naproxen at 5 and 15 minutes from lactose tablets exposed to high percent relative humidity occurred (24). The dissolution rate of sodium naproxen at 5 and 10 minutes, from microcrystalline cellulose tablets made with increasing initial moisture content from 3 to $7 \%$ did not significantly change (17).

\section{Moisture Loss.}

Moisture loss from tablets containing high initial moisture content will cause recrystallization. The effect of this phenomenon will be discussed in the section below. The crushing strength of microcrystalline cellulose tablets showed only a slight decrease or no change, especially in the abscence of water soluble components $(3,14)$. With dibasic calcium phosphate dihydrate tablets, moisture loss is accompanied by general hardening in the bulk of the tablets (25).

\section{Moisture loss also shortened the disintegration} times of the tablets containing microcrystalline cellulose (3,14). The disintegration time of dibasic calcium phosphate dihydrate tablets remained unchanged for short period of exposure to low relative humidity (25). Prolonged exposure to low percent relative humidity slightly shortened the disintegration time ( 25 ). 
Moisture Gain Followed by Moisture Loss.

Partial moisture loss from moisture rich tablets results in formation of solid bridges in the form of recrystallized and/or material hardening of polymeric binding materials. The partial moisture loss generally results in an increase in the crushing strength of the tablets $(16,24,25,27)$. As the percent lactose was increased the tablet hardness increased because the lactose recrystallization effect became more pronounced (17). Dibasic calcium phosphate dihydrate tablets softened by exposure to high percent relative humidity were able to regain some of their loss in hardness after storage at low percent relative humidity (25). Almost complete restoration to original tablet hardness was possible when the initial moisture content was $2.8 \%$ (25). The strength of crystalline bridges formed is dependent on the recrystallization rate. The recrystallization rate affects the tablet hardness by modifying the size and the numbers of the crystalline bridges formed in the void spaces. The recrystallization rate is affected by formulation changes that modifies the formulation moisture sorption properties.

The magnitude of hardness increase in lactose containing tablets at a given moisture content depended on the concentration and the type of binder used (17). When the various binders were compared, the celluloses types gave greater increases in hardness compared to either gelatin or 
povidone. Acacia produced a minimal increase, and starch produced the least increase, in tablet hardness (17). As the amount of the binder was increased, a higher initial moisture concentration in the granulation could be incorporated without getting the severe hardness increases following partial moisture loss. This suggested that the higher binder concentration slowed recrystallization rate of water soluble drug and/or excipients which in turn resulted in formation of fewer crystalline bonds, and hence, the minimal increase in the tablet hardness with partial moisture loss $(17,24,27)$. The greater effectiveness of higher binder concentration in reducing the recrystallization rate is possibly due to increased viscosity which would slow down the rate of diffusion of the dissolved substances to the growing crystal surfaces.

It has been shown that the strength of the crystalline bridges are not dependent on the tablet hardness immediately following compression (24). The lactose based tablets that had been softened by exposure to high percent relative humidity, when exposed overnight to ambient conditions, showed that the hardness increase did not depend on the initial post compression hardness (24). With polymeric materials such as microcrystalline cellulose, recrystallization of water soluble substances may lead to increases in the tablet hardness (17). 
The disintegration times of the microcrystalline cellulose tablets did not increase to their original values after partial moisture loss, indicating that the hydrogen bonds were not regenerated (22). For dibasic calcium phosphate dihydrate tablets, previously conditioned at high relative humidity, a single overnight room condition exposure further prolonged the disintegration times, especially if the tablets had very low or very high moisture content at the time of compression (25). For pure lactose tablets, and also for lactose tablets containing naproxen, the recrystallization effect tended to slightly prolong = disintegration times $(24,28)$.

The recrystallization effect did not significantly change the dissolution rate of naproxen from lactose tablets with high initial moisture concentration at the time of compression, or which had been exposed to high percent relative humidity, followed by an overnight exposure to ambient conditions ( $17,24,27)$, or by change of percent lactose in the formulation (17). Compared to the lactose tablets with an initial moisture content of under $2.3 \%$, the tablets after partial moisture loss, had somewhat lower percent of naprozen dissolved at 5 minutes compared to their initial value, indicating a lag time (17). The dissolution rate of sodium naproxen and the sodium benzoate from the microcrystalline cellulose tablets remained rapid and unchanged (17). Modification of recrystallization rate by 
the presence of different binders had no effect on salicylic acid T50\% dissolution from lactose containing tablets (27). The dissolution rate of naproxen from dibasic calcium phosphate dihydrate tablets after partial moisture loss remained close to their elevated $T 50 \%$ values as obtained after exposure to high percent relative humidity $(24,25)$. In summary, the effect of moisture gain is similar to partial moisture loss in slowing the dissolution rate of naproxen from dibasic calcium phosphate dihydrate tablets.

\section{Conclusions.}

Powder flow properties are affected by numerous factors. In general, the presence of moisture tends to decrease the flow of the powders by increasing their tensile strength. The adsorbed moisture film acts as a low viscosity lubricant during compaction, thereby promoting uniform density within the tablets and decreasing the adhesion of the tablets to the die wall. In addition, the plasticizing effect of moisture on amorphous and polymeric materials, and the recrystallization effect with some crystalline materials contributes to formation of a strong tablet. Conversely, excessive moisture decreases the tablet strength by decreasing the powder tensile strength, increasing both elastic recovery and hydrodynamic resistance. Physical stability of the tablets is significantly altered by 
moisture gain, moisture loss and partial moisture loss. The effects observed are largely dependent upon the formulation.

\section{References.}

1. E. Shotton and N. Harb, J. Pharm. Pharmacol., 17, 504 (1965).

2. D.J. Craik and B.F. Miller, J. Pharm. Pharmacol., 10. $136 \mathrm{~T}(1958)$.

3. K.A. Khan, P. Musikabhumma and J.P. Warr, Drug Dev Indus. Pharm., 7, 525 (1981).

4. T. Eaves and T.M. Jones, Pharm. Acta Helv., 47, 537 $(1972)$.

5. T. Eaves and T.M. Jones, J. Pharm. Sci., 61, 256 (1972).

6. T. Eaves and T.M. Jones, J. Pharm. Sci., 61, 342 (1972).

7. E. Shotton and N. Harb, J. Pharm. Pharmacol., 18, 175 ( 1966$)$.

8. D.J. Craik, J. Pharm. Pharmacol., 10, 73 (1958).

9. J. Jaffe and N.E Foss, J. Pharm. Sci., 58, 26 (1959).

10. E. Shotton and J.E. Rees, J. Pharm. Pharmacol., 18, 160 s ( 1966$)$.

11. J.E. Rees and J.A. Hersey, Pharm. Acta Helv., 47, 235 (1972).

12. J.E. Rees. and E. Shotton, J. Pharm. Sci., 601704 (1971). 
13. N.A. Armstrong and T.M. Jones, Drug Dev. Indus. Pharm., $12,1885(1986)$.

14. G.E. Reier and R.F. Shangraw, J. Pharm. Sci., 55, 510 (1966).

15. C.D. Teng, M.H. Alkan and N.J. Groves, Drug Dev. Indus. Pharm., 12, 2325 (1986).

16. N.A. Armstrong and R.V. Griffiths, Pharm. Acta Helv., $45,692(1970)$.

17. Z.T. Chowhan and L.Palgyi, J. Pharm. Sci., 67, 1385 (1978).

18. H. Ando, S. Watnabe, T. Ohwaki and Y. Miyake, J. Pharm. Sci., 74, 128 (1985).

19. J.M. Lausier, C. Chiang, H.A. Zompa and C.T. Rhodes, J. Pharm. Sci., 66, 1636 (1977).

20. S.A. Sangekar, M. Sarli and P.R. Sheth, J. Pharm. Sci., 61, 939 (1972).

21. A. Otsuka, T. Wakimoto and A. Takeda, Chem. Pharm. Bul1., 26, 967 (1978).

22. H. Nyqvist and M. Nicklasson, Int. J. Pharm. Tech. $\&$ Prod. Mfr., 4, 67 (1983).

23. M. Morita, Y. Nakai, E. Fukuoka and S. Nakajima, Chem. Pharm. Bull., 32, 4076 ( 1984 ).

24. Z.T. Chowhan, Drug Dev. Indus. Pharm., 5, 41 (1979).

25. Z.T. Chowhan, J. Pharm. Pharmacol., 32, 10 (1979).

26. K. Nakabayashi, T. Shimamoto and H. Mima, Chem. Pharm. Bu11., 28, 1090 (1980). 
27. 2.T. Chowhan, J. Pharm. Sci., 69, 1 (1980).

28. K. Nakabayashi, S. Hanatani and T. Shimamoto, Chem. Pharm. Bull., 29, 2057 (1981). 
Bibliography

Amidon, G.E., and Houghton, M.E., Pharm. Manufacturing, 7. $21(1985)$.

Ando, H., Watnabe, S., Ohwaki, T. and Miyake, Y., J. Pharm. Sci., 74, 128 (1985).

Anon, Soap Perfume Cosmet., 55, 368 (1982).

Armstrong, N.A., and Griffiths, R.V., Pharm. Acta Helv., 45, 692 ( 1970$)$.

Armstrong, N.A., and Jones, T.M., Drug Dev. Indus. Pharm., = 12,1885 (1986).

Banker, G., Peck G., and Bailey, G., in "Pharmaceutical

Dosage Forms: Tablets", 1, Lieberman H.A., and Lachman, L., eds., Marcel Dekker, Inc. 88 (1980).

Batuyios, N.H., and Brecht E.A., J. Pharm. Sci., 46, 524 (1957).

Biles, W.E., Swain, J.J., "Optimization and Industrial Experimentation". John Wiley and Sons, Inc. New York, New York, pp 135-147, (1980).

Bohidar, N.R., Schwartz, J.B., Restaino, F.A., J. Pharm. Sci., 64, 966-969 (1975).

Bohidar, N.R., Bavitz, J.F., and Shiromani, P.K., Drug Dev. Indus. Pharm., 12, 1503-1510 (1986).

Bolhuis, G.K., Lerk, C.F., Zijlstra, H.T. and DeBoer, A.H., Pharm. Weekblad, 110, 317 (1975). 
Box, G.E.P., Draper, N.R., and Smith, H.,"Empirical Model Building and Response Surface", John Wiley and Sons, Inc. New York, New York, pp 508-515, (1987).

Chatterjee. S.; Hadi. A.S.; Sensitivity Analysis in

Linear Regression, John Wiley and Sons, Inc. New York, New York, pp 261-262, 1988.

Chowhan, Z.T., and Palgyi, L., J. Pharm. Sci., 67, 1385 (1978).

Chowhan, 2.T., Drug Dev. Indus. Pharm., 5, 41 (1979).

Chowhan, 2.T., J. Pharm. Pharmacol., 32, 10 (1979).

Chowhan, Z.T., J. Pharm. Sci., 69, 1 (1980).

Craik, D.J., J. Pharm. Pharmacol., 10, 73 (1958).

Craik, D.J., and Miller, B.F., J. Pharm. Pharmacol., I0, $136 \mathrm{~T}(1958)$.

Danish, F.Q., and Parrott, E.I., J. Pharm. Sci., 60, 548 (1971).

Dawoodbhai, S., Chueh, H.R., and Rhodes, C.T., Drug

Dev. Indus. Pharm. 13, 1331 (1987).

Dincer. S., and Ozdurmus. S., J. Pharm. Sci., 67, 1070-1073 $(1977)$.

Down, J.R.B., Miller, R.A., Chopra. S.B., and Millar. J.F., Drug Dev. Indus. Pharm., 6, 311-330 (1980).

Draper, N.R., and Smith. H.; Applied Regression Analysis, John Wiley and Sons, Inc. New York, New York, pp 108$111,511-512,(1981)$ 
Eaves, T., and Jones, T.M., Pharm. Acta Helv., 47, 537 (1972).

Eaves, T., and Jones, T.M., J. Pharm. Sci., 61, 256 (1972).

Eaves, T., and Jones, T.M., J. Pharm. Sci., 61, 342 (1972).

El-Shimi, A.F., J. Soc. Cosmet. Chem., 28, 37 (1977).

Fonner, Jr., D.E., Buck. J.R., and Banker, G.S., J. Pharm.

Sci. 59, 1587-1596 (1970).

Ganderton, D., J. Pharm. Pharmacol., 21, Suppl., 95 (1969).

Ganjian, F., Cutie, A.J., and Jochsberger, T., J. Pharm.

Sci., 69, 352 (1980).

Gold, G., and Campbell J.A., J. Pharm. Sci., 53, 52 (1964).

Gold, G., and Palmero, B.T., J. Pharm. Sci., 54, 310 $(1965)$.

Gold, G., and Palmero, B.T., J. Pharm. Sci., 54, 1517 $(1965)$.

Gold, G., Duvall, R.N., Palmero, B.T., and Slater, J.G., J. Pharm. Sci., 55, 1291 (1966).

Gold, G., Duvall, R.N., Palmero, B.T., and Slater, J.G., J. Pharm. Sci., 57, 667 (1968).

Gold, G., Duvall, R.N., Palmero, B.T., and Slater, J.G. Pharm. Sci., 57, 2153 (1968).

Grexa, R.W., and Parmentier, C., J. Cosmet. Toiletries, 94, 29 ( 1979$)$.

Hammerness, F.C., and Thompson, H.O., J. Pharm. Sci., 47, $58(1958)$. 
Hegde, R.P., Rheingold S.W., and Rhodes, C.T., J. Pharm. Sci., 74, 11 (1985).

Herzka, A., J. Soc. Cosmet. Chem., 21, 553 (1970).

Iranloye, T.A. and Parrott, E.L., J. Pharm. Sci., 67, 535 (1978).

Jaffe, J., and Foss, N.E., J. Pharm. Sci., 58, 26 (1959).

Jarosz, P.L., and Parrott, E.L., Drug Dev. Indus. Pharm., 4, 259 (1984).

Jones, T.M. and Pilpel, N., J. Pharm. Pharmacol, 18, 81 ( 1966$)$.

Kassem, A. and Said, S., Can. J. Pharm. Sci., 10, 92 (1975).

Khan, K.A., Musikabhumma, P. and Warr, J.P., Drug Dev Indus. Pharm., 7, 525 (1981).

Kinglake, V., Soap Perfume Cosmet., 54, 607 (1981).

Kinglake, V., Soap Perfume Cosmet., 54, 399 (1981).

Kristensen, H.G., and Jensen, V.G., Dansk Tidssky. Farm., $43,205$ ( 1969$)$.

Lantz, R.J., and Schwartz, J.B., in "Pharmaceutical Dosage Forms: Tablets," $\boldsymbol{E}$, Lieberman, H.A., and Lachman, L. eds., Marcel Dekker, Inc., 22 (1981).

Lausier, J.M., Chiang, C., Zompa, H.A., and Rhodes, C.T., J. Pharm. Sci., 66, 1636 (1977).

Lewis, C.J., and Shotton, E., J. Pharm. Pharmacol., 17, Suppl. 82 S (1965). 
Lewis, C.J., and Train, D., J. Pharm. Pharmacol., 17, 577 ( 1965$)$.

Levy, G., and Gumtow, R.H., J. Pharm. Sci., 52, 1139 (1963). Matsuda, Y., Minamuda, Y., and S. Hayashi, J. Pharm. Sci., $65,1155(1976)$.

Mechtersheimer, B., and Sucker, H., Pharm. Tech., 10, 38 $(1986)$.

Mitsui, T., Fukushima, S., and Takada, S., J. Soc. Cosmet. Chem., 23, 525 (1972).

Mitsui, T., and Takada, S., J. Soc. Cosmet. Chem., 20, 335 (1969).

Monkhouse, D.C. and Lach, J.I., J. Pharm. Sci., 61, 1430 (1972).

Monkhouse, D.C., and Lach, J.L., J. Pharm. Sci., 61, 1435 (1972).

Morita, M., Nakai, Y., Fukuoka. E., and Nakajima, S. , Chem. Pharm. Bull., 32, 4076 (1984).

Myers, R.H., Response Surface Methodology. Allyn and Bacon, Boston Massachusetts, p. 126-173,(1971).

Nakabayashi, R., Shimamoto, T., and Mima, H., Chem. Pharm. Bull., 28, 1090 (1980).

Nakabayashi, R., Hanatani, S., and Shimamoto, T., Chem. Pharm. Bull., 29, 2057 (1981).

Nazareth, M.R., and Huyck, C.L., J. Pharm. Sci., 50, 608 $(1961)$. 
Nazareth, M.R., and Huyck, C.L., J. Pharm. Sci., 50, 620 (1961).

Nelson, E., Nagvi, L.W., Busse, L.W., and Higuchi, T.J., Pharm. Sci., 43, 596 (1954).

Nyqvist, H., and Nicklasson, M., Int. J. Pharm. Tech. \& Prod. Mfr., 4, 67 (1983).

Otsuka, A., Wakimoto T., and Takeda, A., Chem. Pharm. Bul1., 26, 967 (1978).

Parker, J.W., Peck G.E., and Banker, G.S., J. Pharm. Sci. $63,119(1974)$.

Pilpel, N. in "Bentley's Textbook of Pharmaceutics," Rawlins, E.A., ed., Bailliere Tindall, 248 (1977).

Powell, M.J.D., "A Fast Algorithm for Nonlinearly

Constrained Optimization Calculations" in Numerical Analysis, Dundee 1977 (G.A Watson, Ed.), Lecture Notes in Mathematics No. 630, Springer-Verlag, New York, 1978 Raymond, R.L., Cosmet. Toiletries., 94, 49 (1979). Rees. J.E. and Shotton, E., J. Pharm. Sci., 60, 1704 (1971). Rees, J.E., and Hersey, J.A., Pharm. Acta Helv., 47, 235 (1972).

Reier, G.E., and Shangraw, R.F., J. Pharm. Sci., 55, 510 (1966).

Reier, G., Cohn, R., and Rock, S., J. Pharm. Sci., 57, 660 (1968)

Reklatis, G.V., Ravindran, A., and Ragsdell, E.M., "Engineering Optimization: Methods and Applications" 
John Wiley and Sons, Inc. New York, New York, p. 438 $-458,1983$.

Rohdewald, P., Cosmet. Perfume, 90, 35 (1975).

Sangekar, S.A., Sarli, M., and Sheth, P.R., J. Pharm. Sci., $61,939(1972)$.

Schwartz, J.B., Flamholz, J.R., Press, R.H., J. Pharm. Sci. $62,1165-1170(1973)$.

Schwartz, J.B., Flamholz, J.R., Press, R.H., J. Pharm. Sci. $62,1518-1519(1973)$.

Sciarra, J.J., Iannacone, A., and Mores, L., J. Soc. Cosmet. Chem., 27, 209 (1976).

Shah, A.C., and Mlodozeneic, A.R., J. Pharm. Sci., 66, 1377 ( 1977 ).

Shek, E., Ghani, M., Jones, R.E., J. Pharm. Sci. 69, 11351142 ( 1980$)$.

Shotton, E., and Lewis, C.J., J. Pharm. Pharmacol., 16, $111 T(1964)$.

Shotton, E., and Harb, N., J. Pharm. Pharmacol., 17, 504 (1965).

Shotton, E., and Lewis, C.J., J. Pharm. Pharmacol., 17, Suppl. 825 ( 1965$)$.

Shotton, E., and Rees, J.E., J. Pharm. Pharmacol., 18, 160 s (1966).

Shotton, E., and Harb, N., J. Pharm. Pharmacol., 18, 175 (1966).

Sorby, D., J. Pharm. Sci., 54, 667 (1961). 
Sorby, D., and Ple1n, E.M., J. Pharm. Sc1., 50, 355 (1961). Sorby, D., J. Pharm. Sc1., 54, 677 (1965).

Strickland, W.A., Nelson, E., Busse L.W., and Higuchi, T., J. Pharm. Sci., 45, 51 (1956).

Strickland, W.A., Higuch1, T., and Busse L.W., J. Pharm. Soi., 49, 35 (1960).

Takai, T., Takayama, K., Nambu, N., and Nagai, T., Chem. Pharm. Bull., 32, 1942-1947 (1984).

Takayama, K., Nambu, N., and Nagai, T., Chem. Pharm. Bull., $31,4496-4450$ (1983).

Takayama, K., Ima1zumi, H., Nambu, N., and Naga1, T., Chem. Pharm. Bull., 33, 292-300 (1985).

Takenaka, H., Kawashima Y., and Lin, S.Y., J. Pharm. Sd1 69,1388 (1980).

Tanigawara, Y., Yamaoka, K., Nakagawa, T., and Uno. T. Chem.

Pharm. Bull., 30, 1088-1090 (1982).

Teng, C.D., Alkan, M.H., and Groves, N.J., Drug Dev. Indus. Pharm., 12, 2325 (1986).

Train, D., and Hersey, J.A., J. Pharm. Pharmacol., 12, 97T (1960).

Wuster, D.E., and Polli, G.P., J. Pharm. Sc1., 50, 403 (1961).

York, P., J. Pharm. Sc1., 64, 1216 (1975). 